Final Report

FHWA/IN/JTRP-2006/22

\title{
INTERPRETATION OF CONE PENETRATION TESTS IN COHESIVE SOILS
}

\author{
by \\ Kwang Kyun Kim \\ Graduate Research Assistant \\ Monica Prezzi \\ Assistant Professor \\ and \\ Rodrigo Salgado \\ Professor \\ School of Civil Engineering \\ Purdue University
Joint Transportation Research Program
Project No. C-36-45T
File No. 6-18-18
SPR-2632
Conducted in Cooperation with the
Indiana Department of Transportation
Federal Highway Administration \\ and the U.S. Department of Transportation
}

The contents of this report reflect the views of the authors who are responsible for the facts and accuracy of the data presented herein. The contents do not necessarily reflect the official views or policies of the Federal Highway Administration or the Indiana Department of Transportation. This report does not constitute a standard, specification, or regulation.

Purdue University

West Lafayette, Indiana

December 2006 


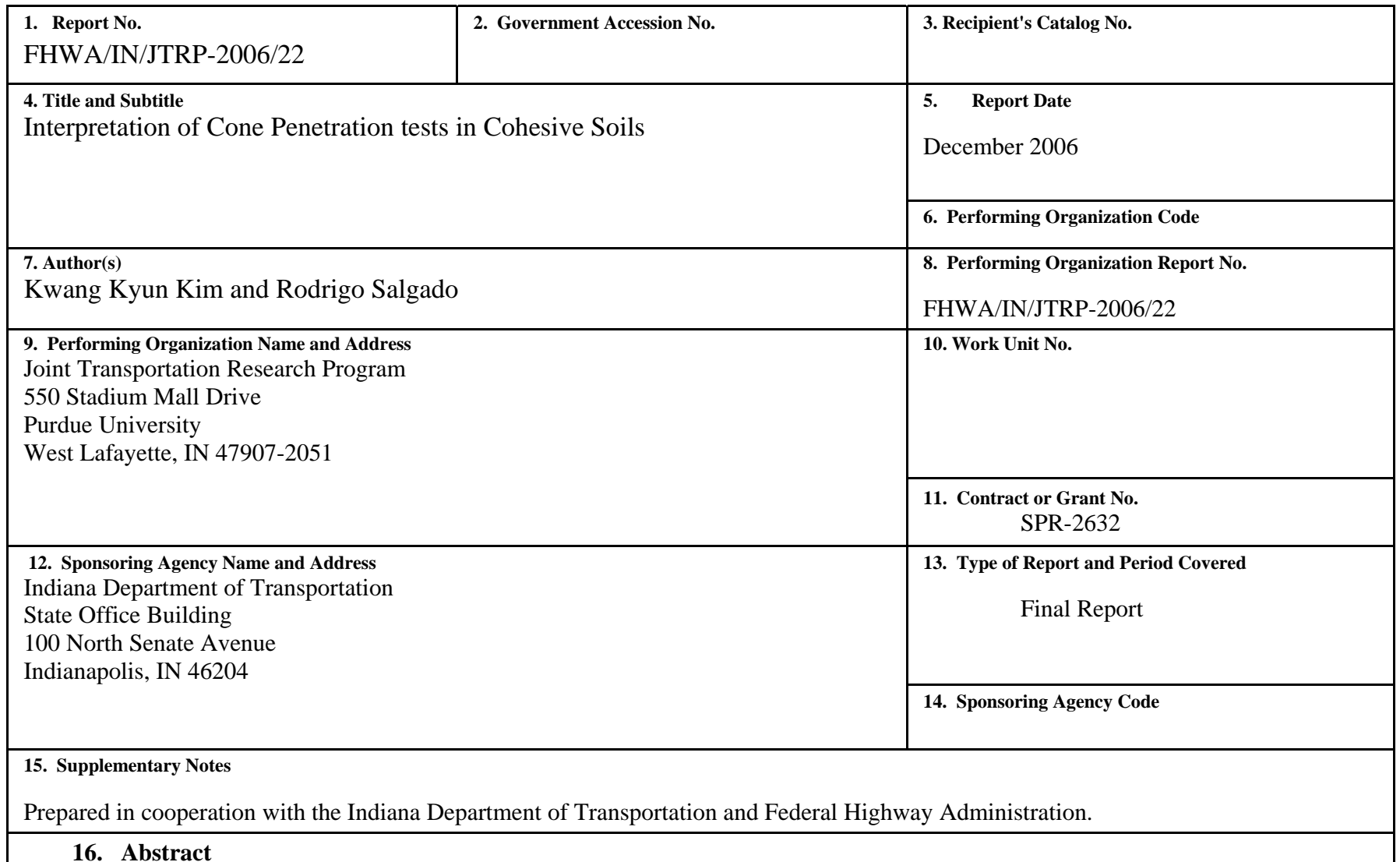

This report focuses on the evaluation of the factors affecting cone resistance measurement during cone penetration in saturated clayey soils and the application of the result to pile shaft capacity analysis. In particular, effects of drainage conditions around the cone tip were studied. Rate effects related to both drainage and shear strength dependence on loading rate were studied. In order to investigate the effects of drainage during penetration, penetration tests were performed with various velocities in the field and in a calibration chamber, and the obtained data were analyzed. For the field tests, two sites which have homogeneous clayey soil layers below the groundwater table were selected, and CPTs were performed with various penetration rates. Penetration tests in the calibration chamber were performed to investigate the transition points between undrained and partially drained, partially drained and fully drained conditions based on cone penetration rate and the coefficient of consolidation.

A series of flexible-wall permeameter tests were conducted for various mixing ratios of clays and sands to obtain values of the coefficient of consolidation, which is a key variable in determining the drainage state during cone penetration. Nine piezocone penetration tests were conducted at different rates in calibration chamber specimen P1 (mixture of $25 \%$ clay and $75 \%$ sand) and eight penetration tests were carried out in calibration chamber specimen P2 (mixture of $18 \%$ clay and $82 \%$ sand). From the results of the penetration tests in the calibration chamber, a cone resistance backbone curve, with $\mathrm{q}_{\mathrm{c}}$ plotted versus normalized penetration rate, was established.

Guidelines were proposed for when to interpret CPT tests, whether in estimating soil properties or in estimating pile resistances, in soils for which penetration takes place under conditions that cannot be established as either drained or undrained a priori.

17. Key Words
Cone Penetration Test (CPT), Pile Design, Bearing
Capacity, Clay, Clayey Soils.

\section{Distribution Statement}

No restrictions. This document is available to the public through the National Technical Information Service, Springfield, VA 22161
19. Security Classif. (of this report) Unclassified

\author{
20. Security Classif. (of this page)
}

Unclassified

21. No. of Pages
226

22. Price 


\section{TECHNICAL Summary}

INDOT Research

Technology Transfer and Project Implementation Information

TRB Subject Code: 62-1 Foundation Soils

Publication No.FHWA/IN/JTRP-2006/22, SPR-2632

December 2006

Final Report

\section{INTERPRETATION OF CONE PENETRATION TESTS IN COHESIVE SOILS}

\section{Introduction}

Various types of in situ tests are relied on for estimating soil properties or directly designing foundations. Among the various in-situ tests, the use of the Cone Penetration Test (CPT) has been increasing steadily. There are many factors affecting the cone resistance measured during penetration through saturated clayey soils. These need to be understood and quantified for effective interpretation of CPT results.

An important use of cone resistance is in the design of pile foundations. In effect, the cone penetrometer could be seen as a small pile, and its penetration through the ground as the plunge of a pile. Thus, in addition to estimation of $s_{u}$ from cone resistance and use of the $\alpha$ method, pile shaft resistance can be estimated by direct correlation between the unit shaft resistance and cone resistance.

This research focuses on the evaluation of the factors affecting cone resistance measurement during cone penetration in saturated clayey soils and the application of the result to CPT interpretation. In particular, the effects of drainage conditions around the cone tip on the measured cone resistance were studied. On the basis of these studies, preliminary guidelines are proposed for interpretation of CPTs in soils for which drainage conditions during penetration cannot be established a priori.

\section{Findings}

In order to investigate the effects of drainage during cone penetration test, penetration tests were performed with various velocities in the field and in a calibration chamber, and the obtained data were analyzed. For the field tests, two sites with homogeneous clayey soil layers below the groundwater table were selected and CPTs were performed with various penetration rates. Penetration tests were also performed in a calibration chamber to investigate the transition points between undrained and partially drained and between partially drained and fully drained conditions based on cone penetration rate and the coefficient of consolidation. A series of flexiblewall permeameter tests were conducted for various mixing ratios of clays and sands to obtain the coefficient of consolidation for the mixing ratios used to prepare the calibration chamber specimens. Nine piezocone penetration tests were conducted for different rates in calibration chamber specimen P1 (mixture of $25 \%$ clay and $75 \%$ Jumun sand) and eight penetration tests were carried out in calibration chamber specimen P2 (mixture of $18 \%$ clay and $82 \%$ Jumun sand). From the results of the penetration tests in the calibration chamber, a backbone curve of cone resistance versus penetration rate was established. Based on the backbone curve, guidelines for CPT interpretation in these soils were proposed.

\section{Implementation}

From the field cone penetration tests performed at various penetration rates, it was observed that cone resistance increased when the drainage condition around the cone tip changed from undrained to partially drained. The true transition point between undrained and partially drained 
conditions in terms of normalized penetration rate $\mathrm{V}=\mathrm{vd}_{\mathrm{c}} / \mathrm{c}_{\mathrm{v}}$ was around 10 for both field tests. The results of flexible-wall permeability tests show that the coefficient of consolidation for mixtures of clay and sand is primarily affected by the clay content. From the results of penetration tests in the calibration chamber specimens, a correlation between cone resistance and drainage condition was obtained. When the drainage condition transitioned from undrained to fully drained, cone resistance increased 4 times (for chamber specimen P1) and 3.1 times (for chamber specimen $\mathrm{P} 2$ ). The transitions from undrained to partially drained and then to drained penetration were observed at essentially the same values of normalized penetration rates for the chamber tests as for the field tests.

\section{Contacts}

For more information:

Prof. Rodrigo Salgado

Principal Investigator

School of Civil Engineering

Purdue University

West Lafayette IN 47907

Phone: (765) 494-5030

Fax: (765) 496-1364

E-mail: rodrigo@purdue.edu
Indiana Department of Transportation

Office of Research \& Development 1205 Montgomery Street

P.O. Box 2279

West Lafayette, IN 47906

Phone: (765) 463-1521

Fax: (765) 497-1665

\section{Purdue University}

Joint Transportation Research Program

School of Civil Engineering

West Lafayette, IN 47907-1284

Phone: (765) 494-9310

Fax: (765) 496-7996

E-mail: jtrp@ecn.purdue.edu

http://www.purdue.edu/jtrp 


\section{TABLE OF CONTENTS}

LIST OF TABLES

IMPLEMENTATION REPORT ………………………...........................................viii

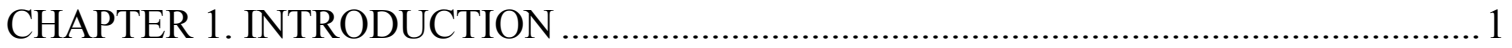

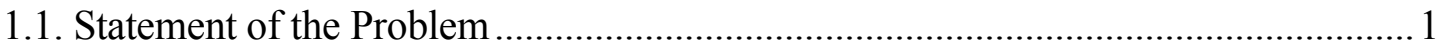



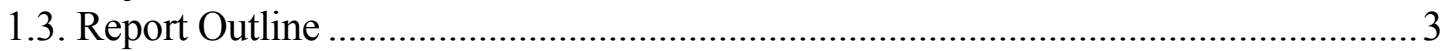

CHAPTER 2. Cone Penetration Test in Clayey Soils .......................................................... 4

2.1. Introduction .................................................................................................. 4

2.2. Empirical Efforts for Correlating Shear Strength to Cone Resistance .......................5

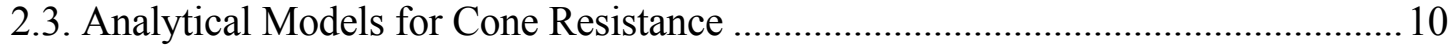

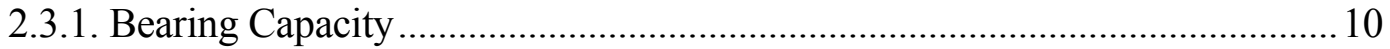

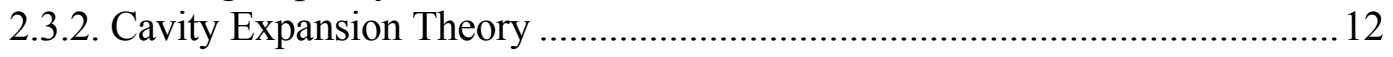

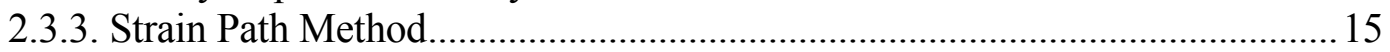

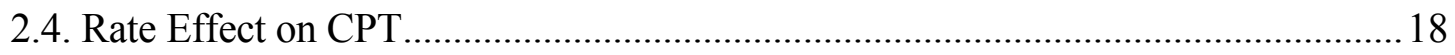



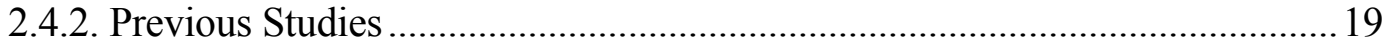

2.4.3. Framework for Rate Effect Consideration ................................................... 22

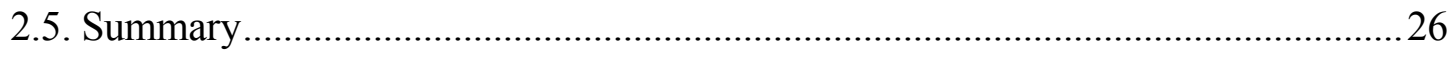

CHAPTER 3. Field Cone Penetration Test.................................................................. 27

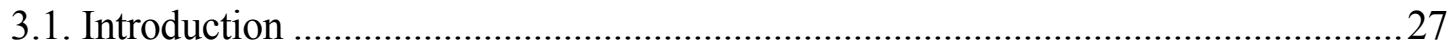

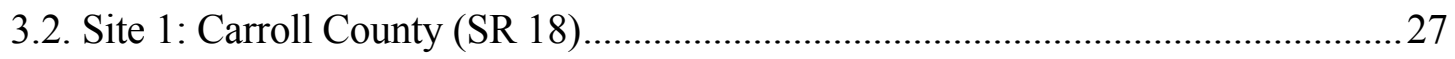

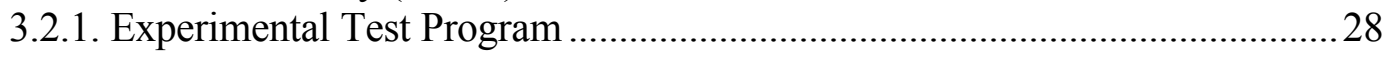

3.2.2. Cone Penetration Test Program ................................................................ 41





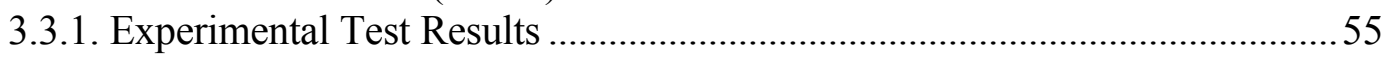

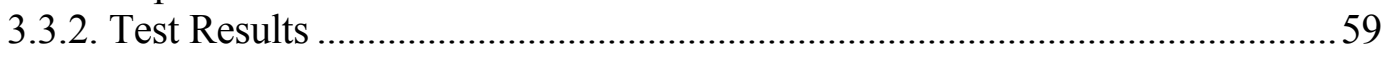

3.4. Interpretation of CPT Results Considering Normalization of the Cone Resistance

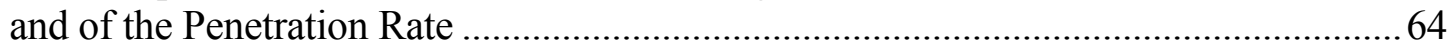

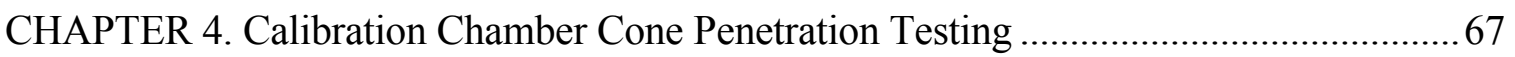

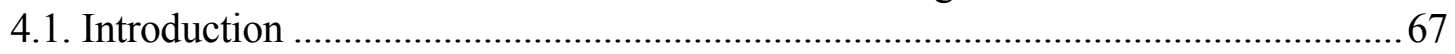

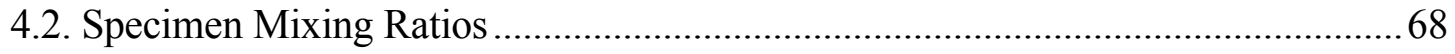

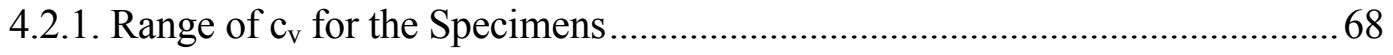




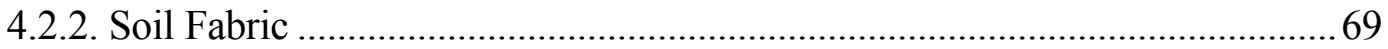

4.3. Flexible Wall Permeameter Test........................................................................... 70

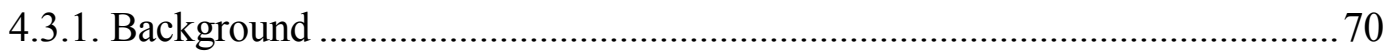

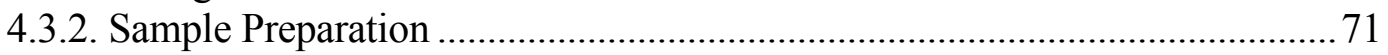

4.3.3. Permeability Test Results ......................................................................... 75

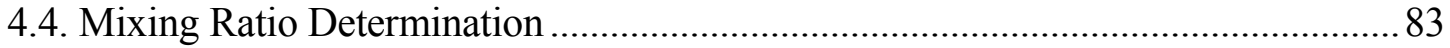

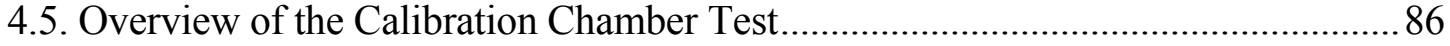

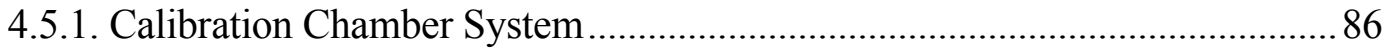

4.5.2. Specimen Preparation Procedure................................................................... 88

4.5.3. Chamber Size and Boundary Effects............................................................. 95

4.5.4. Soil Properties ........................................................................................ 98

4.5.5. Cone Penetration Test Program ................................................................ 99

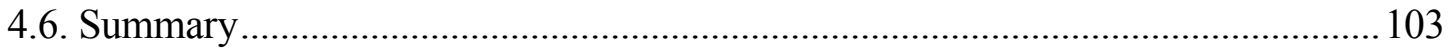

CHAPTER 5. Analysis of Calibration Chamber Cone Penetration Test Results................104

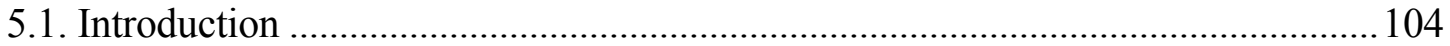

5.2. The Results of Cone Penetration Test in P1 ......................................................... 104

5.3. The Results of Minicone Penetration Tests with a Flat Tip in P1 .........................112

5.4. The Results of Cone Penetration Tests in P2 …………..................................... 119

5.5. Flat Tip Penetration Test Results in P2 ........................................................... 124

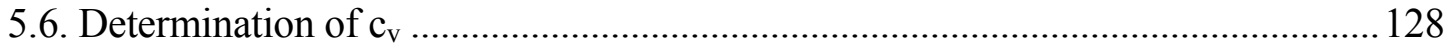

5.7. Normalized Penetration versus Normalized Penetration Rates ............................... 132



CHAPTER 6. Determination of Cone Penetration Rate Effects and cone factor $\mathrm{N}_{\mathrm{k}}$.........135

6.1. Rate Effects in Cone Penetration Testing ...........................................................135

6.2. Criteria for Establishing Drainage Condition Rate Thresholds for CPT ................138

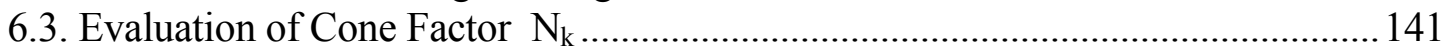

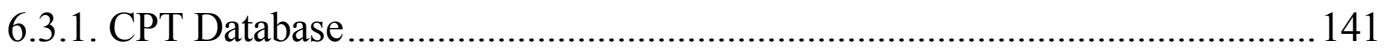

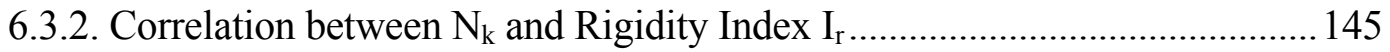

6.3.3. Correlation between $\mathrm{N}_{\mathrm{k}}$ and Rate of Loading ........................................... 149

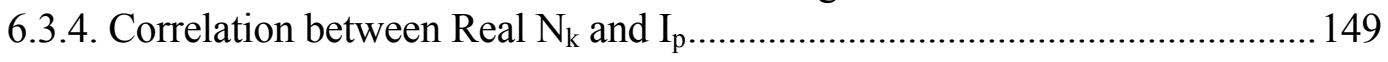

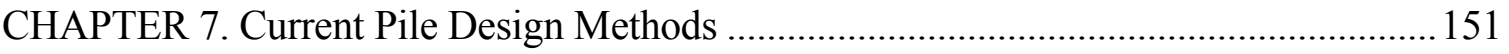

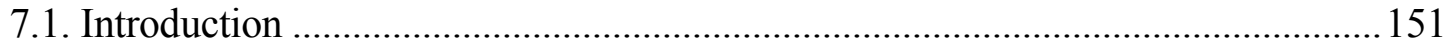

7.2. Pile Design Methods Based on Soil Parameters ……………………………......... 153

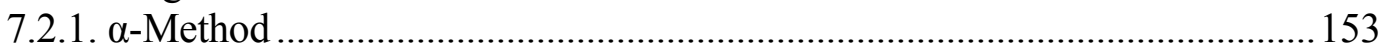

7.2.2. American Petroleum Institute (API) Method .................................................. 156

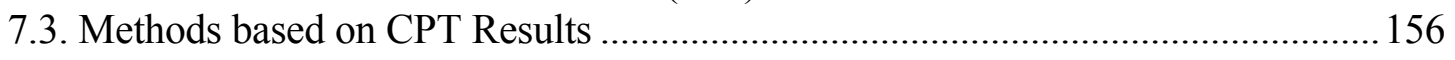

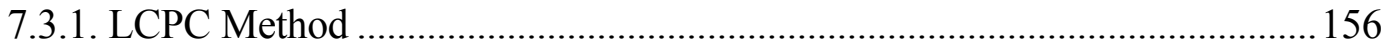

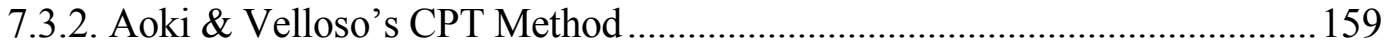

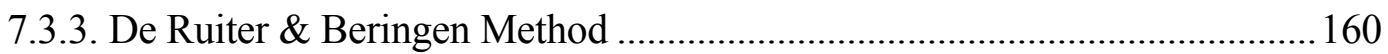

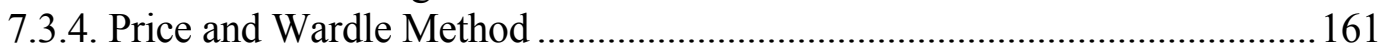

7.3.5. Thorburn \& McVicar and Eslami \& Fellenius Method.................................... 161

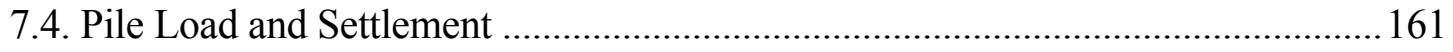




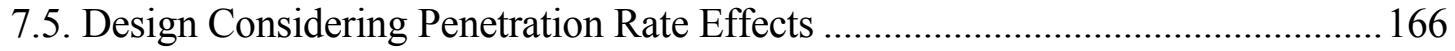

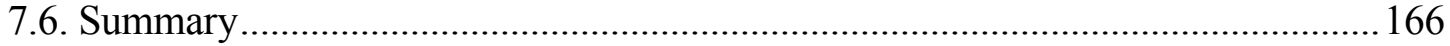

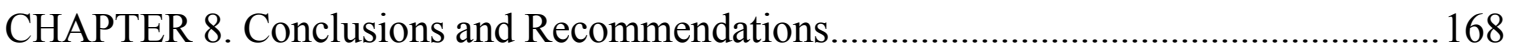

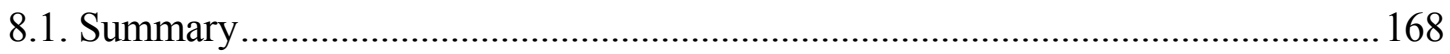

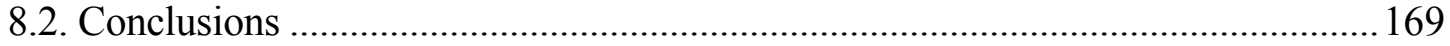

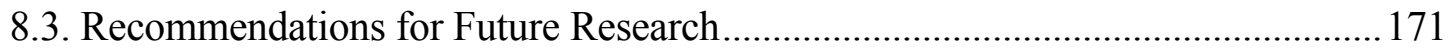

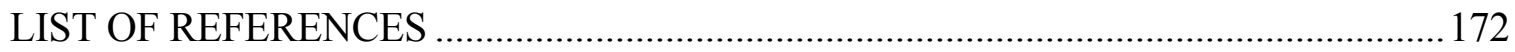




\section{LIST OF TABLES}

Table

Table 2.1 Cone factors from bearing capacity analysis

Page

Table 2.2 Cone factors $\mathrm{N}_{\mathrm{k}}$ derived using different cavity expansion methods (after $\mathrm{Yu}$ et al. 1998).

Table 2.3 Cone factors derived using strain path methods.

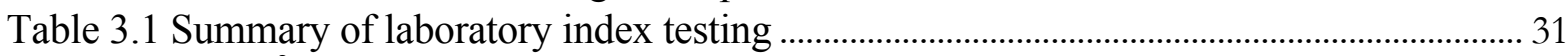

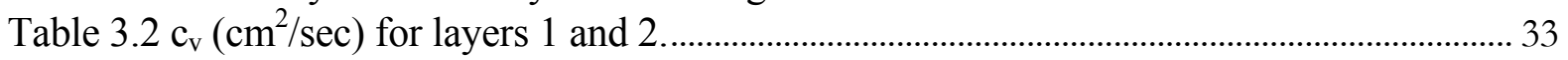

Table 3.3 Effective preconsolidation stress $\sigma_{p}^{\prime}$ and OCR ........................................................... 33

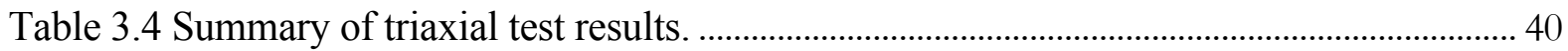



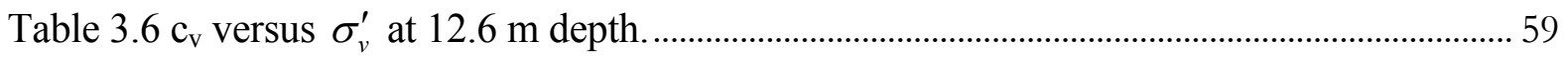

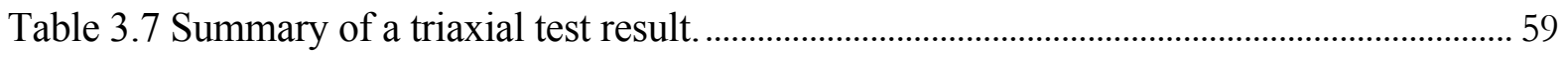

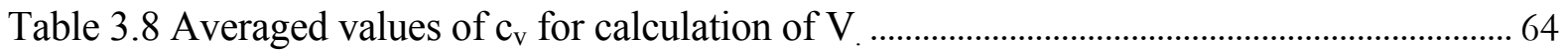

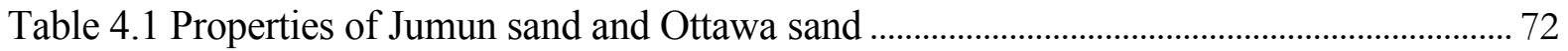

Table 4.2 Flexible-wall permeameter test results for kaolin - Ottawa sand mixtures.................. 78

Table 4.3 Flexible-wall permeameter test results for kaolin - Jumun sand mixtures.................... 80

Table 4.4 Minimum and maximum void ratios for clean and clayey Jumun sands...................... 85

Table 4.5 Boundary conditions in calibration chamber tests. ....................................................... 96

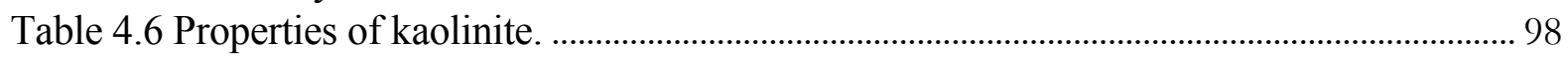

Table 4.7 Summary of Jumun sand Properties. ............................................................................... 98

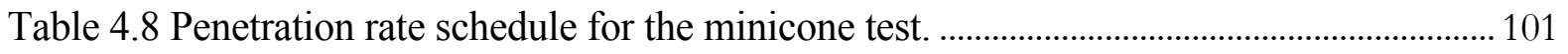

Table 4.9 Penetration rate schedule for the minipile test. ................................................................... 101

Table 5.1 Values of $\mathrm{q}_{\mathrm{t}}$, pore pressure, and $\mathrm{f}_{\mathrm{s}}$ of minicone penetration tests for various rates

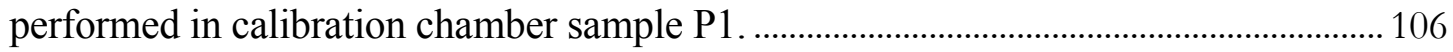

Table 5.2 Tip resistance, pore pressure, and $\mathrm{f}_{\mathrm{s}}$ for various penetration rates with a flat tip...... 113

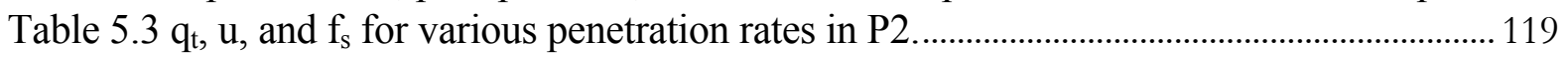

Table 5.4 Values of $\mathrm{q}_{\mathrm{t}}$, pore pressure, and $\mathrm{f}_{\mathrm{s}}$ for various penetration rates with a flat tip.......... 124

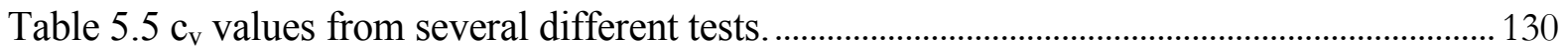

Table $6.1 \mathrm{c}_{\mathrm{v}}$ for soils containing small percentage of fines............................................................. 139

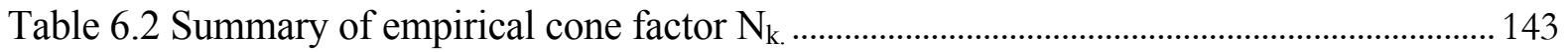

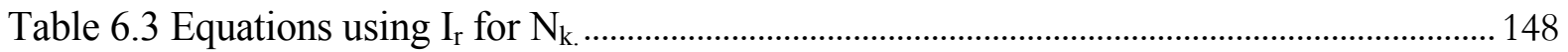



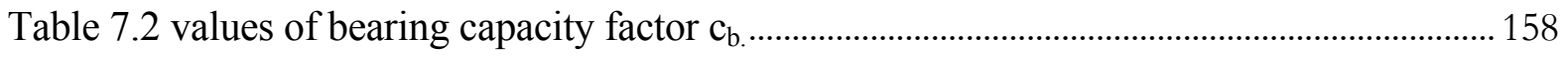

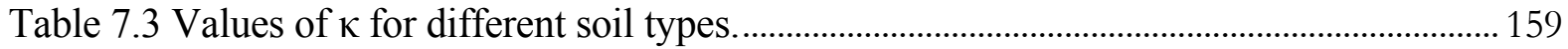

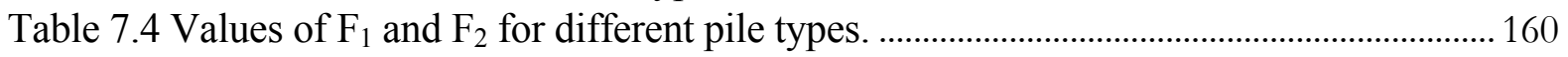




\section{LIST OF FIGURES}

Figure Page

Figure 2.1 Correlations between empirical cone factor $\mathrm{N}_{\mathrm{k}}$ and Plasticity Index $\mathrm{I}_{\mathrm{p}}$ : (a) results

from Baligh et al. (1980), Lunne and Kleven (1981) (b) results from Aas et al. (1986). 8

Figure 2.2 Cone factors derived from unconsolidated-undrained triaxial tests and field vane

shear tests (Stark and Juhrend, 1989). .................................................................. 9

Figure 2.3 Expansion of cavity (after Vesic 1972) ............................................................... 14

Figure 2.4 (a) Deformation of square grid during deep cone penetration in saturated clay and

(b) soil deformation paths during penetration (Baligh, 1985)...................................... 16

Figure 2.5 Influence of rate effect in varved clay (Bemben and Myers 1974).........................20

Figure 2.6 Influence of rate effect in soft clay (Roy et al. 1982) ..............................................20

Figure 2.7 Variation of $\mathrm{q}_{\mathrm{bL}} / \mathrm{q}_{\mathrm{bL}, \mathrm{min}}$ with normalized penetration ratio...................................... 24

Figure 2.8 Rate effect on undrained condition (Tani and Craig, 1995). ..................................25

Figure 3.1 (a) View of the test site and (b) layout of cone penetration test locations................29

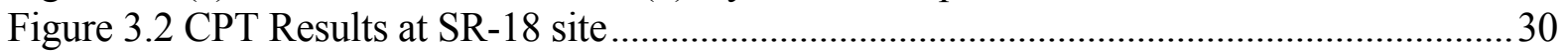

Figure 3.3 Grain size distributions of the soils at $7.7 \mathrm{~m}$ and $9.7 \mathrm{~m}$ depth................................. 31

Figure 3.4 Specimen displacements versus square root of time for Layer 1 (pressure increment

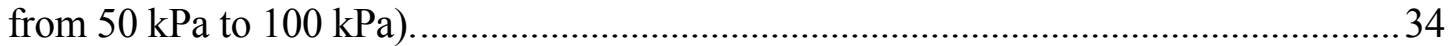

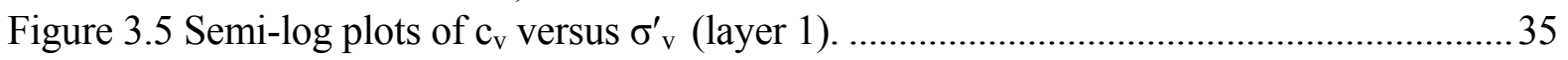

Figure 3.6 Specimen displacements versus square root of time $(7.7 \mathrm{~m}$, Layer 2$)$.................... 36

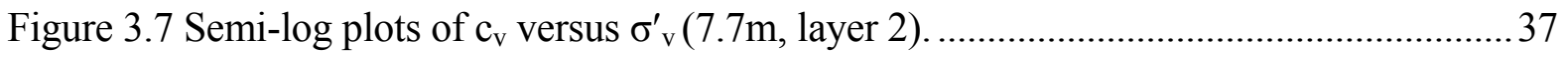

Figure 3.8 Semi-log plots of settlement versus vertical stress curves...................................... 39

Figure 3.9 Cone tip resistances measured at various penetration velocities for clayey silts $(6 \mathrm{~m}-$

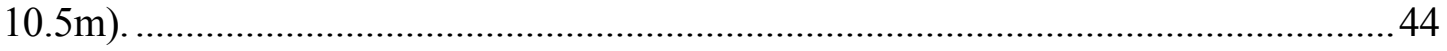

Figure 3.10 Cone tip resistances with various velocities in layer $1(9.2 \mathrm{~m}-10.2 \mathrm{~m}) \ldots \ldots \ldots \ldots \ldots . . . .45$

Figure $3.11 \mathrm{q}_{\mathrm{t}}$ and pore pressure results with varying penetration velocities. ..........................46

Figure 3.12 Effect of penetration rate on $\mathrm{q}_{\mathrm{t}}$, pore pressure, and $\mathrm{f}_{\mathrm{s}}(9.2 \mathrm{~m}-10.2 \mathrm{~m}$ depth, SR 18). 48

Figure 3.13 Cone tip resistances versus penetration velocity in layer $2(7.5 \mathrm{~m}-8.4 \mathrm{~m})$............50

Figure $3.14 \mathrm{q}_{\mathrm{t}}$ and pore pressure results with varying penetration velocities in Layer $2 \ldots \ldots \ldots \ldots . .51$

Figure 3.15 Effect of penetration rate on $\mathrm{q}_{\mathrm{t}}$, pore pressure, and $\mathrm{f}_{\mathrm{s}}(7.4 \mathrm{~m}-8.4 \mathrm{~m}$ depth, SR 18)...53

Figure 3.16 Profiles of $\mathrm{q}_{\mathrm{t}}, \mathrm{f}_{\mathrm{s}}$, pore pressure of CPTs at the SR 49 test site. ...............................56

Figure 3.17 Grain size distributions of the soils in the test layer (SR 49)................................57

Figure 3.18 Semi-log plot of $\mathrm{c}_{\mathrm{v}}$ versus $\sigma_{v}^{\prime}$ at $12.6 \mathrm{~m}$ depth (SR49) ........................................58

Figure 3.19 Cone tip resistance with various velocity in layer $1(9.2 \mathrm{~m}-10.2 \mathrm{~m}) \ldots \ldots \ldots \ldots \ldots \ldots \ldots . . . . . .60$

Figure $3.20 \mathrm{q}_{\mathrm{t}}$ and pore pressure results with varying penetration velocities. ...........................6 61

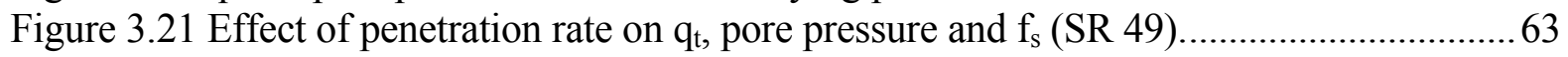

Figure 3.22 Plots of (a) normalized cone resistance and (b) normalized excess pore pressure

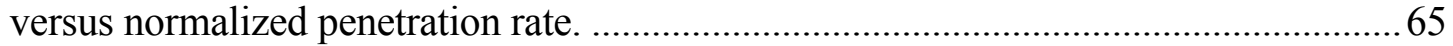

Figure 4.1 Grain size distributions of Jumun sand, Ottawa sand, and Kaolinite clay. ............... 73

Figure 4.2 Flexible wall permeability test setup............................................................... 75

Figure 4.3 Distribution of (a) clay percentage and (b) water content to the samples.................76

Figure 4.4 Plots of $\mathrm{k}, \mathrm{m}_{\mathrm{v}}$, and $\mathrm{c}_{\mathrm{v}}$ for kaolin clay - Ottawa sand mixtures................................ 79 
Figure 4.5 Plots of $\mathrm{k}, \mathrm{m}_{\mathrm{v}}$, and $\mathrm{c}_{\mathrm{v}}$ for kaolin clay - Jumun sand mixtures.

Figure 4.6 (a) Coefficient of consolidation $\mathrm{c}_{\mathrm{v}}$ and (b) normalized cone resistance $\mathrm{V}$ response according to the change of soil mixing ratio at a confining stress of $150 \mathrm{kPa}$..............82

Figure 4.7 Maximum and minimum void ratios of the sand and clay mixtures. .......................8 84

Figure 4.8 The correlations between $\mathrm{e}_{\mathrm{sk}}$ and different mixing ratio of soil mixture.................86

Figure 4.9 Schematic view of the flexible wall calibration chamber..................................... 88



Figure 4.11 Schematic view of the mixing system............................................................. 92

Figure 4.12 Replacement of the consolidation shell to the chamber double-wall shell. ............94

Figure 4.13 Types of boundary conditions in calibration chamber tests................................. 97

Figure 4.14 Grain size distributions of the two test mixtures..............................................99

Figure 4.15 Standard cone, Miniature cone, and Miniature cone with a flat tip...................... 102

Figure 4.16 Cone penetration locations on the top lid..................................................... 102

Figure 5.1 Cone resistance of reference cone penetration test on P1 $(\mathrm{v}=20 \mathrm{~mm} / \mathrm{sec}) \ldots \ldots \ldots . .107$

Figure 5.2 Results of minicone penetration test on P1 ..................................................... 108

Figure 5.3 Effect of penetration rate on $\mathrm{q}_{\mathrm{t}}$ and pore pressure.............................................. 111

Figure 5.4 Effect of penetration rate on friction resistance. ................................................ 111

Figure 5.5 Influence of cone apex angle on measured cone resistance. (after Acar 1981) ...... 114

Figure 5.6 Minicone penetration test results with flat tip on P1......................................... 115

Figure 5.7 Effect of penetration rate on $\mathrm{q}_{\mathrm{t}}$, tip resistance, and pore pressure on $\mathrm{P} 1$............... 117

Figure 5.8 Effect of penetration rate on sleeve friction on P1 .......................................... 118

Figure 5.9 Cone resistance of reference cone penetration test on P2 (v = 20 mm/sec).......... 120

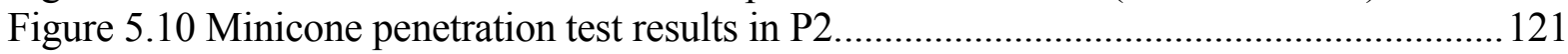

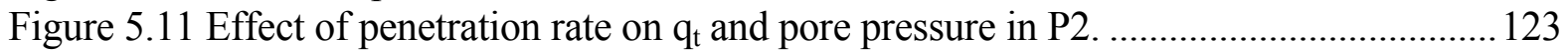

Figure 5.12 Effect of penetration rate on sleeve friction in $\mathrm{P} 2$............................................. 123

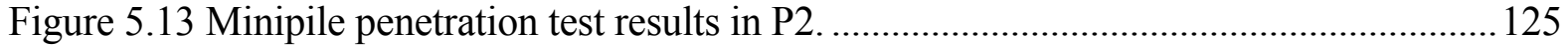

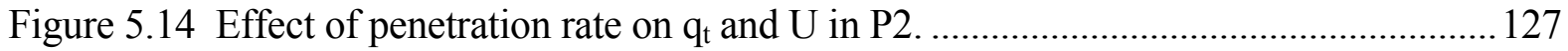

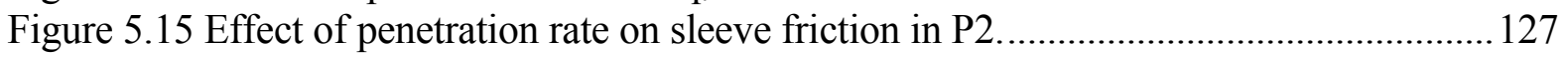

Figure 5.16 Calibration chamber $\mathrm{K}_{0}$-consolidation test..................................................... 131

Figure 5.17 Variation of (a) normalized cone resistance and (b) normalized excess pore pressure, with normalized penetration rate …............................................................. 133

Figure 6.1 Effect of penetration rate on normalized cone resistance and pore pressure. ......... 137

Figure 6.2 Normalized cone resistance versus $c_{\mathrm{v}}$ in standard CPT ....................................... 140

Figure 6.3 Chart for estimating the rigidity index for fine-grained soil ................................. 146

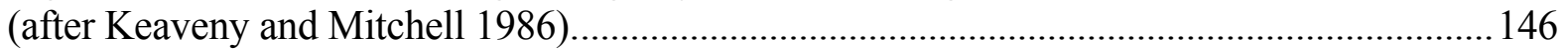

Figure 6.4 Correlation between $I_{r}$ and $I_{p}$ for normally consolidated soil. ........................... 147

Figure 6.5 Correlation between $\mathrm{N}_{\mathrm{k}}$ obtained from theoretical solutions and $\mathrm{I}_{\mathrm{p}}$ based on the

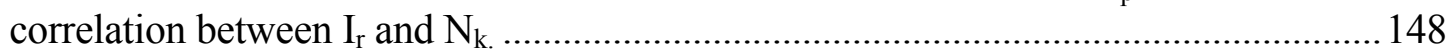



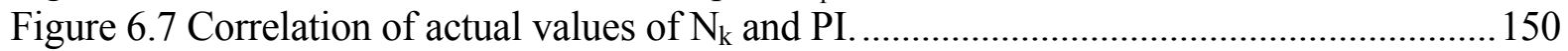

Figure 7.1 Criteria of $\alpha$ and $\mathrm{F}$ for pile capacity prediction (a) Correlation between $\alpha_{\mathrm{p}}$ and $\mathrm{s}_{\mathrm{u}} / \sigma_{\mathrm{v}}$

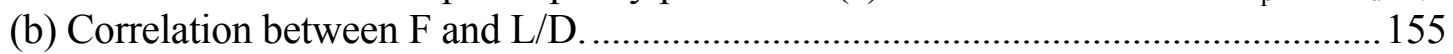

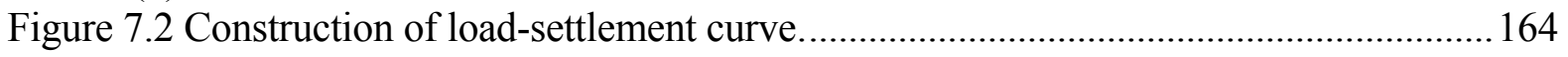

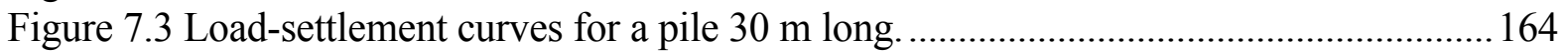


Figure 7.4 (a) Normalized plot of shaft friction settlement relationships for a range of soils from soft to very soft (b) Normalized plot of end bearing versus settlement relationships from soft to very stiff... 165 


\section{IMPLEMENTATION REPORT}

This research has produced advances in the understanding of the relationship between undrained shear strength and cone penetration resistance in terms of the rate of penetration. The rate of penetration can produce two extreme states: undrained penetration, if the rate of penetration is sufficiently high, and drained penetration, if the rate of penetration is sufficiently low.

If penetration is drained, CPT may be interpreted in ways similar to those for sand. That is not addressed in this report. If penetration is undrained, interpretation can be done in a way similar as done for clay. If undrained shear strength $\mathrm{s}_{\mathrm{u}}$ is desired, it can be estimated directly from $\mathrm{q}_{\mathrm{c}}$ in a simple way using the cone factor $\mathrm{N}_{\mathrm{k}}$. Recommended values for the cone factor are given in this report. The penetration rate that must be exceeded for penetration to be undrained and thus for traditional interpretation techniques to be applicable is also given in the present report in terms of the soil's coefficient of consolidation $c_{v}$ and the cone diameter. Both of these results are implementable and should be refined by accumulation of additional data. For a standard cone with $\mathrm{d}_{\mathrm{c}}=35.7 \mathrm{~mm}$ and $\mathrm{v}=20 \mathrm{~mm} / \mathrm{s}$, penetration is undrained for $\mathrm{c}_{\mathrm{v}}$ less than roughly $10^{-4}$ $\mathrm{m}^{2} / \mathrm{s}$, drained for $\mathrm{c}_{\mathrm{v}}$ greater than roughly $10^{-2} \mathrm{~m}^{2} / \mathrm{s}$ and partially drained for intermediate values of $c_{v}$.

If the penetration rate is such that penetration is found to be partially drained, which may be determined based on results given in this report so long as the coefficient of consolidation of the soil may be estimated (which can be done using the CPT itself by using the piezocone and conducting dissipation tests), interpretation of the cone cannot be done as done for clays. In particular, if undrained shear strength $s_{u}$ is desired, it cannot be related to a quantity determined under conditions that are not undrained, unless an empirical cone factor is used. There are enough data, either generated as part of this research or obtained from the literature as part of this research, to propose a credible correlation of this type. However, the value of the cone factor would obviously increase as conditions changed from undrained to drained. It is 
recommended that a theoretical study be conducted that will allow the modeling of partially drained penetration.

Finally, the report summarizes some methods of pile foundation design for axial loads, indicating those soils that may be potentially treated as clay for design purposes, so long as estimates of $s_{u}$ or measured cone resistance can be guaranteed to reflect undrained loading processes. 


\section{CHAPTER 1. INTRODUCTION}

\subsection{Statement of the Problem}

The cone penetration test (CPT) has been widely used for several decades because it is the most effective in-situ test method for obtaining practically continuous soil properties reliably. Data from the CPT can be used directly in foundation design or in the estimation of soil parameters. Undrained shear strength $s_{u}$ is the most important quantity for geotechnical design in clay (Schmertmann 1975). Thus, many attempts have been made to find a clear relationship between cone resistance $q_{\mathrm{c}}$ and undrained shear strength $\mathrm{s}_{\mathrm{u}}$. Many empirical correlations have been developed from in-situ approaches (Lunne and Kleven 1981, Jamiolkowski et al. 1982, Aas et al. 1986, Stark and Juhrend 1989). However, the accuracy of these correlations is poor, and their underlying theory is undependable. The correlations have been developed without a deep understanding of drainage conditions during cone penetration. This is of particular importance in mixtures of clay and sand.

The primary focus of this report is to advance the knowledge related to interpretation of CPT in clayey soils, particularly as pertains to pile design in clayey soils based on the results of CPTs. By clayey soils we mean soils with significant clay content. These may include soils in which the clay content is not high enough for penetration to be fully undrained. Thus, considerable attention has been paid to the effects of partial drainage during penetration on measured $\mathrm{q}_{\mathrm{c}}$ values. Other penetration rate effects, related to the viscous nature of clayey soils, have also been examined. The change in cone resistance with various penetration rates is analyzed. The interpretation and application of CPT results in clayey soils is investigated through a well programmed series of experimental field tests and cone penetration tests in a calibration chamber. The results of this study allow more effective interpretation of the CPT in silts, silty clays, and clays. A 
precise correlation between cone resistance and undrained shear strength is suggested based on clearly defined factors affecting cone resistance.

Determining pile capacity from CPT data is one of the first applications of the cone penetration test. The cone penetrometer can be regarded as a small-scale model pile. Thus, it is understandable that there is a strong relationship between CPT results and the base and shaft resistance of a pile. In clayey soils, pile shaft capacity is usually estimated by correlation between $s_{u}$ and shaft resistance, or by applying a design factor directly to cone resistance. The methods directly using CPT data are considered to be the most applicable methods for estimating pile shaft capacity. Thus, improved understanding of CPT data will also provide a basis for advancing the design of foundations in clayey soils. This study includes the estimation of pile load capacity in clayey soils, which requires an accurate determination of undrained shear strength on the basis of cone resistance. A new shaft capacity analysis for driven piles in clayey soils is suggested based on the suggested correlation between undrained shear strength and cone resistance.

\subsection{Objective of Research}

The main objectives of the present research are:

1. Evaluate drainage during cone penetration and determine the transition points between undrained and partially drained and between partially drained and drained conditions based on cone penetration rate and clay content.

2. Obtain penetration data for different drainage conditions by performing cone penetration tests in the field and in calibration chambers at various penetration rates.

3. Determine reliable values of the cone factor $\mathrm{N}_{\mathrm{k}}$ to allow accurate estimation of undrained shear strength $s_{u}$ from cone resistance $q_{c}$. 
4. Propose a new shaft capacity analysis method for piles in clayey soil based on a correlation between cone resistance and undrained shear strength that reflects the effects of penetration rate.

\subsection{Report Outline}

This report has nine additional chapters:

Chapter 2 presents a comprehensive literature review of cone penetration analysis models. The theoretical and empirical bases for the cone factor $\mathrm{N}_{\mathrm{k}}$ are reviewed. Previous studies of penetration rate effects are summarized.

Chapter 3 deals with the field cone penetration tests performed to investigate rate effects and drainage conditions in clayey soils.

Chapter 4 describes miniature piezocone penetration tests performed in the calibration chamber and the calibration chamber testing plan. Techniques for specimen preparation and test procedure are described. The results of flexible wall permeability tests performed to select specimen mixing ratios are also summarized and the mixing ratios for test specimens are suggested.

Chapter 5 presents test results obtained from the calibration chamber test program. The change of cone resistance with penetration rate and pore pressure transition points between undrained, partially drained, and drained conditions are discussed.

Chapter 6 summarizes the test results of Chapters 3 - 5 and discusses results of CPTs affected by drainage. Factors affecting the cone factor $\mathrm{N}_{\mathrm{k}}$ are investigated, and a correlation for $\mathrm{N}_{\mathrm{k}}$ is suggested.

Chapter 7 presents an overview of the pile design methods currently being used to estimate shaft capacity. The methods are based on undrained shear strength or CPT results. The issues related to pile load response are reviewed.

Chapter 8 consists of a summary, conclusions, and recommendations for further research. 


\section{CHAPTER 2. CONE PENETRATION TEST IN CLAYEY SOILS}

\subsection{Introduction}

The cone penetration test has been mainly used for three applications: 1) to estimate soil properties through an appropriate correlation, 2) to directly perform geotechnical design from CPT data, 3) to determine subsurface stratigraphy. Numerous attempts have been made over the years to develop reliable analytical models for simulating the cone penetration process as well as to derive proper correlations with soil properties from empirical CPT results. Analysis of the problem is difficult due to the large stresses and strains imposed during penetration and complicated soil behavior induced by complex initial soil conditions. Uncertainties associated with pore-water pressure and the time dependent behavior of clay also make the problem more complicated.

The evaluation of the undrained shear strength $s_{u}$ of clay has been one of the earliest and most important applications of the cone penetration test (Schmertmann 1975, Lunne and Kleven 1981). Undrained shear strength $s_{u}$ is one of the most important design parameters in clayey soils, and most geotechnical design in clayey soils are done using $\mathrm{s}_{\mathrm{u}}$. There are several approaches available to determine $s_{\mathrm{u}}$, including empirical equations, laboratory tests, and in-situ tests. Literature on current analytical methods and empirical correlations relating cone penetration results with soil properties is summarized. The focus is on literature concerning:

1) analytical models of cone resistance and undrained shear strength;

2) discussion of cone factor $N_{k}$ values obtained from theoretical methods;

3) summary of $\mathrm{N}_{\mathrm{k}}$ values obtained from field tests;

4) rate effects on cone resistance. 


\subsection{Empirical Efforts for Correlating Shear Strength to Cone Resistance}

Predictions using empirical equations may have low accuracy. This error is usually compensated for by using large safety factors. Laboratory testing, in contrast, may be able to produce more accurate estimates of shear strength if sampling and testing are done well, but is costly and time consuming. The application of CPT results is usually a better alternative and is now used to a larger degree than laboratory testing (Mitchell and Brandon 1998). The undrained shear strength of clay can be estimated from cone resistance $\mathrm{q}_{\mathrm{c}}$ through an equation of the form:

$$
s_{u}=\frac{q_{t}-\sigma_{v}}{N_{k}}
$$

where $\mathrm{N}_{\mathrm{k}}$ is the cone factor and $\sigma_{\mathrm{v}}$ is total overburden stress or in-situ mean stress. Knowledge of the cone factor $\mathrm{N}_{\mathrm{k}}$ is essential for reliable estimation of $\mathrm{s}_{\mathrm{u}}$ from $\mathrm{q}_{\mathrm{c}}$, and numerous attempts have been made by researchers to develop accurate $\mathrm{N}_{\mathrm{k}}$ values by empirical approaches (Lunne and Kleven 1981, Aas et al. 1986, Rochelle et al. 1988, Lunne et al. 1986, Stark and Juhrend 1989). The approach to $\mathrm{N}_{\mathrm{k}}$ determination has traditionally been to perform the CPT, recover samples, and then test them in the laboratory to obtain $s_{u}$. Alternatively, vane shear tests can be performed side-by-side with the CPT to estimate $s_{u}$ (Aas et al. 1986, La Rochelle et al. 1988). The cone factor is then estimated using Eq. (2.1), given that $\mathrm{q}_{\mathrm{c}}, \sigma_{\mathrm{v}}$, and $\mathrm{s}_{\mathrm{u}}$ are all known. However, as noted by Lunne et al. (1976), there are limitations on the accuracy of $s_{u}$ determinations from the vane test that are related to the direction and rate of shearing (Lunne et al. 1976). Therefore, empirical correlations between $\mathrm{q}_{\mathrm{c}}$ and values of $\mathrm{s}_{\mathrm{u}}$ obtained based on field vane shear tests tend to be less reliable than those based on laboratory measurement of $s_{u}$.

Though many researchers have tried to determine $\mathrm{N}_{\mathrm{k}}$ from field cone penetration data, the results were not as definitive as the ones from theoretical efforts. In the early stages of research on the subject, mechanical cones were used in the field tests, and the reported correlations had large scatters. For instance, Amar et al. (1975) showed that the 
obtained cone factor $\mathrm{N}_{\mathrm{k}}$ varied between 5 and 70. As use of the electrical cone started, the accuracy of CPT data improved and the reliability of data increased. When an electrical cone measures pore pressure through a filter element located on the shoulder part of the cone, it becomes possible to correct the measured cone resistance for the pore pressure acting behind the cone tip (Baligh et al, 1981, de Ruiter, 1981). The corrected cone resistance $\mathrm{q}_{\mathrm{t}}$ is calculated by the equation:

$$
q_{t}=q_{c}+(1-a) u_{2}
$$

where $\mathrm{u}_{2}=$ pore pressure acting behind the cone during penetration; $\mathrm{a}=$ cone area ratio. Thus, empirical correlations for $\mathrm{N}_{\mathrm{k}}$, established based on uncorrected cone resistance values from an electrical cone before the mid ' $80 \mathrm{~s}$, when pore pressure measurement became possible, may be less reliable.

Some researchers emphasized that $\mathrm{N}_{\mathrm{k}}$ is related to a plasticity index $I_{p}$, and plotted correlations between $\mathrm{N}_{\mathrm{k}}$ and $\mathrm{I}_{\mathrm{p}}$ (Lunne at el. 1976, Baligh et al. 1980, Lunne and Kleven 1981, Aas et al. 1986, Rochelle et al. 1988). Baligh et al. (1980) collected data at MIT and at NGI and presented $\mathrm{N}_{\mathrm{k}}$ from reference $\mathrm{s}_{\mathrm{u}}$ values obtained from field vane tests and $I_{p}$ (Figure 2.1). Figure 2.1 (a) shows that an average value of $\mathrm{N}_{\mathrm{k}}$ is about 14 and that $\mathrm{N}_{\mathrm{k}}$ decreases from 18 to 10 as $\mathrm{I}_{\mathrm{p}}$ increases from roughly 5 to roughly 50 (Baligh et al. 1980, Lunne and Kleven 1981). Aas et al. (1986) noted that previous researchers did not account for cone area ratios, which increase the uncertainty of correlations based on such data. Aas evaluated field cone test results performed at nine different clay sites and correlated $\mathrm{q}_{\mathrm{c}}$ corrected by Eq. (2.2) with average $\mathrm{s}_{\mathrm{u}}$ determined in the laboratory (average $\mathrm{s}_{\mathrm{u}}$ of triaxial and direct shear tests) as well as $\mathrm{s}_{\mathrm{u}}$ from field vane tests. Figure 2.1(b) shows the correlation between $\mathrm{N}_{\mathrm{k}}$ based on average laboratory-determined $\mathrm{s}_{\mathrm{u}}$ and $\mathrm{I}_{\mathrm{p}}$. The trends of the plots prepared by Aas et al. (1986) are opposite of those of Figure 2.1(a). The cone factor $\mathrm{N}_{\mathrm{k}}$ increases linearly with plasticity index from 13 at $\mathrm{I}_{\mathrm{p}}=0$ to 18.5 at $\mathrm{I}_{\mathrm{p}}=50 \%$. It was also revealed in their study that $\mathrm{N}_{\mathrm{k}}$ values from field vane tests were more variable than values of $\mathrm{N}_{\mathrm{k}}$ from lab tests. However, as shown in Figure 2.1 (a) and (b), the scattered 
values of $\mathrm{N}_{\mathrm{k}}$ do not show trends clear enough to establish a highly reliable correlation between $\mathrm{N}_{\mathrm{k}}$ and $\mathrm{I}_{\mathrm{p}}$.

Jamiolkowski et al. (1982) conducted CPTs in three saturated clay deposits having different stress histories, and obtained similar $\mathrm{N}_{\mathrm{k}}$ values, between 9 and 11. Lunne et al. (1986) evaluated $\mathrm{N}_{\mathrm{k}}$ values on the basis of a series of cone penetration tests in North Sea clay and obtained $s_{u}$ from anisotropic consolidated undrained (ACU) triaxial tests. They tried to correlate $\mathrm{N}_{\mathrm{k}}$ and a function of $\mathrm{B}_{\mathrm{q}}$, the pore pressure ratio. Pore pressure ratio $\mathrm{B}_{\mathrm{q}}$ was proposed by Seneset and Janbu (1984):

$$
B_{q}=\frac{u_{2}-u_{0}}{q_{t}-\sigma_{v}}
$$

where $\mathrm{u}_{2}=$ pore pressure measured between the cone and the friction sleeve, $\mathrm{u}_{0}=$ equilibrium pore pressure, $\sigma_{\mathrm{v}}=$ total overburden stress. They reported that $\mathrm{N}_{\mathrm{k}}$ tends to decrease from 18 to 9 with increasing $\mathrm{B}_{\mathrm{q}}$. They also noted that $\mathrm{N}_{\mathrm{k}}$ varies with OCR, and tried to estimate OCR using $\mathrm{B}_{\mathrm{q}}$. If the data from high OCR clay layers are removed from the suggested graph, the range of $\mathrm{N}_{\mathrm{k}}$ for $\mathrm{NC}$ clay would be shifted down from the suggested range. They also introduced another type of cone factor, $\mathrm{N}_{\mathrm{KE}}$, using a different definition of effective cone resistance $q_{E} . N_{K E}$ and $q_{E}$ are defined as:

$$
\begin{gathered}
N_{K E}=\frac{q_{E}}{s_{u}} \\
q_{E}=q_{t}-\left(u+\gamma_{w} h\right)
\end{gathered}
$$

where $\gamma_{w}=$ unit weight of water, and $\mathrm{h}=$ depth of penetration. 


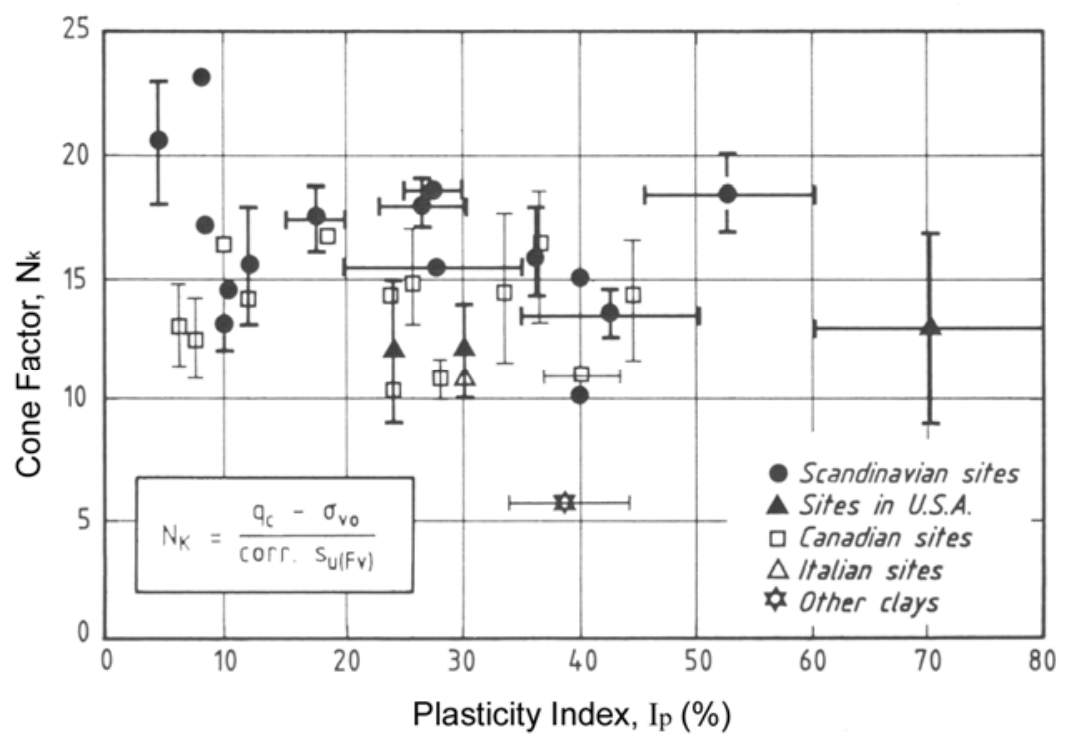

(a)

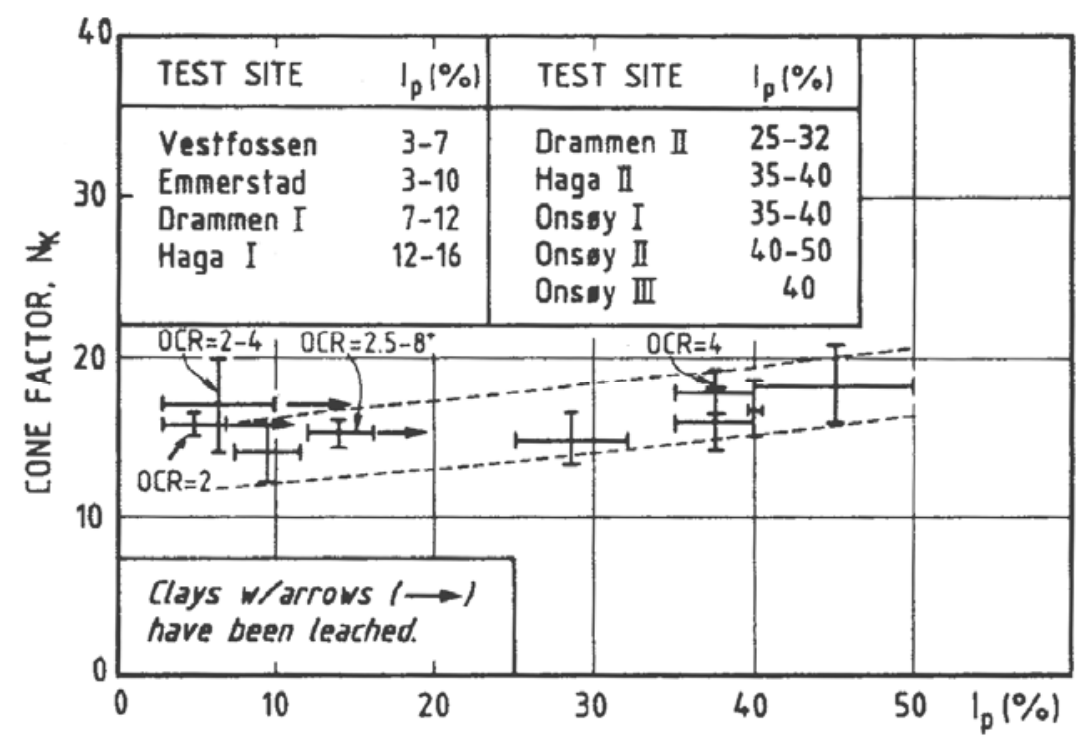

(b)

Figure 2.1 Correlations between empirical cone factor $\mathrm{N}_{\mathrm{k}}$ and Plasticity Index $\mathrm{I}_{\mathrm{p}}$ : (a) results from Baligh et al. (1980), Lunne and Kleven (1981) (b) results from Aas et al. (1986). 
Rad and Lunne (1988) compiled CPT data from published materials in which consolidated undrained compression triaxial tests were used to find $\mathrm{s}_{\mathrm{u}}$ and correlated the data with OCR. They argued that OCR has the strongest influence on the piezocone results. Also, the collected data proved that $\mathrm{N}_{\mathrm{k}}$ calculated from either $\mathrm{s}_{\mathrm{u}-\mathrm{CAUC}}$ or $\mathrm{s}_{\mathrm{u}-\mathrm{CIUC}}$ in normally consolidated clay layers yields results similar to those from analytical solutions, which are discussed in the following section.

Stark and Juhrend (1989) compared cone resistance with both UU triaxial results and field vane shear strength. As is shown in Figure 2.2, The average cone factor $\mathrm{N}_{\mathrm{k}}$ calculated based on unconsolidated-undrained triaxial test results was 11 with a standard deviation of 1.5. On the other hand, the average $\mathrm{N}_{\mathrm{k}}$ based on vane shear tests was 13 .

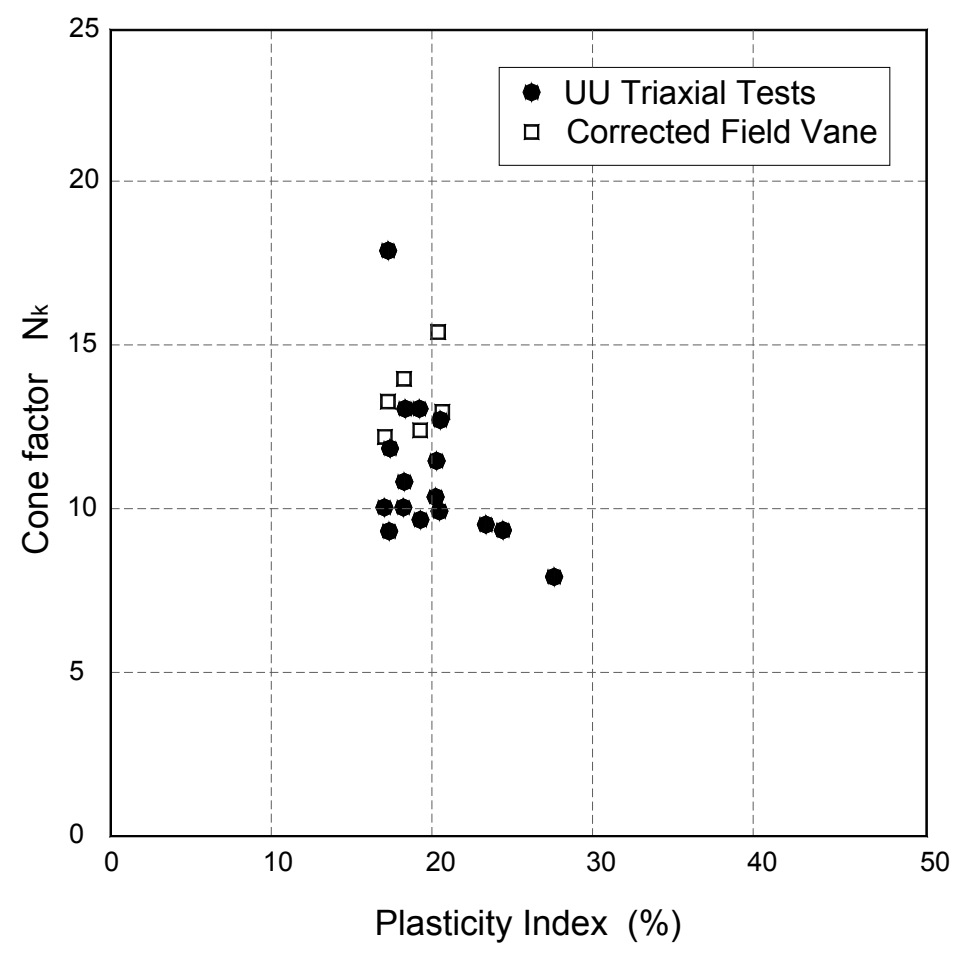

Figure 2.2 Cone factors derived from unconsolidated-undrained triaxial tests and field vane shear tests (Stark and Juhrend, 1989). 


\subsection{Analytical Models for Cone Resistance}

In this section, a review is done of some analytical models for the determination of the cone factor $\mathrm{N}_{\mathrm{k}}$. The difficulty in developing a rigorous model of cone penetration is generally due to large stresses and strains imposed during the penetration process and the complex soil behavior induced from unknown initial soil conditions (Jamiolkowski et al. 1982). Because of these problems, some assumptions to simplify soil behavior, the penetration process, and boundary conditions are essential for any analytical method.

Three general theoretical approaches are commonly used to estimate cone penetration resistance:

(1) bearing capacity analysis;

(2) models based on cavity expansion theory;

(3) strain path methods.

A brief summary and comparison of these methods are given in the following sections.

\subsubsection{Bearing Capacity}

Because of the similarity between installing a pile and pushing a cone into soil, bearing capacity theory has often been used to illustrate the cone penetration process. Bearing capacity analysis of the cone penetration test is based on the fundamental solution

for a strip footing on the surface of an elastic-plastic solid developed by Prandtl (1921), but requires both a shape and depth factor and most require the use of shape factors for circular cone penetration. 
The general bearing capacity equation consists of three different terms (Terzaghi 1943, Meyerhof 1951, Brinch Hansen 1970):

$$
q_{b}=c N_{c}+q_{0} N_{q}+\frac{1}{2} \gamma B N_{\gamma}
$$

where $\mathrm{c}=$ cohesion, $\mathrm{q}_{0}=$ surcharge load, $\mathrm{N}_{\mathrm{c}}, \mathrm{N}_{\mathrm{q}}, \mathrm{N}_{\mathrm{r}}=$ bearing capacity factors. On saturated clay, it is generally assumed that failure occurs under undrained conditions. Therefore clays in the failure state are modeled as a material with $c=\mathrm{s}_{\mathrm{u}}=$ undrained shear strength and $\phi=0$. This condition simplifies Eq. (2.6) to the following equation:

$$
q_{b}=s_{u} N_{c}+q_{0}
$$

Since this method was derived for strip footings sitting on the surface, shape and depth corrections to $\mathrm{N}_{\mathrm{c}}$ are required. Generally depth and shape factors are derived from empirical data or approximate analyses (Meyerhof 1951, Brinch Hansen 1970). Some of the $\mathrm{N}_{\mathrm{k}}$ values derived for piles from the method of bearing capacity theory are presented in Table 2.1.

Table 2.1 Cone factors from bearing capacity analysis.

\begin{tabular}{c|c}
\hline Reference & $\mathrm{N}_{\mathrm{k}}$ \\
\hline Terzaghi (1943) & 9.3 \\
\hline Meyerhof (1951) & 10.4 \\
\hline Begemann (1965) & 9.6 \\
\hline Koumoto and Kaku (1982) & 9.6 \\
\hline
\end{tabular}

Salgado et al. (2004) obtained shape and depth factors using a rigorous analysis based on finite-element limit analysis. They computed bearing capacities for strip, circular and square shape footings at various depths and computed shape and depth factors from 
these values. According to their results, the range of $\mathrm{N}_{\mathrm{c}}$ for deep circular footings is in the $11 \sim 14$ ranges according to lower and upper bound analysis.

\subsubsection{Cavity Expansion Theory}

In the cavity expansion approach, it is assumed that the mobilized cone tip resistance is related to the pressure required to expand a cavity in soil from a radius equal to zero to a radius equal to that of the cone penetrometer. The theory for the expansion of a cylindrical cavity in an elastic, perfectly plastic material, which had initially been proposed by Bishop et al. (1945), was extended by Vesic (1972). He presented approximate solutions for spherical and cylindrical cavity limit pressures and used these solutions to propose bearing capacity factors for deep foundations. He assumed the soil as a linear elastic perfectly plastic material to simplify cavity expansion analysis, and followed the Mohr-Coulomb failure criterion. Expansion of a cavity in soil is illustrated in Figure 2.3. In the figure, the initial cavity radius $R_{i}$ is expanded to $R_{u}$ when a uniformly distributed internal cavity pressure reached its limit value.

As pointed out by Salgado (1993), the fact that Vesic's model doesn't account for the effect of dilatancy means that it has a potential for underpredicting limit pressure and, thus, penetration resistance. After Vesic, significant progress was made in developing cavity expansion solutions by adapting improved soil stress-strain models and yield criteria in both clay and sand (Cater et al. 1986, Yu and Houlsby 1991, Salgado et al. 1997, Salgado and Randolph 2001). More specifically, many researchers have related limit pressure solutions to practical values, such as pile end bearing or cone resistances (Randolph et al. 1979, Salgado 1993, Yasufuku and Hyde 1995, Salgado and Randolph 2001). All cone factors $\mathrm{N}_{\mathrm{k}}$ derived from cavity expansion solutions depend on the rigidity index $\mathrm{I}_{\mathrm{r}}$ of soil. Table 2.2 compares values of $\mathrm{N}_{\mathrm{k}}$ derived using different cavity expansion methods for stiffness indices ranging from 50 to 400 (Yu \& Mitchell 1998). 
Table 2.2 Cone factors $\mathrm{N}_{\mathrm{k}}$ derived using different cavity expansion methods (after Yu et al. 1998).

\begin{tabular}{c|c|c|c|c|c}
\hline $\mathrm{G} / \mathrm{s}_{\mathrm{u}}$ & $\begin{array}{c}\text { Ladanyi and } \\
\text { Johnston } \\
(1974): \\
\text { Rough cone }\end{array}$ & $\begin{array}{c}\text { Vesic (1977) } \\
\text { rough cone }\end{array}$ & $\begin{array}{c}\text { Baligh (1975) } \\
\text { rough cone }\end{array}$ & $\begin{array}{c}\text { Yu (1993) } \\
\text { Smooth cone }\end{array}$ & $\begin{array}{c}\text { Yu (1993) } \\
\text { partly rough cone }\end{array}$ \\
\hline 50 & 8.3 & 9.1 & 15.9 & 8.5 & 10.4 \\
\hline 100 & 9.2 & 10.0 & 16.6 & 9.3 & 11.2 \\
\hline 200 & 10.1 & 10.9 & 17.3 & 10.1 & 12.0 \\
\hline 300 & 10.6 & 11.5 & 17.7 & 10.6 & 12.5 \\
\hline 400 & 11.0 & 11.9 & 18.0 & 10.9 & 12.8 \\
\hline
\end{tabular}




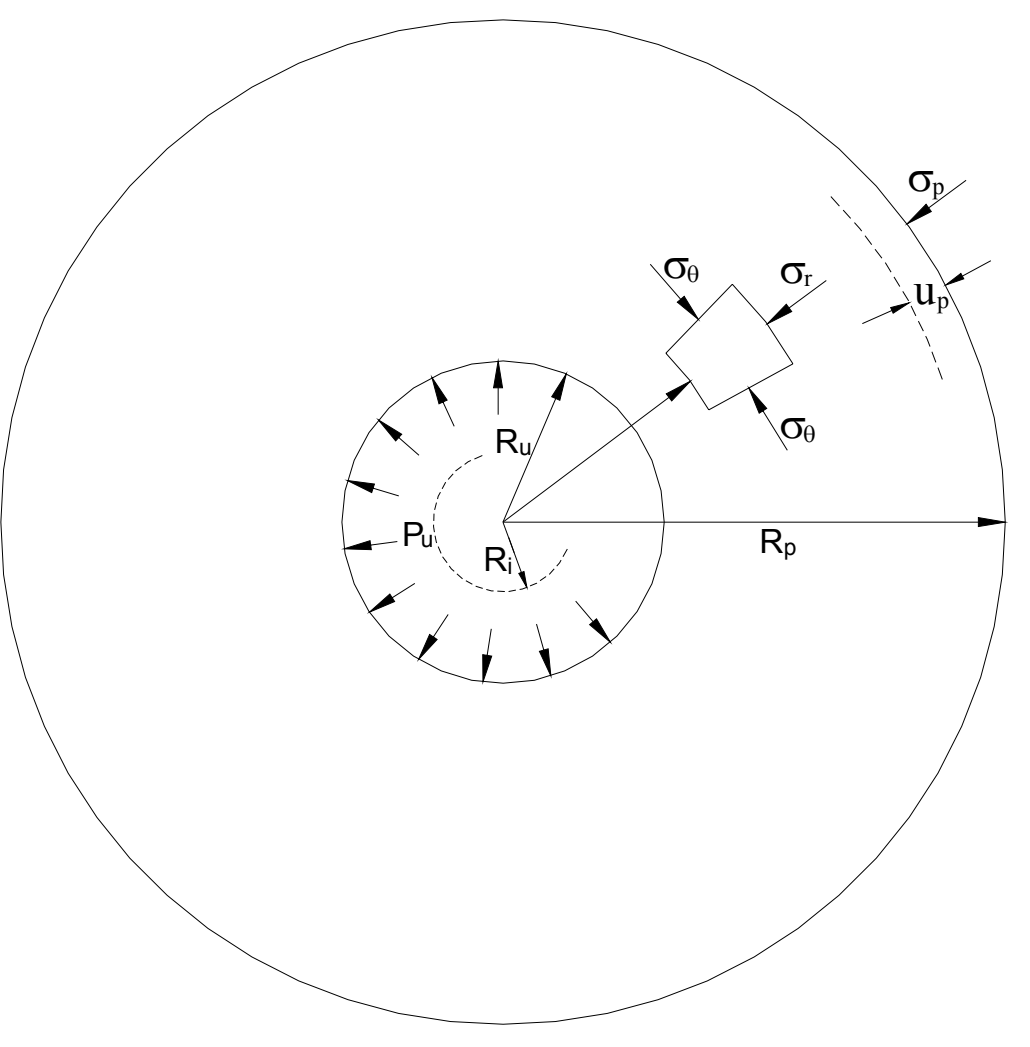

Figure 2.3 Expansion of cavity (after Vesic 1972) 


\subsubsection{Strain Path Method}

Baligh (1975) asserted that soil deformations caused by the installation of a rigid object in the ground are essentially strain-controlled. Based on this concept, Baligh (1985) developed the strain path method to solve problems of deep quasi-static penetration of axisymmetric rigid bodies in saturated clays (e.g., piles, cone penetrometers, samplers, etc.). The basic concept on which this method is based is shown in Figure 2.4. In the method, the continuous penetration of a cone is assumed as a steady-state condition. The soil around a cone is regarded as a steady state of flow passing along a fixed cone penetrometer. This means that the stress and strain fields in the soil are not changed with time from the point of view of the cone tip if homogeneous soil conditions are present. The soil is simplified as a rigid, perfectly plastic material under isotropic conditions. The strain field is obtained by integrating the velocity field along streamlines.

Teh and Houlsby (1991) assumed soil to flow like a viscous fluid and developed $\mathrm{N}_{\mathrm{k}}$ by the strain-path finite element method. A simple linear elastic-perfectly plastic model with von Mises yield surface was used for the analysis. The deviatoric stresses were determined by integrating the appropriate constitutive laws along the streamlines. The difficulty of using the finite element method for cone penetration problems is how to simulate the whole expansion on an initially prepared soil mesh. Teh and Houlsby (1991) combined the merits of strain path method, which correctly accounts for steady state flow, with the finite element method, which reliably computes force equilibrium. The expression for $\mathrm{N}_{\mathrm{k}}$ derived from the strain-path finite element analysis also includes the effect of rigidity index $\mathrm{I}_{\mathrm{r}}$, cone roughness, and in-situ stress: 




(a)



(b)

Figure 2.4 (a) Deformation of square grid during deep cone penetration in saturated clay and (b) soil deformation paths during penetration (Baligh, 1985). 


$$
N_{c}=\frac{4}{3} \cdot\left(1+\ln I_{r}\right)\left(1.25+\frac{I_{r}}{2000}\right)+2.4 \cdot \alpha_{f}-0.2 \cdot \alpha_{s}-1.8 \cdot \Delta
$$

$$
\begin{gathered}
\text { where } \alpha_{f}=\frac{\sqrt{3 \cdot \tau_{f}}}{2 \cdot s_{u}}: \text { cone roughness }\left(0 \leq \alpha_{f} \leq 1.0\right) \\
\alpha_{s}=\text { shaft roughness }\left(0 \leq \alpha_{s} \leq 1.0\right) ; \\
\Delta=\frac{\sigma_{v_{0}}-\sigma_{h_{0}}}{2 s_{u}}: \text { initial stress condition }
\end{gathered}
$$

Cone factors $\mathrm{N}_{\mathrm{k}}$ calculated using the strain-path-based methods of Baligh (1985) and Teh and Houlsby (1991), with stiffness indices ranging from 50 to 500, are shown in Table 2.3.

Table 2.3 Cone factors derived using strain path methods.

\begin{tabular}{c|c|c|c|c}
\hline $\mathrm{G} / \mathrm{s}_{\mathrm{u}}$ & Baligh (1985) & $\begin{array}{c}\text { Teh and Houlsby } \\
(1991) \\
\text { smooth cone, } \\
\triangle=0\end{array}$ & $\begin{array}{c}\text { Teh and Houlsby } \\
(1991) \\
\text { smooth cone, } \\
\triangle=0.5\end{array}$ & $\begin{array}{c}\text { Teh and Houlsby } \\
(1991) \\
\text { rough cone, } \\
\triangle=0.5\end{array}$ \\
\hline 50 & 9.3 & 8.4 & 7.5 & 9.9 \\
\hline 100 & 10.7 & 9.7 & 8.8 & 11.2 \\
\hline 200 & 12.1 & 11.3 & 10.4 & 12.8 \\
\hline 300 & 12.9 & 12.5 & 11.6 & 14.0 \\
\hline 400 & 13.5 & 13.5 & 12.6 & 15.0 \\
\hline 500 & 13.9 & 14.4 & 15.9 & 15.9 \\
\hline
\end{tabular}




\subsection{Rate Effect on CPT}

\subsubsection{Cone Penetration Rate}

The standard rate of penetration for performing the cone penetration test (CPT) is \pm $20 \mathrm{~mm} / \mathrm{s}$ according to the International Reference Test Procedure (IRTP) and the ASTM standard (ASTM D 5778). This standard penetration rate is specified regardless of soil type. During cone penetration at the standard rate, fully drained and fully undrained conditions prevail for clean sand and pure clay, respectively. For soils consisting of mixtures of silt, sand and clay, cone penetration may take place under partially drained conditions at the standard penetration rate, depending on the ratios of these three broad particle size groups. However, the fact that the penetration rate affects the value of cone penetration resistance $\mathrm{q}_{\mathrm{c}}$ for these soils was not taken into account at the time standards were prepared for the CPT. Physically, drainage conditions during penetration are important because, if the penetration rate is sufficiently low for a given soil, the soil ahead of the cone consolidates during penetration, thereby developing larger shear strength and stiffness than it would have under undrained conditions. The closer the conditions are to fully drained during penetration, the higher the value of $\mathrm{q}_{\mathrm{c}}$. Another physical process that is at play for soils with large clay content for penetration under fully undrained conditions is the effect of the rate of loading on shear strength. The higher the penetration rate is, the larger the undrained shear strength $\mathrm{s}_{\mathrm{u}}$ is, and the larger the $\mathrm{q}_{\mathrm{c}}$.

These two physical processes (drainage and loading rate effects), with opposite effects on the change of $\mathrm{q}_{\mathrm{c}}$ with loading rate, appear in a number of studies in the literature, although a detailed treatment of them is not found. A number of studies (Bemben and Myers 1974, Roy et al. 1982, Campanella et al. 1983, Kamp 1982, Filho and Alencar 1982, Powell and Quarterman 1988) have considered rate effects in CPT testing for both clays and sands. In these studies, comparisons were made between data from field CPTs or penetration tests performed in the laboratory at various penetration rates. However, a conceptual framework supported by experimental results that can be used in the interpretation of CPT results in transitional soils is still not available. 
In this section, previous research is briefly summarized and discussed. Some initial experimental efforts were not considered because of unreliable boundary conditions.

\subsubsection{Previous Studies}

Bemben and Myers (1974) investigated the influence on $\mathrm{q}_{\mathrm{c}}$ of penetration rate in slightly overconsolidated clay deposits from about $25 \mathrm{~m}$ to $30 \mathrm{~m}$ in thickness with nine different penetration rates between 0.2 and $200 \mathrm{~mm} / \mathrm{sec}$. The obtained $\mathrm{q}_{\mathrm{c}}$ values versus rate of penetration are shown in Figure 2.5. As shown in the figure, the minimum $\mathrm{q}_{\mathrm{c}}$ is obtained at a rate of $2 \mathrm{~mm} / \mathrm{sec}$; there is about a $40 \%$ increase in $\mathrm{q}_{\mathrm{c}}$ as the penetration rate decreases to $0.5 \mathrm{~mm} / \mathrm{sec}$, and over $50 \%$ when the penetration rate increases to about $200 \mathrm{~mm} / \mathrm{sec}$. They presumed that the increase of $\mathrm{q}_{\mathrm{c}}$ at low penetration rates was associated with the transition from undrained to drained penetration and argued that both undrained and drained failure conditions were obtained in the range of $0.5 \sim 50 \mathrm{~mm} / \mathrm{sec}$. However, it is not possible to define the drainage conditions during cone penetration without either simultaneously measuring excess pore pressure or knowing the consolidation response of the soil in a detailed manner.

Roy et al. (1982) conducted field piezocone penetration tests in sensitive and soft clays with seven different penetration rates varying between 0.5 and $40 \mathrm{~mm} / \mathrm{sec}$, and obtained similar measurements to those by Bemben and Myers. The observed rate effect is shown in Figure 2.6 in the form of $q_{c} / \sigma_{v}^{\prime}$ versus log plot. As shown in the Figure, the minimum ratio $q_{c} / \sigma_{v}^{\prime}$ was measured approximately at a penetration rate of $2.5 \mathrm{~mm} / \mathrm{sec}$. However, simultaneously measured pore pressure results during penetration show stable values as the penetration rate changed from $0.5 \mathrm{~mm} / \mathrm{sec}$ to $40 \mathrm{~mm} / \mathrm{sec}$. Since pore pressures were not observed to drop with decreasing penetration rate, the drainage conditions probably were

undrained for all rates. Thus, the change of $\mathrm{q}_{\mathrm{c}}$ due to the change of penetration rate in the test is probably not explained by transition from drained to undrained conditions. 


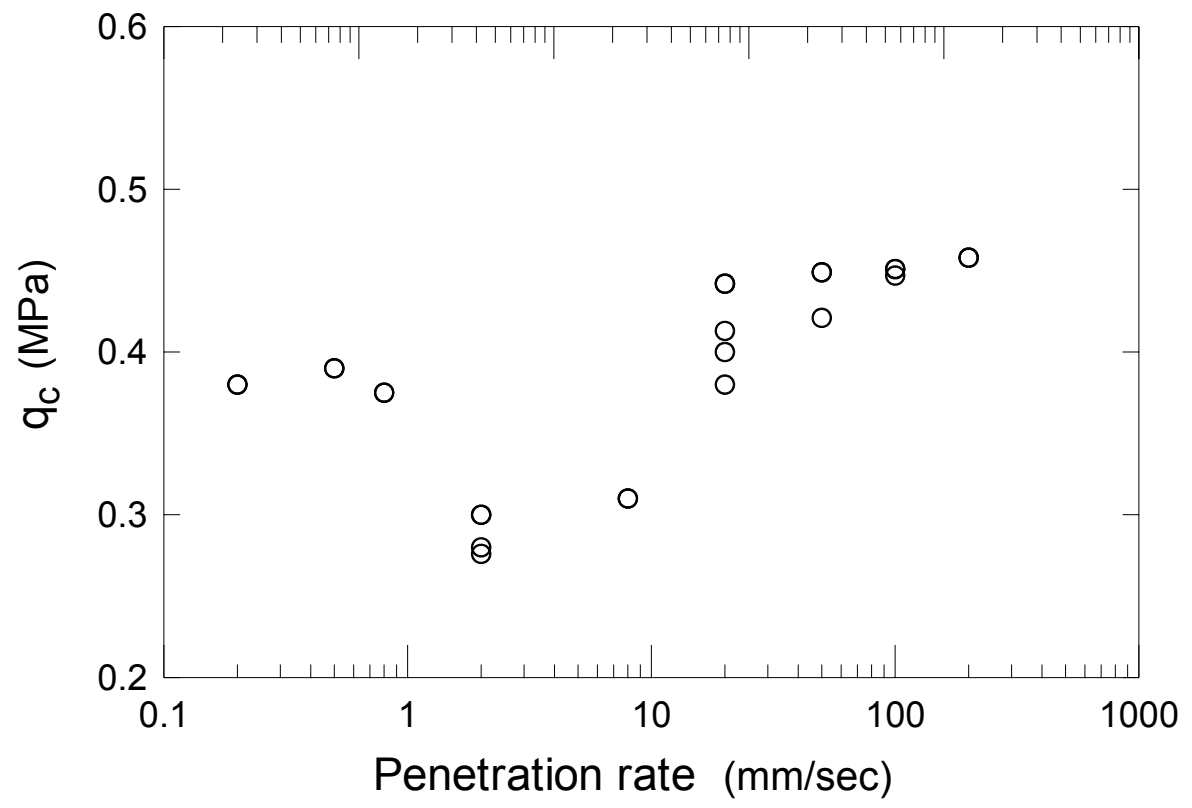

Figure 2.5 Influence of rate effect in varved clay (Bemben and Myers 1974).

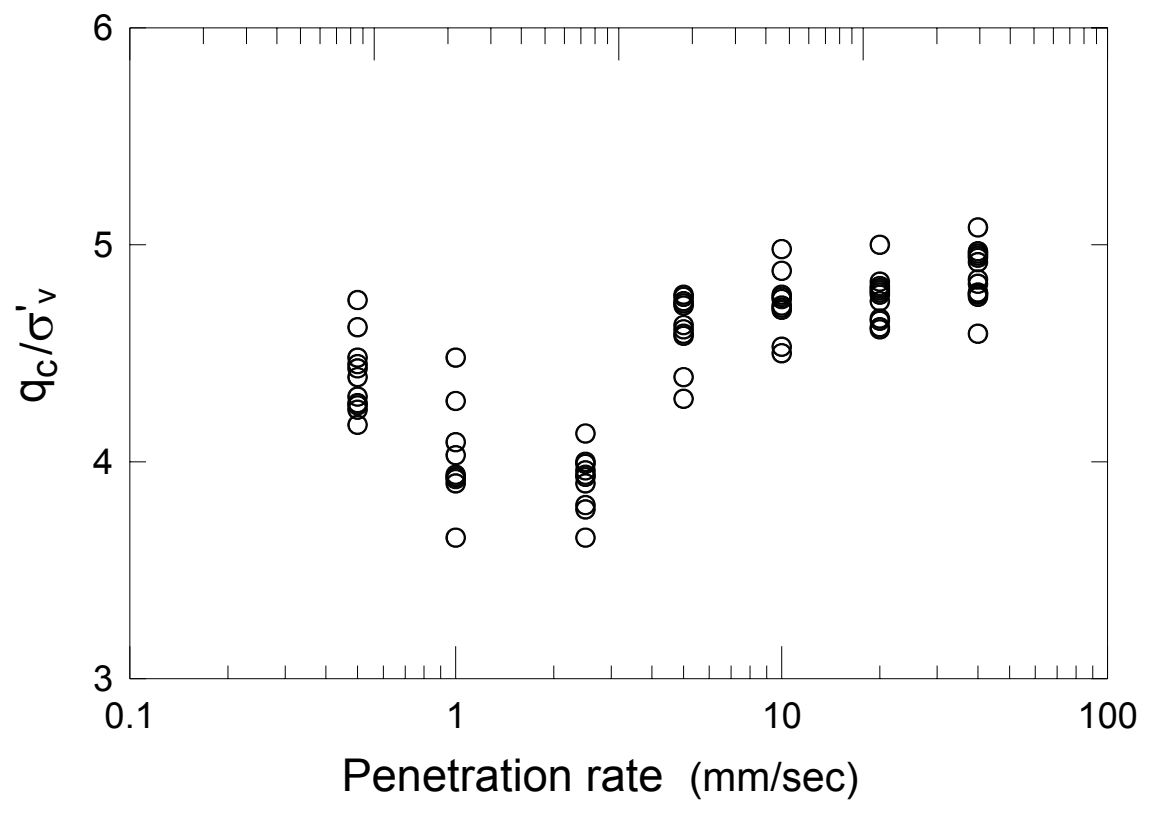

Figure 2.6 Influence of rate effect in soft clay (Roy et al. 1982). 
Campanella et al. (1982) investigated the penetration of silty soils with 4 different rates (from $0.25 \mathrm{~mm} / \mathrm{sec}$ to $20 \mathrm{~mm} / \mathrm{sec}$ ), with partially drained conditions possibly existing at the low penetration rate. Measured pore pressure helped to determine the transition point from undrained to partially drained conditions. The observed penetration was essentially undrained from a penetration speed of $20 \mathrm{~mm} / \mathrm{sec}$ to about $1 \mathrm{~mm} / \mathrm{sec}$, and measured $\mathrm{q}_{\mathrm{c}}$ values in this range were almost the same. As the penetration speed was progressively decreased below $1 \mathrm{~mm} / \mathrm{sec}$, the measured pore pressure during penetration decreased and a corresponding increase was observed for $\mathrm{q}_{\mathrm{c}}$ and $\mathrm{f}_{\mathrm{s}}$.

Filho and Alencar (1982) carried out field CPTs with 3 different penetration rates: $15 \mathrm{~mm} / \mathrm{sec}, 5 \mathrm{~mm} / \mathrm{sec}$ and $0.5 \mathrm{~mm} / \mathrm{sec}$. The obtained results showed that a penetration rate of $0.5 \mathrm{~mm} / \mathrm{sec}$ led to a noticeable reduction in the excess pore pressure and about a $60 \%$ increase in effective cone tip resistance. However, they did not provide detailed properties of the soil at the test site.

Powell and Quarterman (1988) studied the effects of penetration rate at four sites with three different cone velocities $(0.17 \mathrm{~mm} / \mathrm{sec}, 1.67 \mathrm{~mm} / \mathrm{sec}$, and $16.7 \mathrm{~mm} / \mathrm{sec})$. They argued that rate effects are clearly evident in the clay layer and observed a $10 \%$ decrease in cone resistance over the first ten-fold reduction in velocity. However, it is likely that all of the test results were obtained under undrained conditions, and the change in measured $\mathrm{q}_{\mathrm{c}}$ is possibly due to viscous effects in the clays. The rate effect due to viscosity of clayey soils is explained in the following section.

In summary, almost all previous studies tried to investigate the rate effects in the CPT by data from either the field or calibration chambers. But the correlations between penetration rates and cone resistance were developed without full characterization of soil properties or enough consideration of drainage conditions. 


\subsubsection{Framework for Rate Effect Consideration}

Generally it is assumed that, for clean sand, drained behavior prevails during cone penetration at the standard rate of $20 \mathrm{~mm} / \mathrm{sec}$. In contrast, it is assumed that penetration in clays takes place under fully undrained conditions at that penetration rate. In some intermediate soils, cone penetration would take place under partially drained conditions at the standard penetration rate. When the drainage condition changes from undrained to partially drained, the soil ahead of the cone starts to consolidate. Thus $\mathrm{q}_{\mathrm{c}}$ increases due to the increase in soil strength around the cone tip.

The drainage condition during cone penetration is closely related to the coefficient of consolidation of the soil. Mcneilan and Bugno (1985) suggested that undrained response would take place if the permeability $\mathrm{k}$ were less than $10^{-6} \mathrm{~cm} / \mathrm{sec}$, and partially drainage response would be observed if the permeability were between $10^{-6}$ $\mathrm{cm} / \mathrm{sec}$ and $10^{-3} \mathrm{~cm} / \mathrm{sec}$. Campanella and Robertson (1988) also suggested that the soil permeability required for undrained conditions is $10^{-7} \mathrm{~cm} / \mathrm{sec}$ or less. They suggested that the partial drainage range is between $10^{-7} \mathrm{~cm} / \mathrm{sec}$ and $10^{-4} \mathrm{~cm} / \mathrm{sec}$. However these criteria do not appear to have been based on detailed testing programs or rigorous analysis.

It was recently suggested through centrifuge penetration testing with various penetrometers in Australia that the cone resistance $\mathrm{q}_{\mathrm{c}}$ and the drainage condition during cone penetration in clayey soils depends on the normalized penetration rate $\mathrm{V}$. Normalized penetration rate depends on the rate of penetration, the coefficient of consolidation, and the cone diameter. The appropriate $\mathrm{V}$ to analyze the degree of consolidation of soil around the cone during penetration is:

$$
V=\frac{v \cdot d}{c_{v}}
$$

where $\mathrm{v}=$ cone velocity; $\mathrm{d}=$ cone diameter; $\mathrm{c}_{\mathrm{v}}=$ coefficient of consolidation (Finnie and Randolph 1994, House et al. 2001, Randolph and Hope 2005). Several penetration tests were performed in centrifuges with various penetrometers and penetration rates (Finnie 
and Randolph 1994, Randolph and Hope 2005). Finnie and Randolph (1994) performed centrifuge tests with circular foundations in silty sand and silt having $\mathrm{c}_{\mathrm{v}}$ values of $1 \times 10^{-3}$ $\mathrm{m}^{2} / \mathrm{s}$ and $5 \times 10^{-5} \mathrm{~m}^{2} / \mathrm{s}$, respectively. The results represented in a $q_{c} / \sigma_{p}^{\prime}$ versus log $\mathrm{V}$ plot revealed that the transition from drained to partially drained occurs at a $\mathrm{V}$ of about 0.01 , while the undrained limit is about 30.

The ratio of base resistance in the silt under drained conditions to that under undrained conditions was high, around ten. Penetration tests with a cylindrical T-bar penetrometer conducted by House et al. (2001) suggested a rather narrow transition range between drained and undrained conditions, approximate limits of $\mathrm{V}<0.1$ for drained conditions, and $\mathrm{V}>10$ for undrained conditions. In their tests, the tip resistance under drained conditions was about 3.5 times the resistance under undrained conditions. Tests performed with a cone penetrometer by Randolph and Hope (2005) showed only the transition point between undrained and partially drained conditions, which fell around $\mathrm{V}=$ 20. The values of $\mathrm{q}_{\mathrm{c}}$ are plotted in Figure 2.7, as a function of $\mathrm{V}$. Also shown in Figure 2.8 is a plot report by House et al. (2001) based on unpublished data of Watson and Sumasa (2000). However, it should be noted that the centrifuge CPT results are not as reliable as field values because it is unrealistic to employ an extremely small scaled down penetrometer in high centrifuge acceleration (Tani and Craig 1995) and possible scale effects. Besides, estimation of $c_{v}$ in the centrifuge test is not simple because the viscosity of water as a pore fluid becomes low at high levels of centrifugal acceleration.

If undrained conditions are obtained at high penetration rates in low permeability clayey soils, soil shearing rate effects should be considered. Loading rate effects (which may be attributed to soil "viscosity"), were studied by several researchers (e.g., Richardson and Whitman 1963, Vaid and Companella 1977, O'Reilly et al. 1989). It is known that the shear strength of clay increases with loading rate; however, only a small increase in the shear strength of sand is observed with changes in the loading rate. O'Reilly et al. (1989) performed a series of undrained triaxial compression tests at various strain 
rates and showed that, for the soil they studied (a silty clay), the strength increased $15 \%$ for every ten-fold increase in strain rate. Thus, if the cone penetration test is performed in clayey soil under completely undrained conditions, cone resistance, which is related to the soil strength, depends on the penetration rate. As the cone penetration rate increases under undrained conditions, the viscous resistance of clayey soil will lead to an increase of $\mathrm{q}_{\mathrm{c}}$.

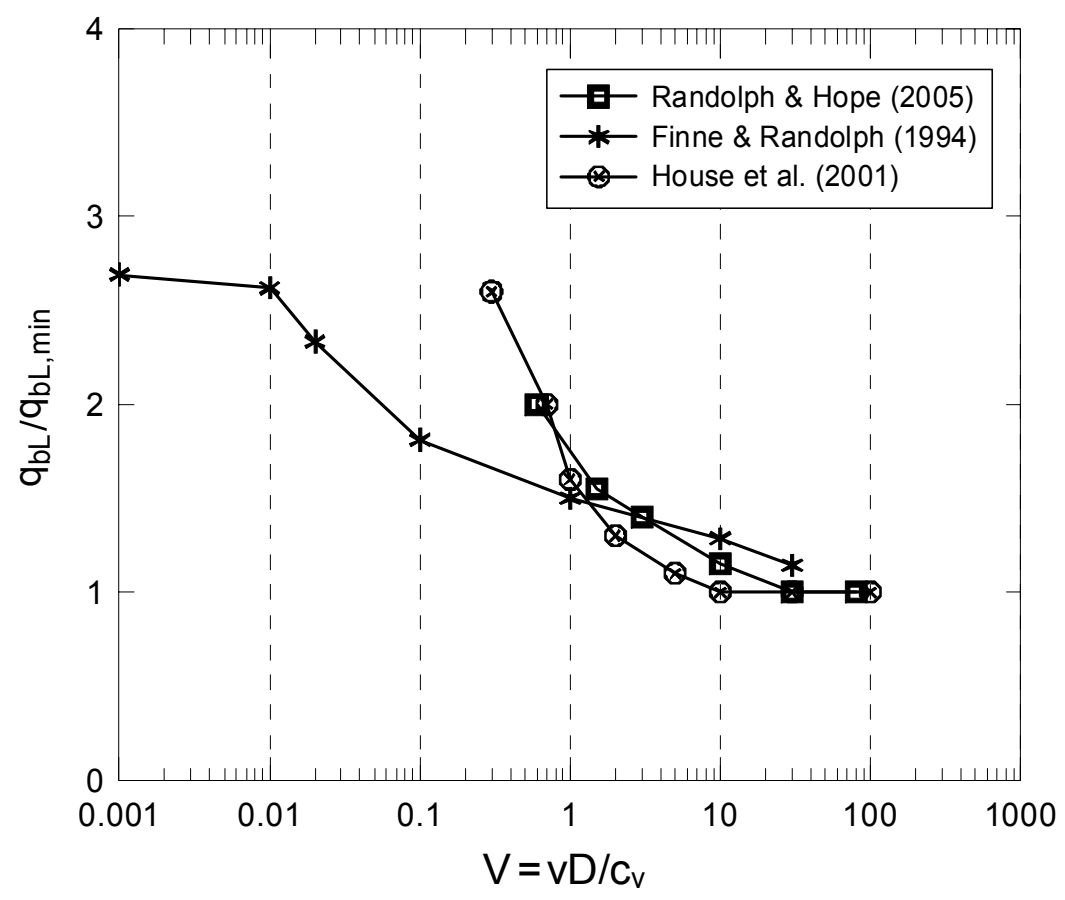

Figure 2.7 Variation of $\mathrm{q}_{\mathrm{bL}} / \mathrm{q}_{\mathrm{bL}, \text { min }}$ with normalized penetration ratio.

Tani and Craig (1995) performed miniature cone penetration tests on homogeneous clayey soils using a centrifuge, and proposed the following relationship between $\mathrm{q}_{\mathrm{c}}$ and penetration rate $v$. 


$$
q_{c}=q_{c}^{*}\left\{1.0+0.1 \cdot \log \left(\frac{v}{v^{*}}\right)\right\}
$$

where $q_{c}^{*}=$ the cone resistance at a reference penetration rate $v^{*}$. This equation indicates that cone resistance $\mathrm{q}_{\mathrm{c}}$ increases $10 \%$ for every ten-fold increase in penetration rate $v$. Figure 2.8 shows the variation of cone resistance due to such rate effects with the logarithm of penetration rate.

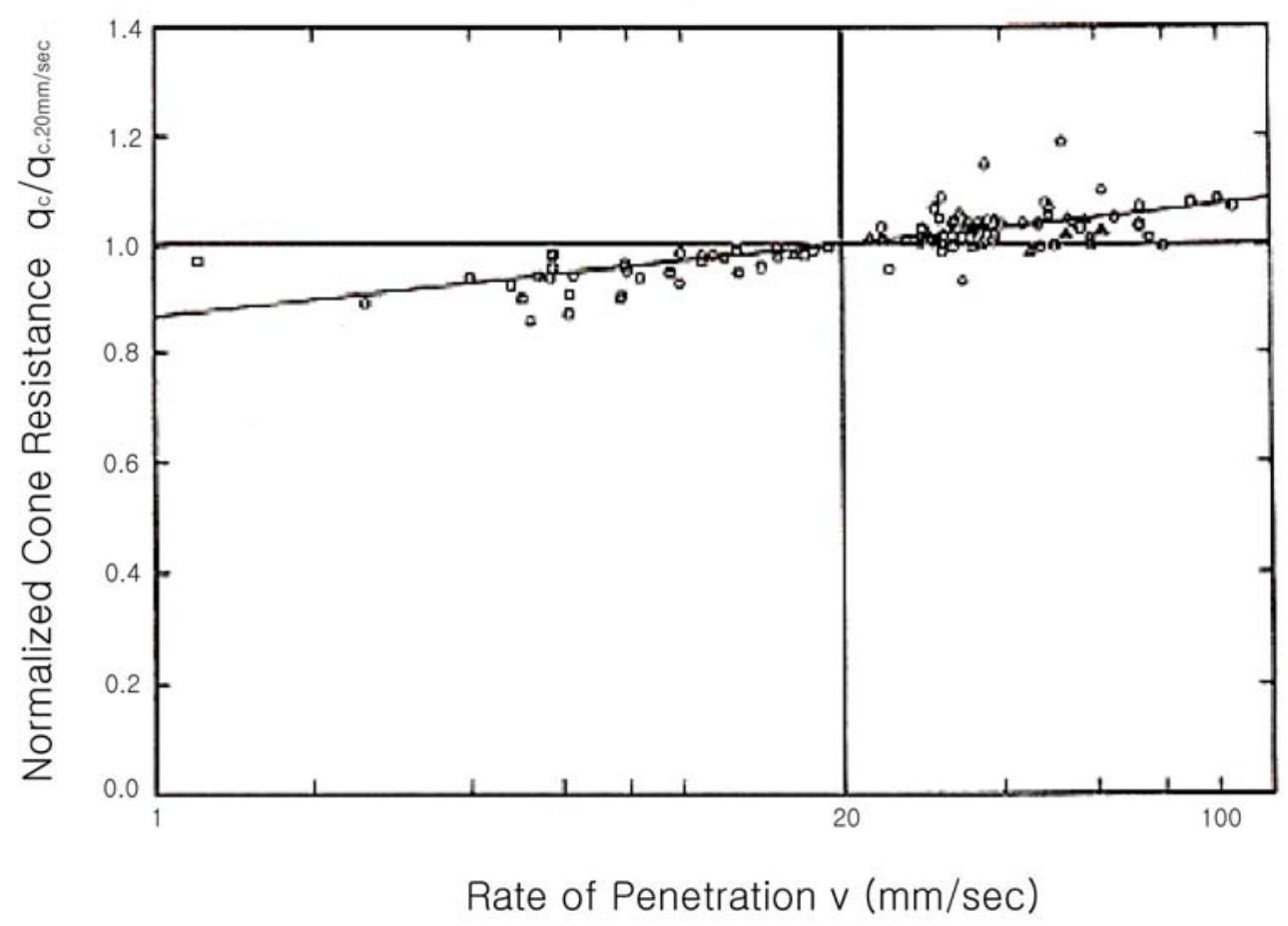

Figure 2.8 Rate effect on undrained condition (Tani and Craig, 1995). 


\subsection{Summary}

The evaluation of undrained shear strength $s_{u}$ of clayey soil has been one of the earliest and most important applications of the cone penetration test. Knowledge of the cone factor $\mathrm{N}_{\mathrm{k}}$ is essential for reliable estimation of $s_{\mathrm{u}}$ from $\mathrm{q}_{\mathrm{c}}$. Numerous attempts have been made by researchers to develop $N_{k}$ values by empirical approaches or by theoretical solutions. The empirical approach to $\mathrm{N}_{\mathrm{k}}$ determination has traditionally been to perform the CPT, and compare the values with $\mathrm{s}_{\mathrm{u}}$ obtained from lab test or vane test. Values of $\mathrm{N}_{\mathrm{k}}$ from empirical efforts were in the range of 10 to 20 .

The general theoretical approaches commonly used to estimate $\mathrm{N}_{\mathrm{k}}$ are the bearing capacity method, cavity expansion theory, and the strain path method. Rigidity index $\mathrm{I}_{\mathrm{r}}$ is sometimes used as a factor in estimating $\mathrm{N}_{\mathrm{k}}$ in the methods based on cavity expansion theory and strain path analysis. The values of $\mathrm{N}_{\mathrm{k}}$ suggested by these methods are mainly between 8.5 and 13 for stiffness indices ranging from 50 to 400 .

Several studies have considered rate effects on $\mathrm{q}_{\mathrm{c}}$ in both clays and sands by comparison of field CPT data performed with various penetration rates, but a consensus on what the rate effects are has not been reached. Recently performed centrifuge penetration tests with various penetrometers suggested some basic criteria for consideration of drainage effects during penetration. 


\section{CHAPTER 3. FIELD CONE PENETRATION TEST}

\subsection{Introduction}

The primary purpose of the field cone penetration testing program in this research was to clarify the rate effect on the cone tip resistance due to the soil type in the field and investigate the effects of drainage conditions during penetration on $\mathrm{q}_{\mathrm{c}}$ by varying the penetration rate and the type of soil. In addition, if $\mathrm{q}_{\mathrm{t}}$ is obtained under undrained conditions, it can be correlated to undrained shear strength.

Two sets of field CPTs were conducted at two sites in the state of Indiana, US. The sites were carefully chosen based on the boring log database of the Indiana Department of Transportation (INDOT). Soil profiles containing a fairly homogeneous and thick clayey soil layer (with sufficient amounts of sand or silt) with values of coefficient of consolidation $\mathrm{c}_{\mathrm{v}}$ that are not as low as that of pure clay were selected. For such sites, CPTs performed at slow penetration rates allow identification of transition from undrained to partially and, in some cases, fully drained conditions. Additionally, only soil layers located below the groundwater level were considered, so that the data are for fully saturated conditions. The CPTs were performed at various velocities, ranging from $20 \mathrm{~mm} / \mathrm{s}$ to 0.01 $\mathrm{mm} / \mathrm{s}$, at the two test sites. One site is located in Carroll County; the other, in Jasper County.

\subsection{Site 1: Carroll County (SR 18)}

The first test site is located near the west side of a bridge over Bachelor's run on State Road 18 in Carroll County, Indiana. The test area is $30 \mathrm{~m}$ from the center line of SR18, and 5m from the embankment of Bachelor's run. In-situ testing included 6 cone penetration tests and 2 drillings for thin-wall tube sampling. Cone penetration tests were

performed in February and March of 2003, and undisturbed samples were taken in June of 2003. A layout of the testing done at the site is given in Figure 3.1. 
The stratigraphy of the SR18 test site, as identified from the CPTs and soil boring results, indicated the occurrence of clayey silt from $5.2 \mathrm{~m}$ to $10.5 \mathrm{~m}$. The groundwater was encountered at approximately $4.5 \mathrm{~m}$ from the ground surface. The soil profile and CPT results for the SR18 test site are shown in Fig. 3.2. CPTs were performed at various rates in two of the clayey silt layers: i) from $7.4 \mathrm{~m} \sim 8.4 \mathrm{~m}$ (Layer 2) and ii) $9.2 \mathrm{~m} \sim 10.2 \mathrm{~m}$ (Layer 1). The CPTs were performed at a center-to-center distance of $1 \mathrm{~m}$ to minimize the effects that a previous penetration test might have on any given penetration test.

\subsubsection{Experimental Test Program}

The main objective of the experimental program is to evaluate the mechanical characteristics of the soil; consequently, CPT data will be analyzed using this detailed information. The performed experimental tests included index tests for basic soil properties, one-dimensional consolidation, and triaxial compression tests. Since soil consolidation properties and undrained shear strengths are essential parameters for the research, consolidation and shear tests were performed. For the one-dimensional consolidation and triaxial tests, collected undisturbed thin-walled tube samples were used. All tubes were carefully sealed in the field and stored in a moisture room until used to minimize any moisture losses. A detailed description of the testing methods and results are presented in the following sections.

\subsubsection{Soil Index and Basic Property Tests}

Grain size distributions for the two soil layers are shown in Figure 3.3. For the size distribution, sieve analyses and hydrometer tests were performed. The results of the index tests are summarized in Table 3.1. The clays at $9.7 \mathrm{~m}$ depth have a liquid limit (LL) of $26.3 \%$ and a plastic limit (PL) of $19.5 \%$. The soil in $7.7 \mathrm{~m}$ depth has LL $=35 \%, \mathrm{PL}=19$ $\%$ and $\mathrm{I}_{\mathrm{p}}=16 \%$. 


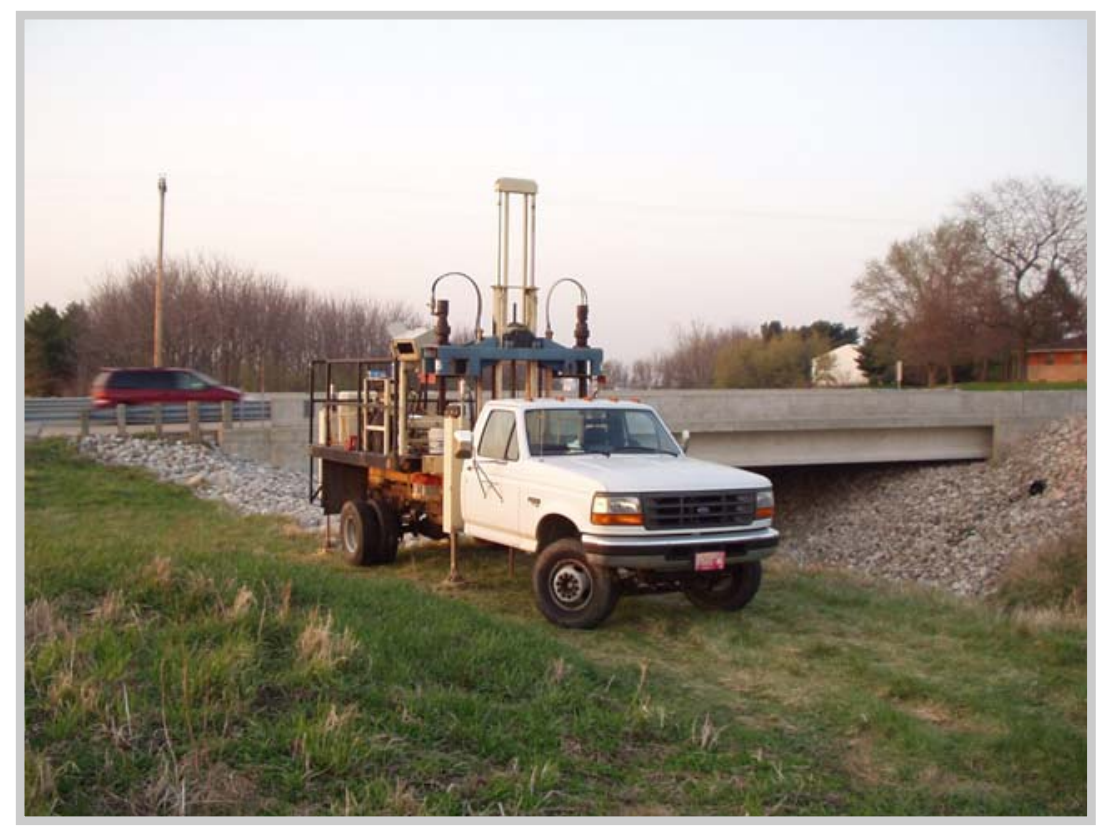

(a)

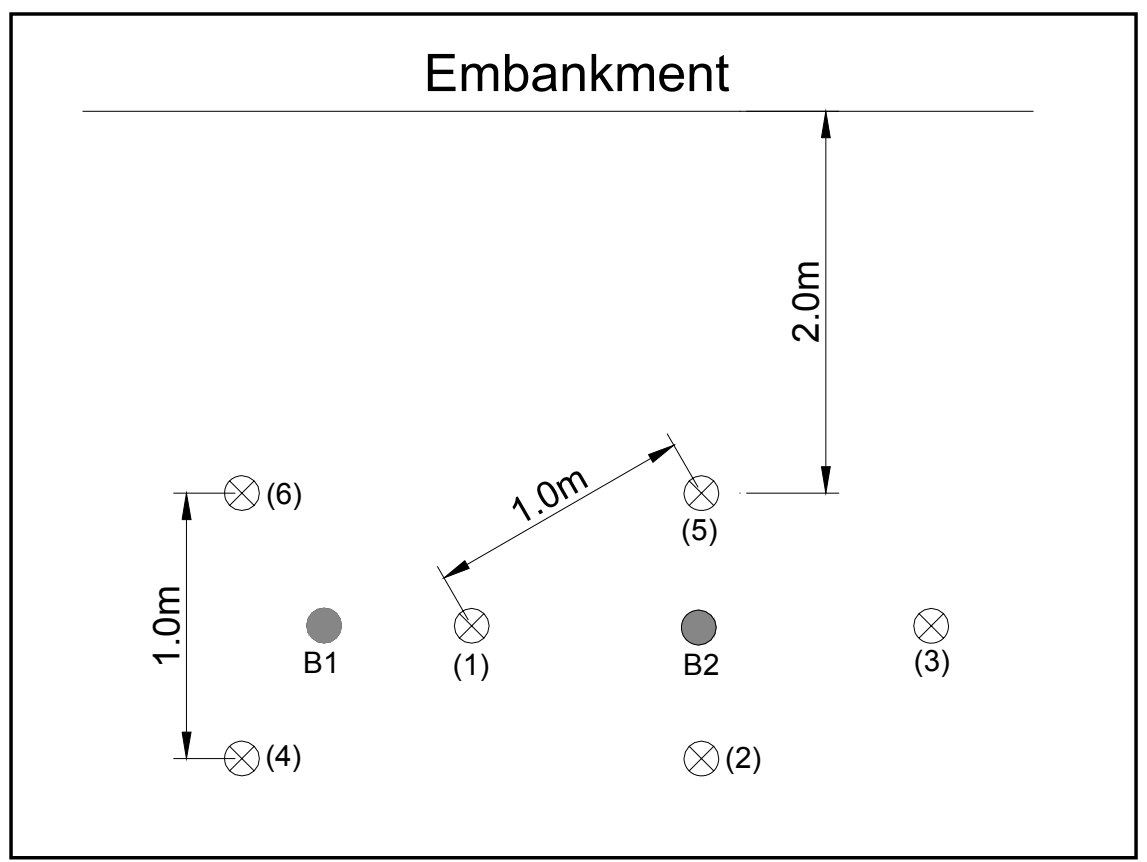

(b)

Figure 3.1 (a) View of the test site and (b) layout of cone penetration test locations. 


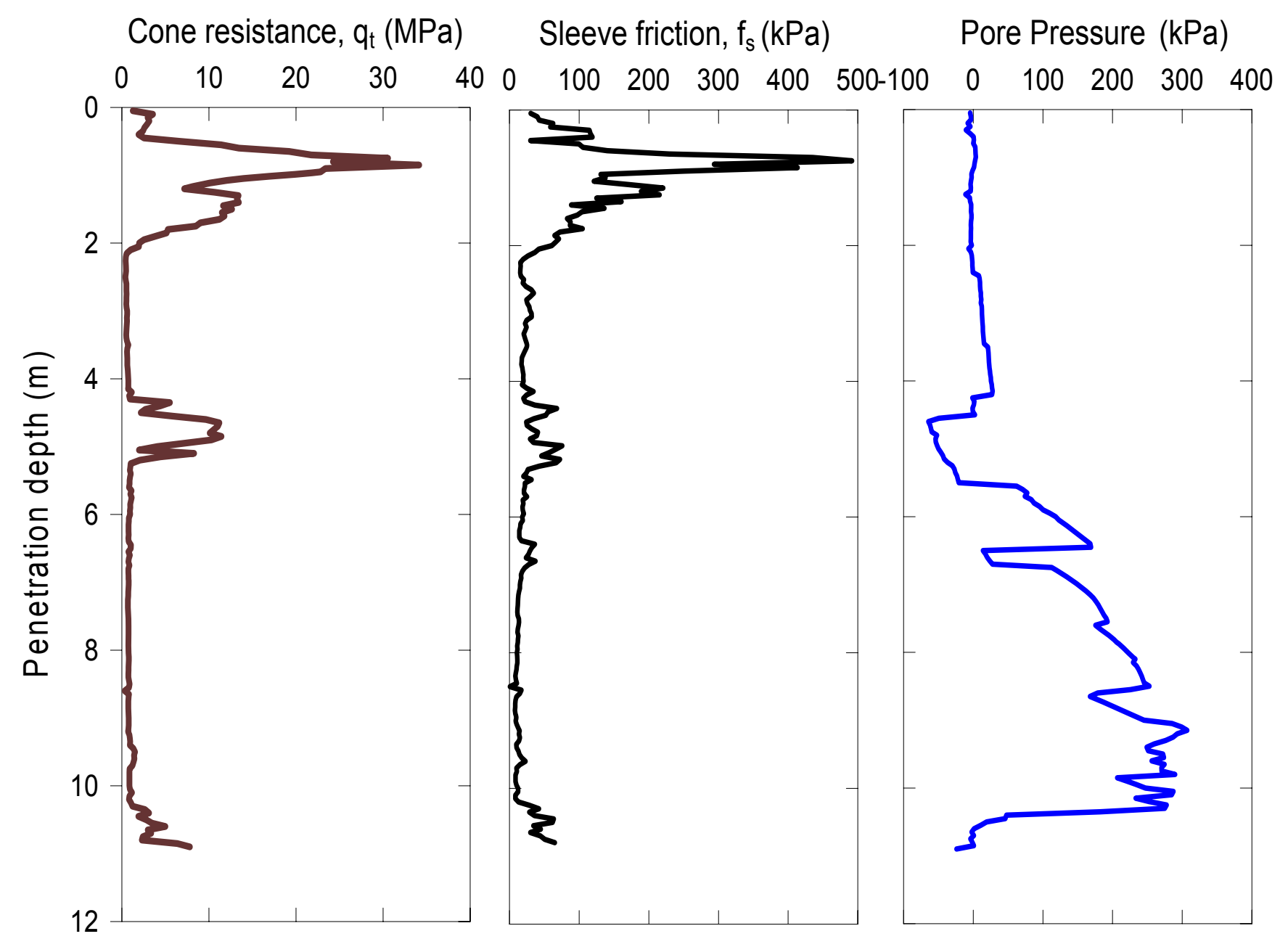

Figure 3.2 CPT Results at SR-18 site 
Table 3.1 Summary of laboratory index testing

\begin{tabular}{cccccccc}
\hline Depth $(\mathrm{m})$ & $\begin{array}{c}\text { \% Sand } \\
(2- \\
0.075 \mathrm{~mm})\end{array}$ & $\begin{array}{c}\text { \% Silt } \\
(0.075-\end{array}$ & $\begin{array}{c}\text { \% Clay } \\
(\text { Below } \\
0.002 \mathrm{~mm})\end{array}$ & $\begin{array}{c}\mathrm{W} \\
(\%)\end{array}$ & $\begin{array}{c}\text { LL } \\
(\%)\end{array}$ & $\begin{array}{c}\text { PL } \\
(\%)\end{array}$ & $\begin{array}{c}\mathrm{I}_{\mathrm{p}} \\
(\%)\end{array}$ \\
\hline 7.7 & 4.5 & 71.5 & 24.0 & 28.1 & 35.1 & 19.0 & 16.1 \\
\hline 9.7 & 12.1 & 76.8 & 11.1 & 23.0 & 26.3 & 19.5 & 6.8 \\
\hline
\end{tabular}

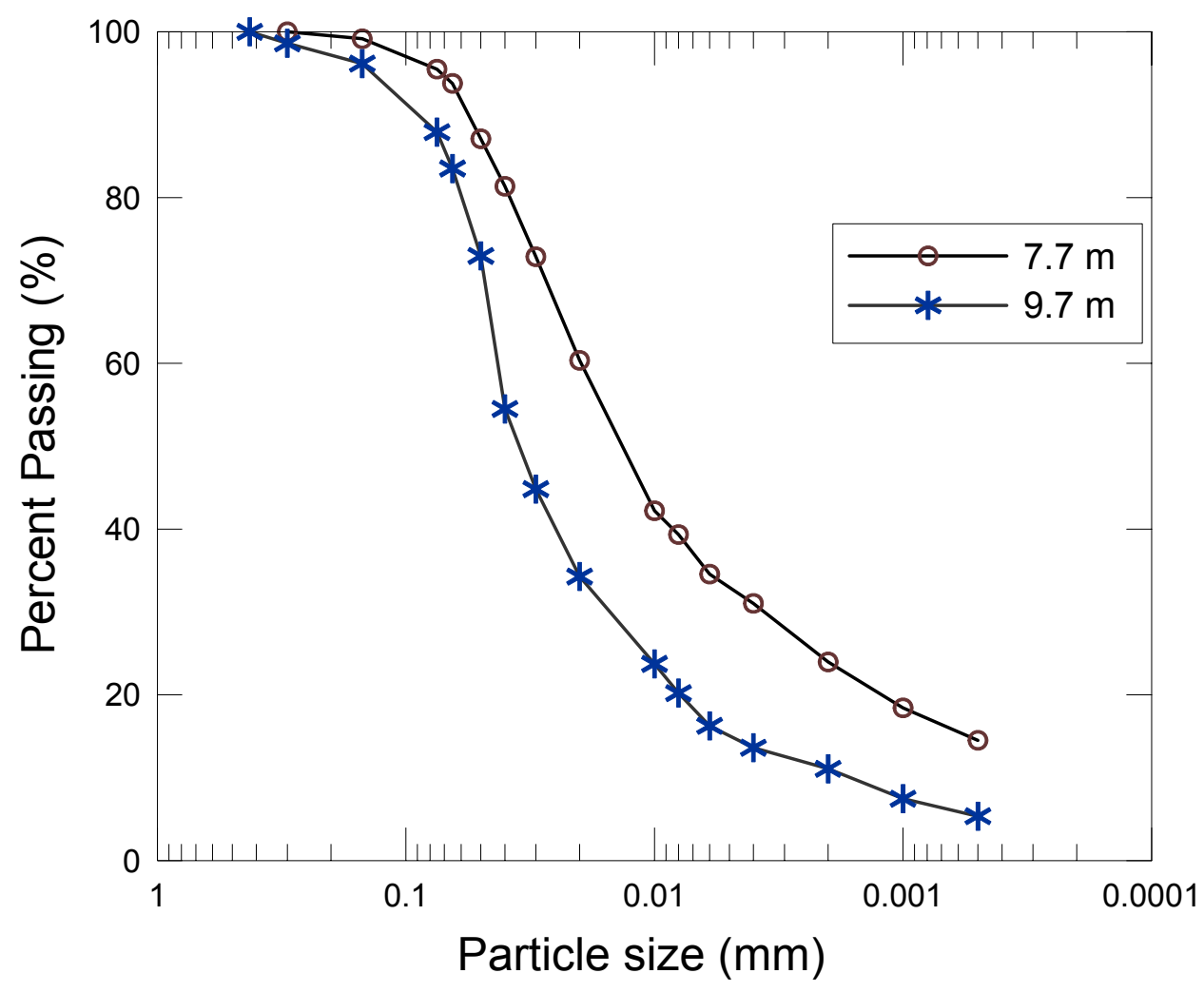

Figure 3.3 Grain size distributions of the soils at $7.7 \mathrm{~m}$ and $9.7 \mathrm{~m}$ depth. 


\subsubsection{Consolidation Tests}

Conventional one-dimensional consolidation tests were performed to obtain the coefficient of consolidation $\mathrm{c}_{\mathrm{v}}$ and to evaluate the over-consolidation ratio (OCR) of the clayey silt layer. Three tests, two on samples from $9.6 \mathrm{~m}$ and $9.9 \mathrm{~m}$ in layer 1 and one on a sample from $7.7 \mathrm{~m}$ in layer 2 , were carried out. The tests were conducted according to the consolidation test procedure as described in ASTM D 2435. The soil specimens were trimmed carefully by a cutting ring connected to a consolidation ring with the internal surfaces in alignment to reduce any disturbance. The consolidation ring used for the test has a diameter of $63.5 \mathrm{~mm}$ and a height of $25.4 \mathrm{~mm}$. The inside of the ring was lubricated with oil to minimize side friction between the ring and the soil specimen. Specimens were loaded in 8 increments up to a maximum applied vertical stress of 1.6 MPa. An LVDT and a data acquisition system were used to obtain high-resolution settlement readings over time.

Figure 3.4 shows specimen displacement versus square root of time plots of two samples at $9.6 \mathrm{~m}$ and $9.9 \mathrm{~m}$ for a vertical pressure increment from $50 \mathrm{kPa}$ to $100 \mathrm{kPa}$. Values of $c_{v}$ at each load increment step were calculated by the square-root-of-time method. The measured values of $c_{v}$ at $9.6 \mathrm{~m}$ and $9.9 \mathrm{~m}$ are shown in the semi-log plots of $c_{\mathrm{v}}$ versus $\sigma^{\prime}{ }_{\mathrm{v}}$ in Figure 3.5. Displacement versus square-root-of-time plots of a sample at 7.7 $\mathrm{m}$ (layer 2) is shown in Figure 3.6 for vertical pressure increment form 25 to $50 \mathrm{kPa}$ and 50 to $100 \mathrm{kPa}$. The plot of $\mathrm{c}_{\mathrm{v}}$ versus $\sigma_{\mathrm{v}}^{\prime}$ at $7.7 \mathrm{~m}$ is shown in Figure 3.7. Values of $\mathrm{c}_{\mathrm{v}}$ for each load increment are summarized in Table 3.2. Semi-log plots of Settlement versus vertical stress are given in Figure 3.8. The effective preconsolidation stress $\left(\sigma_{p}^{\prime}\right)$ was determined for each depth using Casagrande's method (1936) (see values in Table 3.3). The calculated overconsolidation ratios at $9.6 \mathrm{~m}$ and $9.9 \mathrm{~m}$ show that layer 1 is a normally consolidated layer. 
Table $3.2 \mathrm{c}_{\mathrm{v}}\left(\mathrm{cm}^{2} / \mathrm{sec}\right)$ for layers 1 and 2 .

\begin{tabular}{c|ccccccc}
\hline Depth & $12.5 \mathrm{kPa}$ & $25 \mathrm{kPa}$ & $50 \mathrm{kPa}$ & $100 \mathrm{kPa}$ & $200 \mathrm{kPa}$ & $400 \mathrm{kPa}$ & $800 \mathrm{kPa}$ \\
\hline $7.7 \mathrm{~m}$ & 0.00666 & 0.00618 & 0.00837 & 0.00582 & 0.00351 & 0.00264 & 0.00301 \\
$9.6 \mathrm{~m}$ & 0.0281 & 0.0356 & 0.0439 & 0.0405 & 0.0539 & 0.0613 & 0.0677 \\
$9.8 \mathrm{~m}$ & 0.0479 & 0.0633 & 0.0599 & 0.0654 & 0.0727 & 0.0702 & 0.0949 \\
\hline
\end{tabular}

Table 3.3 Effective preconsolidation stress $\sigma_{p}^{\prime}$ and OCR

\begin{tabular}{c||ccc}
\hline Depth & $7.7 \mathrm{~m}$ & $9.6 \mathrm{~m}$ & $9.9 \mathrm{~m}$ \\
\hline $\begin{array}{c}\text { Effective preconsolidation } \\
\text { stress }\left(\sigma_{p}^{\prime}\right)(\mathrm{kPa})\end{array}$ & 103 & 140 & 160 \\
\hline $\begin{array}{c}\text { Vertical effective stress } \\
\left(\sigma_{v}^{\prime}\right)(\mathrm{kPa})\end{array}$ & 113 & 133 & 135 \\
\hline $\mathrm{OCR}$ & 0.91 & 1.05 & 1.18 \\
\hline
\end{tabular}




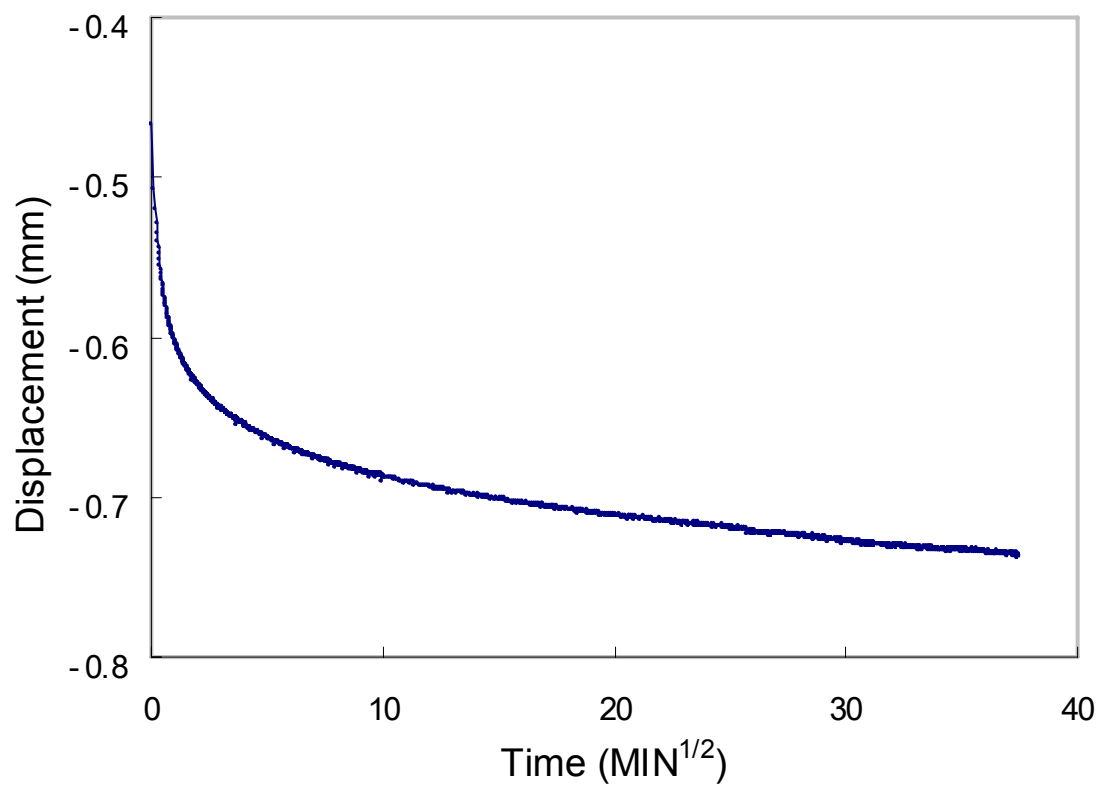

(a) $9.6 \mathrm{~m}$

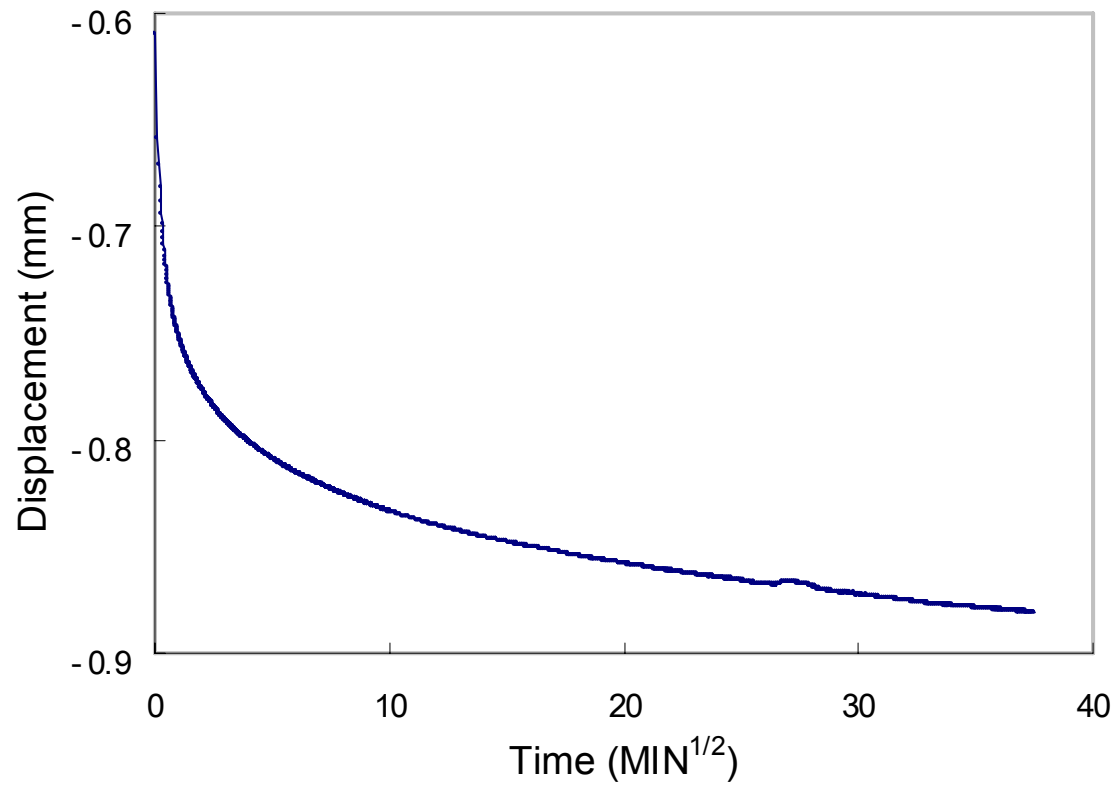

(b) $9.9 \mathrm{~m}$

Figure 3.4 Specimen displacements versus square root of time for Layer 1 (pressure increment from $50 \mathrm{kPa}$ to $100 \mathrm{kPa}$ ). 


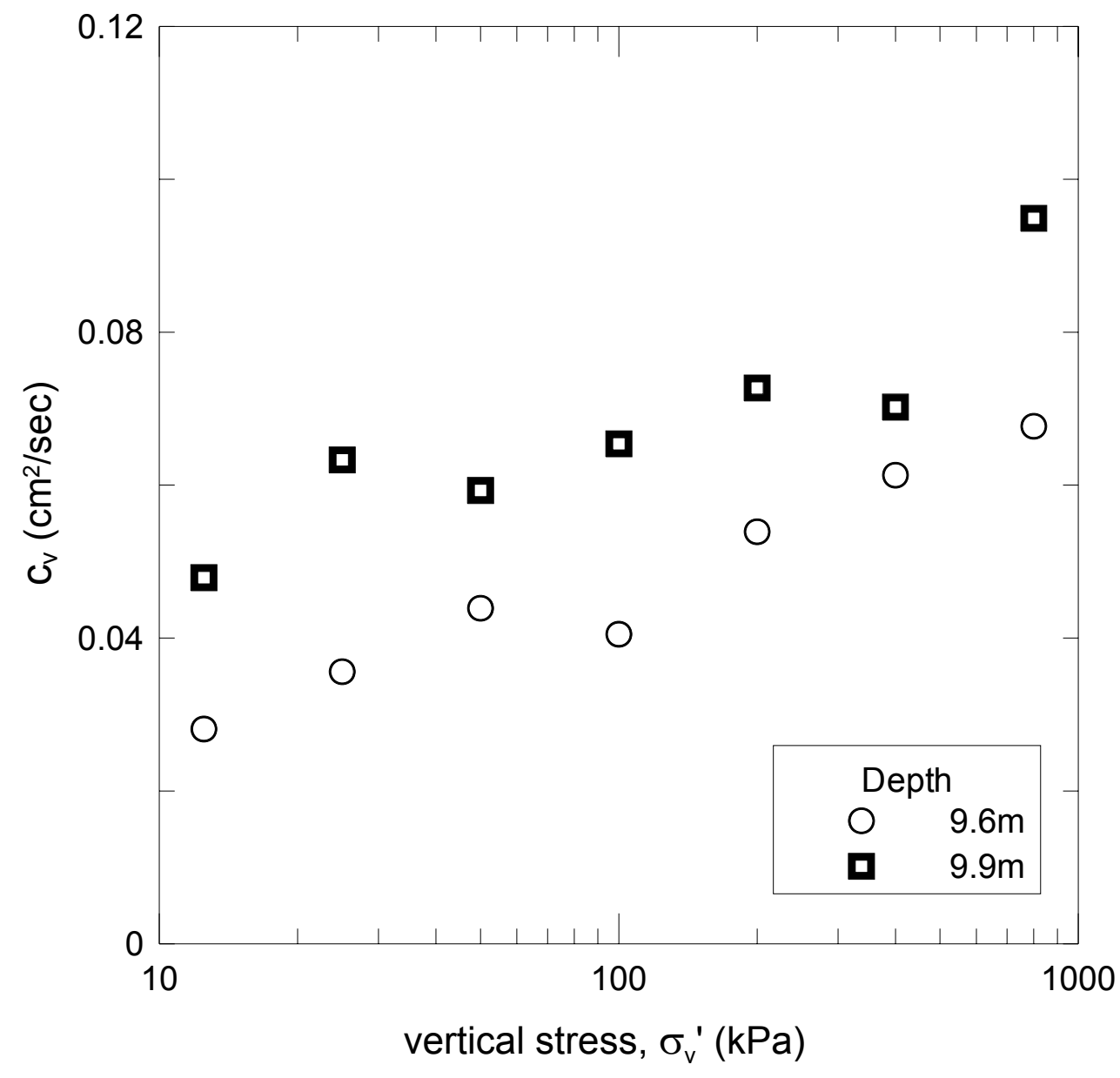

Figure 3.5 Semi-log plots of $c_{v}$ versus $\sigma^{\prime}{ }_{v}$ (layer 1). 

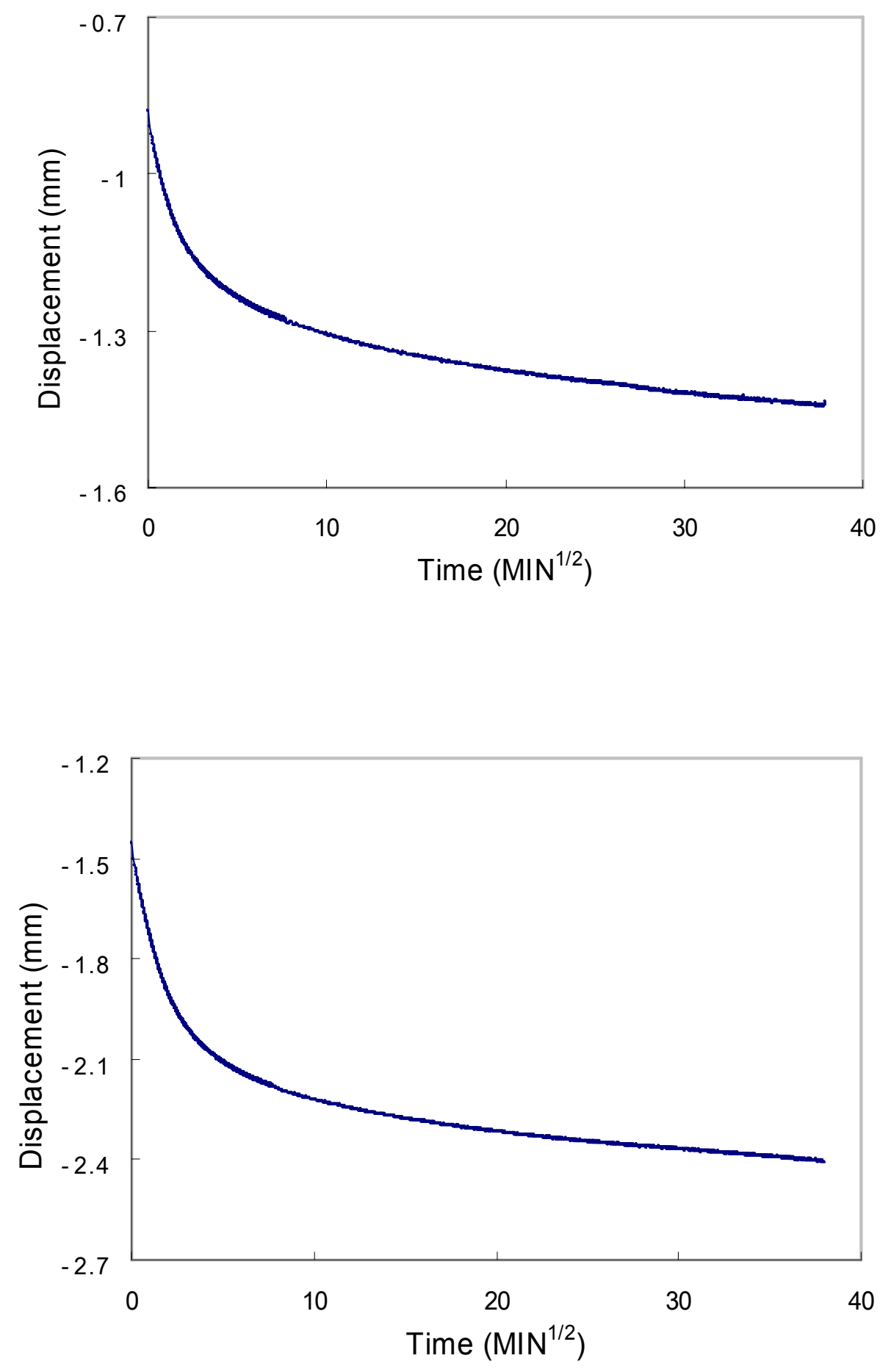

(b) $50-100 \mathrm{kPa}$

Figure 3.6 Specimen displacements versus square root of time (7.7m, Layer 2). 


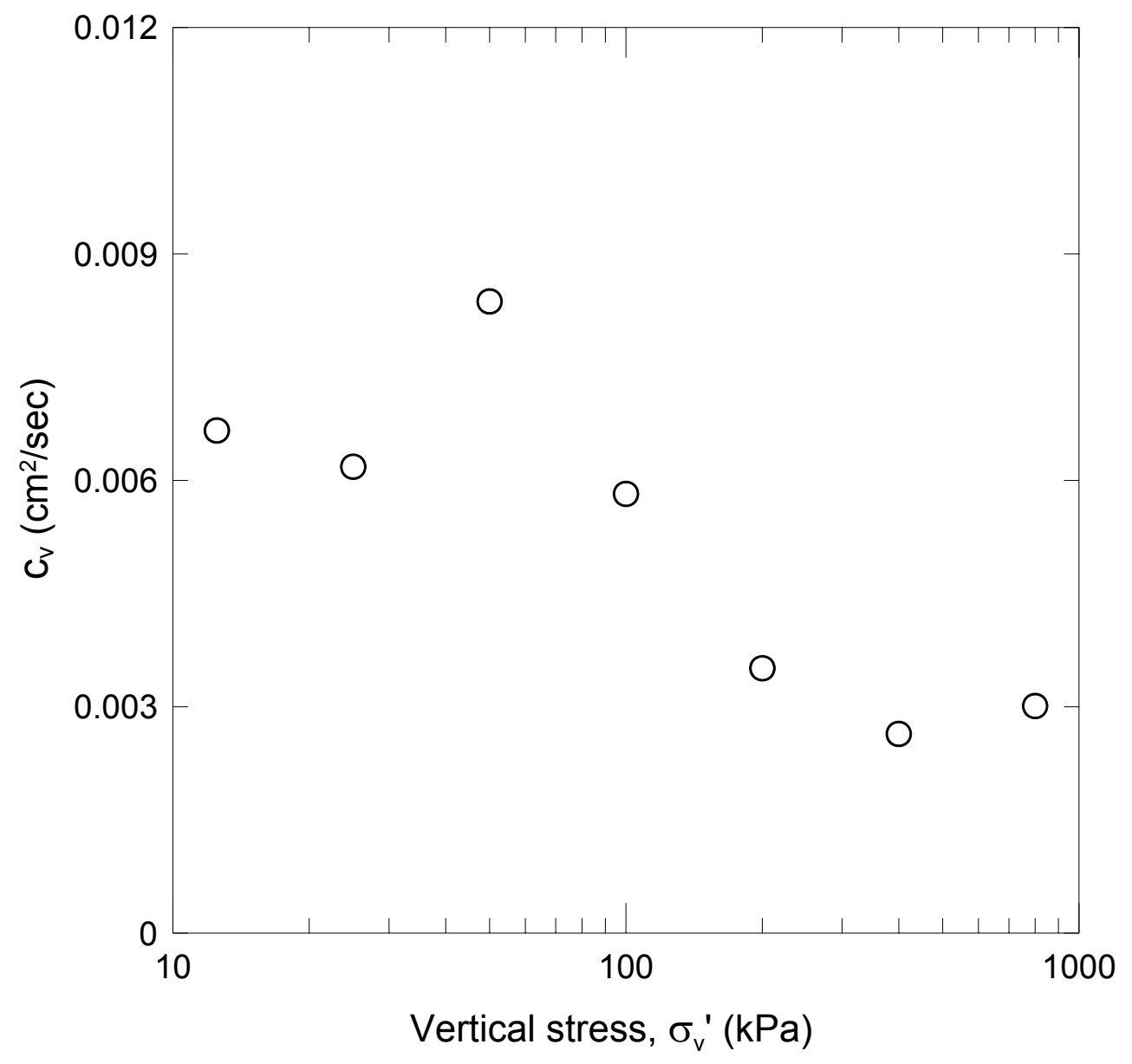

Figure 3.7 Semi- $\log$ plots of $\mathrm{c}_{\mathrm{v}}$ versus $\sigma_{\mathrm{v}}{ }_{\mathrm{v}}(7.7 \mathrm{~m}$, layer 2$)$. 
Terzaghi et al. (1996) indicated that a substantial decrease of $c_{v}$, caused by the change in $\mathrm{m}_{\mathrm{v}}$ (the change of permeability is relatively small), is typically observed in clays when the soil passes from the recompression into the normal compression range. The plot of $c_{v}$ versus $\sigma^{\prime}{ }_{v}$ for the sample of $7.7 \mathrm{~m}$ in Figure 3.7 is in good agreement with this concept. In this graph, $\mathrm{c}_{\mathrm{v}}$ is maximum for a vertical pressure up to $50 \mathrm{kPa}$ and shows an abrupt decrease when the consolidation stress exceeds the preconsolidation stress $(80 \mathrm{kPa})$. In contrast, the $c_{v}$ plots of layer 1 in Figure 3.5 show only gradual $c_{v}$ increases with the load increments.

\subsubsection{Triaxial tests}

The purpose of the isotropically consolidated undrained triaxial compression tests (CIUC) was to provide undrained shear strength data of soil samples from layers 1 and 2. A total of 3 triaxial tests were performed on the collected undisturbed samples of the two layers. For the triaxial tests, a CKC automated static triaxial testing device was used. In the $\mathrm{CKC}$, the axial load is measured with a load cell attached to the rod of a pneumatic pressure loading system, and axial deformation with an LVDT. Connected sensitive differential pressure transducers measure the volume change of the specimen, confining stress, and effective stress. 


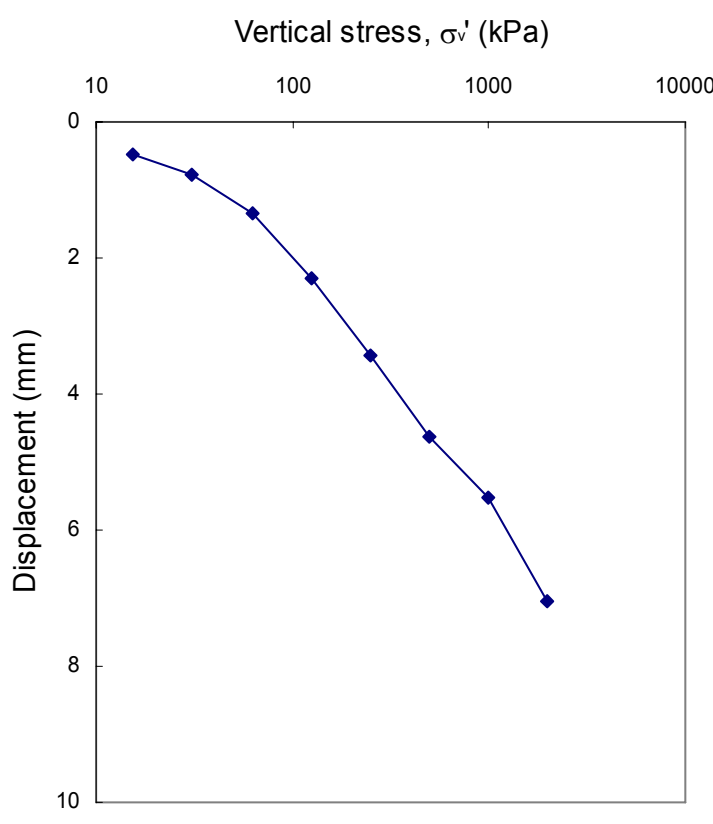

(a) $7.7 \mathrm{~m}$

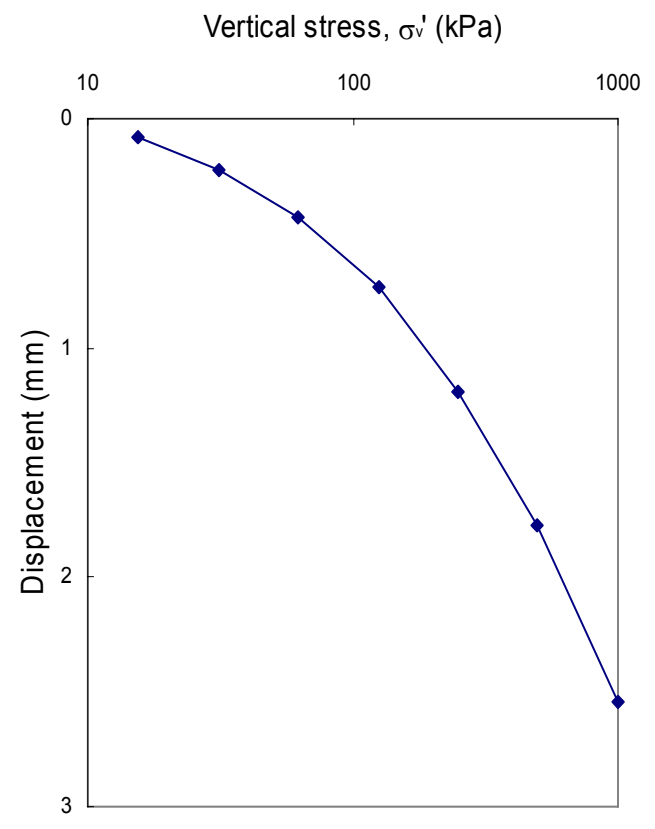

(b) $9.6 \mathrm{~m}$

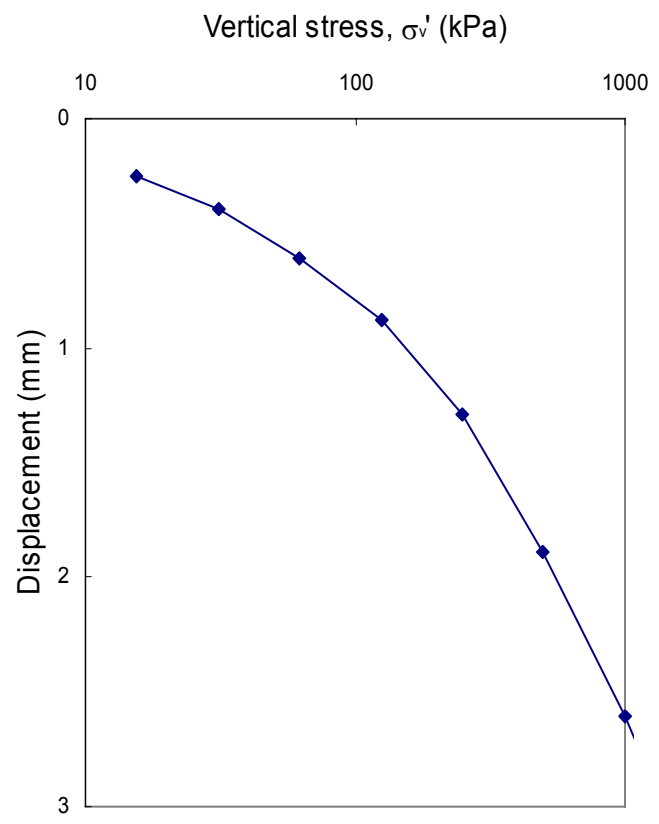

(c) $9.9 \mathrm{~m}$

Figure 3.8 Semi-log plots of settlement versus vertical stress curves. 
Based on the field test results, the locations from which test specimens were obtained were carefully selected. The typical specimen was $71 \mathrm{~mm}$ in diameter and about $150 \mathrm{~mm}$ in height. The specimens were subjected to a back pressure of $300 \mathrm{kPa}$ for 24 hours, and if the degree of saturation checked by employing the Skempton B-value check exceeded 0.95, saturation measures were taken. After saturation, the specimens were isotropically consolidated by applying effective confining stress. The mean stress at the depth where the sample was collected was used as the confining stress. Shearing was performed at a constant rate between $0.02 \%$ and $0.04 \%$ per minute, with specific rates being decided from the consolidation properties of the soil being tested. The specimen was saturated by backpressure saturation. The CU-triaxial test results are summarized in Table 3.4 .

Table 3.4 Summary of triaxial test results.

\begin{tabular}{c|cccc}
\hline Depth $(\mathrm{m})$ & Soil Layer & $\sigma_{v}^{\prime}(\mathrm{kPa})$ & $\sigma_{m}^{\prime}(\mathrm{kPa})$ & $\mathrm{s}_{\mathrm{u}}(\mathrm{kPa})$ \\
\hline 7.8 & 2 & 114 & 76 & 57.5 \\
9.5 & 1 & 131 & 87.3 & 60.5 \\
9.8 & 1 & 134 & 89.3 & 62.1 \\
\hline
\end{tabular}




\subsubsection{Cone Penetration Test Program}

All CPT soundings were done using a standard cone with a projected area of 10 $\mathrm{cm}^{2}$ and a tip apex angle of $60^{\circ}$ and a side friction sleeve with a surface area of $150 \mathrm{~cm}^{2}$. It was manufactured by Hogentogler. Pore pressure was measured through a filter element placed between cone tip and sleeve. The cone has an area ratio of 0.8 , so the corrected total cone resistance $\mathrm{q}_{\mathrm{t}}$ is given by Eq. (2.2):

$$
\begin{aligned}
q_{t} & =q_{c}+u_{2}(1-a) \\
& =q_{c}+0.2 u_{2}
\end{aligned}
$$

The procedure followed for the cone penetration tests are in agreement with ASTM D 5778, except for the penetration rate, which was varied. A total of six CPT soundings were conducted at the site. Soundings were performed at intervals of a meter to evade interference or any effect from previous soundings. Also two boreholes were drilled after cone penetration tests were done to obtain undisturbed soil samples for lab tests. The field test locations are shown in Figure 3.1. The total sounding depths for each CPT was about $10.5 \mathrm{~m}$. Various penetration rates were used in the two test layers, $7.4-8.4 \mathrm{~m}$ (layer 2) and $9.2-10.2 \mathrm{~m}$ (layer 1). The penetration rates for the penetration tests are summarized in Table 3.5.

Table 3.5 Penetration rates.

\begin{tabular}{c|cc}
\hline Test number & Layer $1(9.2-10.1 \mathrm{~m})$ & Layer $2(7.5-8.4 \mathrm{~m})$ \\
\hline CP- 1 & $20 \mathrm{~mm} / \mathrm{sec}$ & $20 \mathrm{~mm} / \mathrm{sec}$ \\
CP- 2 & $0.2 \mathrm{~mm} / \mathrm{sec}$ & $3 \mathrm{~mm} / \mathrm{sec}$ \\
CP- 3 & $1 \mathrm{~mm} / \mathrm{sec}$ & $1 \mathrm{~mm} / \mathrm{sec}$ \\
CP- 4 & $0.1 \mathrm{~mm} / \mathrm{sec}$ & $0.2 \mathrm{~mm} / \mathrm{sec}$ \\
CP- 5 & $0.05 \mathrm{~mm} / \mathrm{sec}$ & $20 \mathrm{~mm} / \mathrm{sec}$ \\
CP- 6 & $20 \mathrm{~mm} / \mathrm{sec}$ & $0.05 \mathrm{~mm} / \mathrm{sec}$ \\
\hline
\end{tabular}


In order to obtain satisfactory pore pressure response during a piezocone test, complete saturation of the piezocone is essential. Small air bubbles entrapped in the filter and inside the cone would affect the maximum pore pressure and cause a time lag when the cone advances from a sand layer to a clay layer, where the cone penetration would generate large excess pore pressures. To achieve complete saturation, the filter element was saturated by applying a vacuum pressure first and then soaking it in a glycerin and water mixture. A funnel was placed over the cone and filled with glycerin and de-aired water solution. Finally, the filter element and cone were assembled submerged in the funnel, and covered well with a membrane filled with the glycerin and water solution until the test was started.

\subsubsection{Test Results}

Figure 3.9 shows cone resistance profiles from the 6 cone penetration tests between $6 \mathrm{~m}$ and $10.5 \mathrm{~m}$ as the scheduled penetration rates in Table 3.5. As shown in the figure, the values of cone resistance present good repeatability for the same penetration rates of $20 \mathrm{~mm} / \mathrm{sec}(6 \mathrm{~m}-7.4 \mathrm{~m}$ and $8.4 \mathrm{~m}-9.2 \mathrm{~m})$. This repeatability also demonstrates the homogeneity of the soil layers. The correlation of $\mathrm{q}_{\mathrm{t}}$ and penetration rate is analyzed in detail in the following sections.

\subsubsection{Layer $1(9.2 \mathrm{~m}-10.2 \mathrm{~m})$}

The CPTs were performed at five different penetration rates $(\mathrm{v}=20,1,0.2,0.1$, and $0.05 \mathrm{~mm} / \mathrm{s})$ in the clayey silt between $9.2 \mathrm{~m}$ and $10.2 \mathrm{~m}$. Fig. 3.10 shows $\mathrm{q}_{\mathrm{t}}$ profiles $\left(\mathrm{q}_{\mathrm{t}}\right.$ is the cone resistance corrected for the pore pressure behind the cone tip) obtained from the tests performed at the various penetration rates considered. As shown in the figure, values of cone resistance for $\mathrm{v}=20 \mathrm{~mm} / \mathrm{s}$ and $\mathrm{v}=1 \mathrm{~mm} / \mathrm{s}$ were almost the same (around 0.8 $\mathrm{MPa})$.

If we compare the cone tip resistance profiles with the corresponding excess pore pressure profiles, it is clear that the main reason for the increase in cone tip resistance with 
decreasing penetration rate is the change in drainage condition. Measured $\mathrm{q}_{\mathrm{t}}$ and excess pore pressure values at each velocity are shown at Figure 3.11 (a)-(e). The filter is located in the shoulder of the cone, and is thus not suitable for representing the exact drainage condition of soil around cone tip during penetration (the measured pore pressure varies with the location of the filter element. Robertson et al. 1986); however, it does give an indication of what the drainage conditions are around the cone tip.

As shown in Figure 3.10 and Figure 3.11(a) and (b), values of cone resistance for velocities of $20 \mathrm{~mm} / \mathrm{sec}$ and $1 \mathrm{~mm} / \mathrm{sec}$ were almost the same (around $0.8 \mathrm{MPa}$ ), but the excess pore pressure for $1 \mathrm{~mm} / \mathrm{sec}$ decreased to an average $210 \mathrm{kPa}$, compared to an average $270 \mathrm{kPa}$ for $20 \mathrm{~mm} / \mathrm{sec}$. Considering the cone resistance for $20 \mathrm{~mm} / \mathrm{sec}$ and 1 $\mathrm{mm} / \mathrm{sec}$ penetration rates, there is no apparent 'rate effect'. The decrease in the excess pore pressure at $1 \mathrm{~mm} / \mathrm{sec}$ velocity, in contrast, indicates that partially drained conditions are in effect around the cone tip. In this range, the increment of cone resistance due to the change in drainage conditions is small and compensated for by the decrease in pore pressure acting on the surface of the cone tip. The increase in $\mathrm{q}_{t}$ due to the change of drainage conditions appears clearly for velocities less than $1 \mathrm{~mm} / \mathrm{sec}$. With decreasing cone velocity below $1 \mathrm{~mm} / \mathrm{sec}, \mathrm{q}_{\mathrm{t}}$ increases significantly and excess pore pressure decreases. Cone resistance at the lowest velocity of $0.05 \mathrm{~mm} / \mathrm{sec}$ was about $2 \mathrm{MPa}, 2.5$ times larger than the cone resistance for $20 \mathrm{~mm} / \mathrm{sec}$. Even with the lowest velocity $(0.05$ $\mathrm{mm} / \mathrm{sec}$ ), partially drained conditions are still in effect because the measured pore pressure at $0.05 \mathrm{~mm} / \mathrm{sec}$ was around $65 \mathrm{kPa}$, and this value is still greater than the hydrostatic pressure of $45 \mathrm{kPa}$ at that depth.

The $\mathrm{q}_{\mathrm{t}}$ and excess pore pressure under partially drained conditions measured for $0.2 \mathrm{~mm} / \mathrm{sec}, 0.1 \mathrm{~mm} / \mathrm{sec}$, and $0.05 \mathrm{~mm} / \mathrm{sec}$ (Figure 3.11(c), (d), and (e)) fluctuate. This is because, under partially drained conditions, $\mathrm{q}_{t}$ and excess pore pressure undergo rapid change even with small changes in consolidation parameters of the surrounding soils. In other words, $\mathrm{q}_{\mathrm{t}}$ and excess pore pressure values are sensitive to changes in the soil drainage rate. Therefore, the fluctuation of $\mathrm{q}_{t}$ and excess pore pressure in Figure 3.5(c)-(e) implies that the consolidation parameters of the soil fluctuate slightly with depth. 


\section{Cone resistance, $\mathrm{q}_{\mathrm{t}}(\mathrm{MPa})$}

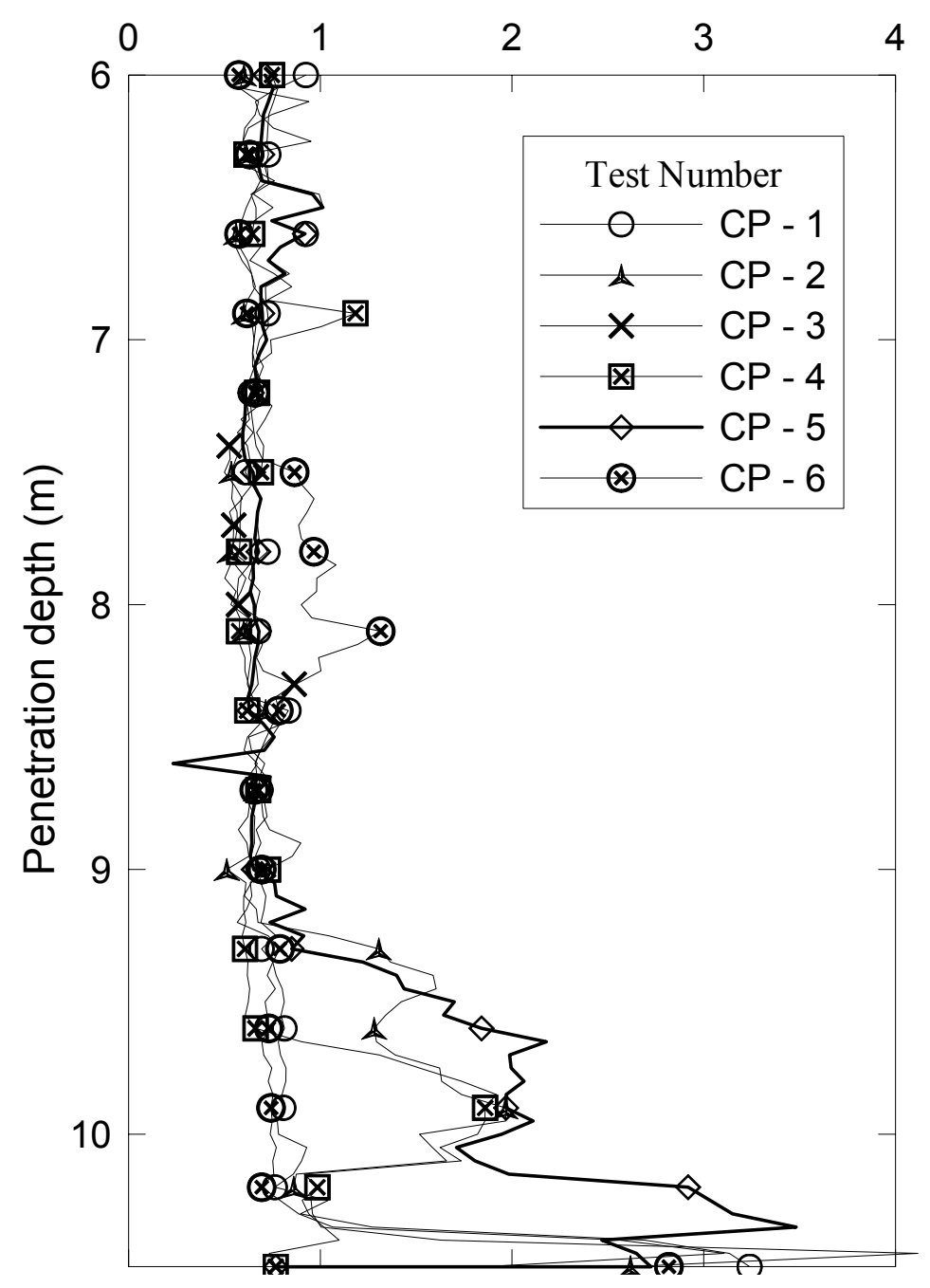

Figure 3.9 Cone tip resistances measured at various penetration velocities for clayey silts $(6 \mathrm{~m}-10.5 \mathrm{~m})$.

The average values of $\mathrm{q}_{\mathrm{t}}$, pore pressure, and $\mathrm{f}_{\mathrm{s}}$ versus cone penetration rates are shown at Figure 3.12. Average $\mathrm{q}_{\mathrm{t}}$ at $0.2 \mathrm{~mm} / \mathrm{sec}$ velocity increased about $70 \%$ as it dropped from $1 \mathrm{~mm} / \mathrm{sec}$, and $\mathrm{q}_{\mathrm{t}}$ at $0.05 \mathrm{~mm} / \mathrm{sec}$ increased up to 2.3 times the value at 20 $\mathrm{mm} / \mathrm{sec}$ in velocity. 


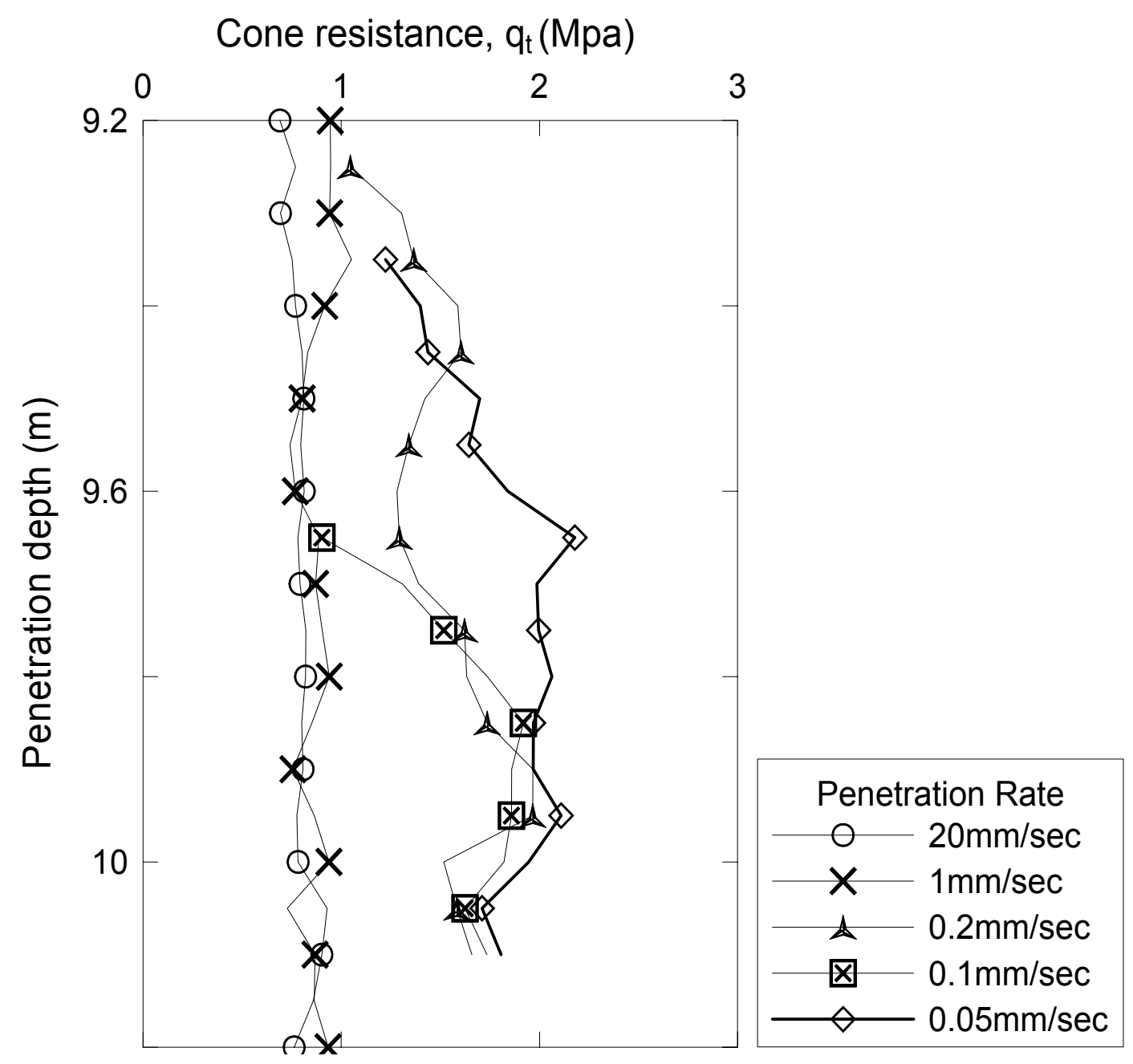

Figure 3.10 Cone tip resistances with various velocities in layer $1(9.2 \mathrm{~m}-10.2 \mathrm{~m})$.

Generally it is known that the sleeve friction measurement of a cone does not give consistent results during cone penetration (Lunne et al, 1986). However, the measured sleeve friction in layer 1 seems to be reliable. The values of $f_{s}$ in layer 1 clearly show a change as the cone velocity decreases. It gradually increased from $10 \mathrm{kPa}$ to about $30 \mathrm{kPa}$ (Figure 3.12). 


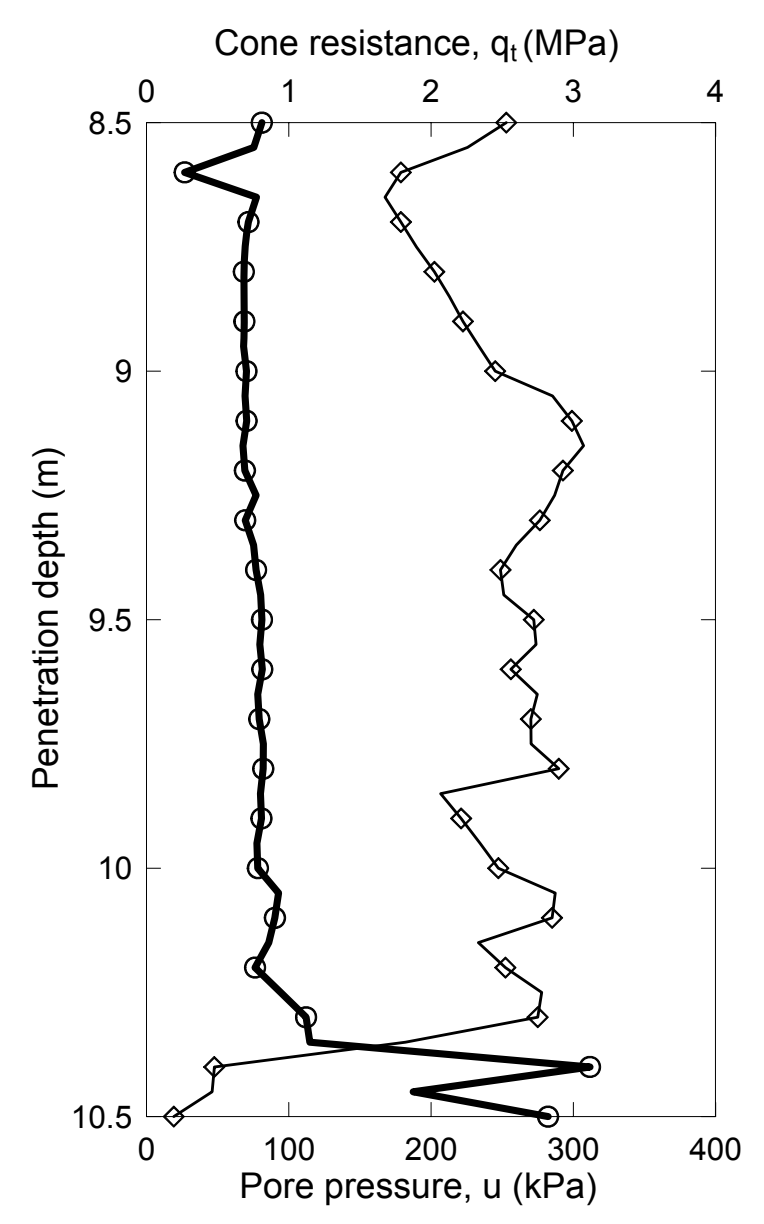

(a) Penetration rate: $20 \mathrm{~mm} / \mathrm{sec}$

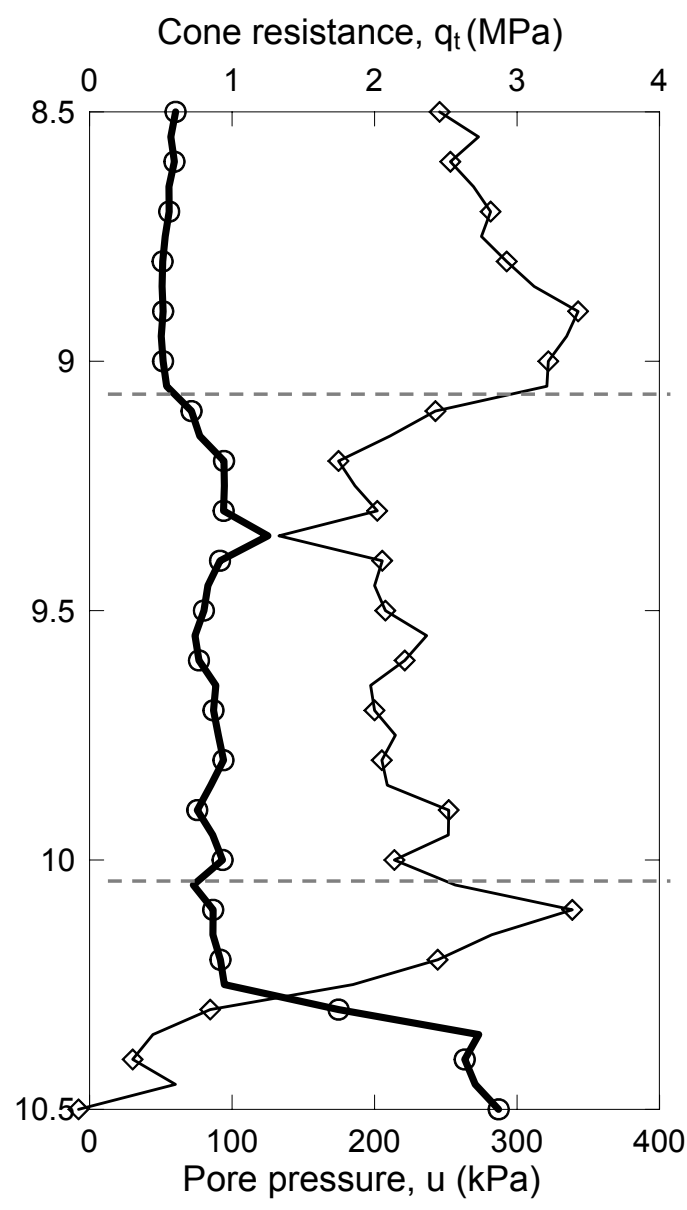

(b) Penetration rate: $1 \mathrm{~mm} / \mathrm{sec}$

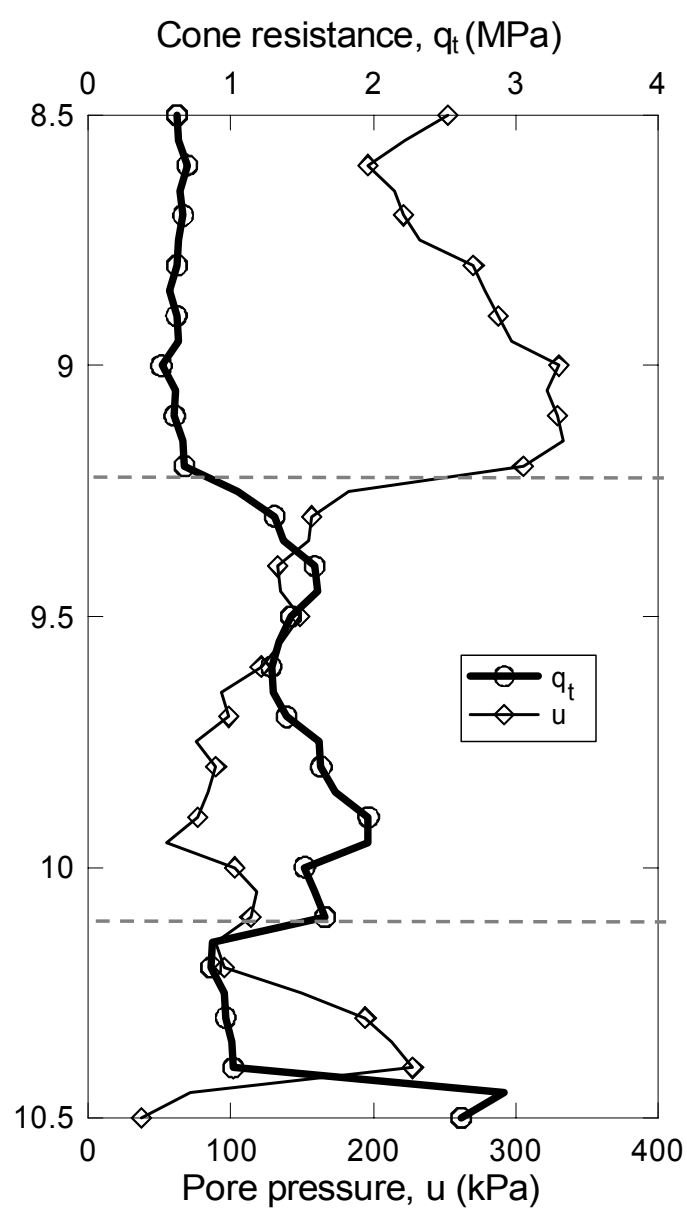

(c) Penetration rate: $0.2 \mathrm{~mm} / \mathrm{sec}$

Figure $3.11 \mathrm{q}_{\mathrm{t}}$ and pore pressure results with varying penetration velocities. 




(d) Penetration rate: $0.1 \mathrm{~mm} / \mathrm{sec}$



(e) Penetration rate: $0.05 \mathrm{~mm} / \mathrm{sec}$

Figure $3.11 \mathrm{q}_{\mathrm{t}}$ and pore pressure results with varying penetration velocities (continued). 

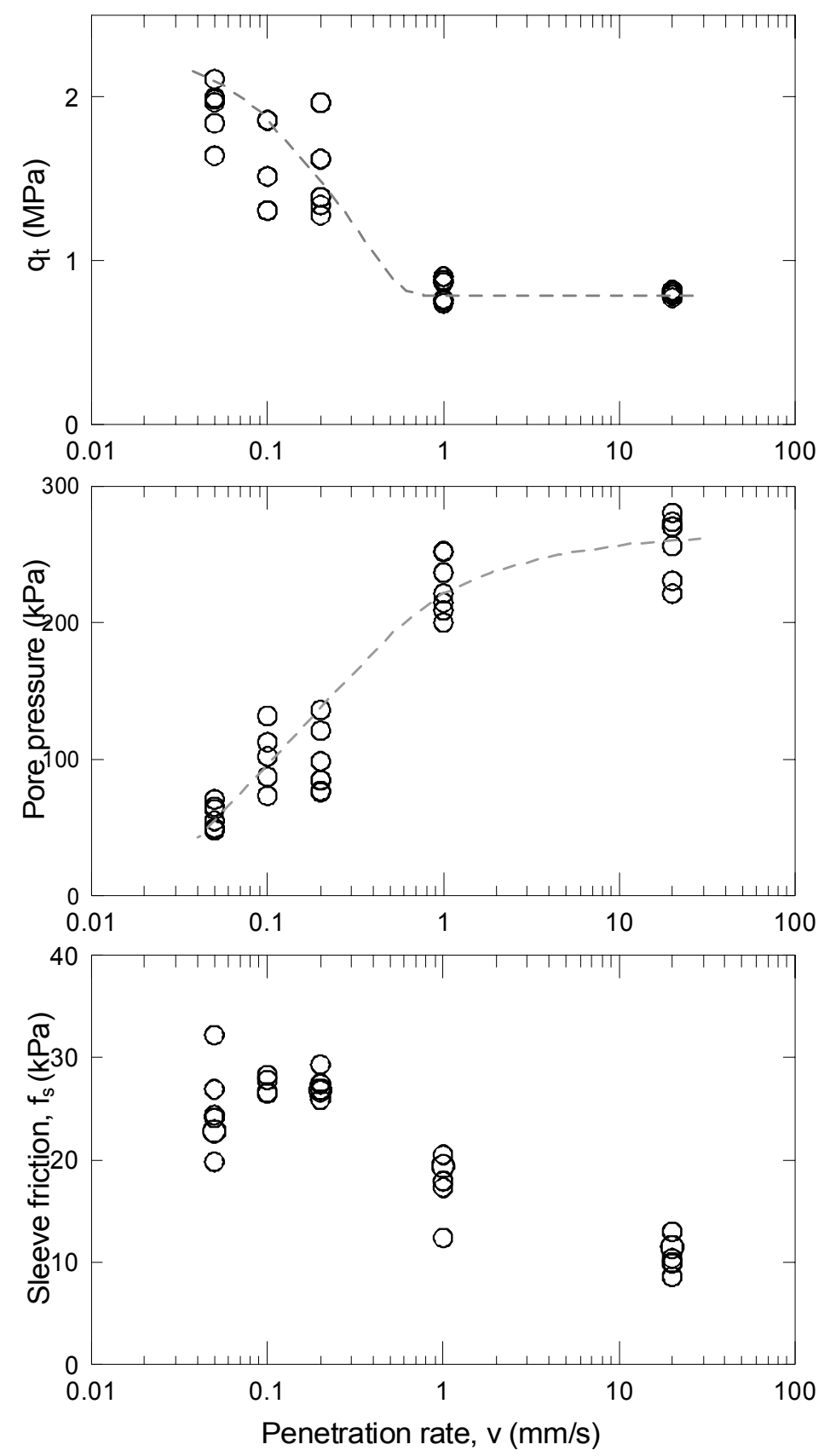

Figure 3.12 Effect of penetration rate on $\mathrm{q}_{\mathrm{t}}$, pore pressure, and $\mathrm{f}_{\mathrm{s}}(9.2 \mathrm{~m}-10.2 \mathrm{~m}$ depth, SR 18). 


\subsubsection{Layer $2(7.4 \mathrm{~m}-8.4 \mathrm{~m})$}

CPTs were performed at five different penetration rates $(\mathrm{v}=20,3,1,0.2$, and $0.05 \mathrm{~mm} / \mathrm{s}$ ) in the clayey silt between $7.4 \mathrm{~m}$ and $8.4 \mathrm{~m}$. Figure 3.13 shows the $\mathrm{q}_{\mathrm{t}}$ profiles with various penetration rates ranging from $20 \mathrm{~mm} / \mathrm{sec}$ to $0.05 \mathrm{~mm} / \mathrm{sec}$ in layer 2 . Measured $\mathrm{q}_{t}$ and excess pore pressure values at each velocity are shown at Figure 3.14 (a)(e). Average values of $\mathrm{q}_{\mathrm{t}}$, pore pressure, and $\mathrm{f}_{\mathrm{s}}$ versus cone penetration rates are shown in Figure 3.15. For penetration rates in the range between $20 \mathrm{~mm} / \mathrm{s}$ and $0.1 \mathrm{~mm} / \mathrm{s}$, penetration seems to occur under undrained conditions. The average $\mathrm{q}_{t}$ for a penetration rate between 3 $\mathrm{mm} / \mathrm{s}$ and $0.2 \mathrm{~mm} / \mathrm{s}$ was about $0.5 \mathrm{MPa}$. As $\mathrm{v}$ dropped to $0.05 \mathrm{~mm} / \mathrm{s}$, the average $\mathrm{q}_{\mathrm{t}}$ increased abruptly to $1 \mathrm{MPa}$. The excess pore pressure decreased from an average of 230 $\mathrm{kPa}$ for penetration rates in the range between 0.2 and $20 \mathrm{~mm} / \mathrm{s}$ to about $110 \mathrm{kPa}$ for $\mathrm{v}=$ $0.05 \mathrm{~mm} / \mathrm{s}$. Considering the changes in $\mathrm{q}_{\mathrm{t}}$ and pore pressure, the transition from undrained to partially drained conditions occurred around a penetration rate of $0.1 \mathrm{~mm} / \mathrm{s}$. 


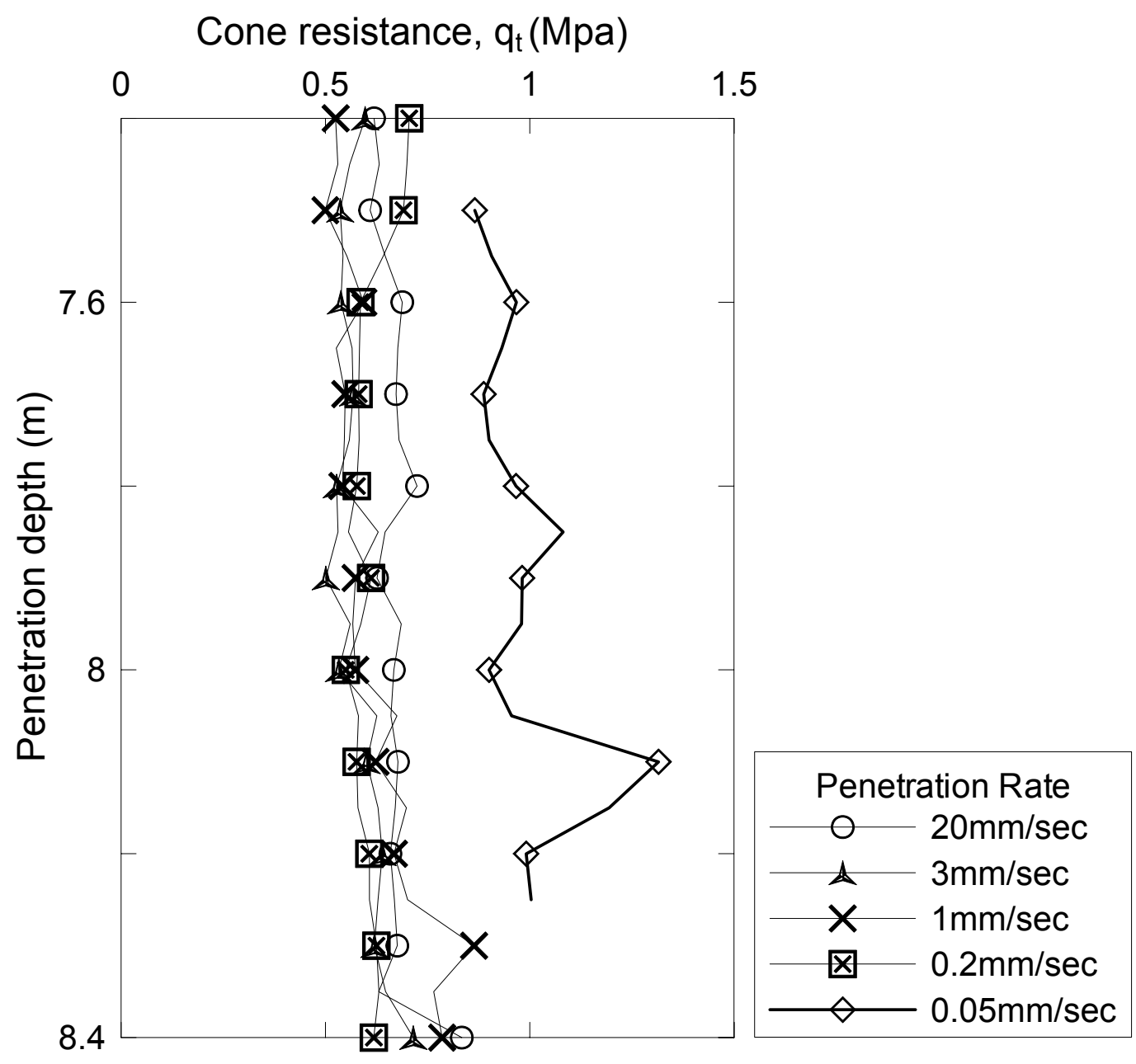

Figure 3.13 Cone tip resistances versus penetration velocity in layer $2(7.5 \mathrm{~m}-8.4 \mathrm{~m})$. 


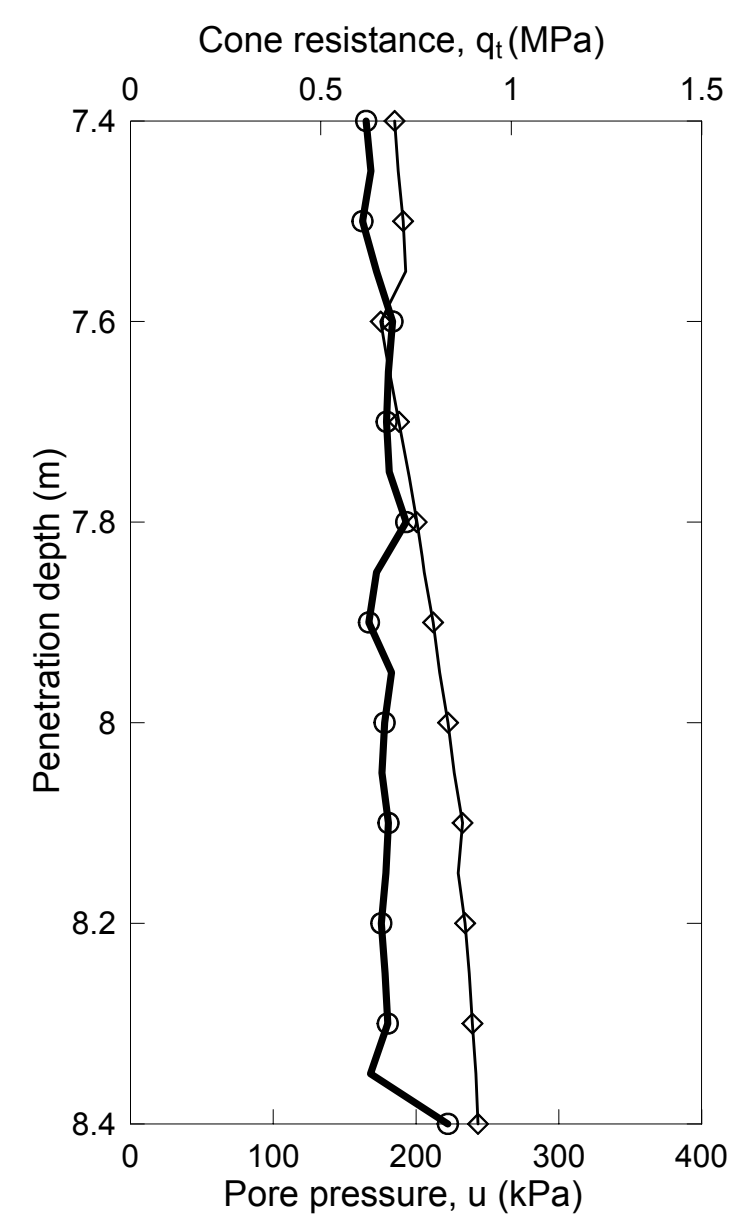

(a)Penetration rate: $20 \mathrm{~mm} / \mathrm{sec}$

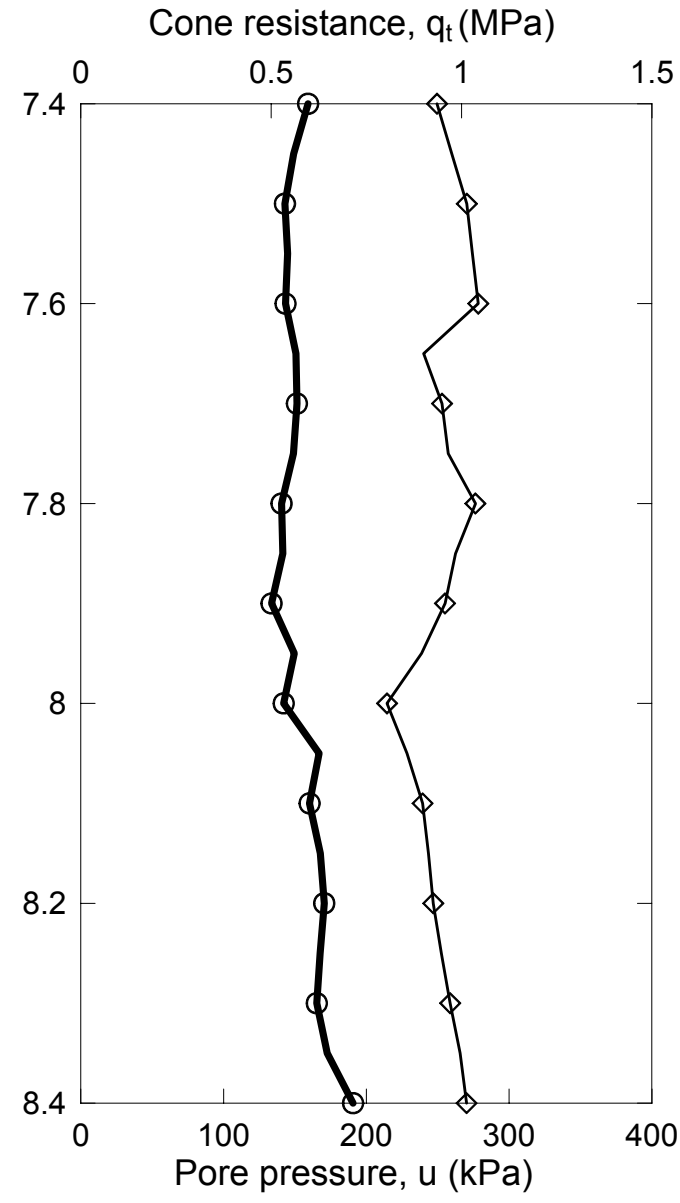

(b) Penetration rate: $3 \mathrm{~mm} / \mathrm{sec}$

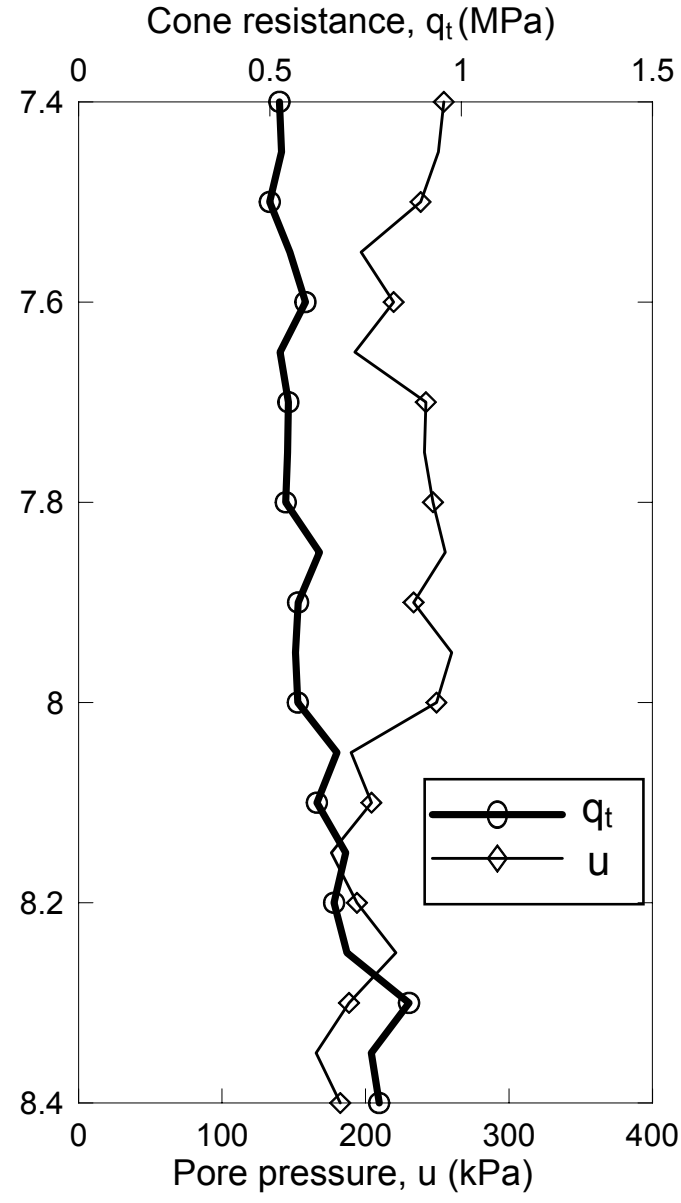

(c) Penetration rate: $1 \mathrm{~mm} / \mathrm{sec}$

Figure $3.14 q_{t}$ and pore pressure results with varying penetration velocities in Layer 2 . 


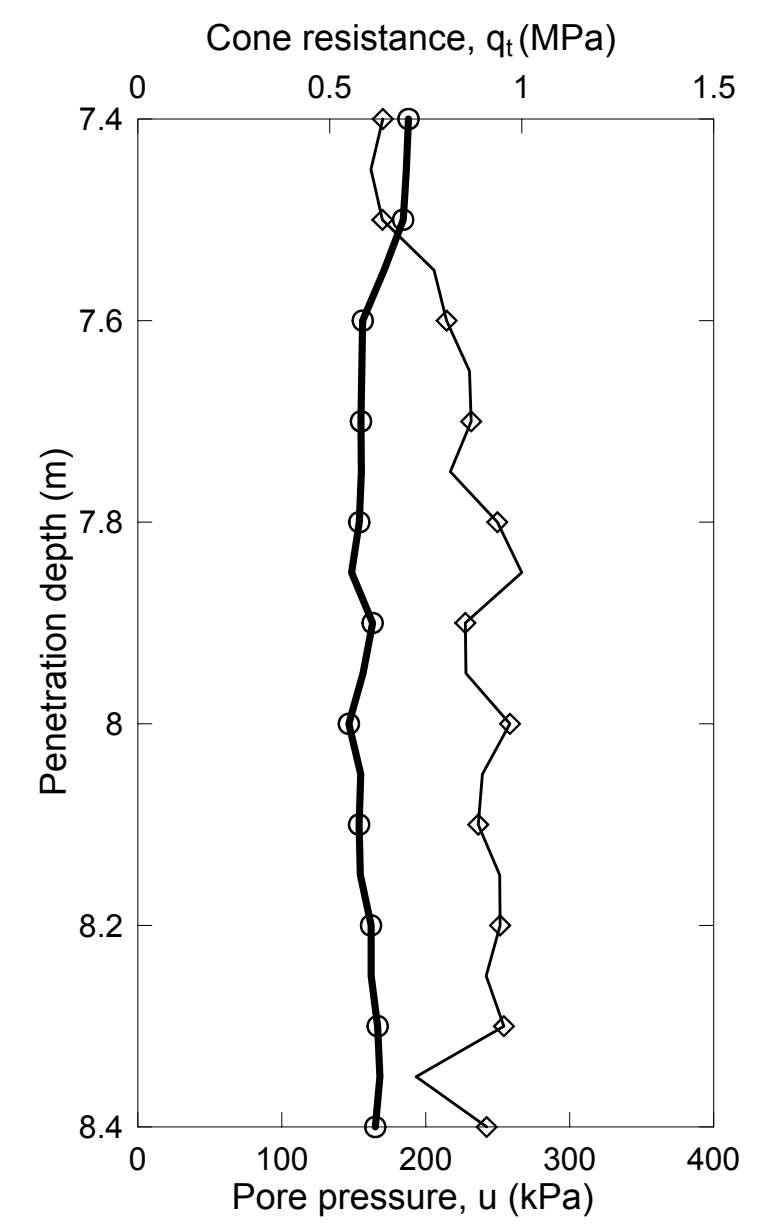

(d) Penetration rate: $0.2 \mathrm{~mm} / \mathrm{sec}$

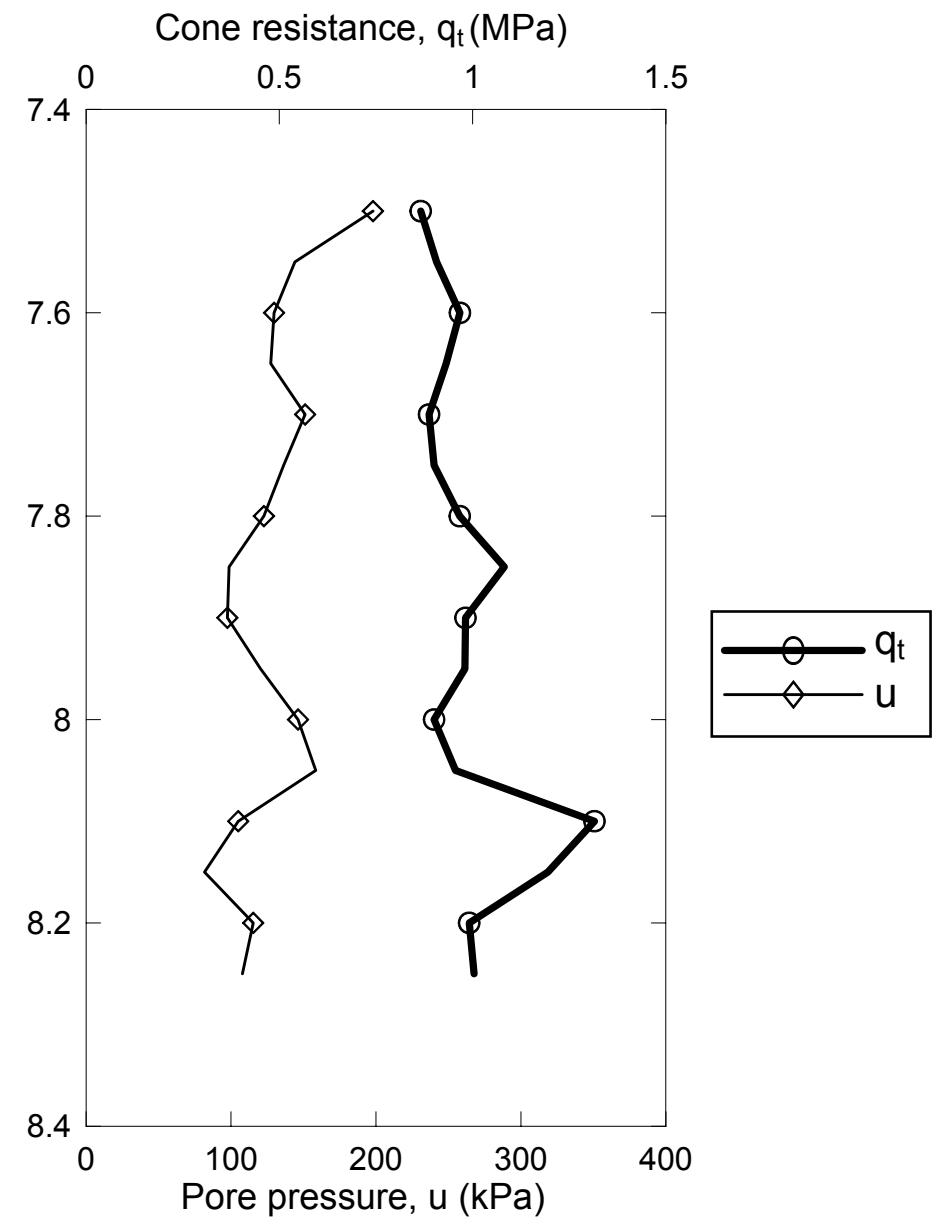

(e) Penetration rate: $0.05 \mathrm{~mm} / \mathrm{sec}$

Figure $3.14 \mathrm{q}_{\mathrm{t}}$ and pore pressure results with varying penetration velocities in Layer 2 (Continued). 

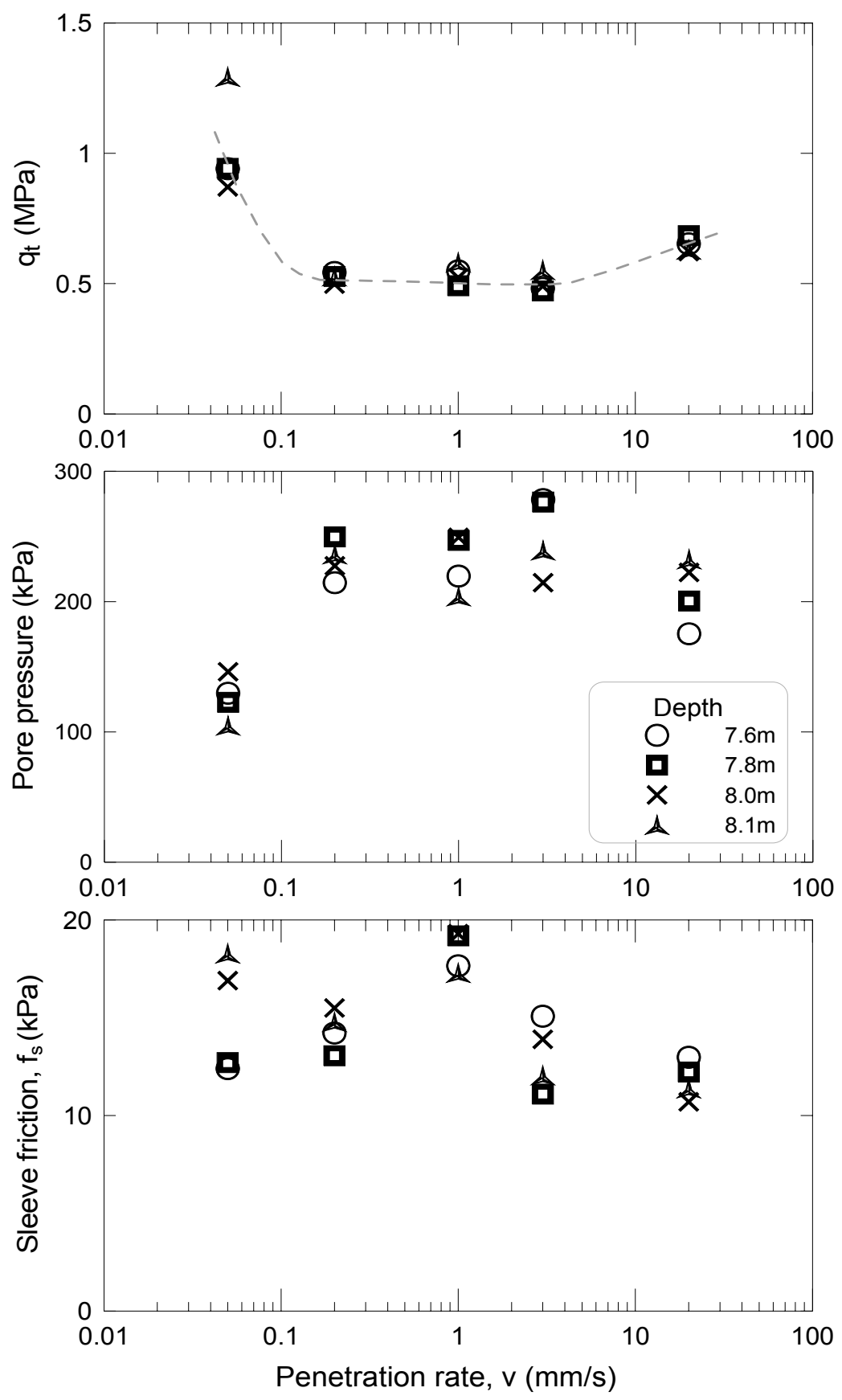

Figure 3.15 Effect of penetration rate on $q_{t}$, pore pressure, and $f_{s}(7.4 m-8.4 m$ depth, $S R$ 18). 
Excess pore pressure decreased from an average $230 \mathrm{kPa}$ for $0.3-20 \mathrm{~mm} / \mathrm{sec}$ to about $110 \mathrm{kPa}$ for $0.05 \mathrm{~mm} / \mathrm{sec}$ velocity (Figure 3.14 and 3.15). Even at the lowest speed in the tests, penetration at full drainage was not observed. Since $c_{v}$ of this layer is lower than that of layer 1 , the rate effect caused by a change in the drainage condition is observed for a lower than for layer 1 .

As discussed in the previous chapter, increases in cone resistance due to increases in penetration rate have been reported (e.g., Tani and Craig 1995, Powell and Quarterman 1988) for field and calibration chamber CPTs performed under undrained conditions (at fast penetration rates). Since cone resistance is directly related to the undrained shear strength $s_{u}$ of the clay, the same loading rate effects observed in the laboratory for $s_{u}$ can be expected to influence $q_{t}$ measurements. Accordingly, cone resistance measured under undrained conditions is expected to increase slightly as a result of the increase in $s_{u}$ caused by penetration rate increases. Miniature cone test results reported by Tani and Craig (1995) showed that cone resistance increased by $10 \%$ for every ten-fold increase in the penetration rate range between $0.1 \mathrm{~mm} / \mathrm{s}$ and $5 \mathrm{~mm} / \mathrm{s}$ on clay till soils. Powell and Quarterman (1988) also reported a $10 \%$ increase of cone resistance measured in field CPTs in clay for an increase in penetration rate from $1.7 \mathrm{~mm} / \mathrm{s}$ to $16.7 \mathrm{~mm} / \mathrm{s}$.

CPTs performed under undrained conditions $(0.2 \mathrm{~mm} / \mathrm{s}-20 \mathrm{~mm} / \mathrm{s})$ for the clayey silt between $7.4 \mathrm{~m}$ and $8.4 \mathrm{~m}$ showed viscous effects at high penetration rates. The average $\mathrm{q}_{\mathrm{t}}$ at $20 \mathrm{~mm} / \mathrm{s}$ was $0.65 \mathrm{MPa}, 30 \%$ higher than $\mathrm{q}_{\mathrm{t}}\left(\mathrm{q}_{\mathrm{t}}=0.5 \mathrm{MPa}\right)$ at $3 \mathrm{~mm} / \mathrm{s}$. Between the penetration rates of $3 \mathrm{~mm} / \mathrm{s}$ and $0.2 \mathrm{~mm} / \mathrm{s}$, the $\mathrm{q}_{\mathrm{t}}$ values were nearly the same.

\subsection{Site 2: Oliver Ditch Site (SR 49)}

The second set of field cone penetration tests was performed at the site where field pile load tests were also conducted. This site is located on the north side of Oliver ditch on state road 49 in Jasper County, Indiana. The test site described here was part of 
the pile load test project planned and performed by Salgado et al. (2004). Prior to the installation of the main piles and reaction piles at the site, 7 CPTs and 4 borings were made to delineate the soil profile of the site. Cone resistance, friction resistance, and pore pressure measured during CPTs in the test layer are shown in Figure 3.16.

A testing program was designed and executed for studying the rate effect for the homogeneous silty clay layer located between depths $12.5 \mathrm{~m}-14.5 \mathrm{~m}$. CPT profiles of the layer are shown in Figure 3.16. The homogeneous silty clay layer is indicated by constant $\mathrm{q}_{\mathrm{t}}$ and pore pressure profiles in Figure 3.16, as well as by a continuous soil boring. Cone penetration tests with various penetration speeds, $20 \mathrm{~mm} / \mathrm{sec}, 2 \mathrm{~mm} / \mathrm{sec}, 0.5 \mathrm{~mm} / \mathrm{sec}, 0.1$ $\mathrm{mm} / \mathrm{sec}, 0.02 \mathrm{~mm} / \mathrm{sec}$ and $0.01 \mathrm{~mm} / \mathrm{sec}$, were performed between $13 \mathrm{~m}-14 \mathrm{~m}$ depth, in the middle of the silty clay layer.

\subsubsection{Experimental Test Results}

A series of laboratory tests were performed to provide reference soil properties for the soil layer in which the penetration tests were performed. The same laboratory test program used for site 1 was followed. The experimental tests included index tests for soil basic properties, one-dimensional consolidation, and triaxial shear tests. As shown by the grain size distribution of the layer in Figure 3.17, the soil consists of $15 \%$ sand, $64 \%$ silt, and $21 \%$ clay. The natural water content of the soils is about $23 \%$ and the liquid limit and plastic limit are $21 \%$ and $12 \%$.

A consolidation test was performed in exactly the same sequence explained in section 3.2.1.1. The measured values of $\mathrm{c}_{\mathrm{v}}$ are shown in the semi-log plots of $\mathrm{c}_{\mathrm{v}}$ versus $\sigma_{v}^{\prime}$ in Figure 3.18, and summarized in Table 3.6. The coefficient of consolidation $\mathrm{c}_{\mathrm{v}}$ at the geostatic stress of the test layer $(100 \mathrm{kPa})$ is $0.00354 \mathrm{~cm}^{2} / \mathrm{sec}$. A triaxial test was also performed following to the same sequence explained in section 3.2.1.2. The CU-triaxial test results are summarized in Table 3.7. 


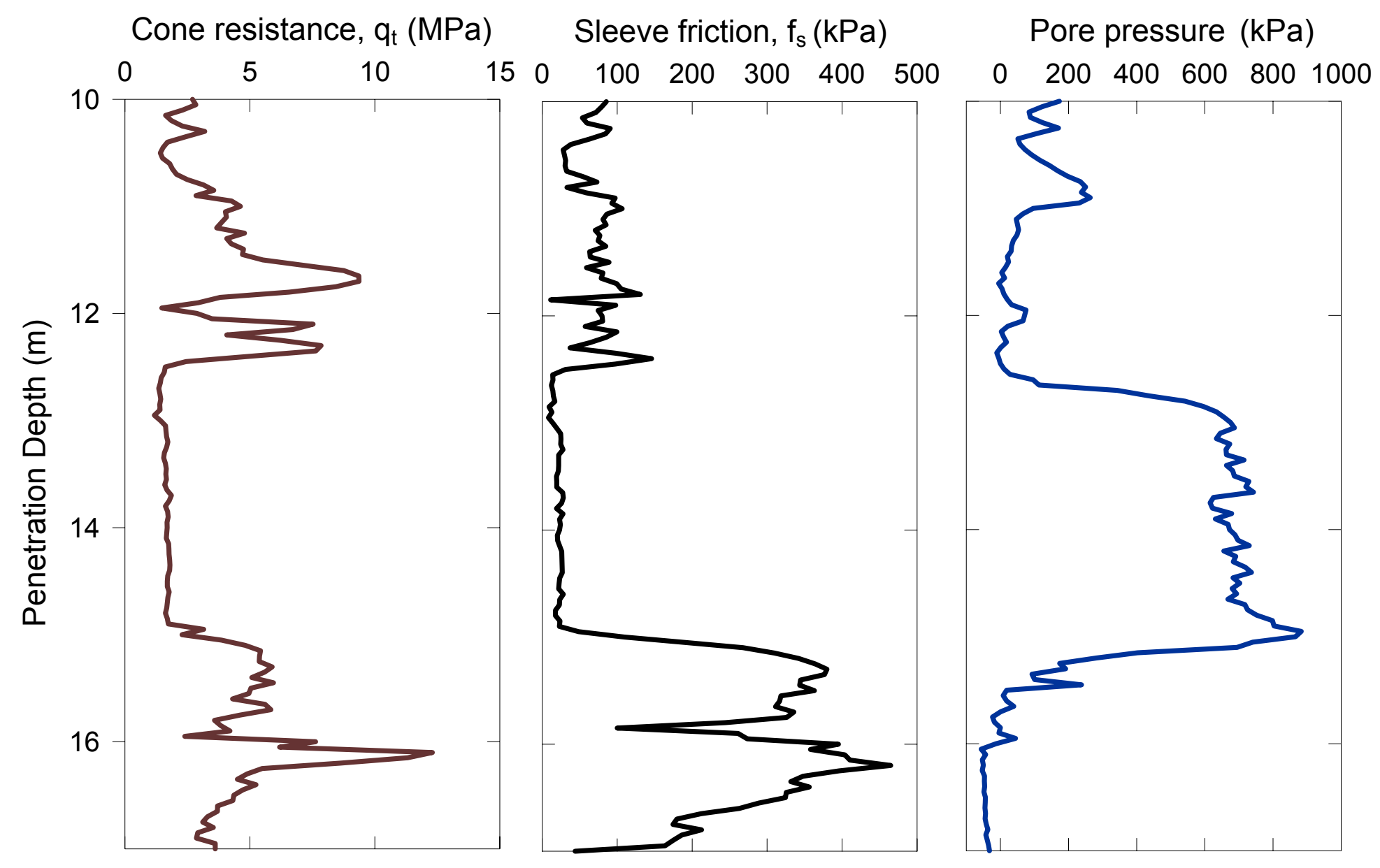

Figure 3.16 Profiles of $\mathrm{q}_{\mathrm{t}}, \mathrm{f}_{\mathrm{s}}$, pore pressure of CPTs at the SR 49 test site. 


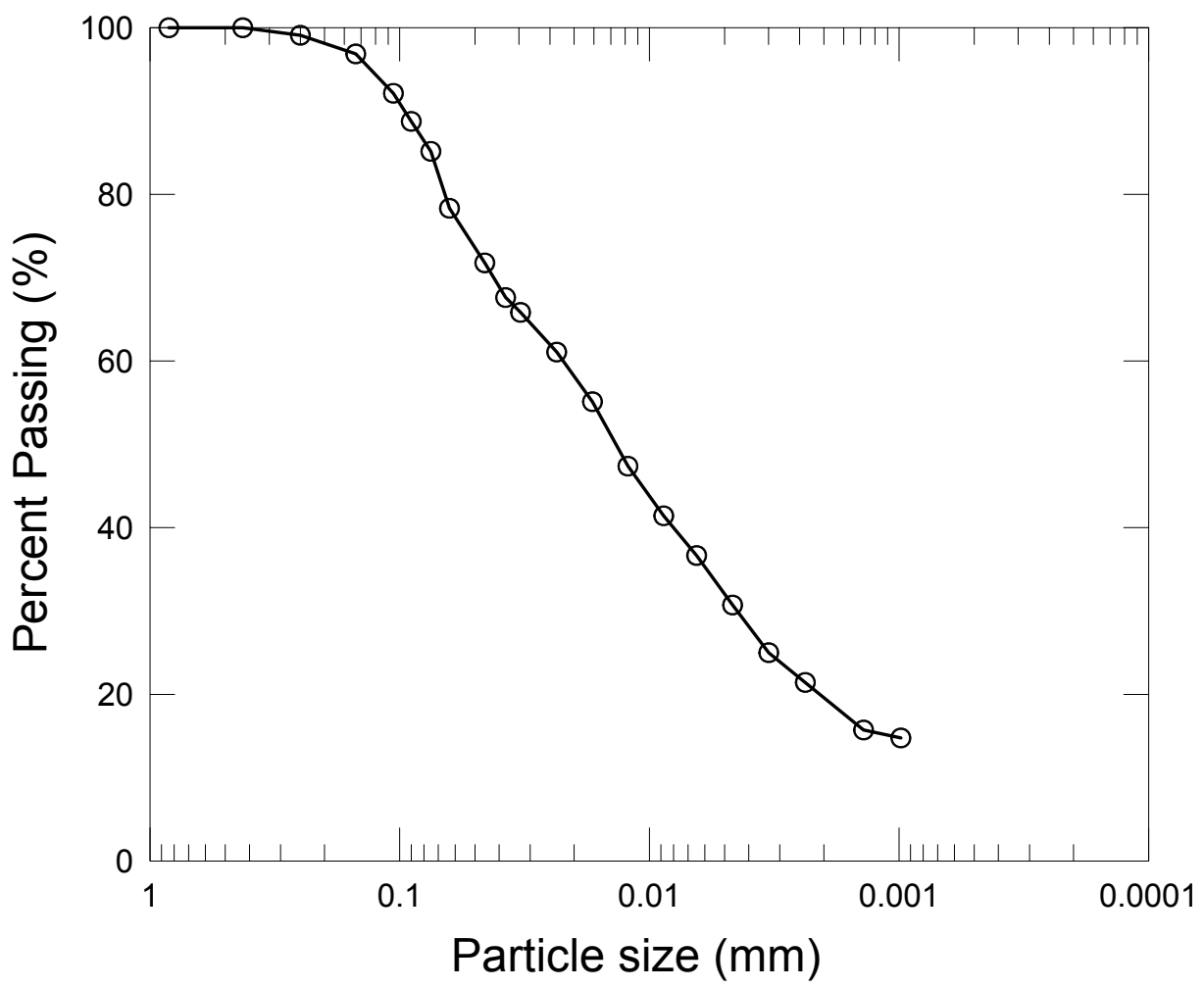

Figure 3.17 Grain size distributions of the soils in the test layer (SR 49). 


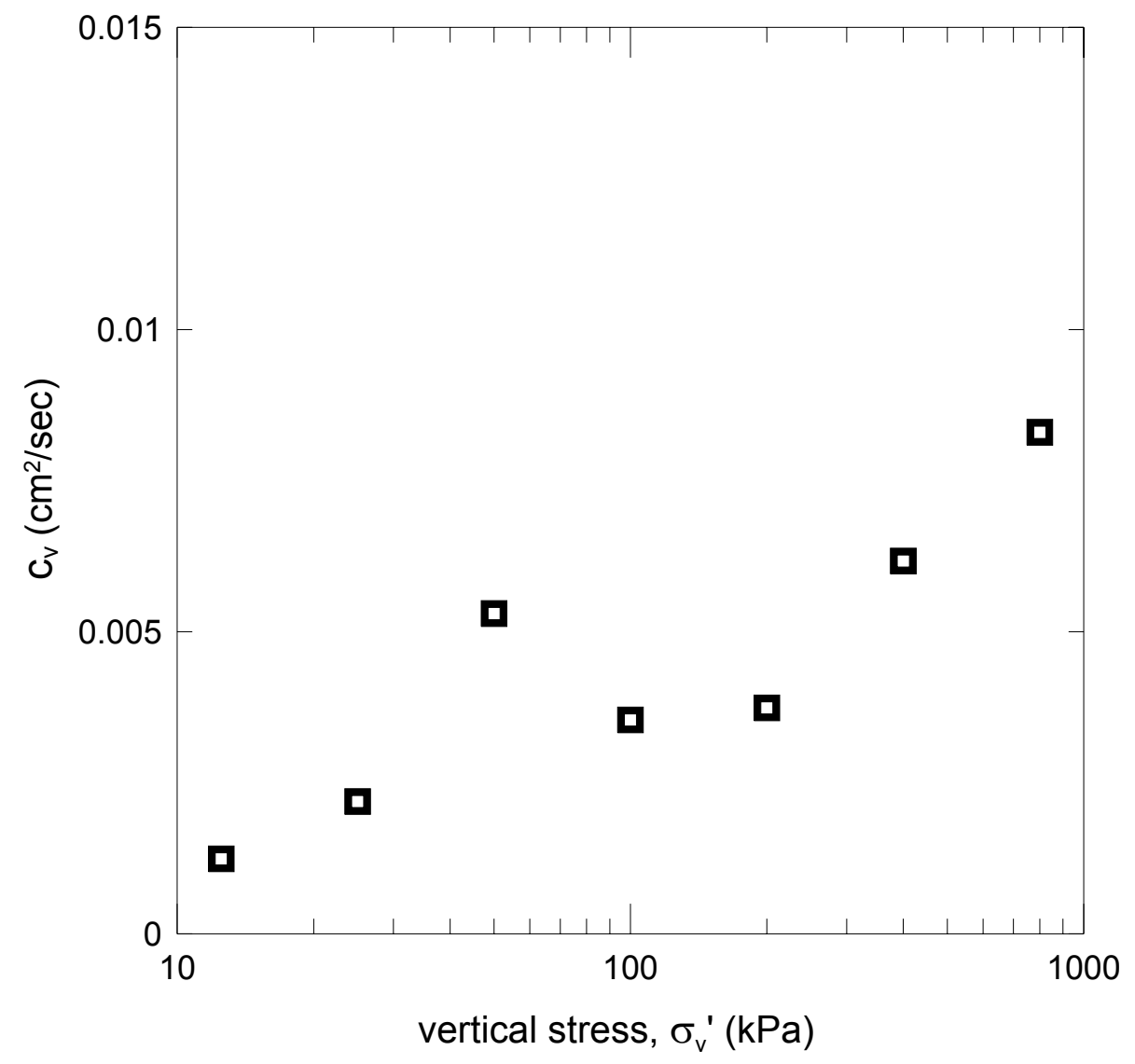

Figure 3.18 Semi-log plot of $\mathrm{c}_{\mathrm{v}}$ versus $\sigma_{v}^{\prime}$ at $12.6 \mathrm{~m}$ depth (SR49). 
Table $3.6 \mathrm{c}_{\mathrm{v}}$ versus $\sigma_{v}^{\prime}$ at $12.6 \mathrm{~m}$ depth.

\begin{tabular}{c||c|c|c|c|c|c|c}
\hline$\sigma_{v}^{\prime}$ & $12.5 \mathrm{kPa}$ & $25 \mathrm{kPa}$ & $50 \mathrm{kPa}$ & $100 \mathrm{kPa}$ & $200 \mathrm{kPa}$ & $400 \mathrm{kPa}$ & $800 \mathrm{kPa}$ \\
\hline $\mathrm{c}_{\mathrm{v}}\left(\mathrm{cm}^{2} / \mathrm{sec}\right)$ & 0.00124 & 0.00219 & 0.00530 & 0.00354 & 0.00374 & 0.00617 & 0.00830 \\
\hline
\end{tabular}

Table 3.7 Summary of a triaxial test result.

\begin{tabular}{c|c|c|c|c|c|c}
\hline Depth $(\mathrm{m})$ & Soil Layer & $\sigma_{\mathrm{v}}(\mathrm{kPa})$ & $\sigma_{\mathrm{m}}(\mathrm{kPa})$ & $\mathrm{s}_{\mathrm{u}}(\mathrm{kPa})$ & $\mathrm{q}_{\mathrm{t}}(\mathrm{MPa})$ & $\mathrm{N}_{\mathrm{k}}$ \\
\hline 12.8 & silty clay & 133 & 88.7 & 102 & 1.34 & 11.8 \\
\hline
\end{tabular}

\subsubsection{Test Results}

CPTs were performed at six penetration rates $(20,2,0.5,0.1,0.02$, and $0.01 \mathrm{~mm} / \mathrm{s})$ in the middle of the silty clay layer located between depths of $13.0 \mathrm{~m}$ and $14.0 \mathrm{~m}$ at the Oliver ditch site (SR 49). Fig. 3.19 shows average values of $\mathrm{q}_{t}$, pore pressure, and $\mathrm{f}_{\mathrm{s}}$ versus cone penetration rates.

The detailed penetration results for each penetration rate are shown in Figure 3.22(a) through (e). Average values of $q_{t}$, pore pressure, and $f_{s}$ versus varying cone penetration rates are shown in Figure 3.23. As $\mathrm{v}$ was reduced from the standard rate of $20 \mathrm{~mm} / \mathrm{s}$, the cone resistance decreased very slightly (due to the effects of viscosity) before starting to increase for penetration rates below $0.1 \mathrm{~mm} / \mathrm{s}$ because of increased drainage. As $\mathrm{v}$ was reduced from $0.1 \mathrm{~mm} / \mathrm{s}$ to $0.02 \mathrm{~mm} / \mathrm{s}$, the average $\mathrm{q}_{\mathrm{t}}$ increased from around 1.4 MPa to 2.0 MPa. Then, $\mathrm{q}_{\mathrm{t}}$ increased steeply to $3 \mathrm{MPa}$ when $\mathrm{v}$ was further decreased to $0.01 \mathrm{~mm} / \mathrm{s}$. Also, the excess pore pressure decreased from an average of 600 $\mathrm{kPa}$ for penetration rates in the range from 20 to $0.1 \mathrm{~mm} / \mathrm{s}$ to around $240 \mathrm{kPa}$ for $\mathrm{v}=0.01$ $\mathrm{mm} / \mathrm{s}$. 


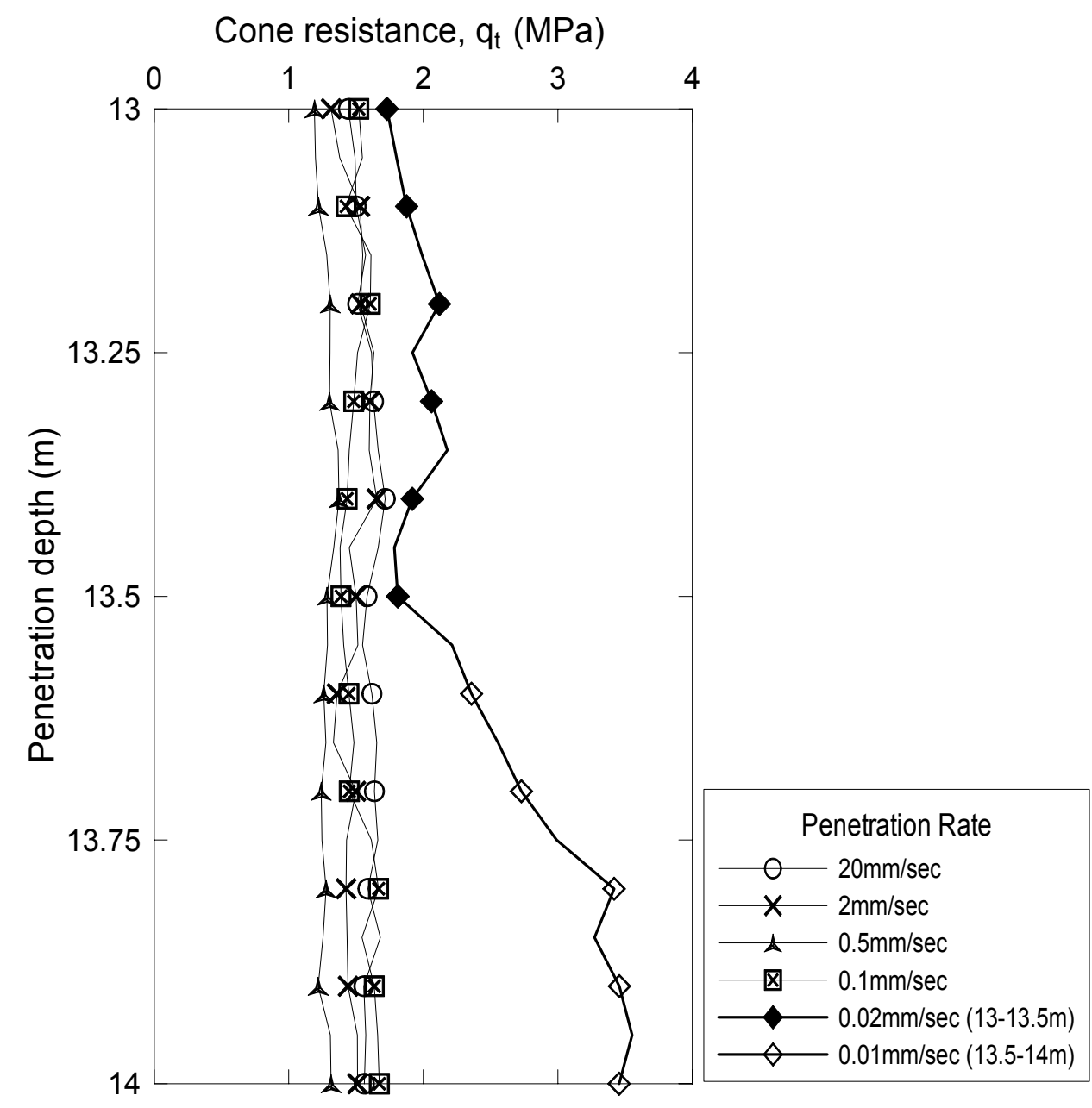

Figure 3.19 Cone tip resistance with various velocity in layer $1(9.2 \mathrm{~m}-10.2 \mathrm{~m})$. 


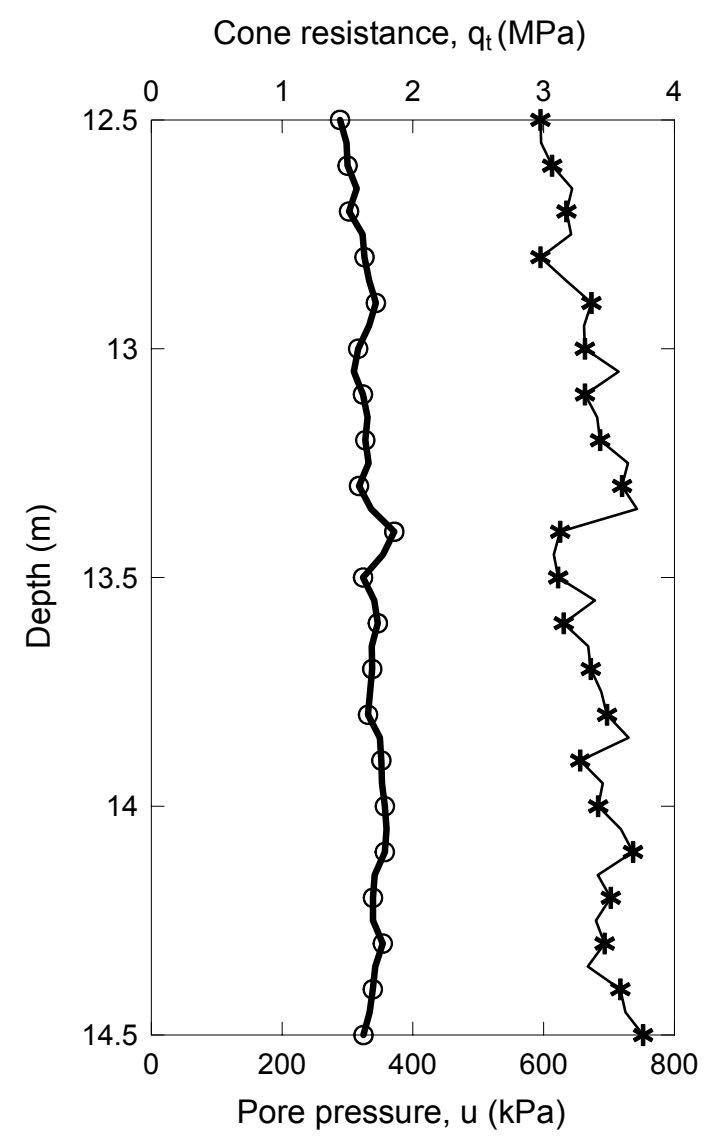

(a)Penetration rate: $20 \mathrm{~mm} / \mathrm{sec}$

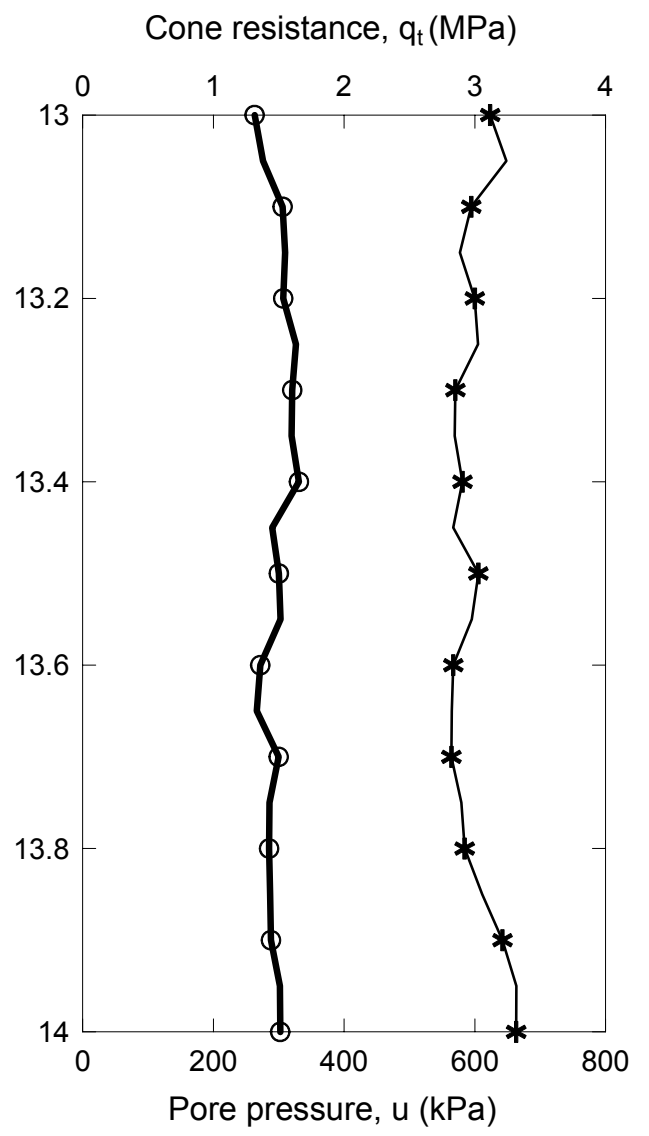

(b) Penetration rate: $2 \mathrm{~mm} / \mathrm{sec}$
Cone resistance, $\mathrm{q}_{\mathrm{t}}(\mathrm{MPa})$

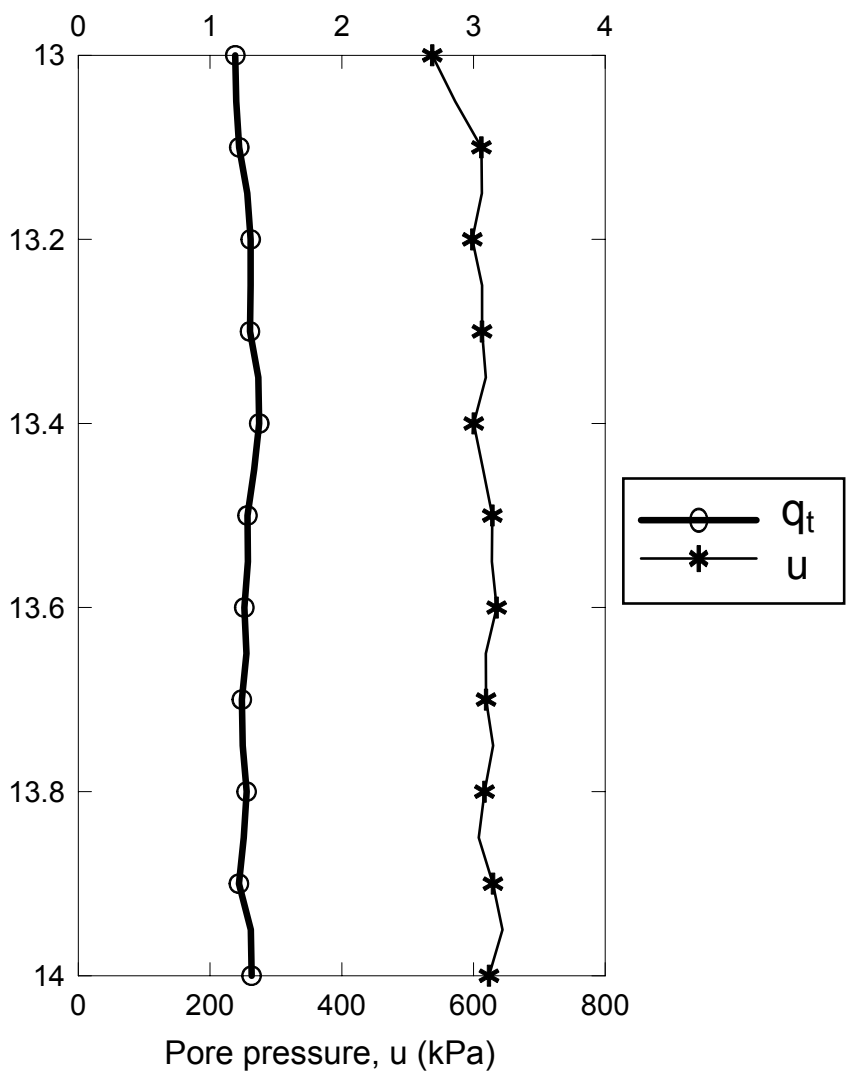

(c) Penetration rate: $0.5 \mathrm{~mm} / \mathrm{sec}$

Figure $3.20 \mathrm{q}_{\mathrm{t}}$ and pore pressure results with varying penetration velocities. 


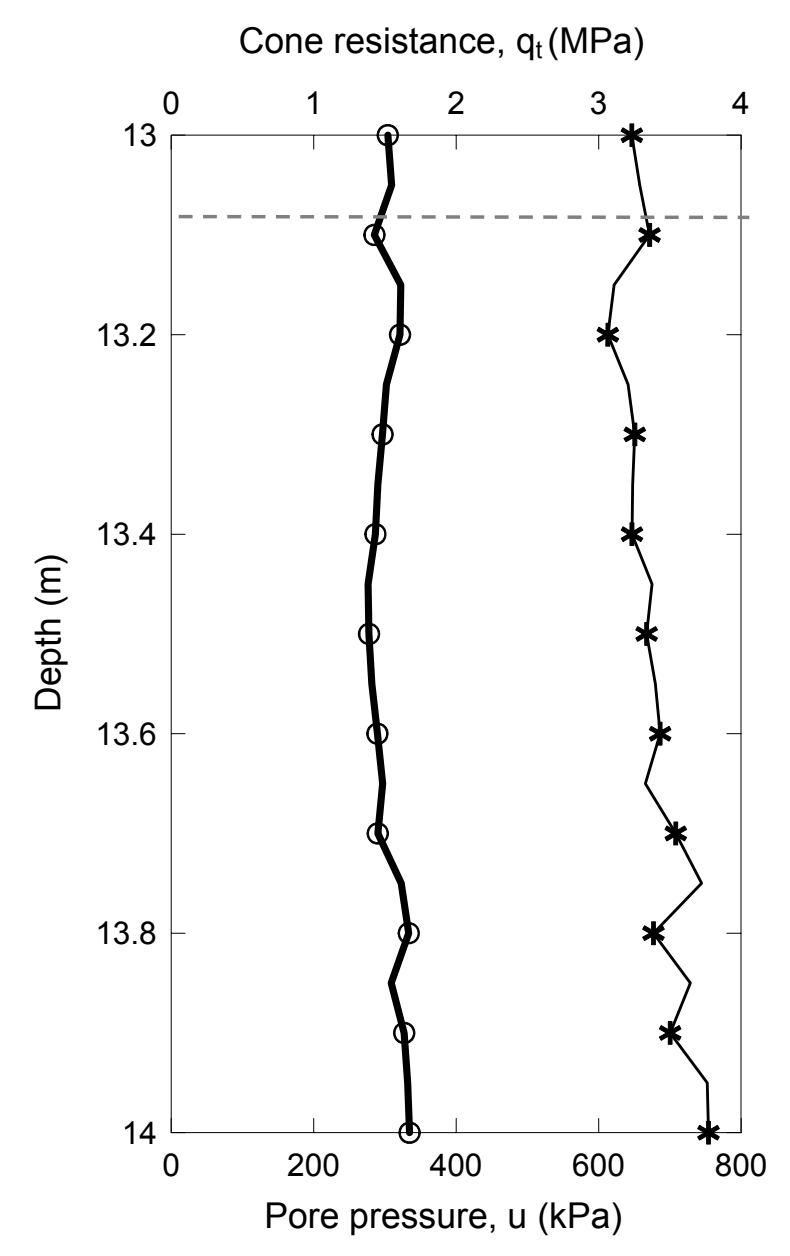

(d)Penetration rate: $0.1 \mathrm{~mm} / \mathrm{sec}$

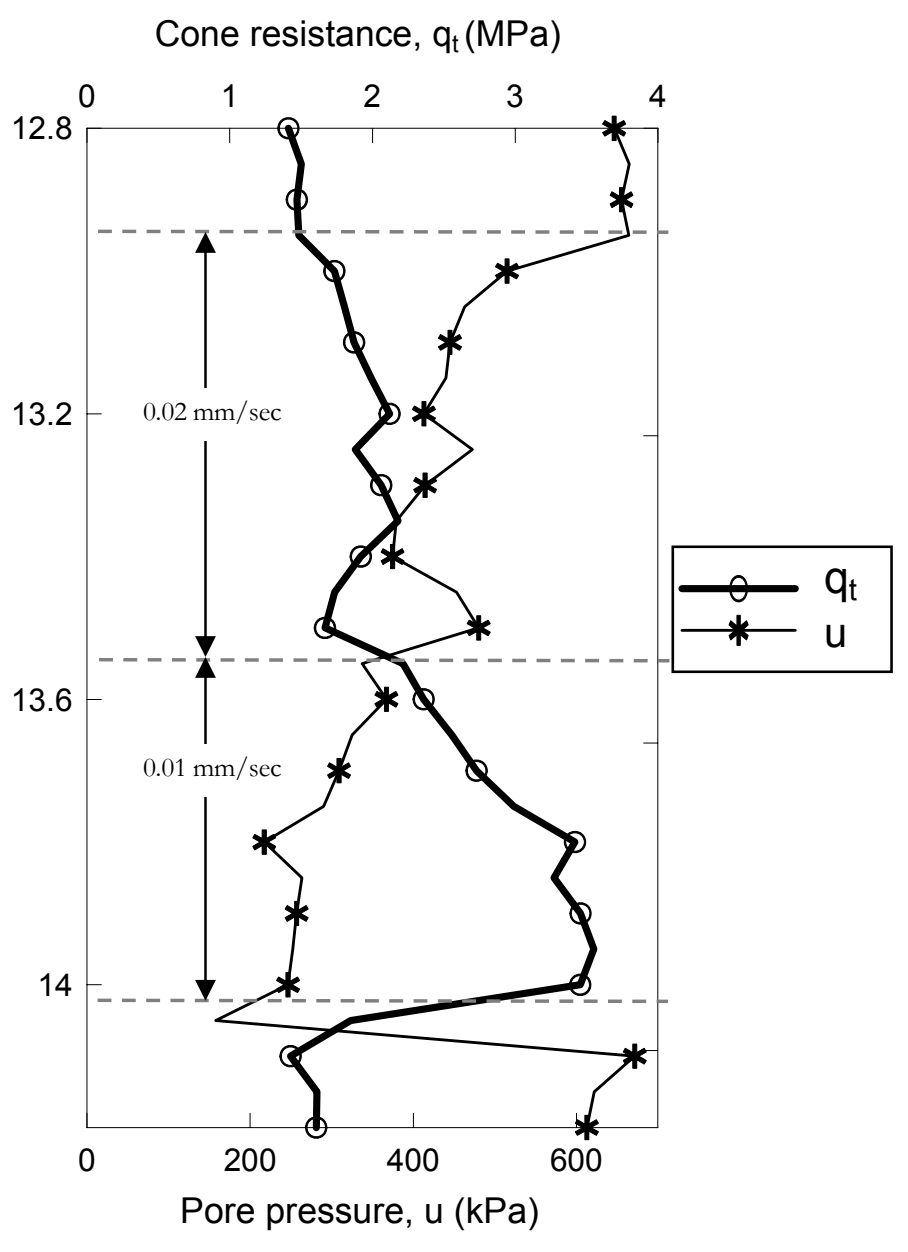

(e) Penetration rate: $0.02-0.01 \mathrm{~mm} / \mathrm{sec}$

Figure $3.20 \mathrm{q}_{\mathrm{t}}$ and pore pressure results with varying penetration velocities (Continued). 

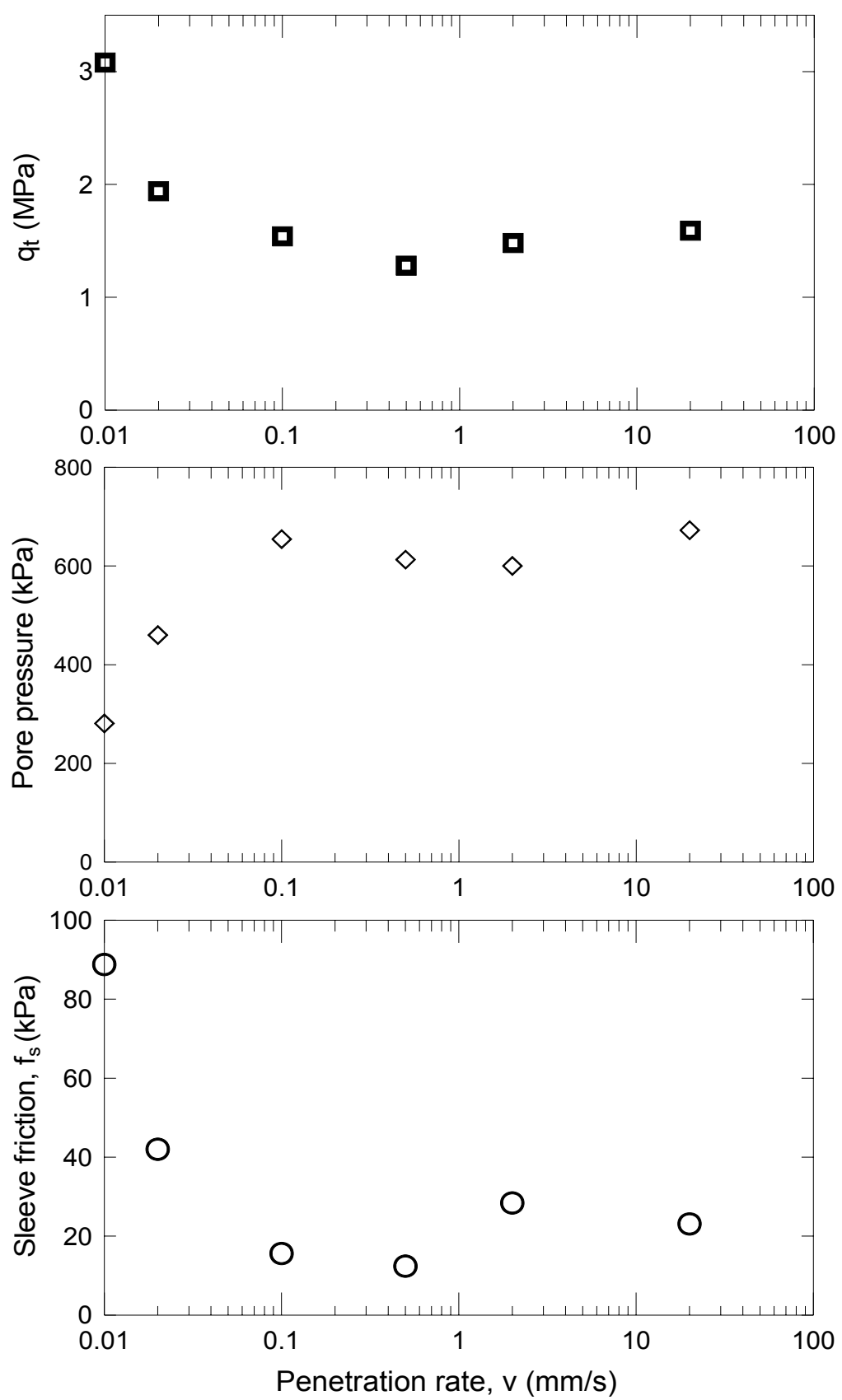

Figure 3.21 Effect of penetration rate on $\mathrm{q}_{\mathrm{t}}$, pore pressure and $\mathrm{f}_{\mathrm{s}}(\mathrm{SR} 49)$. 


\subsection{Interpretation of CPT Results Considering Normalization of the Cone Resistance and} of the Penetration Rate

Two sets of field cone penetration tests at two sites were conducted at various penetration velocities. The increment of cone resistance due to the change in drainage condition from undrained to partially drained was observed in three soil layers. In order to compare the results obtained from different soil layers having different properties, the test results must be normalized. As discussed in chapter 2, the degree of consolidation during penetration is properly considered by using the normalized penetration rate $\mathrm{V}$.

In this study, the values of $c_{v}$ used to calculate $\mathrm{V}$ are the average values obtained from oedometer tests for two loading stages close to the vertical effective stress for the layer in which measurements were obtained (Table 3.8). The values of the normalized cone resistance $q_{t} / \sigma_{v}^{\prime}$ obtained for the two test sites considered are plotted as a function of $\log \mathrm{V}$ in Fig. 3.22(a). With the normalization, the values of $q_{t} / \sigma_{v}^{\prime}$ drop with increasing $\mathrm{V}$ until $\mathrm{V} \approx 4$ and then increase slightly with increasing $\mathrm{V}$. Below that point, the normalized cone resistance increases linearly with decreasing $\log$ of $\mathrm{V}$.

The effect of the cone penetration rate on the excess pore pressure measured is shown in Fig. 3.22(b) as a function of $\log \mathrm{V}$. In this graph, the excess pore pressure is normalized with respect to the maximum value of excess pore pressure measured in a given soil layer. According to this figure, the transition from undrained to partially drained penetration occurs at about $\mathrm{V} \approx 10$.

Table 3.8 Averaged values of $\mathrm{c}_{\mathrm{v}}$ for calculation of $\mathrm{V}$.

\begin{tabular}{c|cccc}
\hline Test layer & $\begin{array}{c}\mathrm{SR} 18 \\
(9.5 \mathrm{~m}-9.8 \mathrm{~m})\end{array}$ & $\begin{array}{c}\mathrm{SR} 18 \\
(9.8 \mathrm{~m}-10 \mathrm{~m})\end{array}$ & $\begin{array}{c}\text { SR18 } \\
\text { Layer 2 }\end{array}$ & SR 49 \\
\hline $\mathrm{c}_{\mathrm{v}}\left(\mathrm{cm}^{2} / \mathrm{sec}\right)$ & 0.0472 & 0.0691 & 0.00467 & 0.00364 \\
\hline
\end{tabular}




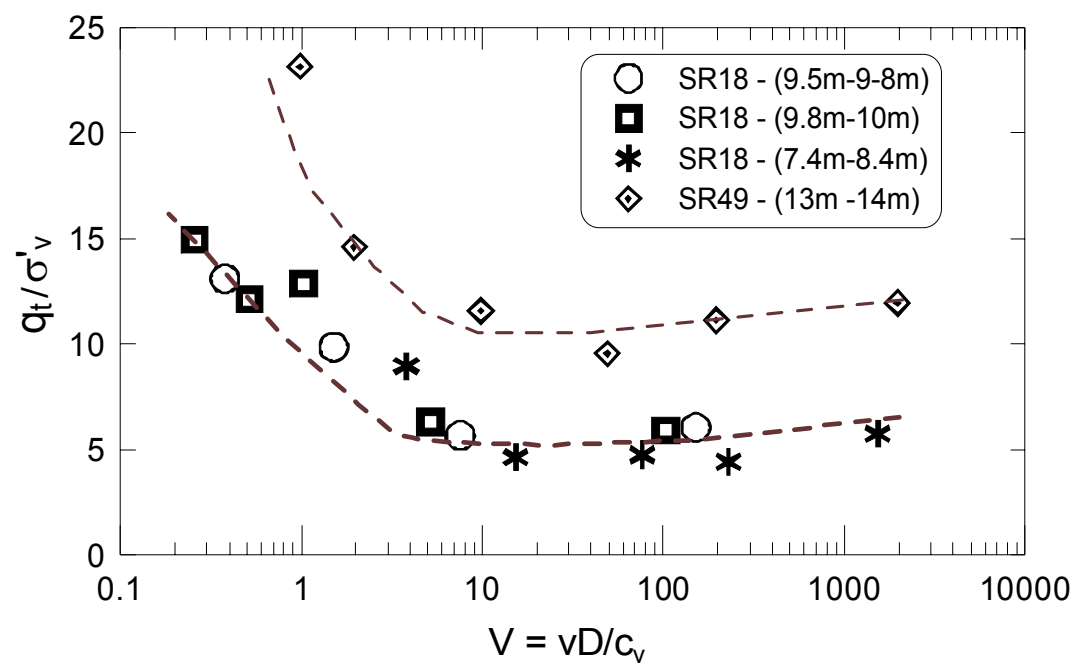

(a)

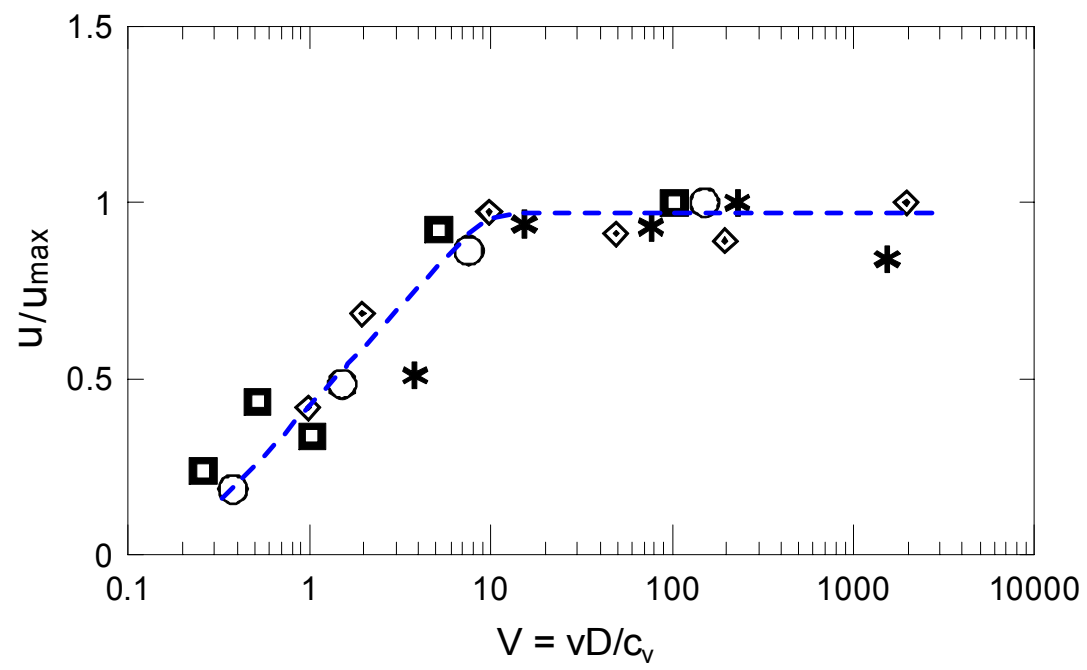

(b)

Figure 3.22 Plots of (a) normalized cone resistance and (b) normalized excess pore pressure versus normalized penetration rate. 
The true transition point between undrained and partially drained penetration should be decided by observations of pore pressure and not $\mathrm{q}_{\mathrm{t}}$. According to Fig. 3.22(b), this transition occurs for $\mathrm{V} \approx 10$. The range between the minimum $\mathrm{q}_{\mathrm{t}}$ in Fig. 3.22(a) $(\mathrm{V} \approx 4)$ and $\mathrm{V} \approx 10$ is an "offset range" within which $\mathrm{q}_{\mathrm{t}}$ would tend to drop because it approaches undrained conditions but would tend to increase because loading rate effects start taking place. From a practical standpoint, if the goal is to determine the value of $\mathrm{V}$ at which penetration resistance stops dropping, then the $\mathrm{V} \approx 4$ read from the $\mathrm{q}_{\mathrm{t}}$ plot may be of greater interest. 


\section{CHAPTER 4. CALIBRATION CHAMBER CONE PENETRATION TESTING}

\subsection{Introduction}

Calibration chamber tests are useful for the development of empirical correlations between soil properties and in situ test results, such as those obtained with the CPT, as well as for providing data for validating theories. Given that homogeneous samples can be prepared in the calibration chamber and that the stress state of the soil sample in the chamber can be controlled, calibration chamber tests offer many advantages over field tests. Uncertainties of in situ test results are related to factors such as lack of soil homogeneity and absence of knowledge of the soil in situ stresses and stress history.

Calibration chamber tests were performed as part of this study (with a miniature cone to minimize boundary effects) with the main objective of investigating some key aspects of cone penetration in clayey soils and their application to both the determination of undrained shear strength from CPT measurements and the estimation of pile load capacity from cone resistance. In particular, the study focused on rate effects due to drainage conditions (and definition of the limiting rates as drainage conditions change from undrained to partially drained, and partially drained to fully drained) and on the correlation between the cone resistance and undrained shear strength.

The following aspects of preparing and performing the calibration chamber tests are presented:

(1) determination of soil mixing ratio for the chamber specimens;

(2) flexible wall permeability tests for the determination of $c_{v}$ of soil mixtures;

(3) Overview of the calibration chamber system;

(4) summary of the test procedure for the cone penetration test in the calibration chamber. 


\subsection{Specimen Mixing Ratios}

\subsubsection{Range of $\mathrm{c}_{\mathrm{v}}$ for the Specimens}

In order to evaluate CPT rate effects in clayey soils, cone penetration speeds in the calibration chamber tests must cover the whole range of expected drainage conditions (from undrained to fully drained conditions). The hydraulic-pushing jack system used for cone penetration in the Korean calibration chamber allows precise control of the penetration rate within the range from $20 \mathrm{~mm} / \mathrm{s}$ to $0.01 \mathrm{~mm} / \mathrm{s}$. The CPTs performed at the fastest speed of $20 \mathrm{~mm} / \mathrm{s}$ should simulate undrained conditions, while those performed at $0.01 \mathrm{~mm} / \mathrm{s}$, the lowest speed, should simulate drained conditions.

For the field CPTs performed in this research, the measured values of $\mathrm{V}$ that correspond to the transition from fully undrained to partially drained conditions was observed to be between 4 and 10 in the case of clayey silt. According to Finnie and Randolph (1994), House et al. (2001), and Randolph and Hope (2005), the transition from fully undrained to partially drained conditions obtained from centrifuge tests is reported to be between $10<\mathrm{V}<30$.

At the test planning stage, in order to decide the clay-sand mixing ratio to use for the calibration chamber test samples, a value of $\mathrm{V}$ of 60 (twice as high as the upper limit of 30 suggested in the literature) was assumed to guarantee coverage all the way up to fully undrained penetration. Since the miniature cone diameter is fixed (cone diameter $=11.3$ $\mathrm{mm})$ and the range of the cone velocity is also set by the equipment capability $(20 \mathrm{~mm} / \mathrm{s}$ to $0.01 \mathrm{~mm} / \mathrm{s}$ ), the soil samples had to have appropriate $\mathrm{c}_{\mathrm{v}}$ values based on the limiting values of V. Flexible-wall permeability tests were performed to estimate the values of $c_{\mathrm{v}}$ for the soil mixtures considered initially. Tests were conducted on samples containing between 10 and $30 \%$ clay and 90 and $70 \%$ sand. Based on the obtained values of $c_{v}$, the values of $\mathrm{V}$ for the tested samples were then calculated and the mixing ratios for two specimens were

chosen. Detailed test procedures and results of the flexible wall permeability tests are described in section 4.3. 


\subsubsection{Soil Fabric}

It has been recognized (e.g., Thevanayagam, 1998; Salgado et al. 2000, Carraro et al. 2003) that up to a certain value of fines content, the finer particles either do not actively participate in the transfer of contact friction forces or contribute in a small way. As the fines content increases, a fines content will be reached for which the fines, on average, separate adjacent sand particles (Salgado et al. 2000). The concept of the skeleton void ratio $e_{\mathrm{sk}}$ is frequently used to determine the fines content for which this happens (Kuerbis et al. 1988, Thevanayagam, 1998, Salgado et al. 2000). If it is assumed that the specific gravity of the fines and sand particles are the same, the $\mathrm{e}_{\mathrm{sk}}$ can be defined as:

$$
e_{s k}=\frac{e+f}{1-f}=\frac{e+1}{1-f}-1
$$

where $\mathrm{e}=$ global void ratio of the soil and $f=$ ratio of weight of fines to total weight of soil. Whenever $\mathrm{e}_{\mathrm{sk}}$ is greater than the maximum void ratio $\left(\mathrm{e}_{\max }\right)_{f=0}$ of the clean sand, the sand particles are, on average, separated by the fines, and the mechanical behavior of the soil is no longer controlled by the sand matrix (Salgado et al. 2000). The soil is then said to have a "floating fabric". A "non-floating fabric" represents a fabric in which the sand particles in the soil matrix are in contact and thus dominate in the transmission of the frictional forces. Since the soil fabric is one of the key factors controlling the load response of transitional soils, the mixing ratio of the mixtures was selected in such a way as to produce a floating fabric for one calibration chamber sample and a non-floating fabric for the other. 


\subsection{Flexible Wall Permeameter Test}

\subsubsection{Background}

Hydraulic conductivity tests using a flexible wall permeameter were performed to derive the coefficient of consolidation $\mathrm{c}_{\mathrm{v}}$ of soil mixtures using experimentally determined hydraulic conductivity $\mathrm{K}$ and the coefficient of volume compressibility $\mathrm{m}_{\mathrm{v}}$. The tests were performed on reconstituted soil samples with various mixing ratios of sands and clays in accordance with ASTM D 5084. The test has been widely used to determine K of soils because it has several advantages. Since confining pressure is applied to the flexible membrane, side-wall leakage between soil sample and the membrane, which commonly occurs in a rigid wall permeability test, can be avoided. Moreover, the stress-state variables of a soil specimen can be controlled during the experiments, making it possible to relate the permeability of the soils to their stress state (Samingan et al. 2003). The definition of K from the flexible wall permeability test is given by

$$
K=\frac{\Delta Q \cdot L}{A \cdot h \cdot \Delta t}
$$

where $\mathrm{K}=$ hydraulic conductivity; $\Delta Q=$ quantity of flow for given time interval $\Delta t$; $\mathrm{L}=$ length of the specimen; $\mathrm{A}=$ cross-sectional area of the specimen; $h=$ average head loss across the specimen; $\Delta t=$ interval of time. The definition of $\mathrm{m}_{\mathrm{vi}}$ under an isotropic state of stress on the flexible wall test is given by

$$
m_{v i}=\frac{1}{1+e_{1}}\left(-\frac{\delta e}{\delta p}\right)=\frac{\frac{\Delta V_{s p}}{V_{s p}}}{\Delta \sigma_{3}^{\prime}}
$$

where $\mathrm{e}_{1}=$ the void ratio at the start of the load increment $\delta p ; \Delta V_{s p}=$ the volume change of the specimen; $V_{s p}=$ the initial volume of the specimen; $\Delta \sigma_{3}^{\prime}=$ the increment of effective confining stress. There is some difference between the coefficient of volume compressibility $\mathrm{m}_{\mathrm{vi}}$ obtained under isotropic confining stress in the flexible wall 
permeability test and $\mathrm{m}_{\mathrm{v}}$ obtained under the anisotropic confining stress of the $1 \mathrm{D}$ consolidation test (Head 1992). Therefore, in order to get the same value of $\mathrm{c}_{\mathrm{v}}$ from the flexible wall permeameter test as that derived from the oedometer test, $\mathrm{m}_{\mathrm{vi}}$ obtained from the flexible wall test must be converted to $\mathrm{m}_{\mathrm{v}}$ of the oedometer test by an appropriate factor. The theoretical relationship between the coefficient of volume compressibility for isotropic conditions and one-dimensional consolidation can be derived from the ratio of constrained modulus $\mathrm{D}$ and bulk modulus $\mathrm{B}$, which is given by

$$
\frac{m_{v i}}{m_{v}}=\frac{\frac{1}{B}}{\frac{1}{D}}=\frac{D}{B}=\frac{\frac{E^{\prime}\left(1-v^{\prime}\right)}{\left(1+v^{\prime}\right)\left(1-2 v^{\prime}\right)}}{\frac{E^{\prime}}{3\left(1-2 v^{\prime}\right)}}=\frac{3\left(1-v^{\prime}\right)}{1+v^{\prime}}
$$

where $\mathrm{E}^{\prime}=$ modulus of deformation of soil, $v^{\prime}=$ the Poisson's ratio of the soil for drained conditions. If a typical value of $v^{\prime}$, about $1 / 3$, is adopted, the relationship between $m_{v}$ and $m_{v i}$ would be $m_{v}=1 / 1.5 \cdot m_{v i}($ Head 1992, Carraro 2004).

The coefficient of consolidation $\mathrm{c}_{\mathrm{v}}$ is computed from the measurement of hydraulic conductivity $\mathrm{K}$ and the coefficient of volume compressibility $\mathrm{m}_{\mathrm{v}}$ by the following equation, which is derived in Terzaghi's one-dimensional consolidation theory:

$$
c_{v}=\frac{K}{\rho_{w} \cdot g \cdot m_{v}}
$$

where $\rho_{w}=$ density of water, $\mathrm{g}=$ acceleration of gravity.

\subsubsection{Sample Preparation}

Two different types of sands, Ottawa sand and Jumun sand, and kaolin clay were used for the permeability tests. Ottawa sand is generally used for standard soil tests in US, and Jumun sand, the standard sand in Korea, was used for the calibration chamber tests. 
The properties of mixtures using the two different sands are evaluated and compared to determine if the results from the calibration chamber tests using Jumun sand are comparable to results that would be obtained using Ottawa sand and therefore have general applicability. Also by comparing the results from two sands having different void ratios, the sensitivity of $c_{v}$ values to the mixing ratio of sand and clay is investigated.

The properties of Jumun sand and Ottawa sand are summarized in Table 4.1. The grain size distributions of the Ottawa and Jumun sands and kaolinite are shown in Figure 4.1 .

Table 4.1 Properties of Jumun sand and Ottawa sand

\begin{tabular}{c|cc}
\hline Property & Jumun sand & Ottawa sand \\
\hline $\mathrm{G}_{\mathrm{s}}$ & 2.65 & 2.65 \\
\hline $\mathrm{C}_{\mathrm{u}}$ & 1.49 & 1.89 \\
\hline $\mathrm{D}_{50}(\mathrm{~mm})$ & 0.53 & 0.31 \\
\hline $\mathrm{e}_{\max }$ & 0.605 & 0.495 \\
\hline $\mathrm{e}_{\min }$ & 0.980 & 0.767 \\
\hline
\end{tabular}




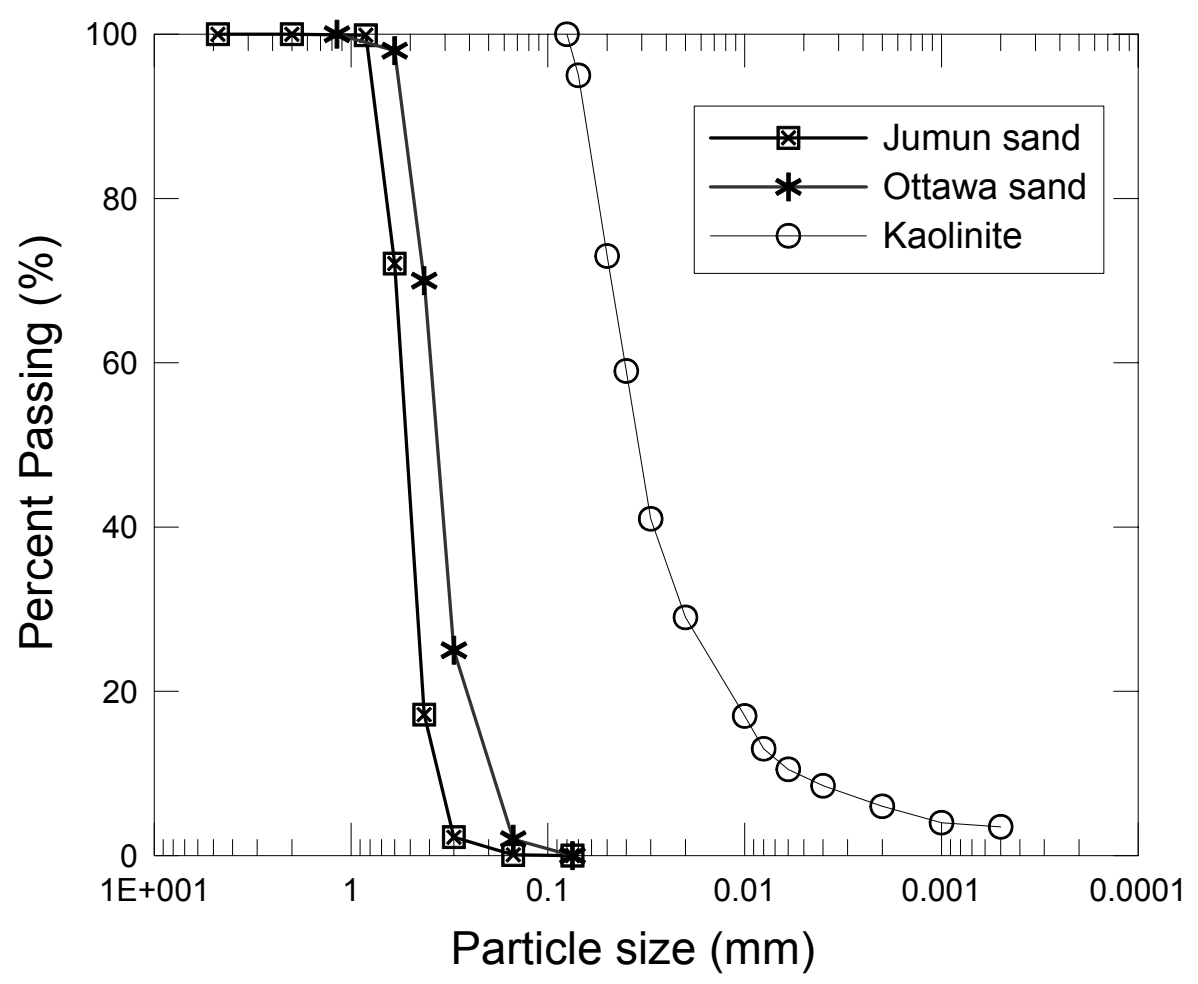

Figure 4.1 Grain size distributions of Jumun sand, Ottawa sand, and Kaolinite clay.

The soil samples tested in the flexible-wall permeameter were prepared by a slurry consolidation technique similar to that used for the preparation of chamber samples in order to produce similar condition of specimens. The procedure for the specimen preparation is briefly described here:

(1) In all the tests, dry clays and sands were thoroughly mixed at the determined mixing ratio, by placing the contents in a closed jar and shaking it.

(2) Deaired and deionized water was added to the soil to mix it into slurry. The slurry water contents correspond to approximately one and a half times the soil mixtures' liquid limits.

(3) After mixing, the slurry was deposited in the assembled mold, which was mounted on the triaxial cell base. The mold was prepared as follows: a $150 \mathrm{~mm}$ height, $72 \mathrm{~mm}$ diameter split mold was mounted around the triaxial base pedestal and a membrane, 
and a $50 \mathrm{~mm}$ height collar was mounted on top of the split mold to provide additional room for the slurry.

(4) The slurry was consolidated under an applied vertical pressure of $50 \mathrm{kPa}$.

(5) After the consolidation, the collar ring was removed and the extra part of the sample over the split mold was trimmed off, and then the top of the mold is leveled off.

(6) A top cap with a porous stone was placed on top of the soil sample and the membrane rolled over the sides of the top cap and fixed in place by two o-rings.

(7) About $25 \mathrm{kPa}$ vacuum was applied to the specimen and then the split mold was removed. A plexiglass cell chamber was set in place and the cell top was carefully put in place. The cell was filled with deaired water.

(8) The isotropic confining stress was increased to the target pressure, through 4 stages $(70 \mathrm{kPa}, 100 \mathrm{kPa}, 150 \mathrm{kPa}$, and $220 \mathrm{kPa}$ ) for the Ottawa sand and kaolinite specimens and 3 stages $(100 \mathrm{kPa}, 150 \mathrm{kPa}$, and $220 \mathrm{kPa})$ for the Jumun sand and kaolinite specimens.

A photograph of the flexible wall permeability test setup is shown in Figure 4.2.

It has been recognized that the slurry consolidation method is appropriate to produce a homogenous specimen containing fines (Sheeran and Krizek 1971, Katagiri and Imai 1994). However, segregation is one of the possible problems that can arise in a soil sample, if it contains a small percentage of clay. Therefore, it was essential to verify the specimen homogeneity. Three specimens containing $14.5 \%, 19 \%, 21.8 \%$ of fines were selected after the permeability test and the homogeneity of each specimen was examined. For the inspection of homogeneity, specimens were removed from the cell after the test and horizontally divided into five layers. For each sliced layer, a clay percentage and water content were measured. The uniformity results from three specimens are shown in Figure 4.3. As shown in Figure 4.3(a), the percentages of fines are almost the same through all layers. Figure 4.3(b) also shows a uniform distribution of water content through all layers. 
Therefore, it has been verified that the specimens are homogeneous with respect to the fines content and water content.

\subsubsection{Permeability Test Results}

A total of 16 flexible-wall permeameter tests were performed: 10 tests with mixtures of Ottawa sand and kaolin clay $(10 \%, 14.5 \%, 15 \%, 16.6 \%, 19 \%, 21 \%, 21.8 \%$ $24 \%$, and $29.1 \%$ of kaolin clay), and 6 tests with mixtures of Jumun sand and kaolin clay $(16 \%, 17.5 \%, 18.5 \%, 22 \%, 22.2 \%$, and $25 \%$ of kaolin clay). The fines content of each mixture was defined as the ratio of the dry weight of fines to the total dry weight of the mixture.

Values of $c_{v}$ were computed by Eq. 4.5 using measured values of $\mathrm{K}$ and $\mathrm{m}_{\mathrm{v}}$, and the values of normalized velocity $\mathrm{V}$ were calculated by Eq. 2.25 using $20 \mathrm{~mm} / \mathrm{sec}$ of velocity and $11.3 \mathrm{~mm}$ of miniature cone diameter. All obtained values of $\mathrm{K}, \mathrm{m}_{\mathrm{v}}$, and $\mathrm{c}_{\mathrm{v}}$ for the various mixtures of clay and Ottawa sand are summarized in Table 4.2 and plotted in Figure 4.4. A summary of the test results for the mixtures of kaolin clay and Jumun sand are shown at Table 4.3 and plotted in Figure 4.5.

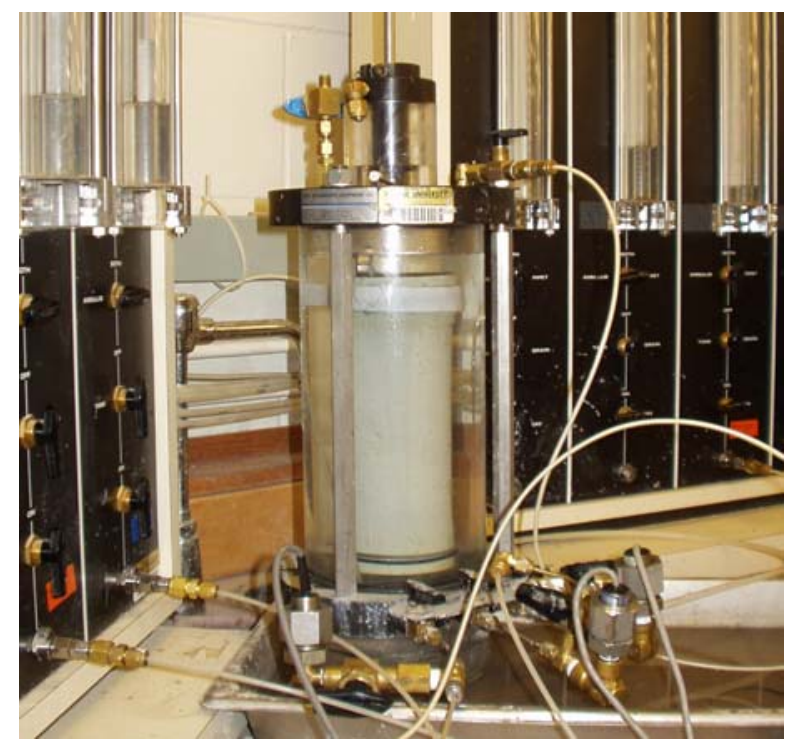

Figure 4.2 Flexible wall permeability test setup. 


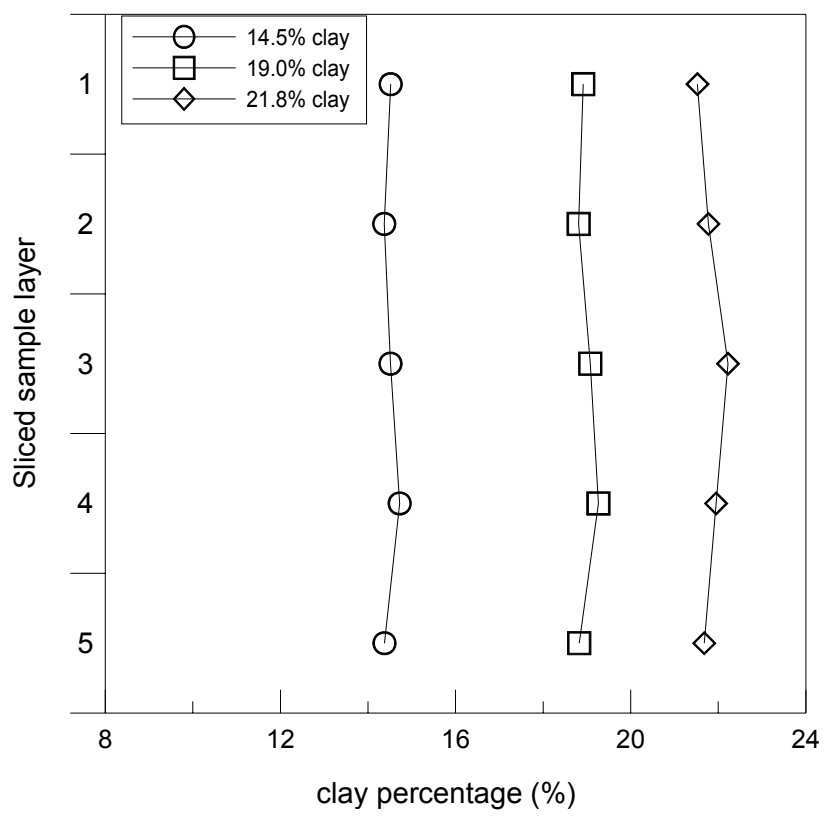

(a)

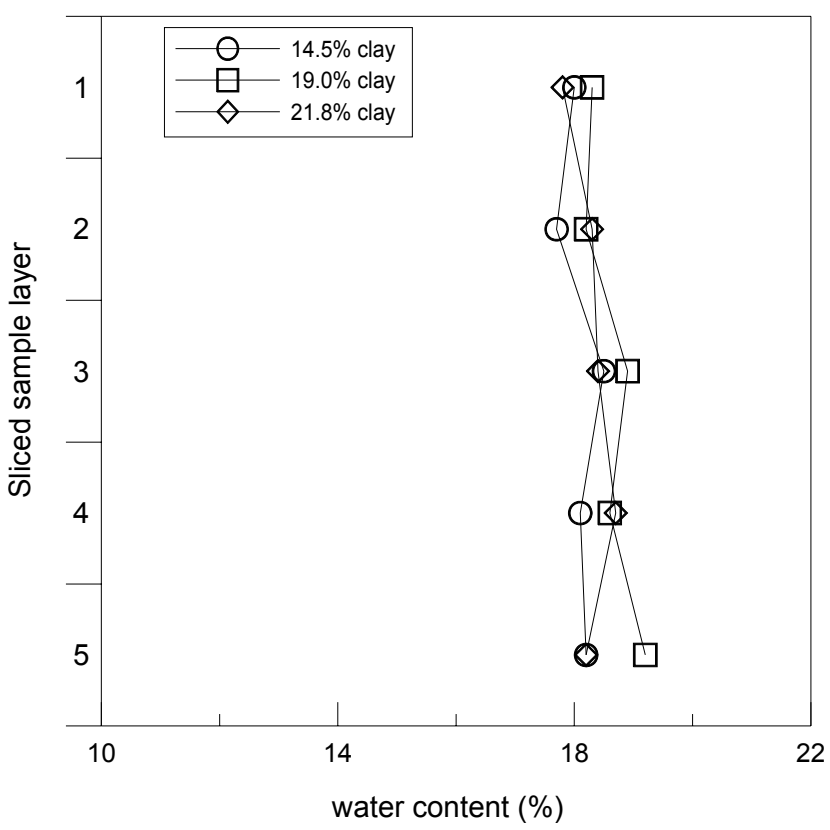

(b)

Figure 4.3 Distribution of (a) clay percentage and (b) water content to the samples. 
The hydraulic conductivity and $\mathrm{m}_{\mathrm{v}}$ values obtained at an isotropic confining stress of $150 \mathrm{kPa}$ (approximately the stress level for the calibration chamber tests) were used to obtain the reference value of $\mathrm{c}_{\mathrm{v}}$.

As the results for the mixtures of clay and Ottawa sand in Figure 4.4 indicates, hydraulic conductivity $\mathrm{K}$ decreased more than two orders of magnitude as the fines content in the samples increased from $10 \%$ to $29 \%$. In the same range, hydraulic conductivity $\mathrm{K}$ decreased from $5.6 \times 10^{-6} \mathrm{~m} / \mathrm{sec}$ to $9.7 \times 10^{-8} \mathrm{~m} / \mathrm{sec}$. In contrast, $\mathrm{m}_{\mathrm{v}}$ increased an order of magnitude as the fines content of the sample increased in the same range, from $3.2 \times 10^{-5}$ $\mathrm{m}^{2} / \mathrm{kN}$ to $2.3 \times 10^{-4} \mathrm{~m}^{2} / \mathrm{kN}$. The calculated $\mathrm{c}_{\mathrm{v}}$ from these values decreased from about $3 \times 10^{-4} \mathrm{~m}^{2} / \mathrm{sec}$ to $2 \times 10^{-6} \mathrm{~m}^{2} / \mathrm{sec}$ as the clay contents in the sample increased from 10 to 29 \%. Thevanayagam et al. (2001) published values of $\mathrm{K}, \mathrm{m}_{\mathrm{v}}$, and $\mathrm{C}_{\mathrm{v}}$ for various mixtures of sands and nonplastic silts and indicated that the mixtures containing $15-25 \%$ of nonplastic silt tested at around $100 \mathrm{kPa}$ of confining stress had values of $\mathrm{c}_{\mathrm{v}}$ ranging from $1 \times 10^{-3}$ $\mathrm{m}^{2} / \mathrm{sec}$ to $7 \times 10^{-5} \mathrm{~m}^{2} / \mathrm{sec}$.

The results of the tests with the mixture of kaolin clay and Jumun sand in the range of $16 \%$ to $25 \%$ of clay show a similar trend to that observed for the mixture of Ottawa sand and kaolin clay (Fig. 4.5). The value of $\mathrm{c}_{\mathrm{v}}$ for the Jumun sand mixture with $16 \%$ kaolin clay was $2.7 \times 10^{-4} \mathrm{~m}^{2} / \mathrm{sec}$, and the value of $\mathrm{c}_{\mathrm{v}}$ for $25 \%$ clay decreased to $3.5 \times 10^{-6} \mathrm{~m}^{2} / \mathrm{sec}$.

Fig. 4.6(a) shows the percentage of clay of the soil mixtures studied versus $c_{v}$ for an isotropic confining stress of $150 \mathrm{kPa}$. From this graph, it can be seen that the $\log \mathrm{c}_{\mathrm{v}}$ has an approximately linear relationship with the clay content of the soil mixtures. The calculated $\mathrm{c}_{\mathrm{v}}$ for the mixtures of Ottawa sand and kaolin clay decreased from about $1.8 \times 10^{-}$ ${ }^{4} \mathrm{~m}^{2} / \mathrm{s}$ to $4.3 \times 10^{-7} \mathrm{~m}^{2} / \mathrm{s}$ as the clay content in the samples increased from $10 \%$ to $29 \%$. The test results with the mixtures of Jumun sand and $16 \%$ to $25 \%$ of kaolin clay showed similar trends. The value of $c_{v}$ for the Jumun sand mixture with $16 \%$ kaolin clay was $2.7 \times 10^{-4} \mathrm{~m}^{2} / \mathrm{s}$, and the value of $\mathrm{c}_{\mathrm{v}}$ for the sand mixture with $25 \%$ clay was $3.5 \times 10^{-6} \mathrm{~m}^{2} / \mathrm{s}$. 
Table 4.2 Flexible-wall permeameter test results for kaolin - Ottawa sand mixtures.

\begin{tabular}{|c|c|c|c|c|c|}
\hline clay percentage & $\sigma_{3}(\mathrm{kPa})$ & $\mathrm{k}(\mathrm{m} / \mathrm{sec})$ & $\mathrm{mv}_{\mathrm{v}}(1 / \mathrm{kPa})$ & $\mathrm{c}_{\mathrm{v}}\left(\mathrm{m}^{2} / \mathrm{sec}\right)$ & $\mathrm{vD} / \mathrm{c}_{\mathrm{v}}$ \\
\hline \multirow{4}{*}{$10.0 \%$} & 70 & $1.38 \mathrm{E}-05$ & 4.07E-05 & $3.46 \mathrm{E}-04$ & 0.65 \\
\hline & 100 & 8.71E-06 & 4.12E-05 & $2.16 \mathrm{E}-04$ & 1.05 \\
\hline & 150 & $5.62 \mathrm{E}-06$ & $3.23 \mathrm{E}-05$ & $1.77 \mathrm{E}-04$ & 1.27 \\
\hline & 220 & $4.00 \mathrm{E}-06$ & $1.90 \mathrm{E}-05$ & $2.15 \mathrm{E}-04$ & 1.05 \\
\hline \multirow{4}{*}{$14.5 \%$} & 70 & 4.03E-06 & $1.65 \mathrm{E}-04$ & 2.49E-05 & 9.08 \\
\hline & 100 & $2.98 \mathrm{E}-06$ & 8.30E-05 & $3.66 \mathrm{E}-05$ & 6.17 \\
\hline & 150 & $2.57 \mathrm{E}-06$ & 7.57E-05 & $3.46 \mathrm{E}-05$ & 6.53 \\
\hline & 220 & 2.37E-06 & $6.12 \mathrm{E}-05$ & $3.96 \mathrm{E}-05$ & 5.71 \\
\hline \multirow{4}{*}{$15.0 \%(1)$} & 70 & $5.96 \mathrm{E}-06$ & $3.87 \mathrm{E}-05$ & $1.57 \mathrm{E}-04$ & 1.44 \\
\hline & 100 & $5.76 \mathrm{E}-06$ & $6.25 \mathrm{E}-05$ & $9.41 \mathrm{E}-05$ & 2.40 \\
\hline & 150 & $3.76 \mathrm{E}-06$ & $5.21 \mathrm{E}-05$ & $7.36 \mathrm{E}-05$ & 3.07 \\
\hline & 220 & $3.09 \mathrm{E}-06$ & $3.91 \mathrm{E}-05$ & 8.06E-05 & 2.81 \\
\hline \multirow{4}{*}{$15.0 \%(2)$} & 70 & $9.60 \mathrm{E}-07$ & 5.32E-05 & $1.84 \mathrm{E}-05$ & 12.28 \\
\hline & 100 & 8.27E-07 & $5.55 \mathrm{E}-05$ & $1.52 \mathrm{E}-05$ & 14.88 \\
\hline & 150 & 7.74E-07 & $4.51 \mathrm{E}-05$ & $1.75 \mathrm{E}-05$ & 12.92 \\
\hline & 220 & $6.88 \mathrm{E}-07$ & 3.99E-05 & $1.76 \mathrm{E}-05$ & 12.85 \\
\hline \multirow{4}{*}{$16.6 \%$} & 70 & $1.86 \mathrm{E}-06$ & $1.97 \mathrm{E}-04$ & $9.62 \mathrm{E}-06$ & 23.49 \\
\hline & 100 & $1.53 \mathrm{E}-06$ & $9.51 \mathrm{E}-05$ & $1.64 \mathrm{E}-05$ & 13.79 \\
\hline & 150 & $1.19 \mathrm{E}-06$ & 7.79E-05 & $1.56 \mathrm{E}-05$ & 14.48 \\
\hline & 220 & $1.07 \mathrm{E}-06$ & 7.79E-05 & $2.06 \mathrm{E}-05$ & 10.95 \\
\hline \multirow{4}{*}{$19.0 \%$} & 70 & $1.36 \mathrm{E}-06$ & 3.34E-04 & 4.15E-06 & 54.52 \\
\hline & 100 & $1.34 \mathrm{E}-06$ & $1.47 \mathrm{E}-04$ & $9.26 \mathrm{E}-06$ & 24.41 \\
\hline & 150 & $1.13 \mathrm{E}-06$ & $1.24 \mathrm{E}-04$ & $9.28 \mathrm{E}-06$ & 24.35 \\
\hline & 220 & 9.87E-07 & 8.13E-05 & $1.17 \mathrm{E}-05$ & 19.35 \\
\hline \multirow{4}{*}{$21.0 \%$} & 70 & 4.78E-07 & 3.93E-04 & $1.24 \mathrm{E}-06$ & 181.92 \\
\hline & 100 & 3.91E-07 & $1.71 \mathrm{E}-04$ & $2.33 \mathrm{E}-06$ & 96.94 \\
\hline & 150 & $2.95 \mathrm{E}-07$ & $1.27 \mathrm{E}-04$ & $2.36 \mathrm{E}-06$ & 95.71 \\
\hline & 220 & $2.32 \mathrm{E}-07$ & $8.25 \mathrm{E}-05$ & $2.87 \mathrm{E}-06$ & 78.73 \\
\hline \multirow{4}{*}{$21.8 \%$} & 70 & $8.46 \mathrm{E}-07$ & $4.39 \mathrm{E}-04$ & $1.97 \mathrm{E}-06$ & 115.00 \\
\hline & 100 & $5.99 \mathrm{E}-07$ & $2.11 \mathrm{E}-04$ & $2.90 \mathrm{E}-06$ & 77.85 \\
\hline & 150 & 4.05E-07 & $1.52 \mathrm{E}-04$ & 2.72E-06 & 83.00 \\
\hline & 220 & $3.46 \mathrm{E}-07$ & 7.22E-05 & 4.89E-06 & 46.18 \\
\hline \multirow{4}{*}{$24.0 \%$} & 70 & 4.76E-07 & $3.85 \mathrm{E}-04$ & $1.26 \mathrm{E}-06$ & 179.41 \\
\hline & 100 & $3.90 \mathrm{E}-07$ & $1.90 \mathrm{E}-04$ & 2.09E-06 & 108.17 \\
\hline & 150 & $2.57 \mathrm{E}-07$ & $1.64 \mathrm{E}-04$ & $1.60 \mathrm{E}-06$ & 141.60 \\
\hline & 220 & $1.80 \mathrm{E}-07$ & $1.25 \mathrm{E}-04$ & $1.46 \mathrm{E}-06$ & 154.30 \\
\hline \multirow{4}{*}{$29.1 \%$} & 70 & $1.40 \mathrm{E}-07$ & $5.24 \mathrm{E}-04$ & $2.73 \mathrm{E}-07$ & 827.22 \\
\hline & 100 & $1.20 \mathrm{E}-07$ & $2.70 \mathrm{E}-04$ & $4.53 \mathrm{E}-07$ & 498.61 \\
\hline & 150 & $9.70 \mathrm{E}-08$ & $2.28 \mathrm{E}-04$ & 4.33E-07 & 521.67 \\
\hline & 220 & $8.46 \mathrm{E}-08$ & $1.62 \mathrm{E}-04$ & 5.33E-07 & 423.64 \\
\hline
\end{tabular}



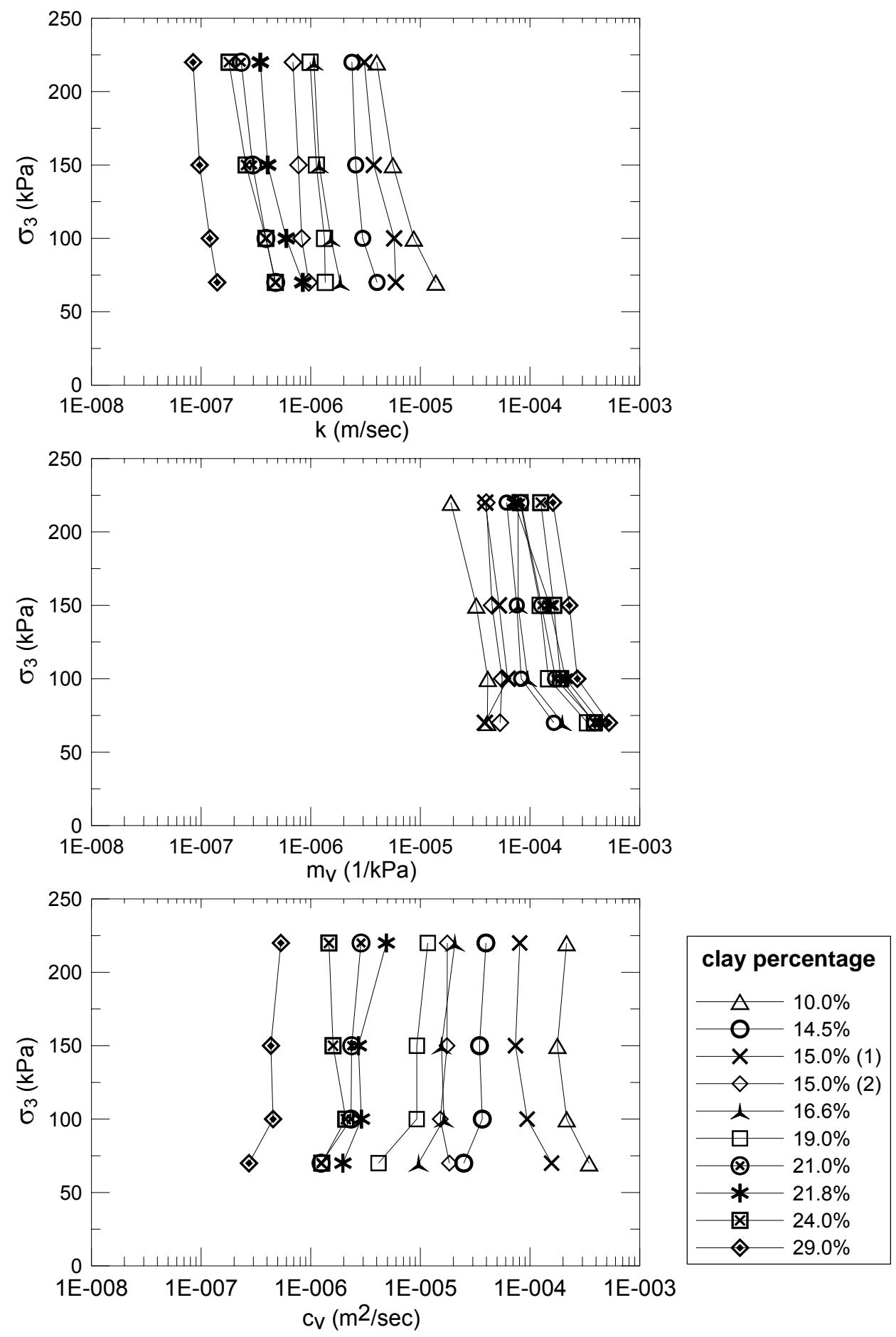

Figure 4.4 Plots of $\mathrm{k}, \mathrm{m}_{\mathrm{v}}$, and $\mathrm{c}_{\mathrm{v}}$ for kaolin clay - Ottawa sand mixtures. 
Table 4.3 Flexible-wall permeameter test results for kaolin - Jumun sand mixtures.

\begin{tabular}{c|c|c|c|c|c}
\hline clay percentage & $\sigma_{3}(\mathrm{kPa})$ & $\mathrm{k}(\mathrm{m} / \mathrm{sec})$ & $\mathrm{m}_{\mathrm{v}}(1 / \mathrm{kPa})$ & $\mathrm{c}_{\mathrm{v}}\left(\mathrm{m}^{2} / \mathrm{sec}\right)$ & $\mathrm{vD} / \mathrm{c}_{\mathrm{v}}$ \\
\hline \multirow{3}{*}{$16.0 \%$} & 100 & $1.01 \mathrm{E}-05$ & $3.34 \mathrm{E}-05$ & $3.08 \mathrm{E}-04$ & 0.73 \\
& 150 & $8.81 \mathrm{E}-06$ & $3.34 \mathrm{E}-05$ & $2.69 \mathrm{E}-04$ & 0.84 \\
& 220 & $7.99 \mathrm{E}-06$ & $4.17 \mathrm{E}-05$ & $1.95 \mathrm{E}-04$ & 1.16 \\
\hline \multirow{2}{*}{$17.5 \%$} & 100 & $7.01 \mathrm{E}-06$ & $1.15 \mathrm{E}-04$ & $6.19 \mathrm{E}-05$ & 3.65 \\
& 150 & $5.44 \mathrm{E}-06$ & $7.10 \mathrm{E}-05$ & $7.81 \mathrm{E}-05$ & 2.89 \\
& 220 & $4.86 \mathrm{E}-06$ & $4.44 \mathrm{E}-05$ & $1.12 \mathrm{E}-04$ & 2.02 \\
\hline \multirow{3}{*}{$18.5 \%$} & 100 & $5.37 \mathrm{E}-06$ & $7.69 \mathrm{E}-05$ & $7.12 \mathrm{E}-05$ & 3.17 \\
& 150 & $4.77 \mathrm{E}-06$ & $8.12 \mathrm{E}-05$ & $5.98 \mathrm{E}-05$ & 3.78 \\
& 220 & $4.45 \mathrm{E}-06$ & $7.94 \mathrm{E}-05$ & $5.71 \mathrm{E}-05$ & 3.96 \\
\hline \multirow{2}{*}{$22.0 \%$} & 100 & $2.30 \mathrm{E}-06$ & $5.59 \mathrm{E}-05$ & $4.20 \mathrm{E}-05$ & 5.38 \\
& 150 & $2.49 \mathrm{E}-06$ & $5.59 \mathrm{E}-05$ & $4.54 \mathrm{E}-05$ & 4.97 \\
& 220 & $2.35 \mathrm{E}-06$ & $6.92 \mathrm{E}-05$ & $3.47 \mathrm{E}-05$ & 6.51 \\
\hline \multirow{2}{*}{$22.2 \%$} & 150 & $1.05 \mathrm{E}-06$ & $9.09 \mathrm{E}-05$ & $1.18 \mathrm{E}-05$ & 19.23 \\
& 220 & $6.68 \mathrm{E}-07$ & $5.57 \mathrm{E}-05$ & $1.22 \mathrm{E}-05$ & 18.47 \\
\hline \multirow{2}{*}{$25.0 \%$} & 100 & $3.47 \mathrm{E}-07$ & $1.62 \mathrm{E}-04$ & $2.18 \mathrm{E}-06$ & 103.57 \\
& 150 & $4.07 \mathrm{E}-07$ & $1.20 \mathrm{E}-04$ & $3.45 \mathrm{E}-06$ & 65.54 \\
& 220 & $3.83 \mathrm{E}-07$ & $1.02 \mathrm{E}-04$ & $3.81 \mathrm{E}-06$ & 59.36 \\
\hline
\end{tabular}



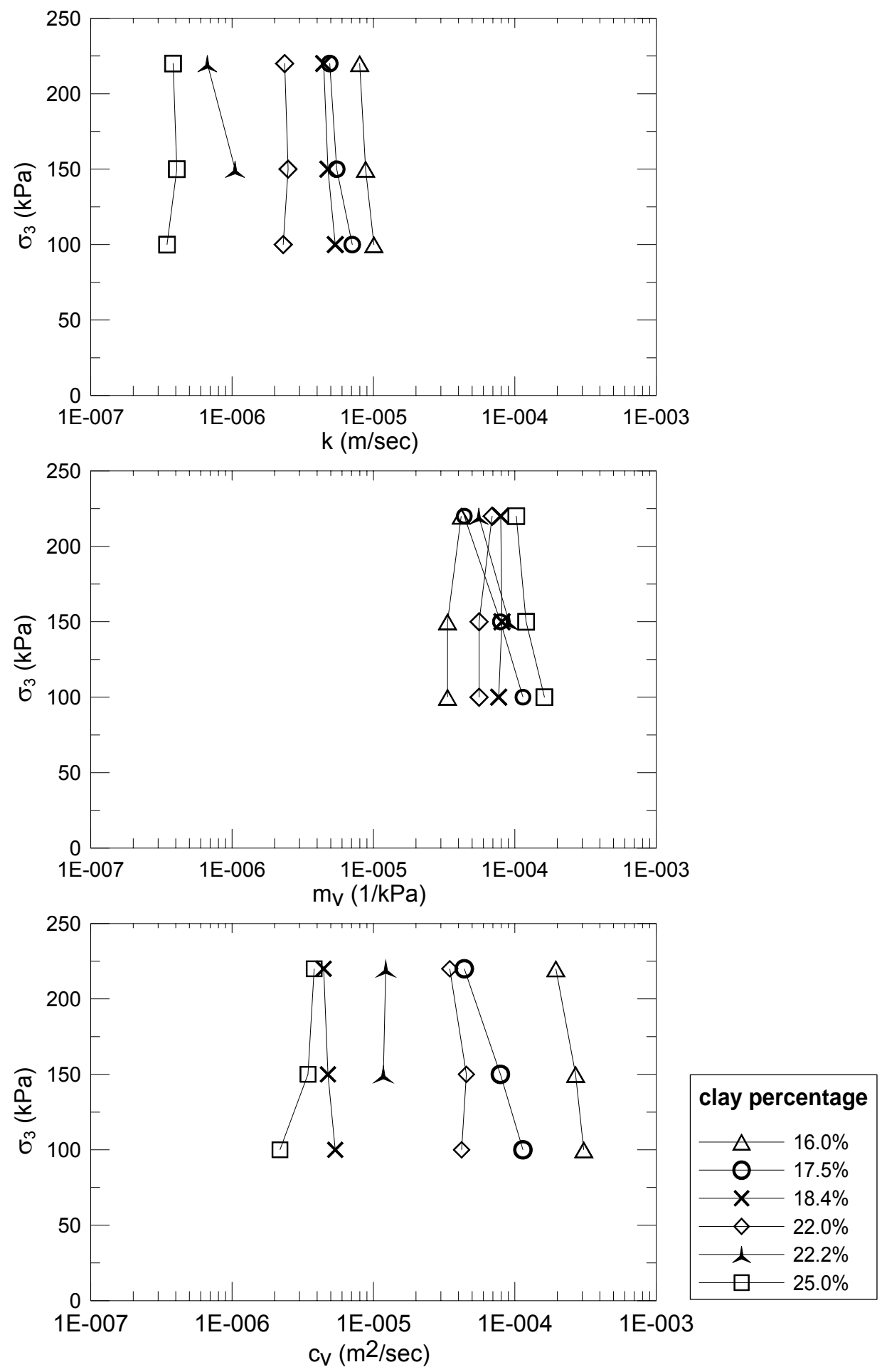

Figure 4.5 Plots of $\mathrm{k}, \mathrm{m}_{\mathrm{v}}$, and $\mathrm{c}_{\mathrm{v}}$ for kaolin clay - Jumun sand mixtures. 


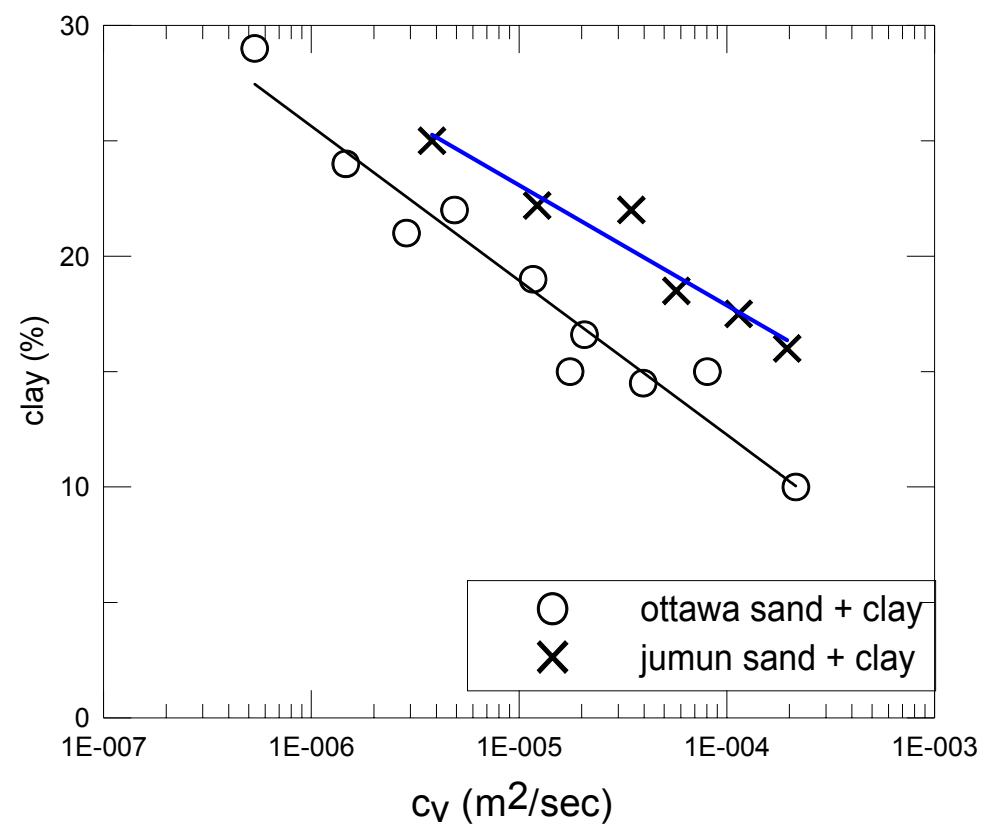

(a)

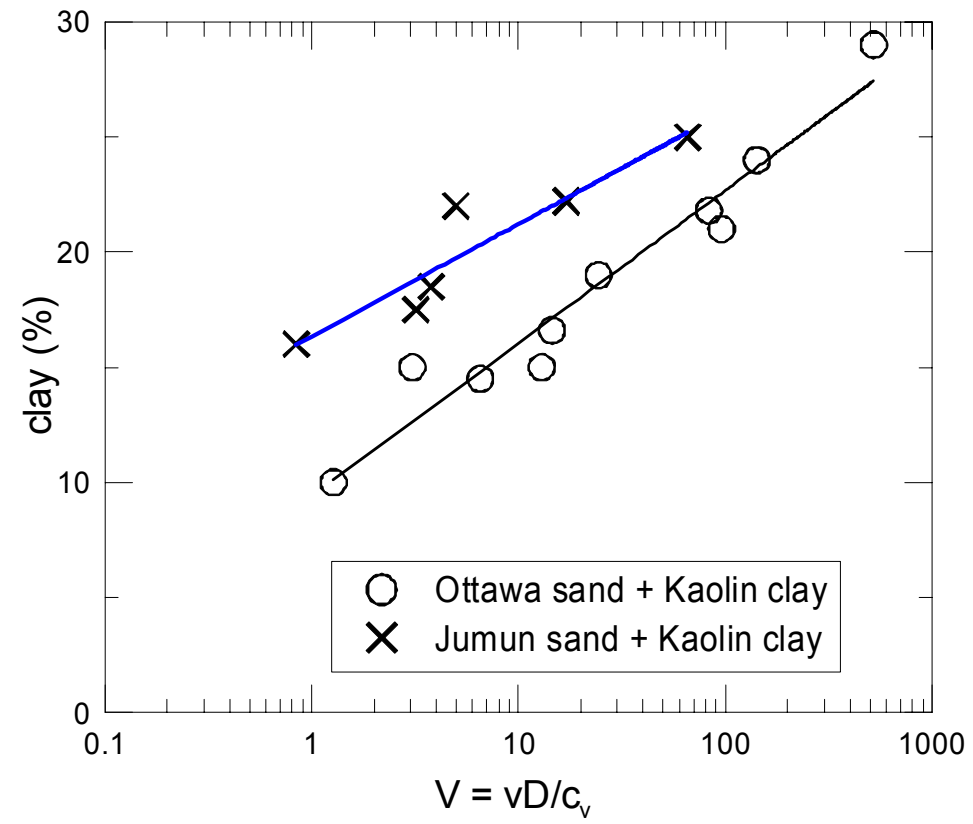

(b)

Figure 4.6 (a) Coefficient of consolidation $c_{v}$ and (b) normalized cone resistance V response according to the change of soil mixing ratio at a confining stress of $150 \mathrm{kPa}$. 
The values of $c_{v}$ for the mixtures of Jumun sand and kaolin clay are higher than those of the mixtures of Ottawa sand and kaolin clay at the same mixing ratio. The difference in the values of $c_{v}$ between the mixtures can be understood by referring to the difference in the minimum and maximum void ratios $\left(\mathrm{e}_{\max }\right.$ and $\left.\mathrm{e}_{\min }\right)$ between Ottawa sand and Jumun sand. The variation of the $e_{\max }$ and $e_{\min }$ values with fines content is shown in Fig. 4.7. The $e_{\max }$ and $e_{\min }$ of the clean sands and the mixtures of sand and clay were determined according to ASTM D 4253 and ASTM D 4254. Carraro (2004) obtained the $e_{\max }$ and $e_{\min }$ values of clean Ottawa sand and mixtures of Ottawa sand with $2 \%, 5 \%$, and $10 \%$ kaolin clay. As shown in the figure, both $\mathrm{e}_{\max }$ and $\mathrm{e}_{\min }$ of Jumun clean sand are somewhat higher than those of clean Ottawa sand. Accordingly, more clay particles are needed to fill the voids between Jumun sand particles. Also, both $\mathrm{e}_{\max }$ and $\mathrm{e}_{\min }$ of the mixtures with Jumun sand and kaolin clay are somewhat higher than those of the Ottawa sand mixtures with kaolin clay for the same mixing ratios. Based on the $c_{v}$ values shown in Fig. 4.6(a), values of $\mathrm{V}$ were calculated for $\mathrm{v}=20 \mathrm{~mm} / \mathrm{s}$ and $\mathrm{d}=11.3 \mathrm{~mm}$ (the miniature cone diameter). The variation of $\mathrm{V}$ with the clay percentage of the soil mixtures is shown in Fig. 4.7(b).

\subsection{Mixing Ratio Determination}

As discussed previously, it was assumed, before any tests were performed, that, so long as a V of 60 was used, CPTs at $20 \mathrm{~mm} / \mathrm{s}$ (the maximum penetration speed) would be performed under undrained conditions. Reduction of penetration rates towards the lower bound of $0.01 \mathrm{~mm} / \mathrm{s}$ would allow identification of the transition from fully undrained to partially drained conditions and then drained at slower cone penetration rates. Thus, a soil with $c_{v} \leq 3.76 \times 10^{-6} \mathrm{~m}^{2} / \mathrm{s}$ was believed to be required. Based on the flexible wall test results, a mixing ratio of $25 \%$ clay and $75 \%$ Jumun sand $\left(c_{v}=3.45 \times 10^{-6} \mathrm{~m}^{2} / \mathrm{s}\right)$ was selected for the first sample to be tested in the calibration chamber. This mixture would cover the range from $\mathrm{V}=0.033$ to $\mathrm{V}=66$ for a minicone diameter of $11.3 \mathrm{~mm}$ and penetration speeds between $0.01 \mathrm{~mm} / \mathrm{s}$ and $20 \mathrm{~mm} / \mathrm{s}$. 
Finnie and Randolph (1994) and House et al. (2001), based on centrifuge penetration test results, indicated that the transition between partially drained and fully drained conditions occurs at $0.01 \leq \mathrm{V} \leq 0.1$. Therefore, a $\mathrm{V}$ value less than 0.01 at the slowest cone penetration rate $(0.01 \mathrm{~mm} / \mathrm{s})$ was required to allow penetration under fully drained conditions. Accordingly, the other chamber specimen was prepared with a mixing ratio of $18 \%$ clay and $82 \%$ Jumun sand $\left(c_{\mathrm{v}}=6.9 \times 10^{-5} \mathrm{~m}^{2} / \mathrm{s}\right)$. The value of $\mathrm{V}$ for this soil mixture was equal to 0.0016 for the minimum penetration speed of $0.01 \mathrm{~mm} / \mathrm{s}$ and a cone diameter of $11.3 \mathrm{~mm}$.

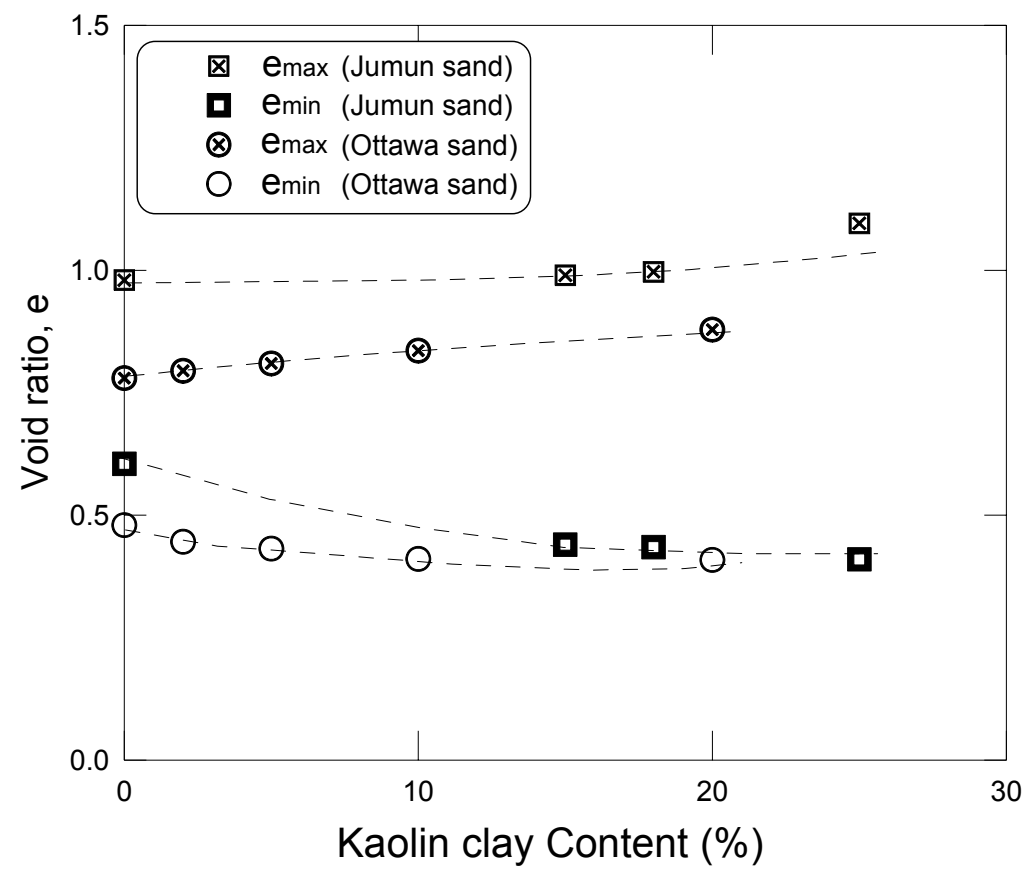

Figure 4.7 Maximum and minimum void ratios of the sand and clay mixtures. 
The soil fabric of the mixtures was also considered in the decision of the mixing ratios to be selected for further testing. The relationships between the $\mathrm{e}_{\mathrm{sk}}$ calculated using Eq. 4.1 and the global void ratio and fines content of soil mixtures with different mixing ratios are shown in Fig. 4.8. Table 4.4 gives minimum and maximum void ratios of clean and clayey Jumun sand as a function of clay content. If the $e_{\text {sk }}$ of the soil mixture is greater than the maximum void ratio $\mathrm{e}_{\max }\left(\mathrm{e}_{\max }=0.96\right.$ for Jumun sand) of the clean sand, then the soil mixture has a floating fabric. In contrast, if $\mathrm{e}_{\mathrm{sk}}$ of the soil mixture is smaller than $\mathrm{e}_{\max }$ of the clean sand, then the soil has a non-floating fabric.

The mixture of $25 \%$ kaolin clay and $75 \%$ Jumun sand under $150 \mathrm{kPa}$ of isotropic confining stress in the flexible-wall permeability test had $\mathrm{e}_{\mathrm{sk}}=1.12$, which indicates that this sample was just into the floating fabric range. In contrast, the $\mathrm{e}_{\mathrm{sk}}$ of the mixture of $18 \%$ kaolin clay with Jumun sand under the same confining stress was equal to 0.87 , which is smaller than the $\mathrm{e}_{\max }$ of clean Jumun sand, with the sample then having a nonfloating fabric.

An interesting connection between soil composition, type of fabric and the possibility of drained rates of penetration is evident from the discussion. If a soil has clay content above a certain threshold value, it is likely that it will both have a non-floating fabric (and thus start behaving less as a sand and more as the fines in the pores of the sand matrix) and offer undrained or partially drained penetration conditions but very unlikely fully drained penetration conditions, even at very slow penetration rates.

Table 4.4 Minimum and maximum void ratios for clean and clayey Jumun sands.

\begin{tabular}{c|cc}
\hline Kaolin clay (\%) & $\mathrm{e}_{\min }$ & $\mathrm{e}_{\max }$ \\
\hline 0 & 0.605 & 0.980 \\
\hline 15 & 0.440 & 0.990 \\
\hline 18 & 0.435 & 0.997 \\
\hline 25 & 0.410 & 1.096 \\
\hline
\end{tabular}




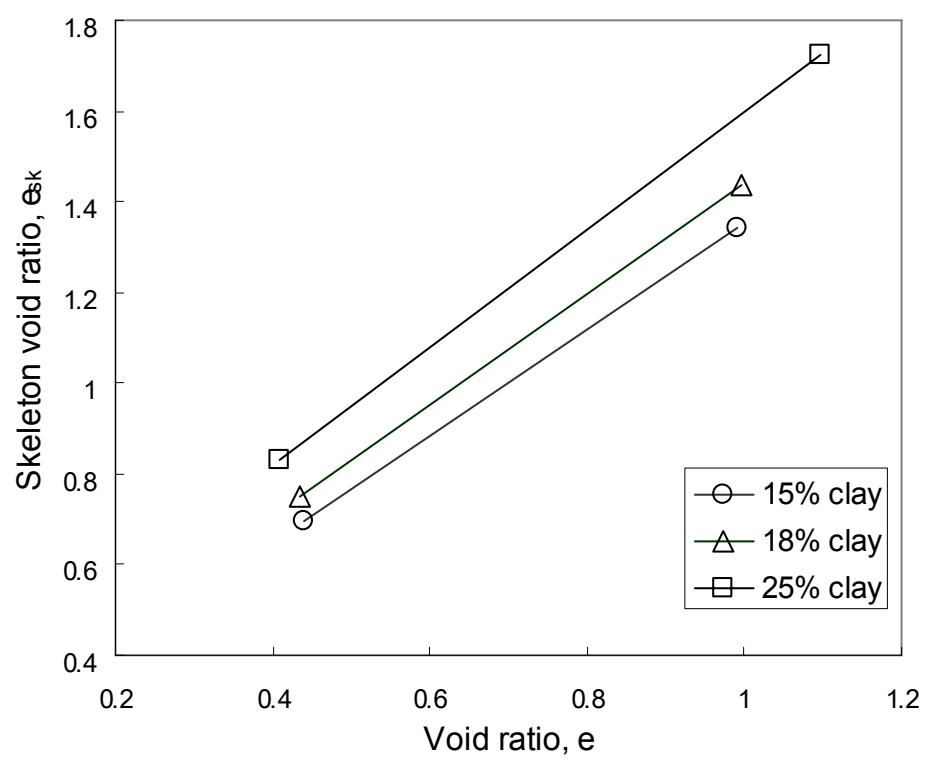

Figure 4.8 The correlations between $\mathrm{e}_{\mathrm{sk}}$ and different mixing ratio of soil mixture.

\subsection{Overview of the Calibration Chamber Test}

\subsubsection{Calibration Chamber System}

The calibration chamber penetration tests with the miniature cone (borrowed from Fugro) were performed at the Korea University Calibration Chamber Laboratory (KUCCL) in Seoul, Korea. The complete calibration chamber system includes a slurry mixing system, a slurry consolidometer used to consolidate the samples, a double-wall calibration chamber, and a control panel with a computerized data acquisition system.

The calibration chamber at KUCCL, which was manufactured in 2001, has an inside diameter of $1.2 \mathrm{~m}$ and a height of $1.0 \mathrm{~m}$. A schematic of the chamber system is shown in Figure 4.9. A detailed description of the chamber of KUCCL was prepared by Kim (2004). The top surface of the cylindrical test chamber is a stiff steel plate and the 
lateral surface is a flexible rubber membrane which is used to apply the horizontal stress by water pressure. The chamber has a double-metal wall system which permits the simulation of $\mathrm{K}_{0}$ consolidation (Figure 4.9). The inner wall is thin enough to allow lateral movement through water pressure change between the inner and outer walls. If the water between the inner wall and the outer wall is controlled to maintain the same pressure as that between the inner wall and the lateral surface of the specimen during the chamber test, the lateral displacement of the inner wall will compensate for the compressed volume of the water between the membrane and the inner wall. Therefore, the lateral displacement of the specimen will be also zero. This double-wall system allows the chamber cell volume to be kept constant so that consolidation, as well as any other tests in the chamber, can be carried out under $\mathrm{K}_{0}$ conditions. Thus, four traditional boundary conditions, designated as B1 through B4, can be realized using this equipment. The boundary conditions are described in detail in section 4.5.3.

The soil sample is contained in a rubber membrane and lateral stress is applied and controlled by water-pressure in double wall system. Vertical stress is applied and controlled by the piston under the bottom plate.

The slurry consolidometer is used to produce uniform and repeatable clayey specimens by consolidating well-mixed slurry. The loading system for slurry consolidation consists of a reaction frame with a hydraulic cylinder jack and an aluminum piston plate with a piston rod. 




Figure 4.9 Schematic view of the flexible wall calibration chamber.

\subsubsection{Specimen Preparation Procedure}

The calibration chamber specimen preparation procedure consists of two basic steps. The first step is the slurry consolidation in the consolidometer, and the second step is the reconsolidation in the calibration chamber. To produce homogeneous and reproducible clayey soil samples, and to simulate the fabric of natural alluvial soils, the specimen was formed from a high-water content slurry by consolidation under $\mathrm{K}_{0}$ conditions. This 
technique is known to produce homogeneous and reproducible clayey soil specimens (Krizek and Sheeran 1970, Huang 1986). Such initial water contents result in an initial slurry height of approximately 1.3 times the desired final specimen height and leads to considerable volume changes during consolidation. In order to accommodate these volume changes, a two-story consolidometer of twice the height of the chamber is required. After the initial consolidation is done in the consolidometer, the consolidometer cell is removed and the calibration chamber cell is assembled around the specimen without disturbance. The specimen is then reconsolidated by an increased vertical stress. The detailed procedure is described next.

\subsubsection{Slurry Consolidation}

The slurry consolidometer is shown in Figure 4.10. It is composed of two aluminum tubes assembled in two stories. Each tube has a $1.2 \mathrm{~m}$ inside diameter and $1 \mathrm{~m}$ in height, so the total height is $2 \mathrm{~m}$. The lower tube is split longitudinally into two semicircular walls and bolted together. It is designed so that the consolidometer can be easily disassembled after the initial consolidation stage without any disturbance of the soil specimen. The inside surface of the lower tube is lined with sand paper to hold the membrane against the vertical movement of the slurry caused by consolidation. The upper tube, which provides additional storage for watery slurry in the initial consolidation stage, is bolted to the lower one. Eight pore pressure transducers were installed on the bottom of the consolidometer before the assembly of the slurry consolidometer. Attached stainless steel needles on the transducers allowed measurement of the excess pore pressure of the center of the specimen. The base plate of the chamber was covered by 2 filter papers and 1 non-woven textile to provide a drainage layer.

The mixing ratio of the first calibration chamber test (hereafter referred to as P1) was selected as $25 \%$ clay and $75 \%$ sand by weight. The mixing ratio of $18 \%$ clay and $82 \%$ sand by weight (hereafter referred to as P2) was used for the second test. The initial water contents of two specimens were selected as $35 \%$ for P1 and $33 \%$ for P2. If too 
much water is added to mix the slurry, the sand and clay would be segregated during consolidation. In contrast, if the water content of the slurry is too low, workability would be deteriorated and homogeneity of the specimen would be lost. In order to minimize these conflicting problems, several mixing tests were performed with different water contents and appropriate water contents were determined.

The slurry was prepared by mixing kaolin clay and Jumun sand with deaired and deionized water in a 200 liter capacity, impeller-type, mixing cylinder. The mixing system is shown in Figure 4.11. Mixing was continued with applied vacuum until the slurry was completely homogenized. After the mixing, the slurry container was moved by crane to above the assembled consolidometer. The slurry was injected into the consolidometer through a hollow tube. Great care was taken while pouring the slurry into the consolidometer to avoid air bubble entrapment. After the slurry was filled up to $150 \mathrm{~mm}$ of height, filter paper and a $20 \mathrm{~mm}$ thick sand layer was spread on top of the filled slurry to provide an upper drainage layer. Then the top plate was seated and a hydraulic cylinder with a reaction frame was installed one after another.

The vertical consolidation pressure was increased up to $200 \mathrm{kPa}$ in several stages. This consolidation pressure was selected to give sufficient strength to the soil specimen, so that the specimen is able to stand alone without disturbance during the process of dismantling the consolidometer and assembling the chamber cell. Vertical pressure was applied to the top of a rigid piston plate by hydraulic pressure and the slurry was one-dimensionally consolidated with a double drainage path provided by the top and bottom drainage layers. The vertical settlement of the slurry specimen was measured by an LVDT having a measurement range of $300 \mathrm{~mm}$, and the excess pore pressure generated in the middle of the specimen during the consolidation stage was monitored by a pore pressure transducer so that the degree consolidation could be determined. 



Figure 4.10 Schematic view of consolidometer.

\subsubsection{Chamber Consolidation}

Due to the frictional resistance between the specimen and the consolidometer wall (upper cell) or the rubber membrane (lower cell) generated during consolidation, the soil sample obtained after the initial consolidation stage is not uniform in the vertical direction (A. B. Huang, 1986). Therefore, once the initial consolidation stage is completed, the specimen is subjected to reconsolidation in the double-wall calibration chamber cell, which does not cause any side wall friction, to a higher vertical effective stress than that 
applied in the consolidometer. The following is the detailed procedure for the chamber consolidation:
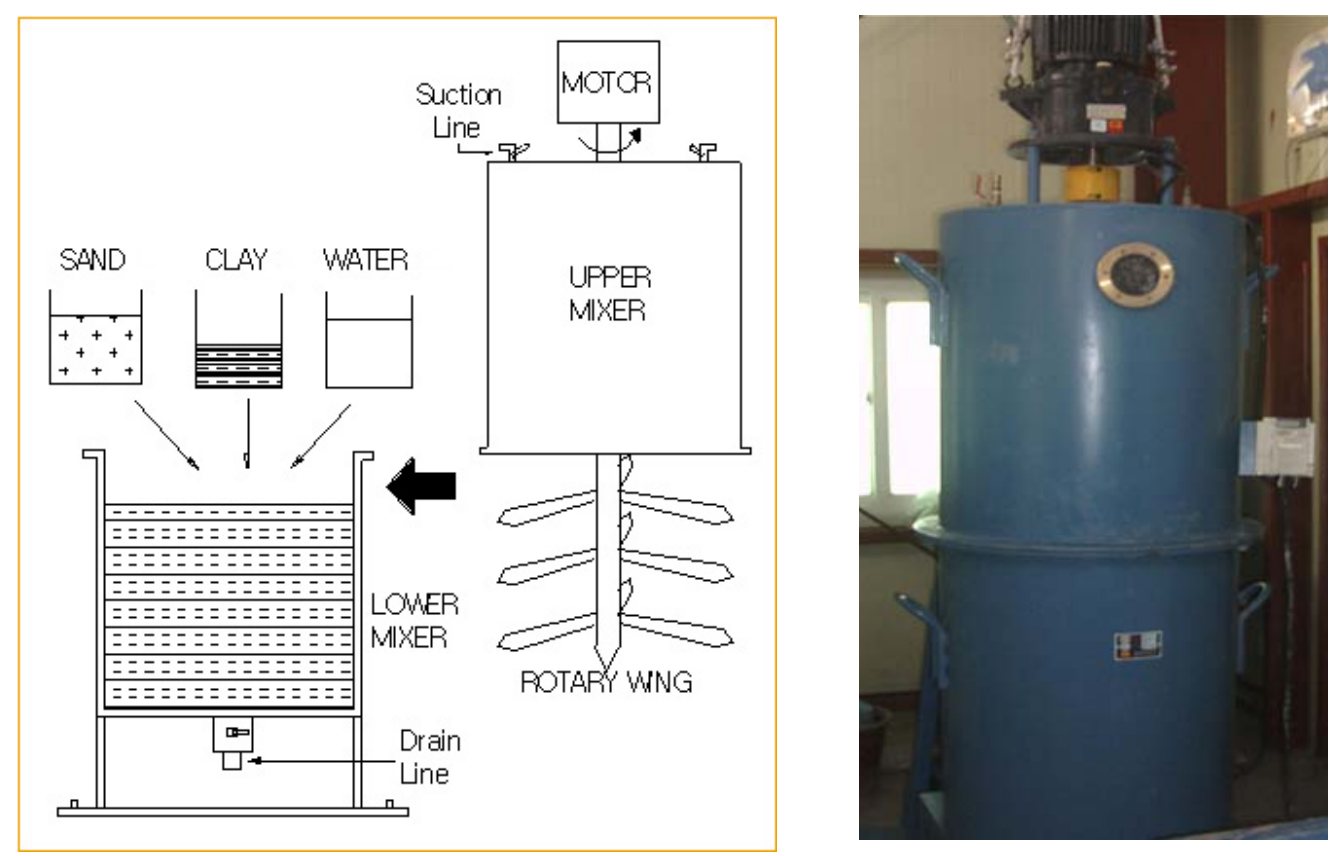

Figure 4.11 Schematic view of the mixing system.

After the initial consolidation was completed, the final heights of the two samples were $1220 \mathrm{~mm}(\mathrm{P} 1)$ and $1250 \mathrm{~mm}(\mathrm{P} 2)$.

(a) The upper tube is carefully taken off the slurry consolidometer and excess of consolidation specimen over the lower cell is trimmed and leveled.

(b) A sand layer and a filter paper are put on top of the trimmed soil specimen to make a drainage layer. Then a top plate is placed on the top of the specimen.

(c) The membrane is rolled over the sides of the top plate and secured in place by two o-rings. 
(d) The top and bottom drainage lines were connected to the top plate and bottom plate, completely isolating the specimen from outside. A $25 \mathrm{kPa}$ vacuum pressure was slowly applied to the specimen. The negative pore pressure generated by suction increases the strength of the specimen. As a result, the specimen can be protected from bulging or collapsing caused by a mild impact or vibration that may occur during dismantling of the lower consolidometer cell.

(e) The lower part of the consolidometer is dismantled carefully and removed (Figure $4.12(\mathrm{a}))$.

(f) The double wall chamber shell is moved above the specimen by a crane and then carefully down around it. The top lid is placed and secured to the double wall through 24 equally spaced rods (Figure 4.12 (b)).

(g) Fill the inner and outer cell with deaired water and $200 \mathrm{kPa}$ of back-pressure was applied to fully saturate the specimen. Then the vertical consolidation stress of 230 $\mathrm{kPa}$ was applied to the specimen under $\mathrm{K}_{0}$ conditions. 


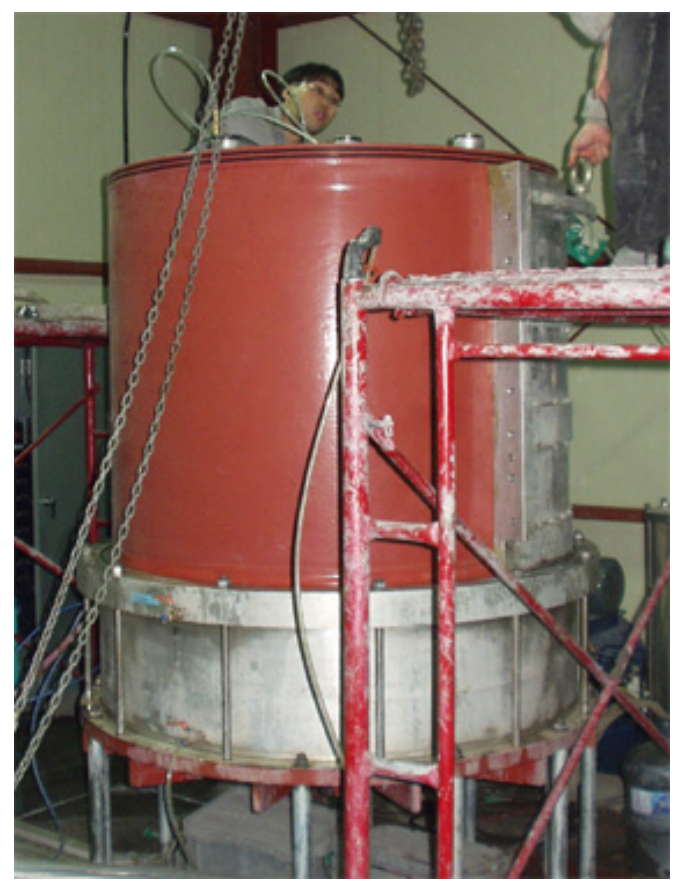

(a) Dismantling lower part of the consolidometer

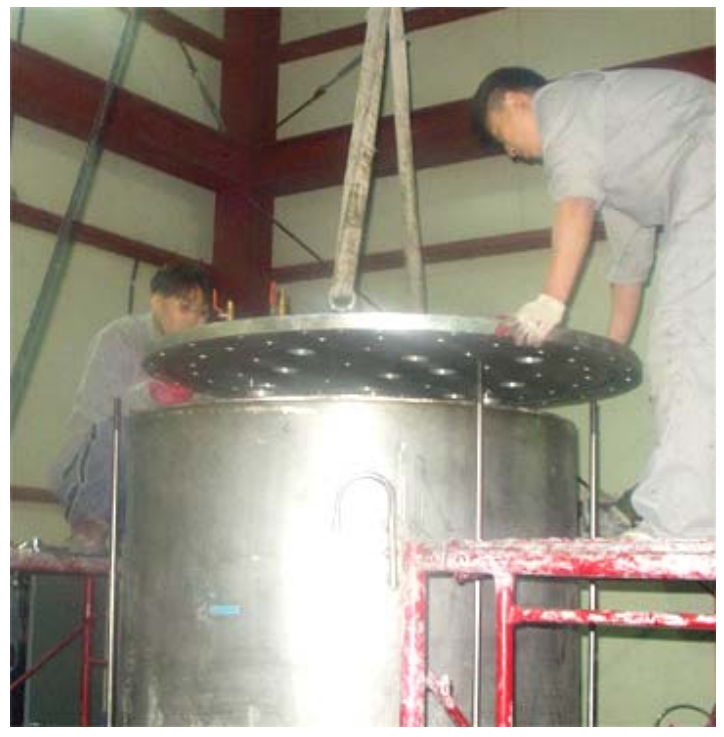

(b) Placing and securing the top lid to the double wall

Figure 4.12 Replacement of the consolidation shell to the chamber double-wall shell. 


\subsubsection{Chamber Size and Boundary Effects}

Due to chamber size and boundary effects, test results obtained in the calibration chamber may not be the same as those performed in the field. Calibration chamber size effects on cone penetration resistance have been extensively investigated by a number of researchers (Parkin 1982, Houlsby and Hitchman 1988, Been et al. 1988, Schnaid and Houlsby 1991, Salgado et al. 1998, Lee and Salgado 2000).

In calibration chamber tests, four different types of traditional boundary conditions are available. These boundary conditions, indicated as $\mathrm{BC} 1, \mathrm{BC} 2, \mathrm{BC} 3$, and $\mathrm{BC} 4$, are divided by stress and strain conditions imposed on the top, bottom, and lateral surfaces of the specimen. Each boundary condition is described in Table 4.5 and Figure 4.13. Cone penetration resistance in the field is believed to exist between the results under a rigid boundary condition and constant stress boundary condition. So cone resistance obtained from rigid wall boundary is always too high due to higher stresses exist at the radius of the chamber boundary; under a constant stress boundary condition, cone resistance is too low. True values of cone resistance are much closer to those obtained under a constant stress boundary condition, so generally $\mathrm{BC} 2$ and $\mathrm{BC} 3$ are avoided for cone penetration test in a calibration chamber. Since lateral boundary conditions are the most important in the cone penetration test (Houlsby and Hitchman 1988, and Salgado et al. 1998), similar cone resistance values are obtained from the specimen under $\mathrm{BC} 1$ or $\mathrm{BC} 4$, unless the cone approaches too close to the bottom of the chamber. The chamber system used in this research has a rigid bottom supported by piston. Therefore $\mathrm{BC} 4$ was used. However, the boundary effect from the bottom was practically eliminated by keeping a distance of $200 \mathrm{~mm}$ from the cone tip to the bottom plate. The fact that the soils in both samples had high void ratio also minimized boundary effects. 
Table 4.5 Boundary conditions in calibration chamber tests.

\begin{tabular}{c|c|c}
\hline $\begin{array}{c}\text { Types of Boundary } \\
\text { Conditions }\end{array}$ & Lateral Boundary Conditions & $\begin{array}{c}\text { Top \& Bottom Boundary } \\
\text { Conditions }\end{array}$ \\
\hline BC1 & Constant Stress & Constant Stress \\
\hline BC2 & No Displacement & No Displacement \\
\hline BC3 & No Displacement & Constant Stress \\
\hline BC4 & Constant Stress & No Displacement \\
\hline
\end{tabular}




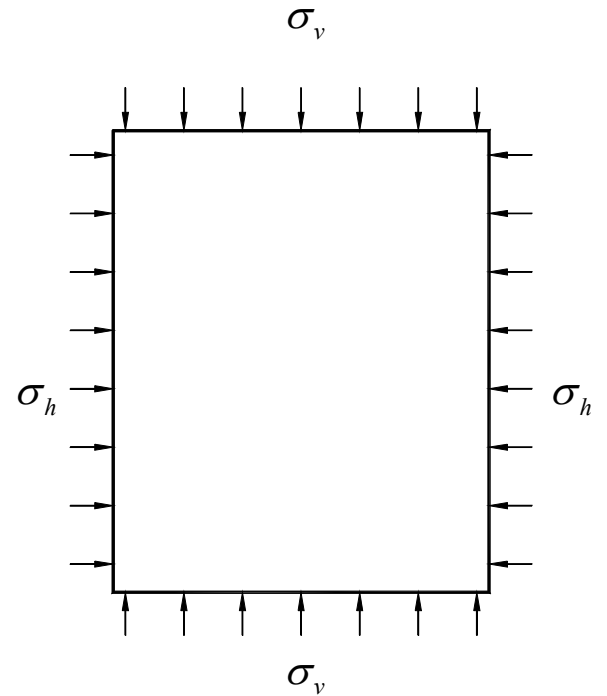

(a) $\mathrm{BC} 1$

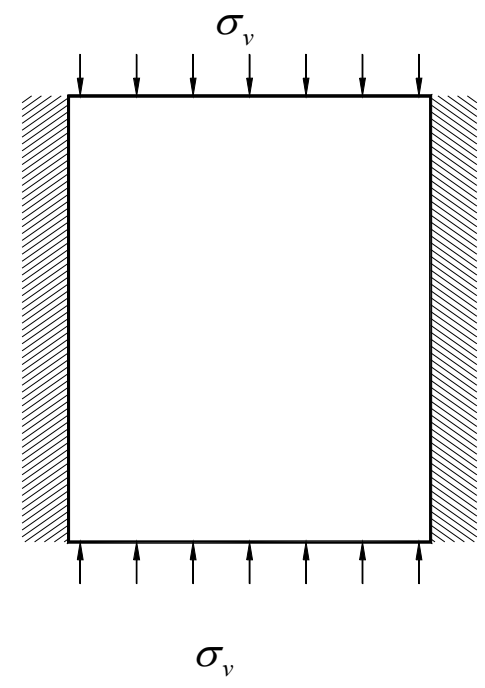

(c) BC 3

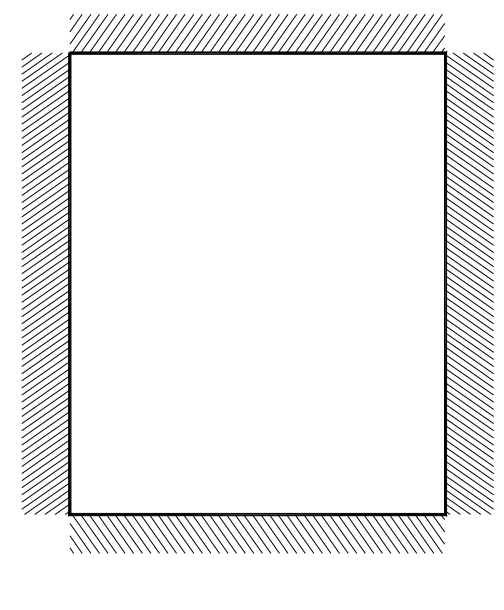

(b) $\mathrm{BC} 2$

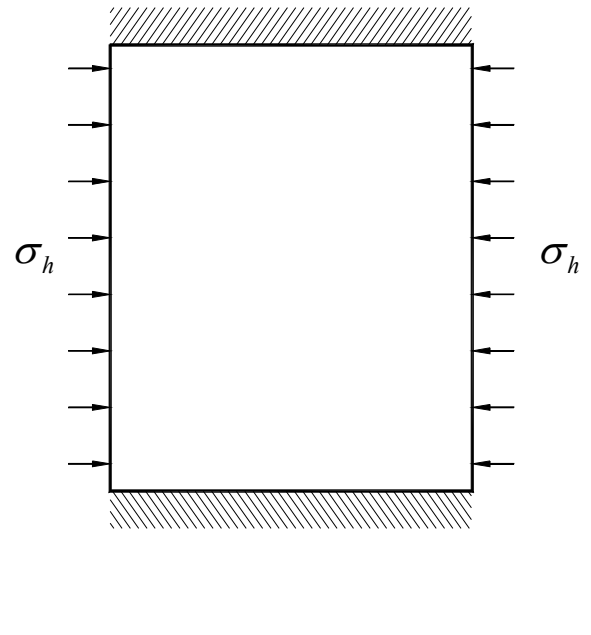

(d) BC 4

Figure 4.13 Types of boundary conditions in calibration chamber tests. 


\subsubsection{Soil Properties}

Kaolinite and Jumun sands were utilized in the experiments. The Atterberg limits test, hydrometer test, and specific gravity test were conducted on a sample of kaolin clay. XRF (X-Ray Fluorescence) analysis was performed to measure the elemental composition of kaolinite. Sieve analysis, $\mathrm{e}_{\max }$ and $\mathrm{e}_{\min }$ tests were performed on Jumun sand. The grain size distributions of Jumun sand and kaolin clay were already shown in Figure 4.1. The specific gravity, Atterberg limits, and composition of kaolinite are shown in Table 4.6. The specific gravity, $e_{\max }$ and $e_{\min }$ of Jumun sand are shown at Table 4.7. The grain size distributions of the two test mixtures are shown in Figure 4.14.

Table 4.6 Properties of kaolinite.

\begin{tabular}{|c|c|c|}
\hline \multicolumn{2}{|c|}{ Property } & Value \\
\hline \multicolumn{2}{|c|}{$\mathrm{G}_{\mathrm{s}}$} & 2.63 \\
\hline \multicolumn{2}{|c|}{ Liquid Limit, LL } & $67.2 \%$ \\
\hline \multicolumn{2}{|c|}{ Plastic Limit, PL } & $30.7 \%$ \\
\hline \multirow{3}{*}{ Composition } & $\mathrm{SiO}_{2}$ & $47.15 \%$ \\
\hline & $\mathrm{Al}_{2} \mathrm{O}_{3}$ & $35.58 \%$ \\
\hline & $\mathrm{Fe}_{2} \mathrm{O}_{3}$ & $1.08 \%$ \\
\hline
\end{tabular}

Table 4.7 Summary of Jumun sand Properties.

\begin{tabular}{|c|c|}
\hline Property & Value \\
\hline $\mathrm{G}_{\mathrm{s}}$ & 2.65 \\
\hline $\mathrm{e}_{\max }$ & 0.98 \\
\hline $\mathrm{e}_{\min }$ & 0.605 \\
\hline
\end{tabular}




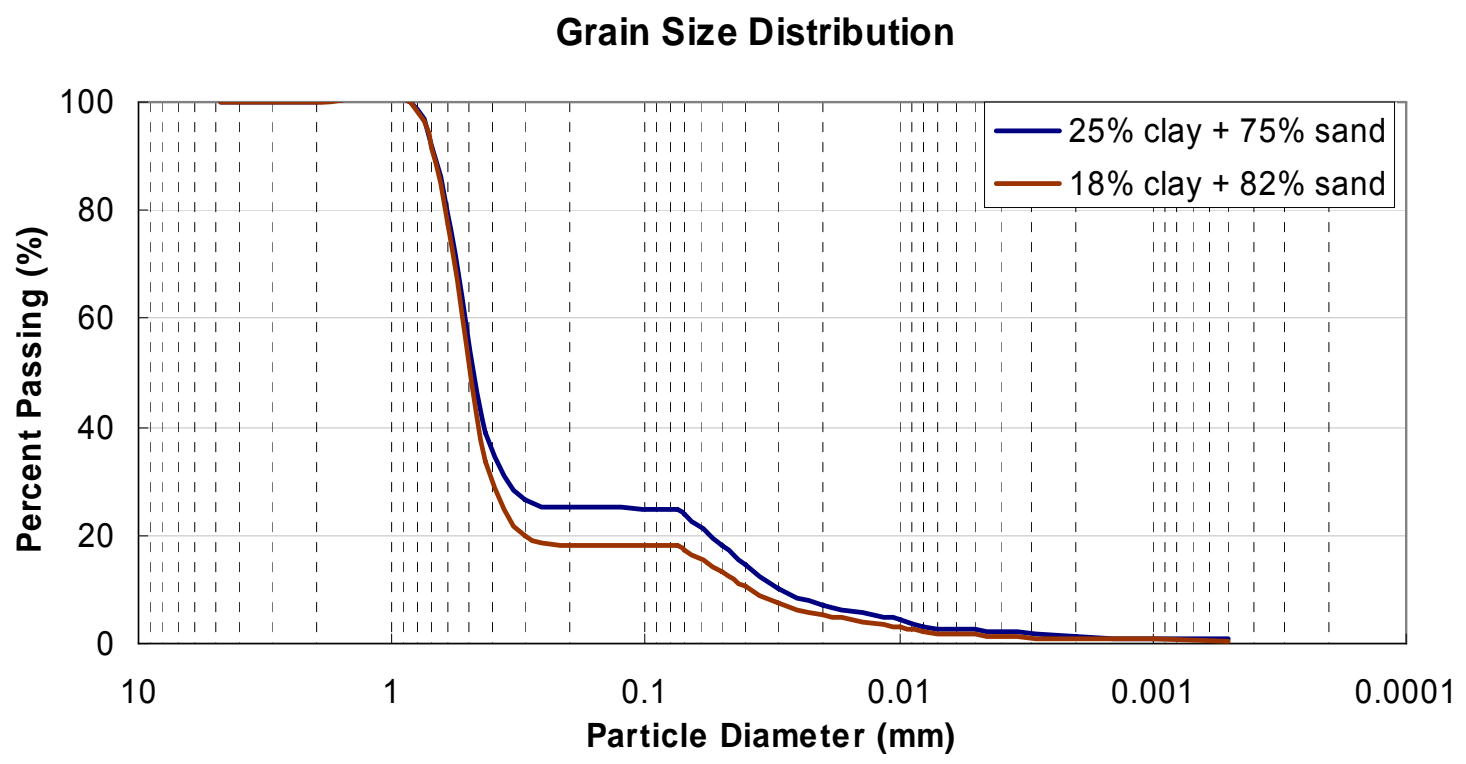

Figure 4.14 Grain size distributions of the two test mixtures.

\subsubsection{Cone Penetration Test Program}

A total of 8 cone penetration tests were conducted on each specimen including 1 standard cone, 5 miniature piezocone penetration tests and 2 miniature cone penetration tests with a flat tip. To overcome the boundary effect problem, a miniature cone $(\mathrm{D}=11.3$ $\mathrm{mm}$ ) was used for the penetration tests with various velocities. The normal size cone was used to obtain a reference cone resistance value. Penetration tests with the standard cone were performed with the normal penetration rate of $20 \mathrm{~mm} / \mathrm{sec}$. Penetration tests with the minicone were conducted at various rates between $20 \mathrm{~mm} / \mathrm{sec}$ and $0.01 \mathrm{~mm} / \mathrm{sec}$ for P1 and $20 \mathrm{~mm} / \mathrm{sec}$ and $0.05 \mathrm{~mm} / \mathrm{sec}$ for P2. The available penetration depth of the test was around $750 \mathrm{~mm}$ out of the $950 \mathrm{~mm}$ total specimen length, so as do not get closer than $200 \mathrm{~mm}$ to the bottom plate. This length is enough to give a stable resistance value for two different penetration rates when we assume that penetration data is stabilized after the cone 
advances 5D. Therefore, each penetration test was done in two stages with two different penetration rates. For five soundings, minicone penetration tests were performed with 9 different rates between $20 \mathrm{~mm} / \mathrm{sec}$ and $0.01 \mathrm{~mm} / \mathrm{sec}$ on $\mathrm{P} 1$. The detailed penetration rate schedule for minicone penetration tests and penetration tests with a flat tip is summarized in Table 4.8 and Table 4.9 , respectively.

The standard cone has a $10 \mathrm{~cm}^{2}$ projected tip area, a cone apex angle of $60^{\circ}$, and a $150 \mathrm{~cm}^{2}$ friction sleeve area. The miniature piezocone penetrometer has a tip area of $1 \mathrm{~cm}^{2}$, a diameter of $11.3 \mathrm{~mm}$, a cone apex angle of $60^{\circ}$, and a length of $175 \mathrm{~mm}$. It was loaned by Fugro B.V. of the Netherlands. It is also equipped with a friction sleeve with an area of $15 \mathrm{~cm}^{2}$ as well as pore water pressure transducer at the $U_{2}$ location. A flat shape tip for the minicone was manufactured and used for two holes to investigate the effect of the cone tip shape on penetration tests. Figure 4.15 shows the standard cone, the miniature cone, and the miniature cone with the flat tip used in the testing.

The top plate of the chamber has 9 holes to provide access for the cone penetrometer. A plan view of the test holes is shown in Figure 4.16. Penetration and extraction of the cone was controlled by the hydraulic pushing system mounted on the chamber lid. The hydraulic system had a maximum stroke of $790 \mathrm{~mm}$. After the penetration tests, all pressures were carefully released and the pushing system was moved to another hole for the next test. After the piezocone is locked in to the hydraulic pushing system on the chamber and positioned in the hole, the specimen was gradually repressurized by the back pressure $200 \mathrm{kPa}$ and the vertical effective compression pressure of $430 \mathrm{kPa}$. The penetration depth was measured using a depth encoding system and all data during the test were recorded using a data acquisition system controlled by Labview. 
Table 4.8 Penetration rate schedule for the minicone test.

\begin{tabular}{c|c|c|c}
\hline \multicolumn{2}{c|}{ P1 (25\% clay + 75\% sand $)$} & \multicolumn{2}{c}{ P2 (18\% clay + 82\% sand $)$} \\
\hline Test number & $\begin{array}{c}\text { Penetration rate } \\
(\mathrm{mm} / \mathrm{sec})\end{array}$ & Test number & $\begin{array}{c}\text { Penetration rate } \\
(\mathrm{mm} / \mathrm{sec})\end{array}$ \\
\hline 1 & 20 & 1 & 20 \\
\hline 2 & 8 & 2 & 10 \\
\hline 3 & 2 & 3 & 2 \\
\hline 4 & 0.25 & 4 & 1 \\
\hline 5 & 0.1 & 5 & 0.5 \\
\hline 6 & 0.05 & 6 & 0.2 \\
\hline 7 & 0.035 & 7 & 0.1 \\
\hline 8 & 0.02 & 8 & \\
\hline 9 & 0.01 & & 0.05 \\
\hline
\end{tabular}

Table 4.9 Penetration rate schedule for the minipile test.

\begin{tabular}{c|c|c|c}
\hline \multicolumn{2}{c|}{ P1 $(25 \%$ clay $+75 \%$ sand $)$} & \multicolumn{2}{c}{ P2 $(18 \%$ clay $+82 \%$ sand $)$} \\
\hline Test number & $\begin{array}{c}\text { Penetration rate } \\
(\mathrm{mm} / \mathrm{sec})\end{array}$ & Test number & $\begin{array}{c}\text { Penetration rate } \\
(\mathrm{mm} / \mathrm{sec})\end{array}$ \\
\hline 1 & 20 & 1 & 20 \\
\hline 2 & 2 & 2 & 5 \\
\hline 3 & 0.1 & 3 & 1 \\
\hline 4 & 0.05 & 4 & 0.2 \\
\hline 5 & 0.02 & 5 & 0.1 \\
\hline
\end{tabular}




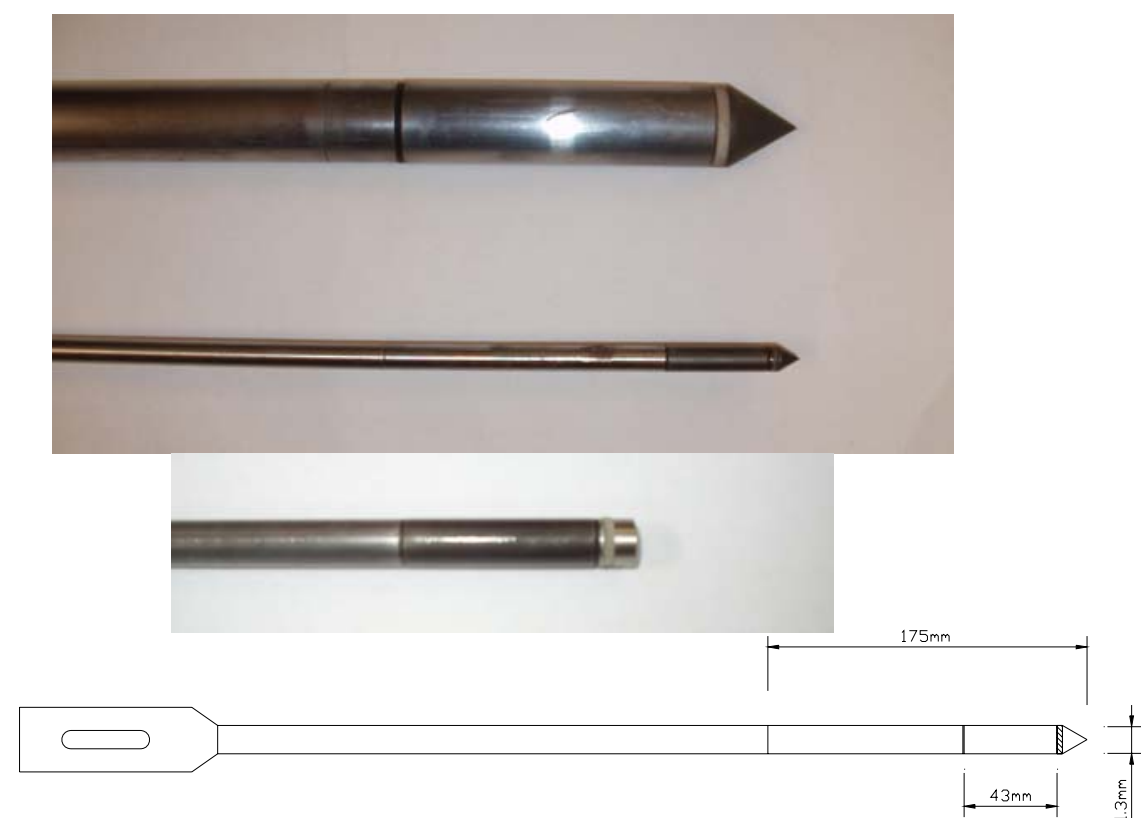

Figure 4.15 Standard cone, Miniature cone, and Miniature cone with a flat tip.

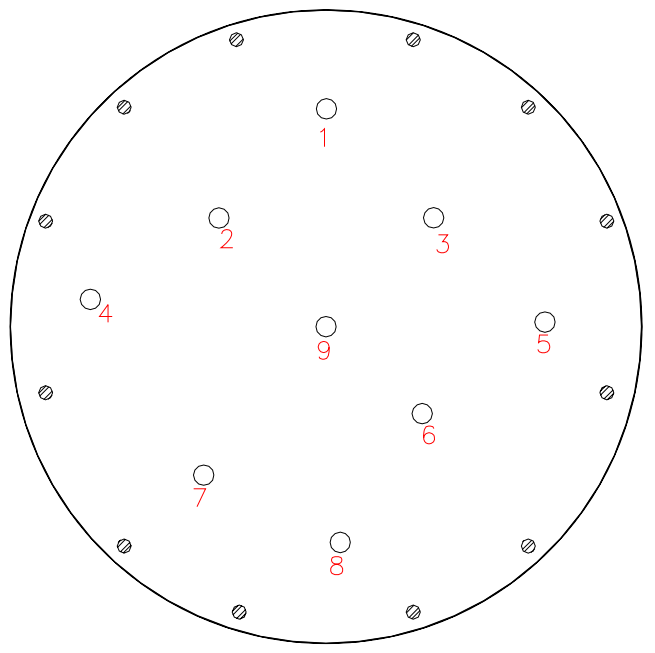

Figure 4.16 Cone penetration locations on the top lid. 


\section{6. $\underline{\text { Summary }}$}

Calibration chamber cone penetration tests were used to investigate rate effects due to change of drainage conditions. A general overview of the calibration chamber used in the cone penetration program was provided in this chapter. Detailed test procedures were described.

A series of flexible-wall permeameter tests were conducted for various mixing ratios of clays and sands to obtain values of consolidation coefficient $\mathrm{c}_{\mathrm{v}}$ used to determine mixing ratios of chamber specimens. The results of the tests show that coefficient of consolidation for mixtures of clay and sand is primarily affected by the clay content. From the test results, it was recognized that $\log \mathrm{c}_{\mathrm{v}}$ has a linear relationship with clay content. Based on the flexible wall test results, a mixing ratio of $25 \%$ clay and $75 \%$ Jumun sand $\left(\mathrm{c}_{\mathrm{v}}\right.$ $=3.45 \times 10^{-6} \mathrm{~m}^{2} / \mathrm{sec}$ ) was selected for the first specimen and a mixing ratio of $18 \%$ clay and $78 \%$ Jumun sand $\left(c_{\mathrm{v}}=6.9 \times 10^{-5} \mathrm{~m}^{2} / \mathrm{sec}\right)$ was selected for the second test.

A two-stage slurry consolidation technique was used to prepare homogeneous specimens. The specimens were prepared under $\mathrm{K}_{0}$ condition, and the penetration tests were performed with BC 4 boundary condition. A total of 8 cone penetration tests were conducted on each specimen including 1 standard cone, 5 miniature piezocone penetration tests and 2 miniature cone penetration tests with a flat tip with various penetration ratios. Test results are summarized in the next chapter. 


\section{CHAPTER 5. ANALYSIS OF CALIBRATION CHAMBER CONE PENETRATION TEST RESULTS}

\subsection{Introduction}

This chapter presents the results of the cone penetration tests in the calibration chamber and their interpretation. The standard cone, the miniature cone with a regular conical tip and miniature flat-tip penetrometer were used for the penetration tests in two different specimens. The penetration data are analyzed to study the effects of penetration rate and drainage conditions. From the obtained data, the transition points from undrained to partially drained and from partially drained to fully drained conditions can be determined. The determination of the coefficient of consolidation using various methods is also discussed.

\subsection{The Results of Cone Penetration Test in P1}

A series of penetration tests with the miniature cone and the reference cone was performed on specimen P1 with the penetration rates described in Table 4.6. A profile of cone resistance obtained from the reference cone is shown in Figure 5.1. Profiles of cone resistance and excess pore pressure measured by the minicone for 9 different penetration rates are plotted in Figures 5.2(a) through (i). The cone resistance was defined as the corrected cone resistance $\mathrm{q}_{\mathrm{t}}$, which was obtained from the measured cone resistance $\mathrm{q}_{\mathrm{c}}$ and the measured pore pressure behind the cone tip by Eq. 2.2.

It took about five cone diameters of initial advancement for the $\mathrm{q}_{\mathrm{t}}$ cone values to stabilize and reach steady-state conditions. Accordingly, the penetration results for the initial $60 \mathrm{~mm}$ of penetration were disregarded, and average values of measured cone resistance and pore pressure were calculated based on measurements made thereafter.

As shown in Figures 5.2(a) and (b) and Figure 5.3, the steady-state values of $\mathrm{q}_{\mathrm{t}}$ for penetration rates of $20 \mathrm{~mm} / \mathrm{s}$ and $8 \mathrm{~mm} / \mathrm{s}$ are almost the same and equal to $0.71 \mathrm{MPa}$ 
and 0.69 MPa, respectively, and the corresponding steady-state values of measured pore pressure are $295 \mathrm{kPa}$ and $270 \mathrm{kPa}$. These results show that, for penetration rates of 20 $\mathrm{mm} / \mathrm{s}$ and $8 \mathrm{~mm} / \mathrm{s}$, cone penetration occurred under undrained conditions. The values of $\mathrm{q}_{\mathrm{t}}$ started to increase slowly as $\mathrm{v}$ decreased from $8 \mathrm{~mm} / \mathrm{s}$ to $2 \mathrm{~mm} / \mathrm{s}$ and finally to $0.25 \mathrm{~mm} / \mathrm{s}$. The measured average $\mathrm{q}_{\mathrm{t}}$ values showed an increase of $30 \%$ (from $0.7 \mathrm{MPa}$ to $0.91 \mathrm{MPa}$ ) for a reduction in $\mathrm{v}$ from $8 \mathrm{~mm} / \mathrm{s}$ to $0.25 \mathrm{~mm} / \mathrm{s}$. For this change in $\mathrm{v}$, the pore pressure gradually decreased from an average of $270 \mathrm{kPa}$ to $222 \mathrm{kPa}$; a reduction of about $20 \%$.

As explained in chapter 3 , the change of the drainage condition can be indicated by comparing the point that the pore pressure starts to decrease and the point that the cone resistance starts to increase. Therefore, the change of the values of measured pore pressure and cone resistance shows that the drainage condition of the soil surrounding the penetrating cone had changed from undrained to partially drained in this penetration speed range.

The values of $\mathrm{q}_{\mathrm{t}}$ increased from $0.91 \mathrm{MPa}$ to $3.14 \mathrm{MPa}$ for a change in $\mathrm{v}$ from $0.25 \mathrm{~mm} / \mathrm{s}$ to $0.02 \mathrm{~mm} / \mathrm{s}$. The cone resistance increased by about 3.5 times, as $\mathrm{v}$ decreased by an order of magnitude. For the same change in $\mathrm{v}$, the excess pore pressure dropped from $222 \mathrm{kPa}$ to $8 \mathrm{kPa}$. The drastic decrease in pore pressure observed indicates that the drainage conditions abruptly changed from partially drained to drained with this decrease in v. The nearly zero excess pore pressure for a penetration rate of $0.02 \mathrm{~mm} / \mathrm{s}$ indicates that the penetration test was performed under drained conditions. At the slowest speed $(0.01 \mathrm{~mm} / \mathrm{s})$ possible, the CPTs were also performed under fully drained conditions. The average values of $\mathrm{q}_{\mathrm{t}}$ and excess pore pressure for $\mathrm{v}=0.01 \mathrm{~mm} / \mathrm{s}$ are almost the same as the values measured for $\mathrm{v}=0.02 \mathrm{~mm} / \mathrm{s}$.

Sleeve friction resistance $\mathrm{f}_{\mathrm{s}}$ is also measured simultaneously during penetration tests. It is known that the sleeve friction measurement of a cone does not give as reliable results as the cone tip results. However, as discussed in section 3.2.3, measured sleeve friction resistance in the field tests consistently changed in accordance with the change of cone resistance as drainage conditions changed (Figure 3.12, 3.13, 3.17 and 3.23). 
However, the values of $f_{s}$ obtained from this test did not show the same trend as $q_{t}$ and pore pressure drainage conditions changed. This issue will be discussed further in the following chapter with the complete calibration chamber test results.

Table 5.1 Values of $\mathrm{q}_{\mathrm{t}}$, pore pressure, and $\mathrm{f}_{\mathrm{s}}$ of minicone penetration tests for various rates performed in calibration chamber sample P1.

\begin{tabular}{c||ccccccccc}
\hline $\begin{array}{c}\text { Penetration rate } \\
(\mathrm{mm} / \mathrm{sec})\end{array}$ & 20 & 8 & 2 & 0.25 & 0.1 & 0.05 & 0.035 & 0.02 & 0.01 \\
\hline $\mathrm{q}_{\mathrm{t}}(\mathrm{MPa})$ & 0.71 & 0.69 & 0.83 & 0.91 & 1.37 & 2.26 & 2.48 & 3.14 & 3.13 \\
Pore pressure $(\mathrm{kPa})$ & 295 & 270 & 233.2 & 222.6 & 184.9 & 82.4 & 63.4 & 8 & 13 \\
Local friction $\mathrm{f}_{\mathrm{s}}(\mathrm{kPa})$ & - & 14.2 & 12.9 & 11.0 & 12.2 & 13.1 & 11.8 & 12.5 & 12.1 \\
\hline
\end{tabular}




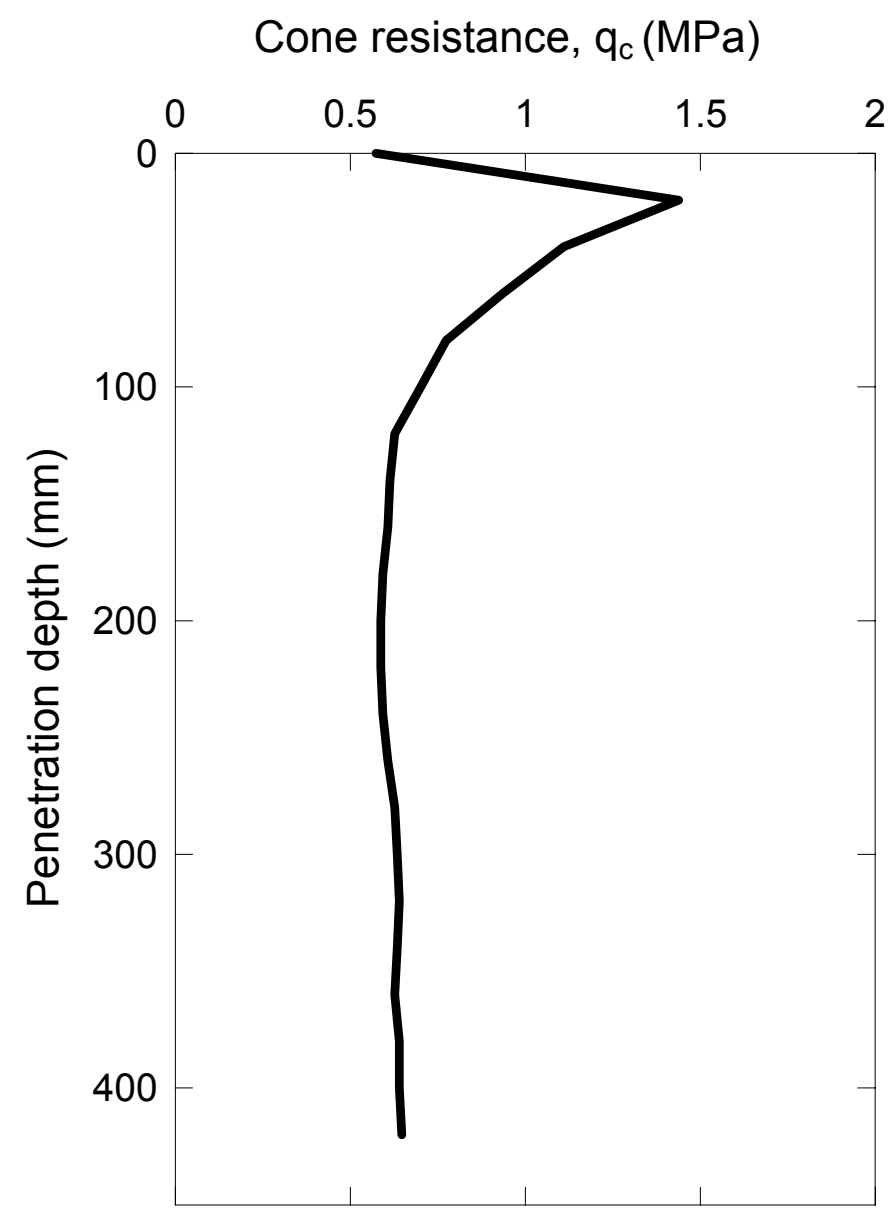

Figure 5.1 Cone resistance of reference cone penetration test on P1 $(\mathrm{v}=20 \mathrm{~mm} / \mathrm{sec})$. 


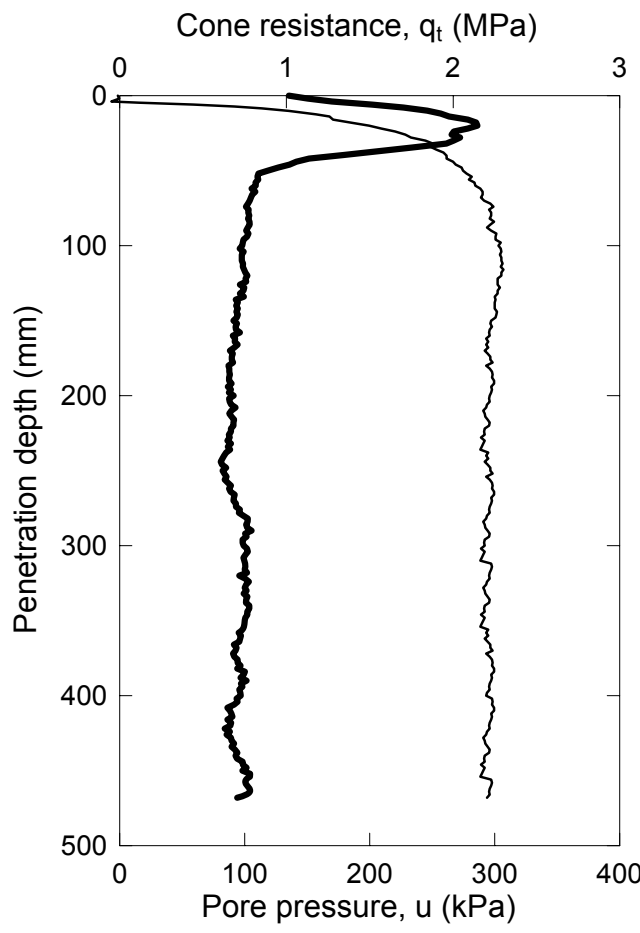

(a) Penetration rate: $20 \mathrm{~mm} / \mathrm{sec}$
Cone resistance, $\mathrm{q}_{\mathrm{t}}(\mathrm{MPa})$

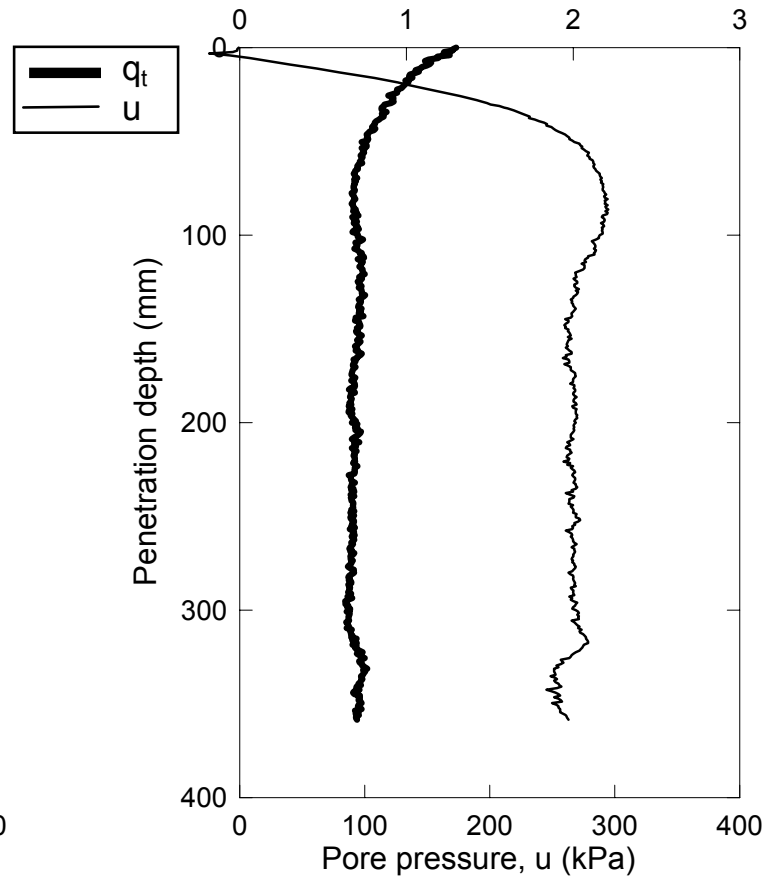

(b) Penetration rate: $8 \mathrm{~mm} / \mathrm{sec}$

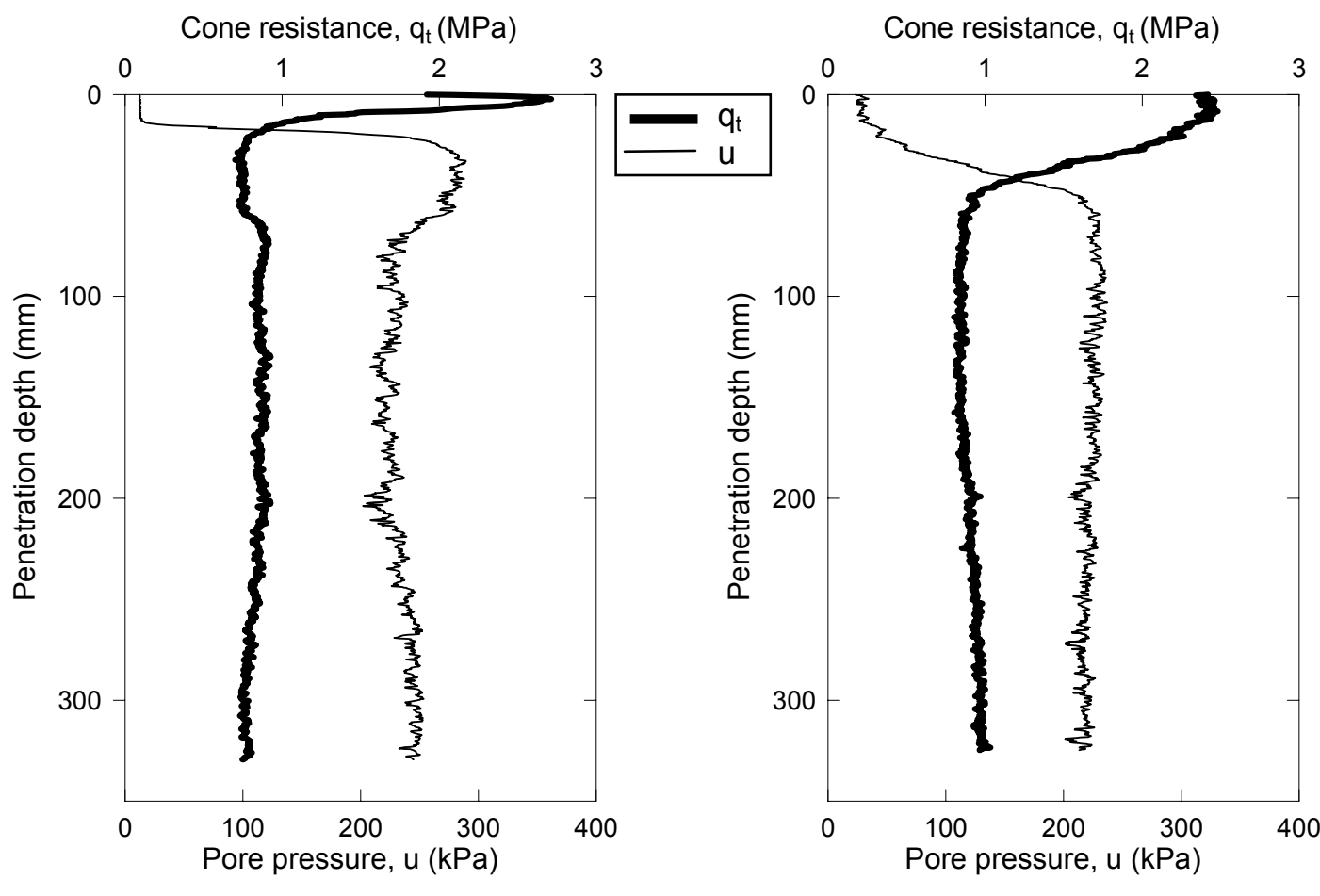

(c) Penetration rate: $2 \mathrm{~mm} / \mathrm{sec}$

(d) Penetration rate: $0.25 \mathrm{~mm} / \mathrm{sec}$

Figure 5.2 Results of minicone penetration test on P1. 


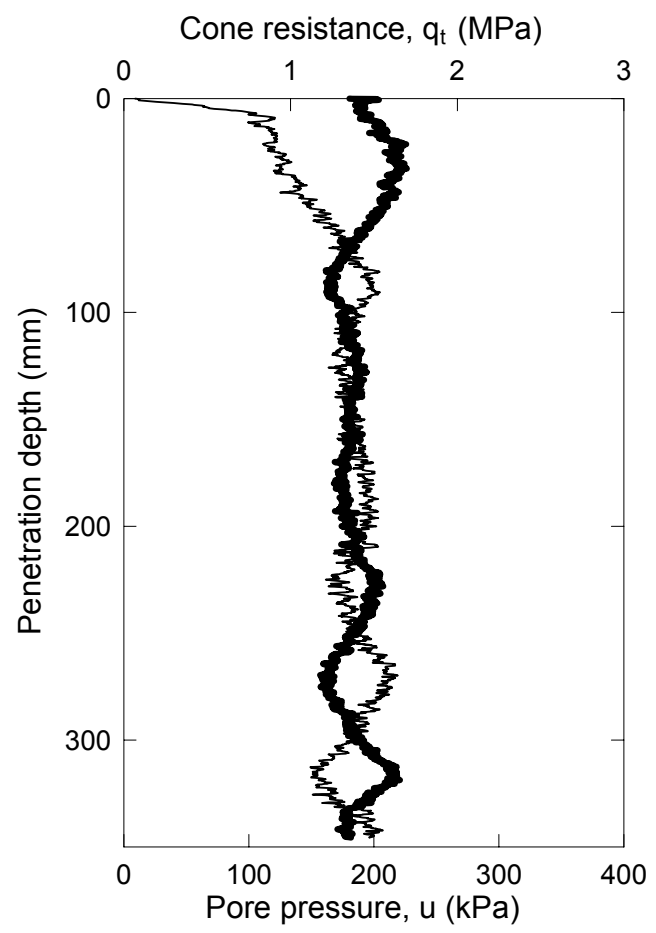

(e) Penetration rate: $0.1 \mathrm{~mm} / \mathrm{sec}$

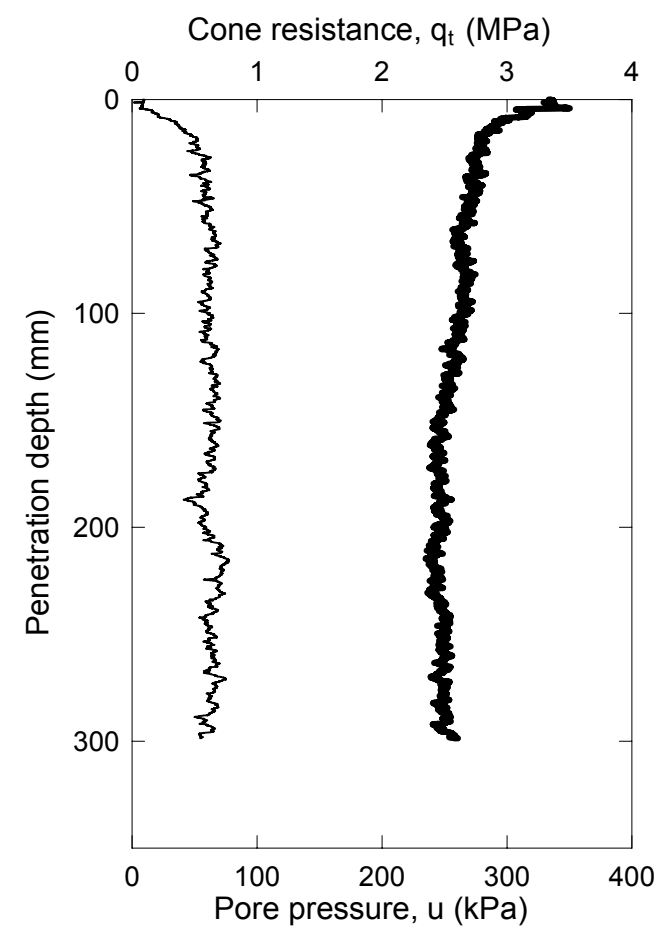

(g) Penetration rate: $0.035 \mathrm{~mm} / \mathrm{sec}$

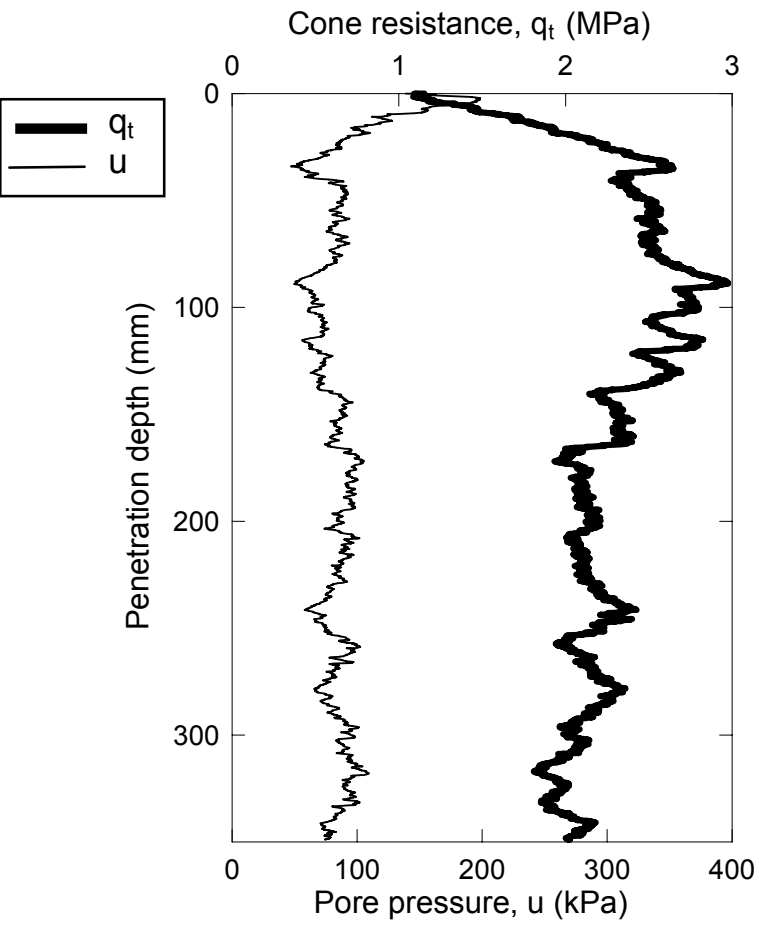

(f) Penetration rate: $0.05 \mathrm{~mm} / \mathrm{sec}$

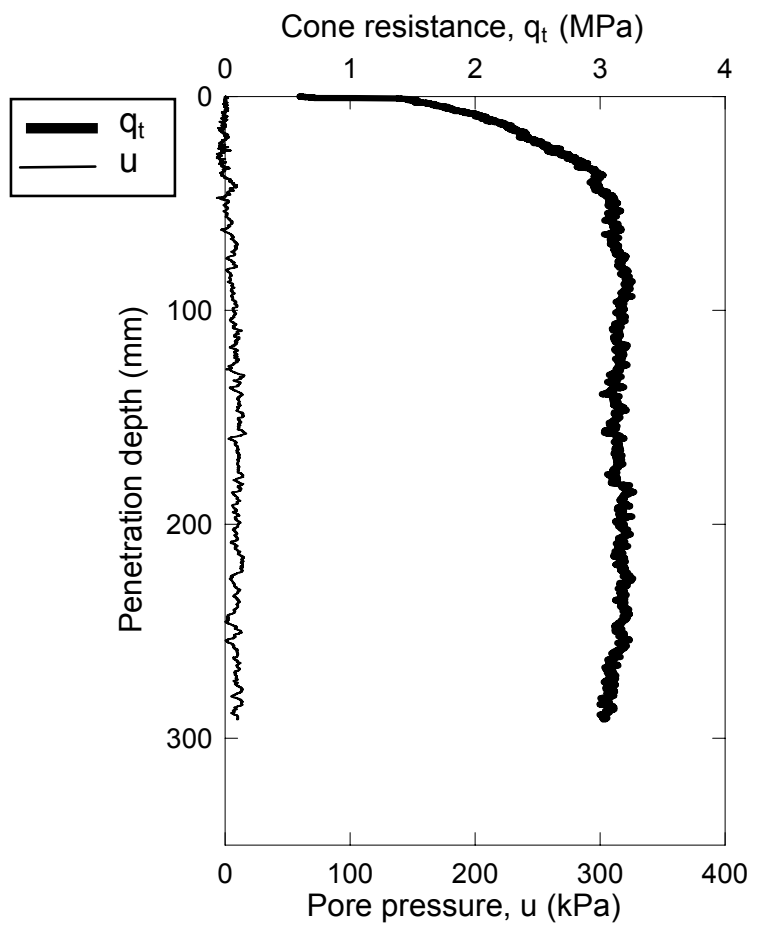

(h) Penetration rate: $0.02 \mathrm{~mm} / \mathrm{sec}$

Figure 5.2 Results of minicone penetration test on P1 (continued). 


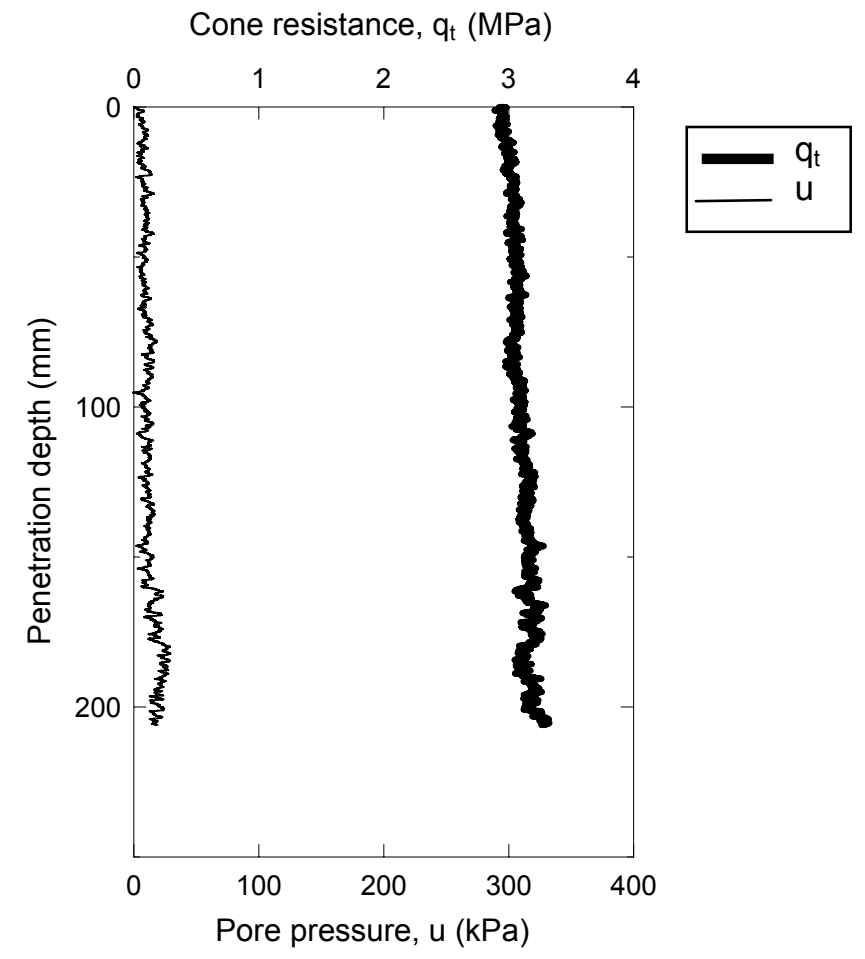

(h) Penetration rate: $0.01 \mathrm{~mm} / \mathrm{sec}$

Figure 5.2 Results of minicone penetration test on P1 (continued). 


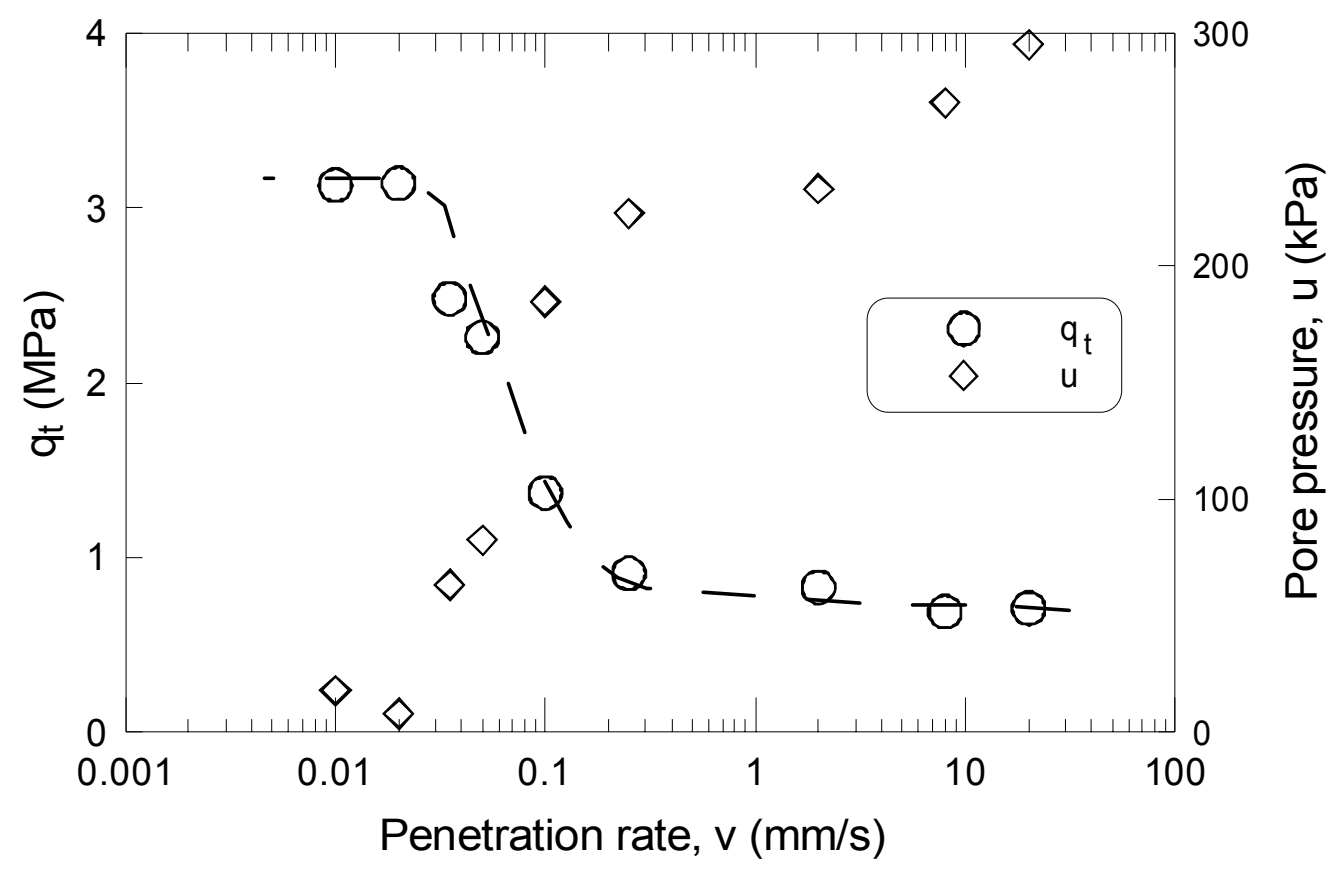

Figure 5.3 Effect of penetration rate on $\mathrm{q}_{\mathrm{t}}$ and pore pressure.

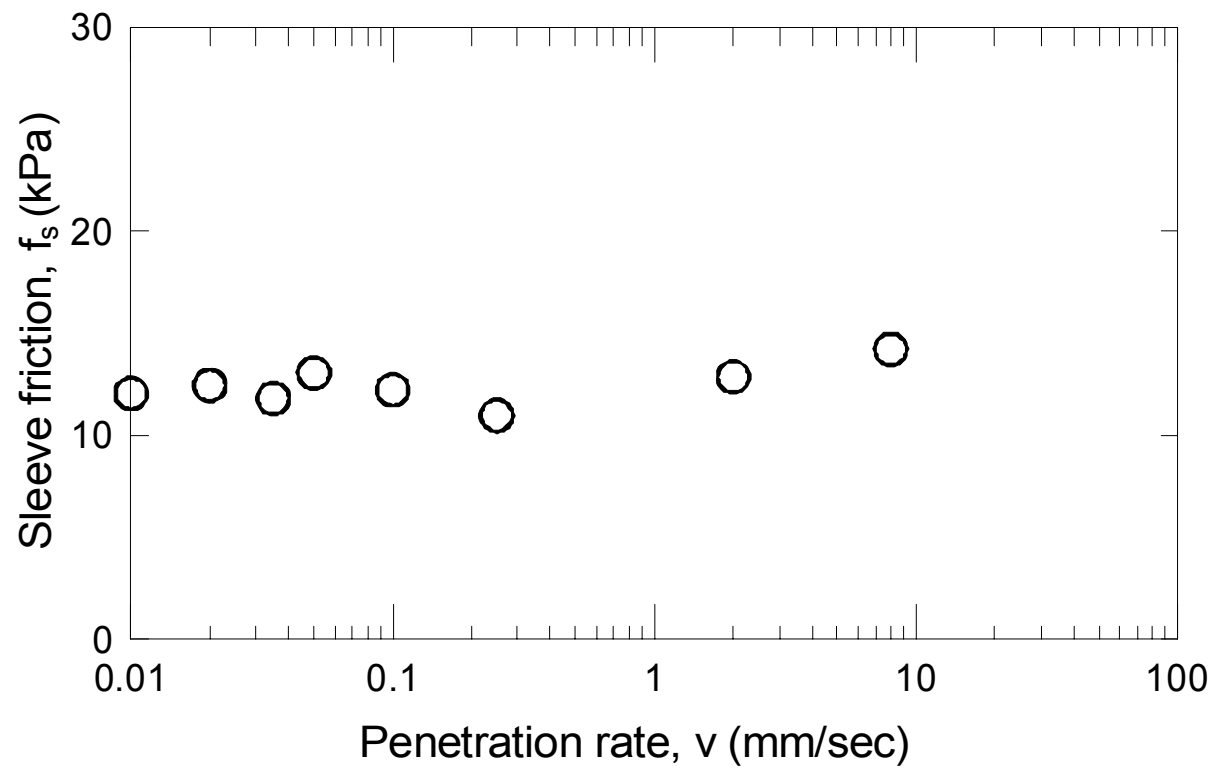

Figure 5.4 Effect of penetration rate on friction resistance. 


\subsection{The Results of Minicone Penetration Tests with a Flat Tip in P1}

A series of miniature penetration tests with a flat tip were performed to investigate the impact of the shape of the tip on penetration resistance. These results, obtained for both a cone tip and a flat tip under the same conditions, provide insights into the relationship between cone resistance and limit unit pile base resistance. Some tests performed in resedimented clays reported that the cone resistance for sharp tips (less than $30^{\circ}$ apex angle) is larger than those for normal cone tip ( $60^{\circ}$ apex angle). However, for apex angles larger than $30^{\circ}$, only a small influence of apex angle was observed (Muromachi 1974). The Influence of cone apex angle on measured cone resistance is shown in Figure 5.5.

The profiles of cone resistance and excess pore pressure generated during penetration tests with the flat tip for 5 different penetration rates $(20 \mathrm{~mm} / \mathrm{sec}, 2 \mathrm{~mm} / \mathrm{sec}$, $0.1 \mathrm{~mm} / \mathrm{sec}, 0.05 \mathrm{~mm} / \mathrm{sec}$, and $0.02 \mathrm{~mm} / \mathrm{sec}$ ) are shown in Figures 5.6(a) through (e). Average steady-state values of $\mathrm{q}_{\mathrm{t}}$, pore pressure and $\mathrm{f}_{\mathrm{s}}$ are summarized in Table 5.2. The average values of tip resistance and pore pressure are presented in Figure 5.7 and compared with the results obtained using conical cone tip. For the rate of $20 \mathrm{~mm} / \mathrm{sec}$ and 2 $\mathrm{mm} / \mathrm{sec}$, the average values of $\mathrm{q}_{\mathrm{t}}$ for the flat tip were about $0.8 \mathrm{MPa}$, and the pore pressures were $290 \mathrm{kPa}$ and $271 \mathrm{kPa}$. The values of tip resistance are $15 \%$ higher than those for the normal cone tip and pore pressures were almost equal. That the difference is small is illustrated in Figure 5.7, which shows that the values of tip resistance and pore pressure from the flat tip correspond to those from the normal tip at the same speed. The two transition points in the drainage curve seem to be identical for the two cone tip shapes. Cone resistance and pore pressure measured for the flat tip in the three different drainage conditions correspond to the values from the conical tip. The values of tip resistance and pore pressure for the penetration tests performed at $0.1 \mathrm{~mm} / \mathrm{sec}$ and $0.05 \mathrm{~mm} / \mathrm{sec}$ (under partially drained conditions) are $1.75 \mathrm{MPa}, 2.88 \mathrm{MPa}$, and $130.6 \mathrm{kPa}$, and $54.8 \mathrm{kPa}$, respectively. Values of tip resistance and pore pressure for $0.02 \mathrm{~mm} / \mathrm{sec}$ are $3.28 \mathrm{MPa}$ and $27.1 \mathrm{kPa}$, also matching the results from the conical tip with at the same speed. 
The overall values of flat tip resistances for the entire tested penetration rate range are almost equal to the cone resistances at the same penetration rates. The transition points indicating change in drainage conditions seem to be identical for the two tip shapes. In this case, for the clayey sand with a "floating fabric", the shape of the cone tip does not affect the tip resistance results.

Table 5.2 Tip resistance, pore pressure, and $\mathrm{f}_{\mathrm{s}}$ for various penetration rates with a flat tip.

\begin{tabular}{c|ccccc}
\hline Penetration rate $(\mathrm{mm} / \mathrm{sec})$ & 20 & 2 & 0.1 & 0.05 & 0.02 \\
\hline Tip resistance $(\mathrm{MPa})$ & 0.814 & 0.807 & 1.75 & 2.88 & 3.28 \\
Pore pressure $(\mathrm{kPa})$ & 290.9 & 271.4 & 130.6 & 54.8 & 27.1 \\
Local friction $\mathrm{f}_{\mathrm{s}}(\mathrm{kPa})$ & 13.0 & 11.8 & 10.6 & 8.6 & 7.0 \\
\hline
\end{tabular}




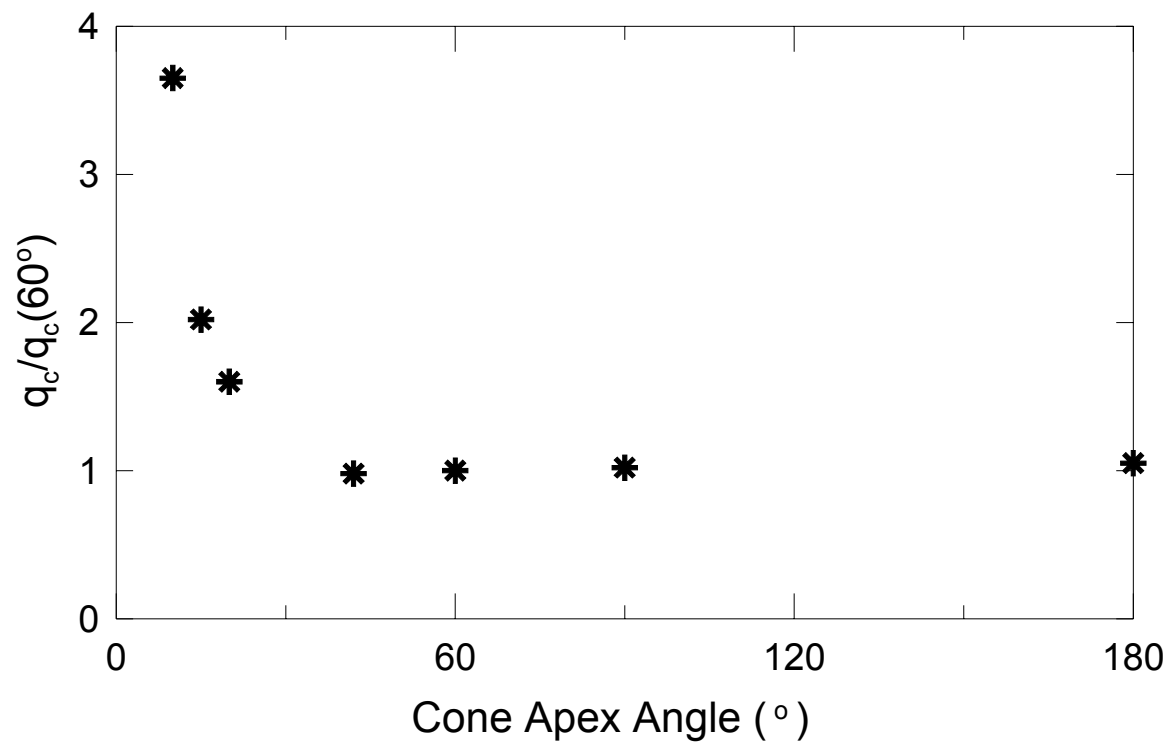

Figure 5.5 Influence of cone apex angle on measured cone resistance. (after Acar 1981) 


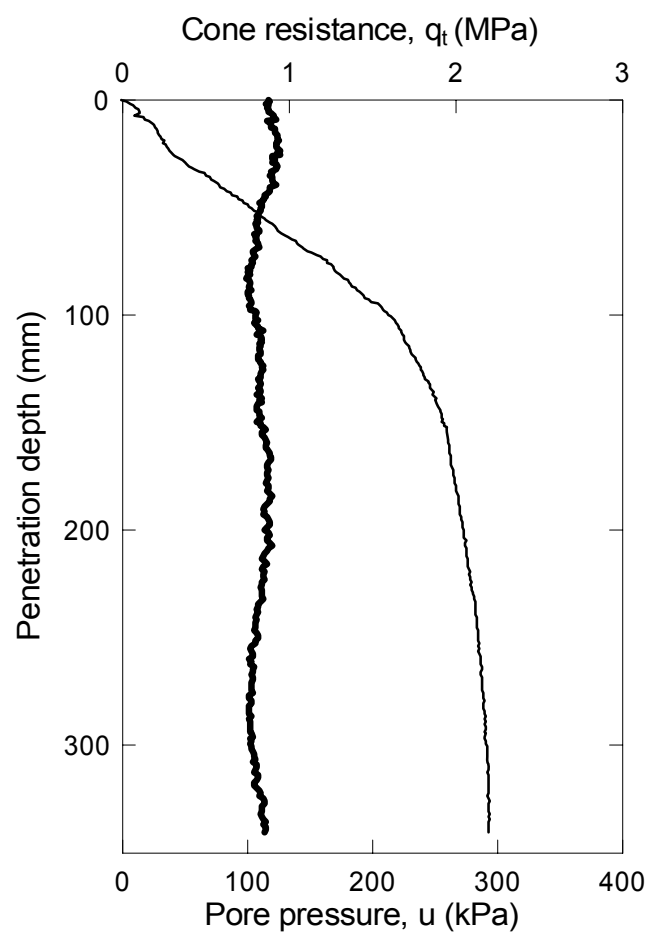

(a) Penetration rate: $20 \mathrm{~mm} / \mathrm{sec}$

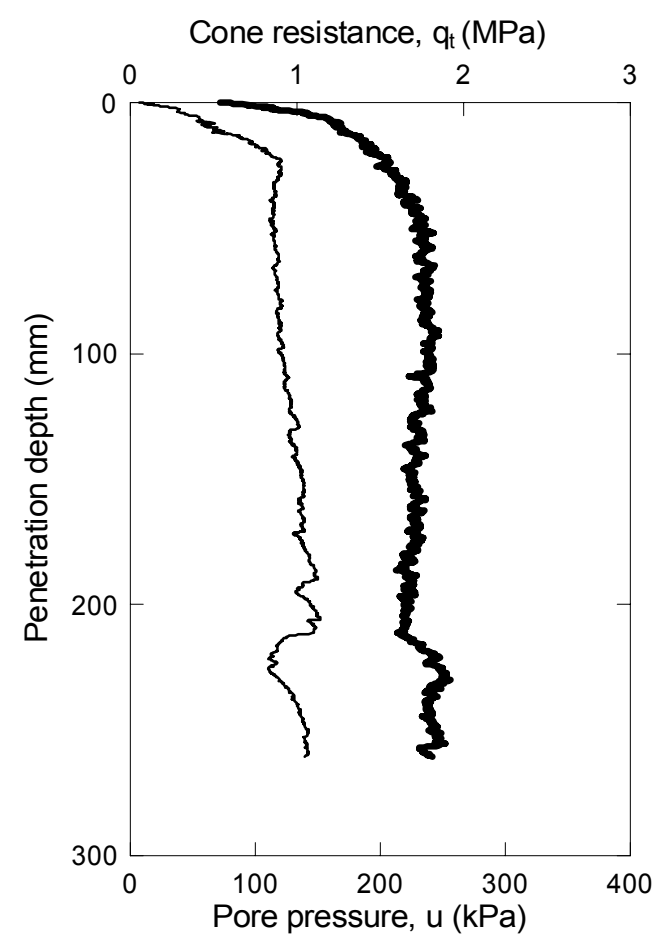

(c) Penetration rate: $0.1 \mathrm{~mm} / \mathrm{sec}$

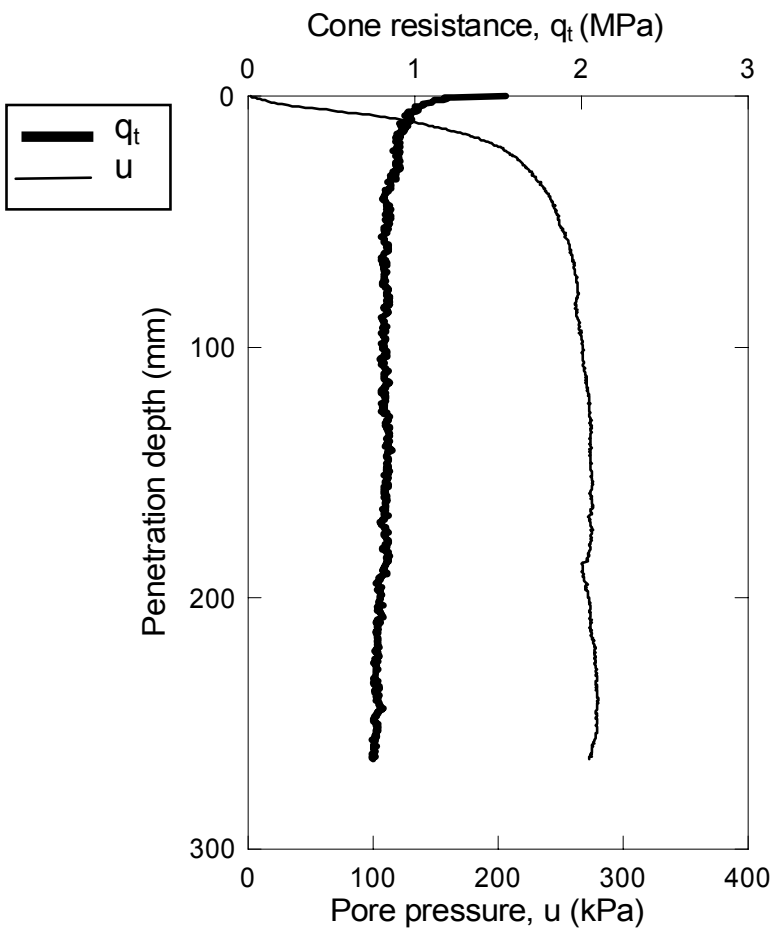

(b) Penetration rate: $2 \mathrm{~mm} / \mathrm{sec}$

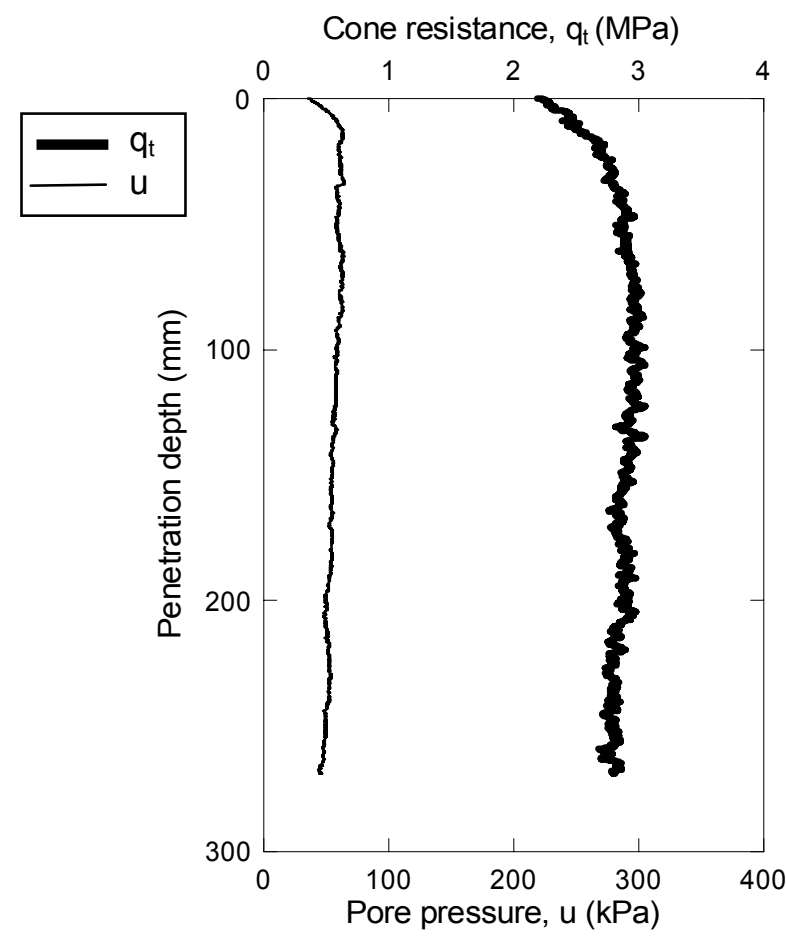

(d) Penetration rate: $0.05 \mathrm{~mm} / \mathrm{sec}$

Figure 5.6 Minicone penetration test results with flat tip on P1. 


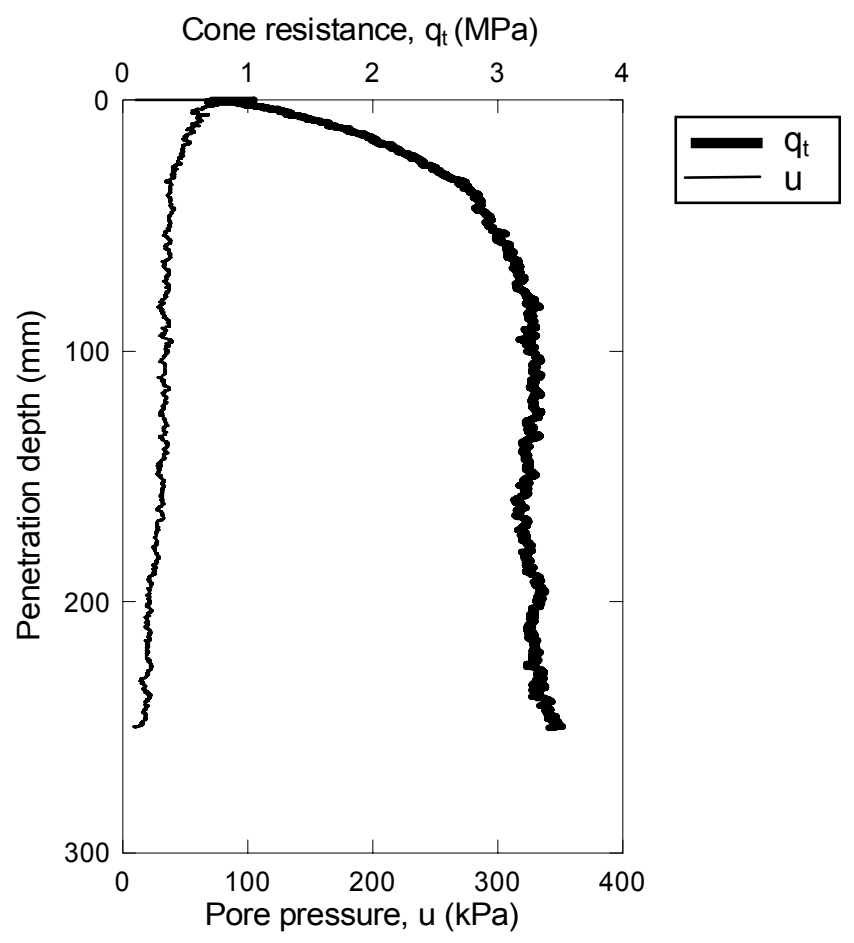

(e) Penetration rate: $0.02 \mathrm{~mm} / \mathrm{sec}$

Figure 5.6 Minicone penetration test results with flat tip on P1 (continued). 


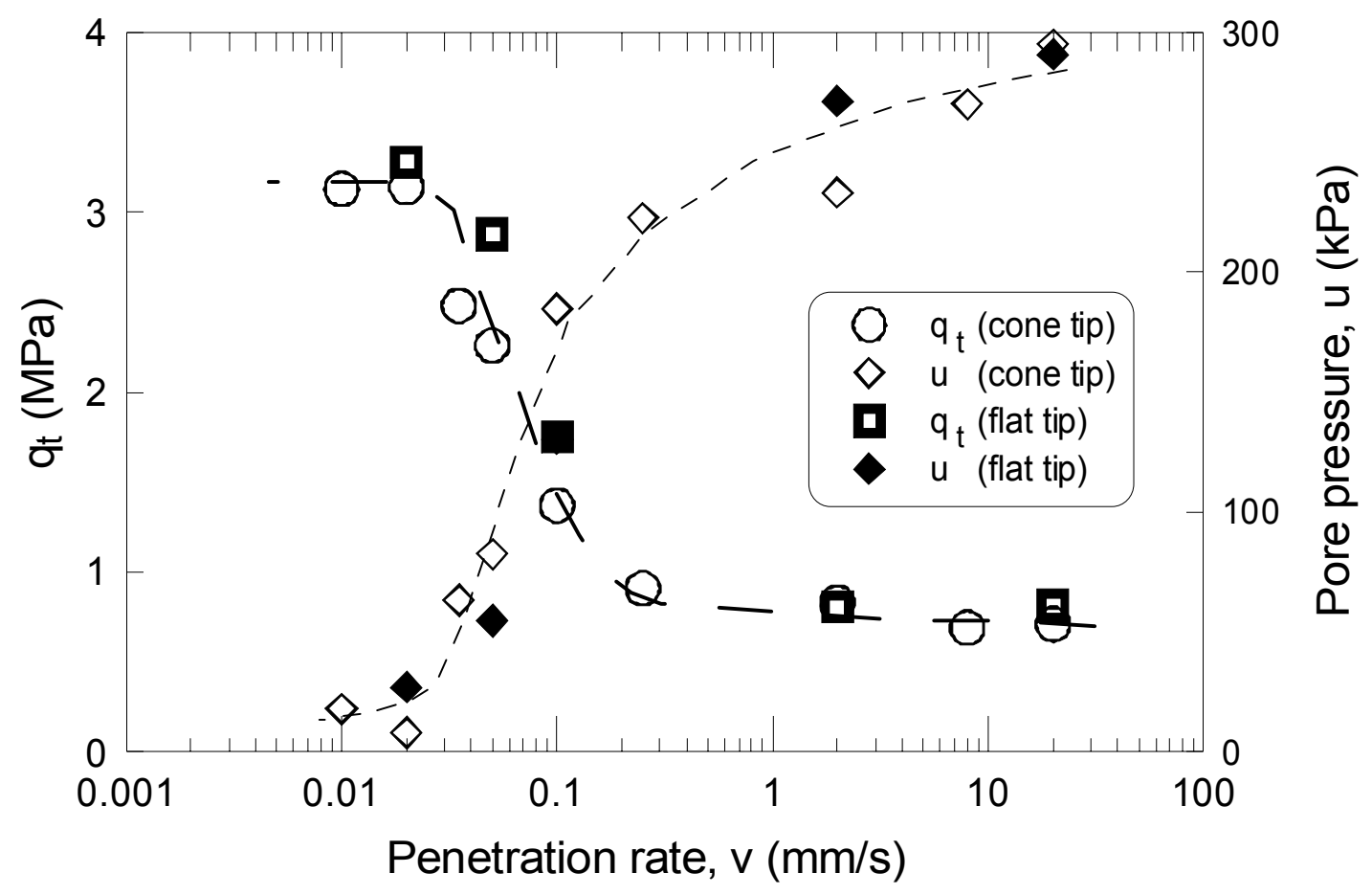

Figure 5.7 Effect of penetration rate on $\mathrm{q}_{\mathrm{t}}$, tip resistance, and pore pressure on $\mathrm{P} 1$. 


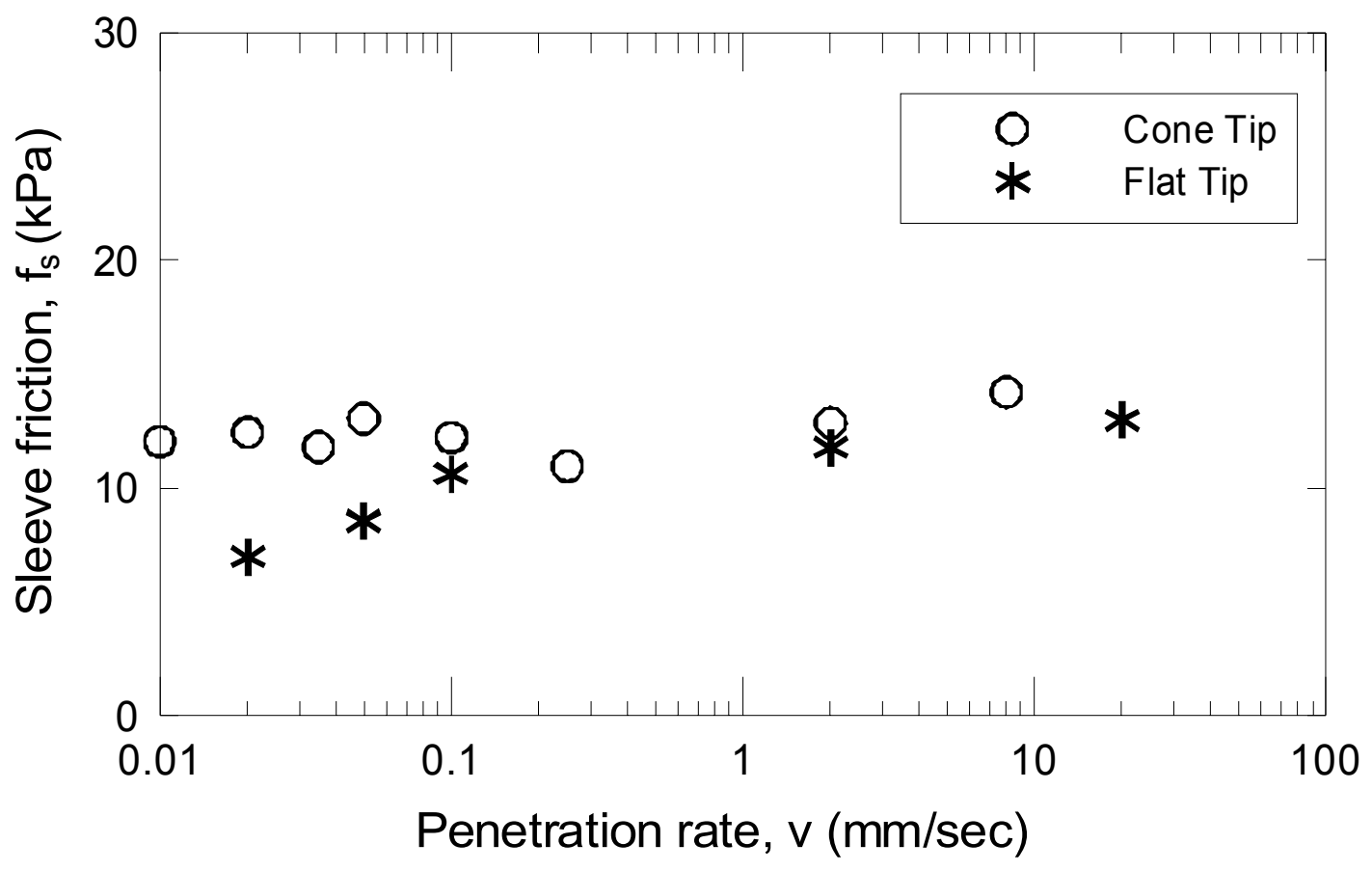

Figure 5.8 Effect of penetration rate on sleeve friction on $\mathrm{P} 1$. 


\subsection{The Results of Cone Penetration Tests in $\mathrm{P} 2$}

Specimen P2 consists of $18 \%$ kaolin clay and $82 \%$ Jumun sand by weight. The specimen had a water content of $22.2 \%$ and a void ratio of 0.59 . The penetration tests performed in $\mathrm{P} 2$ focused mainly on identifying the transition between partially drained and fully drained conditions. A profile of cone resistance obtained from the reference cone is shown in Figure 5.9. Profiles of the minicone penetration test results conducted on P2 with 8 penetration rates are summarized in Table 4.6 and are shown in Figure 5.10(a) through (h). The steady state values of $\mathrm{q}_{\mathrm{t}}$, pore pressure, and $\mathrm{f}_{\mathrm{s}}$ averaged from a depth of 5D to the end of the test are summarized in Table 5.3 and are displayed in Figure 5.11.

For penetration rates of $20 \mathrm{~mm} / \mathrm{s}$ and $2 \mathrm{~mm} / \mathrm{s}$, the values of $\mathrm{q}_{\mathrm{t}}$ were almost equal (1.28 $\mathrm{MPa}$ and $1.34 \mathrm{MPa}$ ). However, the excess pore pressure decreased by about $40 \%$ for this change in penetration speed. This excess pore pressure difference indicates that even with the $20 \mathrm{~mm} / \mathrm{s}$ maximum penetration speed, the penetration was likely not fully undrained, and it certainly was not for $2 \mathrm{~mm} / \mathrm{s}$. The similar values of $\mathrm{q}_{\mathrm{t}}$ measured for penetration rates of $20 \mathrm{~mm} / \mathrm{s}$ and $2 \mathrm{~mm} / \mathrm{s}$ were due to the offsetting effects of greater drainage versus lower shear strength resulting from slower penetration. The transition from partially drained to fully drained conditions took place for a penetration rate of about 0.1 $\mathrm{mm} / \mathrm{s}$. The average $\mathrm{q}_{\mathrm{t}}$ at fully drained conditions, for penetration rates of $0.1 \mathrm{~mm} / \mathrm{s}$ and $0.05 \mathrm{~mm} / \mathrm{s}$, was around $4 \mathrm{MPa}$. This value is about three times the $\mathrm{q}_{\mathrm{t}}$ measured under undrained conditions.

Measured sleeve friction $f_{s}$ is shown in Figure 5.12. The increased values of $f_{s}$ at $0.1 \mathrm{~mm} / \mathrm{sec}$ and $0.05 \mathrm{~mm} / \mathrm{sec}$ produce a plot resembling the backbone curve observed for $\mathrm{q}_{\mathrm{t}}$.

Table $5.3 \mathrm{q}_{\mathrm{t}}, \mathrm{u}$, and $\mathrm{f}_{\mathrm{s}}$ for various penetration rates in $\mathrm{P} 2$.

\begin{tabular}{c||cccccccc}
\hline Penetration rate $(\mathrm{mm} / \mathrm{sec})$ & 20 & 10 & 2 & 1 & 0.5 & 0.2 & 0.1 & 0.05 \\
\hline $\mathrm{q}_{\mathrm{t}}(\mathrm{MPa})$ & 1.28 & 1.34 & 1.65 & 2.28 & 2.78 & 3.49 & 3.99 & 3.9 \\
Pore pressure $(\mathrm{kPa})$ & 246 & 219.1 & 145.8 & 103.3 & 48.2 & 23.9 & 6.26 & 6.26 \\
Sleeve friction $\mathrm{f}_{\mathrm{s}}(\mathrm{kPa})$ & 6.9 & 10.2 & 7.0 & 11.6 & 10.8 & 13.3 & 15.8 & 16.7 \\
\hline
\end{tabular}




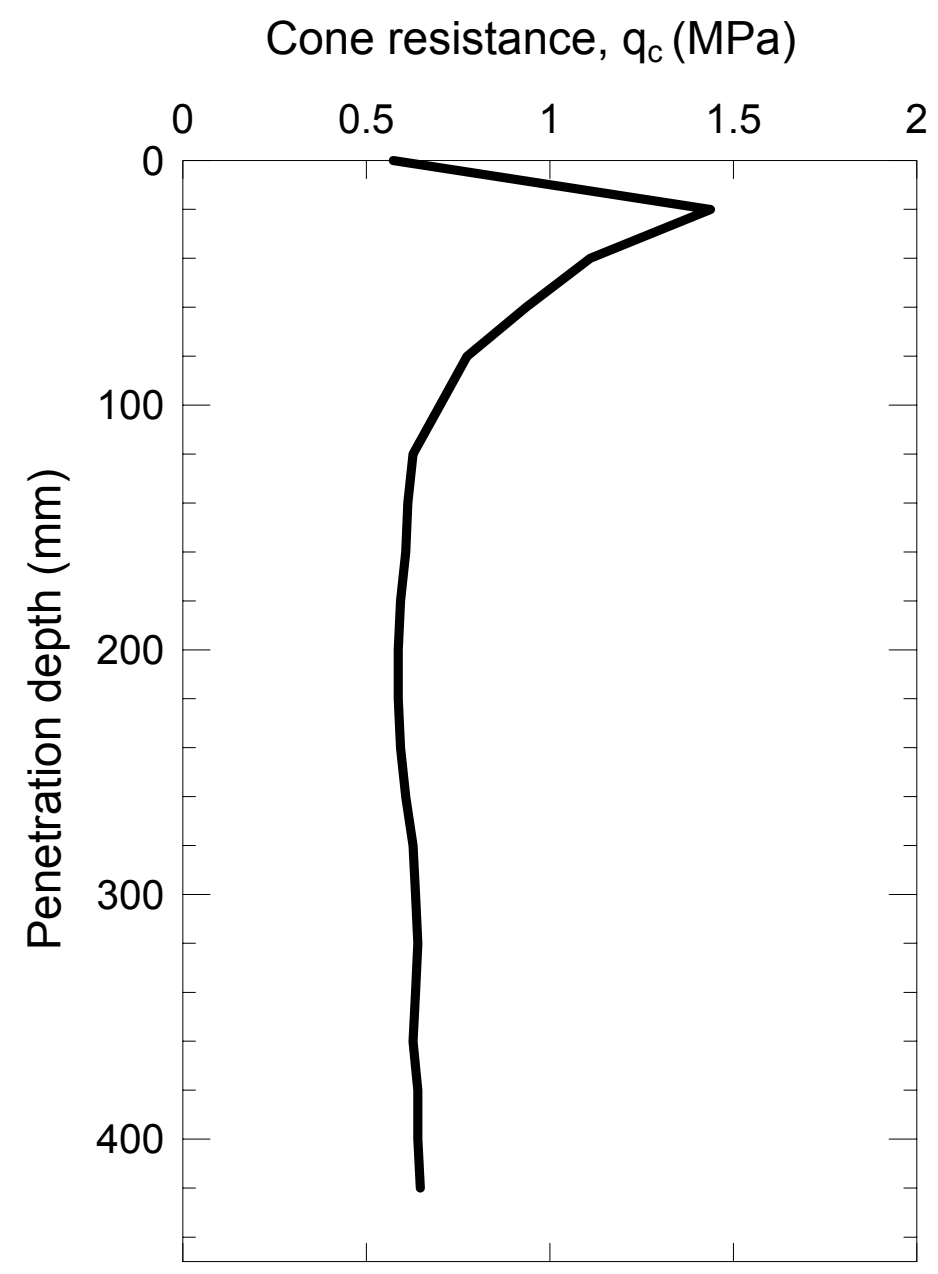

Figure 5.9 Cone resistance of reference cone penetration test on P2 $(\mathrm{v}=20 \mathrm{~mm} / \mathrm{sec})$. 


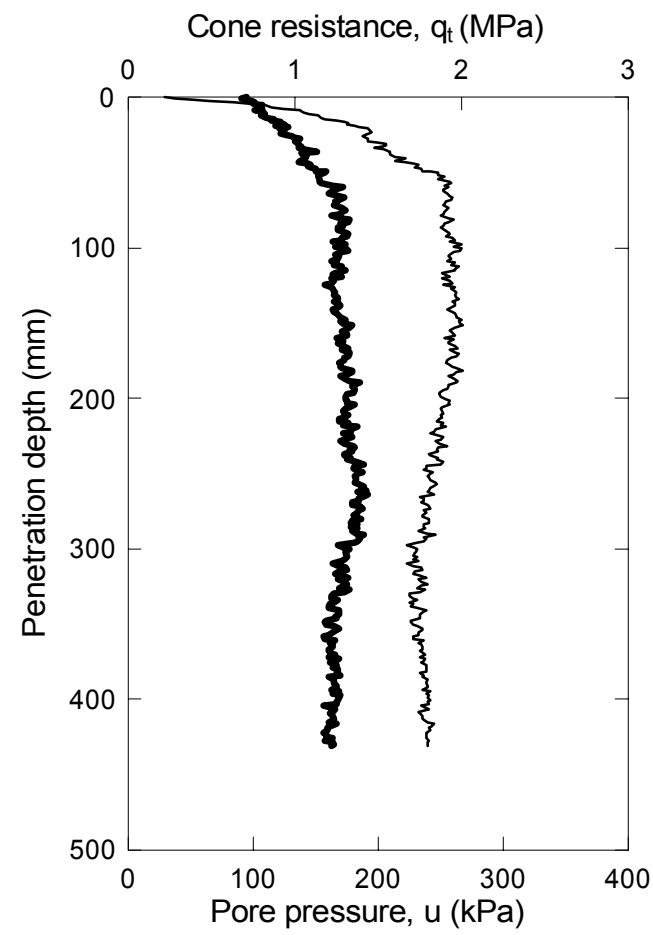

(a) Penetration rate: $20 \mathrm{~mm} / \mathrm{sec}$

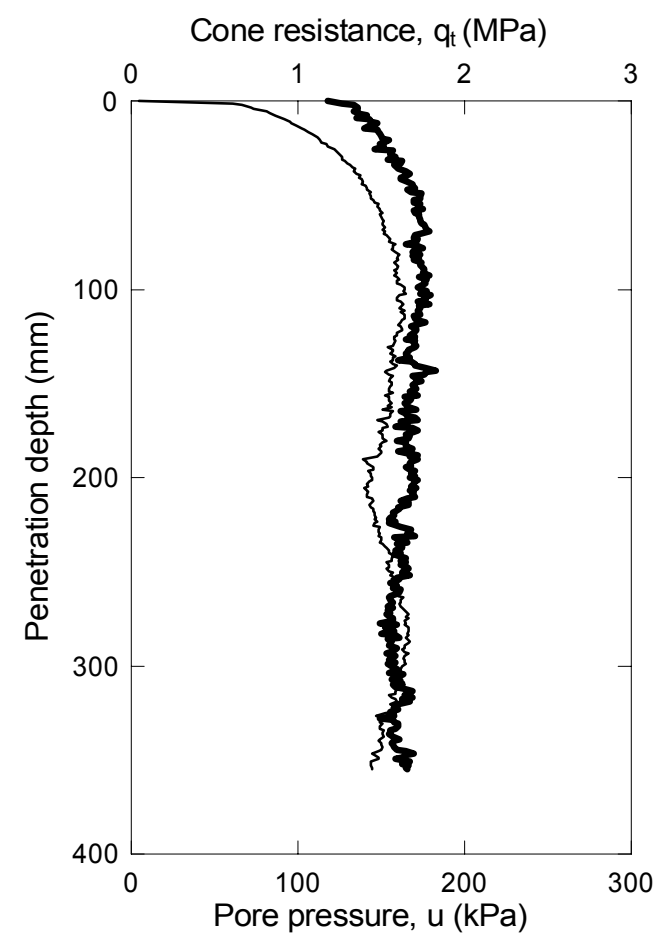

(c) Penetration rate: $2 \mathrm{~mm} / \mathrm{sec}$

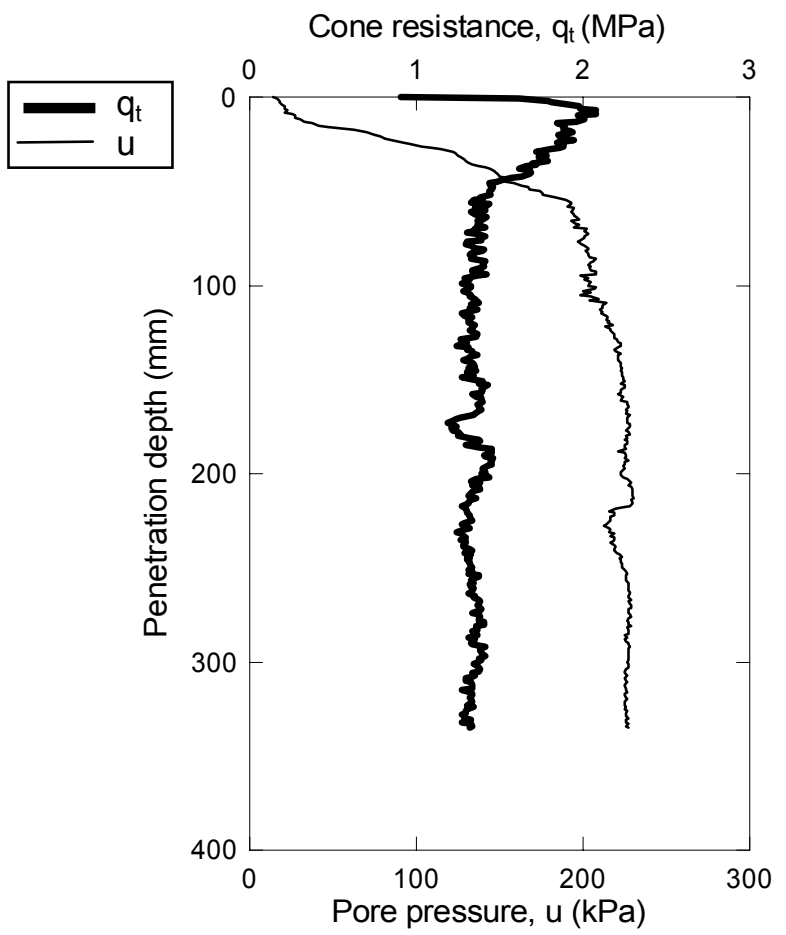

(b) Penetration rate: $8 \mathrm{~mm} / \mathrm{sec}$

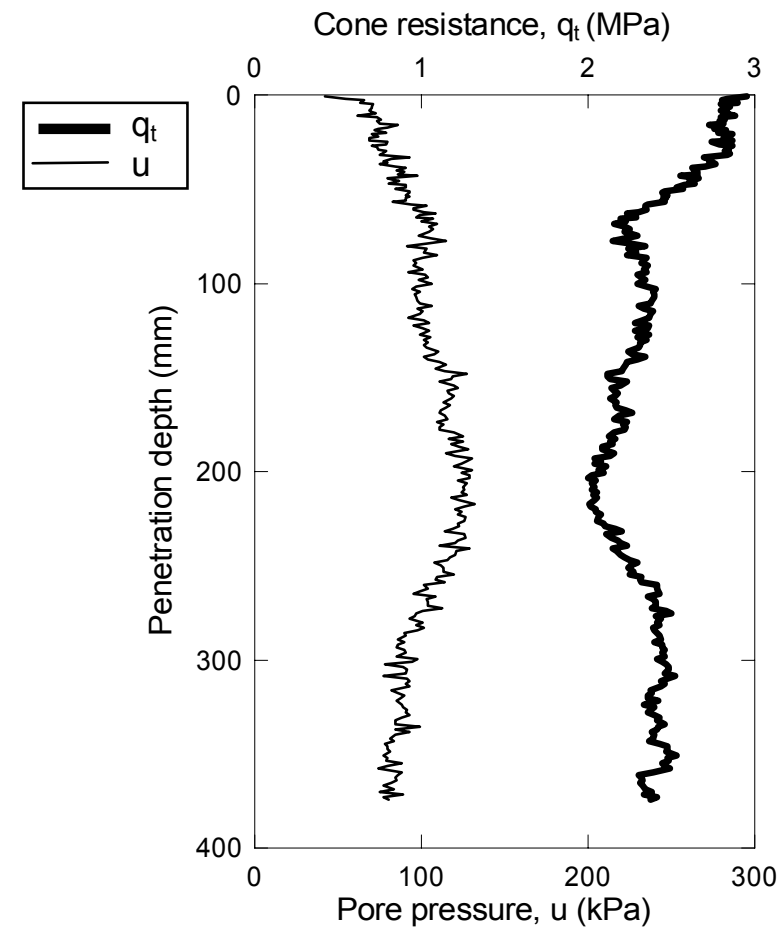

(d) Penetration rate: $1 \mathrm{~mm} / \mathrm{sec}$

Figure 5.10 Minicone penetration test results in P2. 

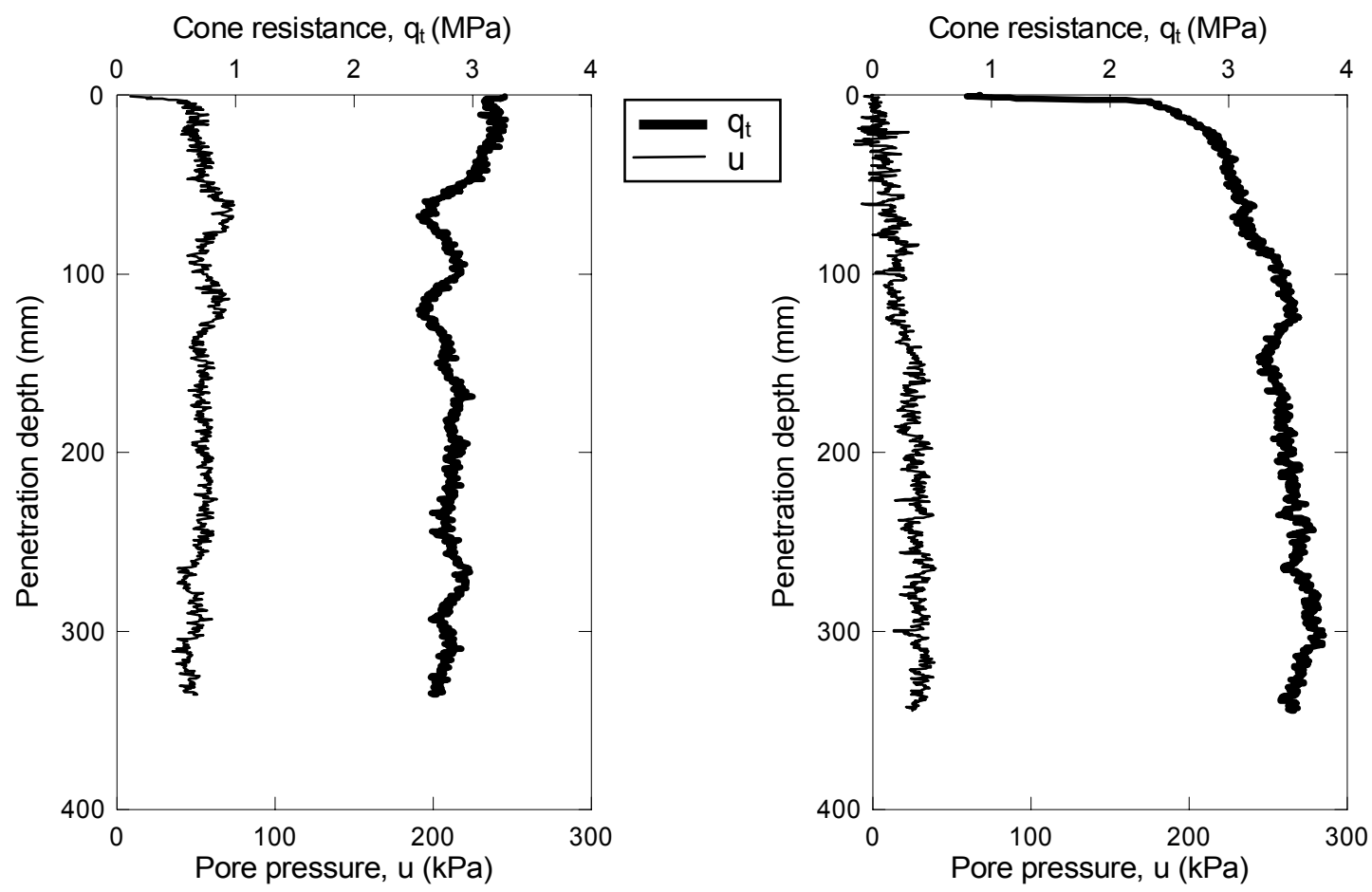

(e) Penetration rate: $0.5 \mathrm{~mm} / \mathrm{sec}$

(f) Penetration rate: $0.2 \mathrm{~mm} / \mathrm{sec}$

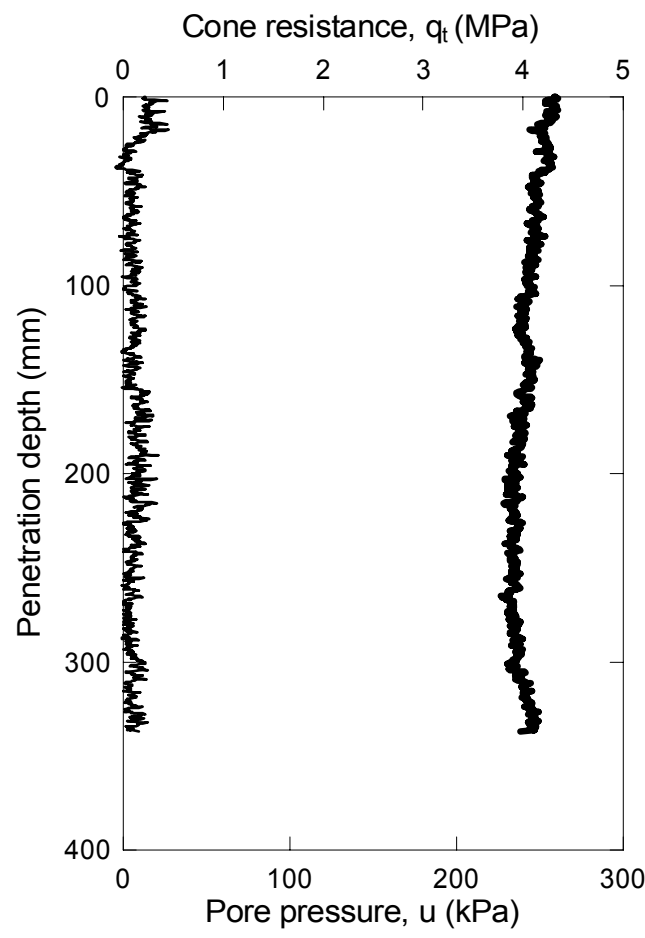

(g) Penetration rate: $0.1 \mathrm{~mm} / \mathrm{sec}$

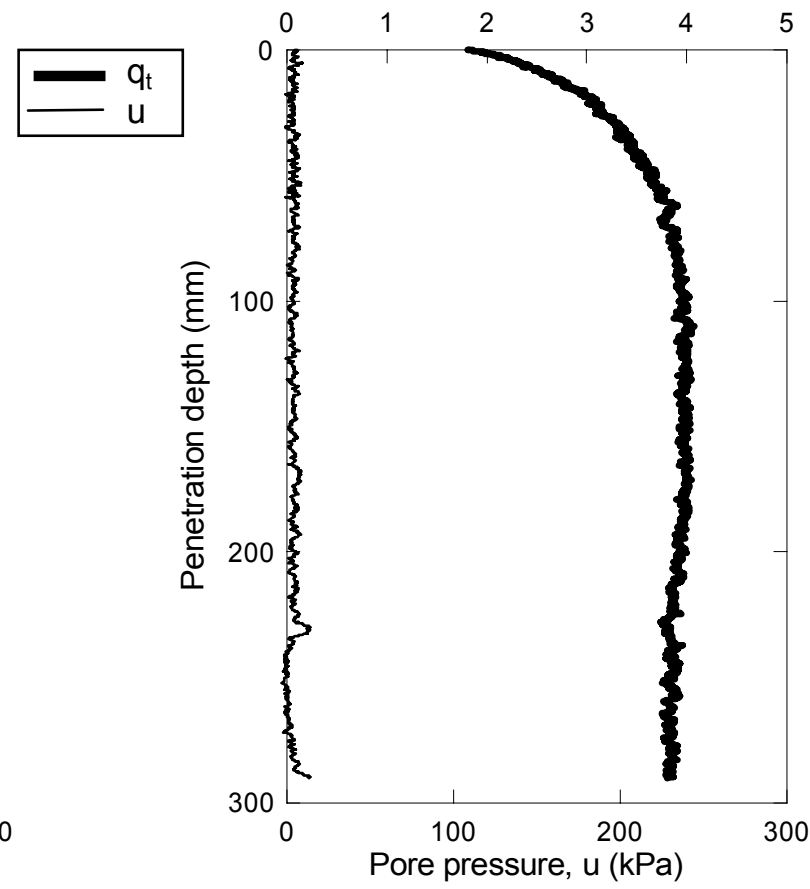

(h) Penetration rate: $0.05 \mathrm{~mm} / \mathrm{sec}$

Figure 5.10 Minicone penetration test results in P2 (continued). 


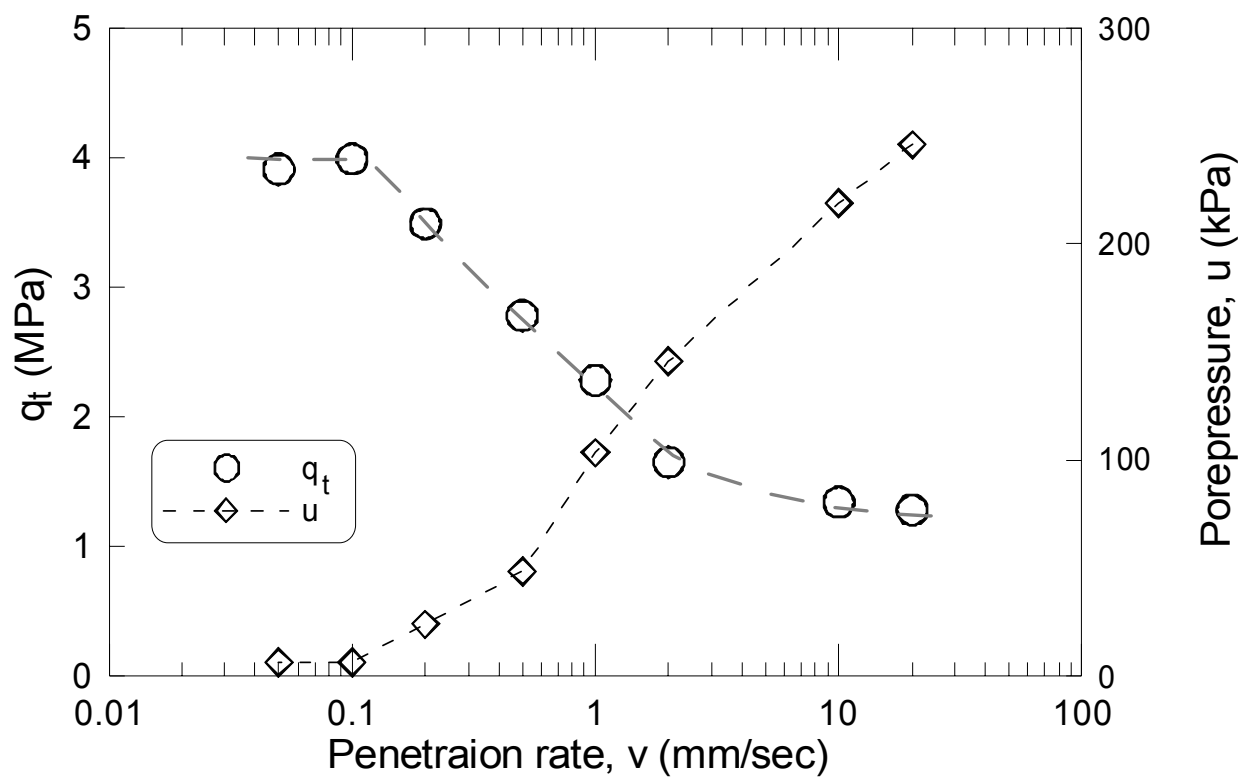

Figure 5.11 Effect of penetration rate on $\mathrm{q}_{\mathrm{t}}$ and pore pressure in $\mathrm{P} 2$.

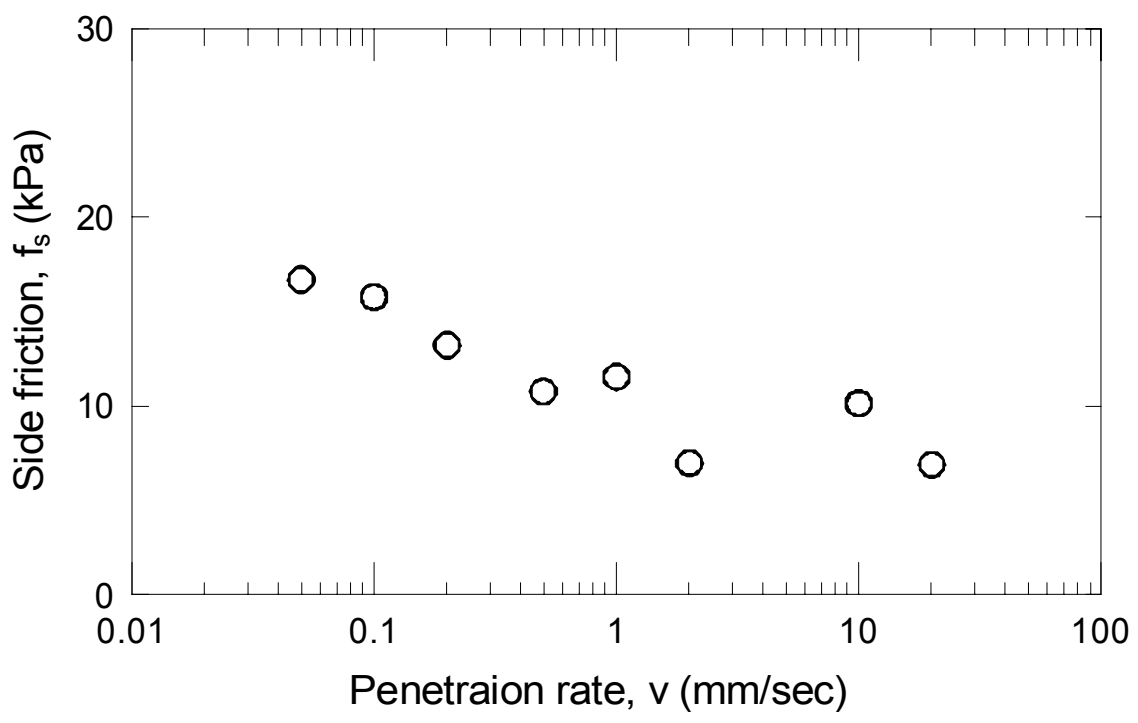

Figure 5.12 Effect of penetration rate on sleeve friction in P2. 


\subsection{Flat Tip Penetration Test Results in $\mathrm{P} 2$}

The profiles of tip resistance and pore pressure with the flat tip for 5 different penetration rates are shown at Figure 5.13. Average steady-state values of tip resistance, pore pressure, and $\mathrm{f}_{\mathrm{s}}$ are summarized in Table 5.4, and displayed in Figure 5.14 with the results for the normal cone tip.

The shape of the tip influenced the values measured in the penetration tests performed in $\mathrm{P} 2$. For $\mathrm{v}=20 \mathrm{~mm} / \mathrm{s}$, the resistance of the flat tip was $2.1 \mathrm{MPa}, 64 \%$ higher than the cone resistance measured at the same speed. Over the whole range of penetration rates, the flat tip resistance values were higher than the corresponding cone resistance values, but this difference reduced as drainage increased. Under fully drained conditions, for $\mathrm{v}=0.1 \mathrm{~mm} / \mathrm{s}$, the flat tip resistance was $4.4 \mathrm{MPa}$ and the cone resistance was $4.0 \mathrm{MPa}$, a much more modest difference, practically justifying an assumption often made for sands that $\mathrm{q}_{\mathrm{c}} \approx \mathrm{q}_{\mathrm{bL}}$, where $\mathrm{q}_{\mathrm{bL}}$ is the limit unit base resistance of a pile in sand under the same conditions as those under which $\mathrm{q}_{\mathrm{c}}$ was measured. Also, the observed drainage transition zones for the flat tip are somewhat narrower than those for the cone. However, only a small difference in the excess pore pressure measurements was observed.

Average values of $f_{s}$ versus penetration rates are shown in Figure 5.15. As indicated in the figure, values of $f_{s}$ are scattered and do not show a clear trend with penetration rate.

Table 5.4 Values of $\mathrm{q}_{\mathrm{t}}$, pore pressure, and $\mathrm{f}_{\mathrm{s}}$ for various penetration rates with a flat tip.

\begin{tabular}{c||ccccc}
\hline Penetration rate $(\mathrm{mm} / \mathrm{sec})$ & 20 & 5 & 1 & 0.2 & 0.1 \\
\hline $\mathrm{q}_{\mathrm{t}}(\mathrm{MPa})$ & 2.1 & 2.08 & 2.53 & 4.51 & 4.37 \\
Pore pressure $(\mathrm{kPa})$ & 245.3 & 162.1 & 49.9 & 16.5 & 3.1 \\
Sleeve friction $\mathrm{f}_{\mathrm{s}}(\mathrm{kPa})$ & 13.42 & 6.47 & 6.32 & 8.18 & 6.58 \\
\hline
\end{tabular}




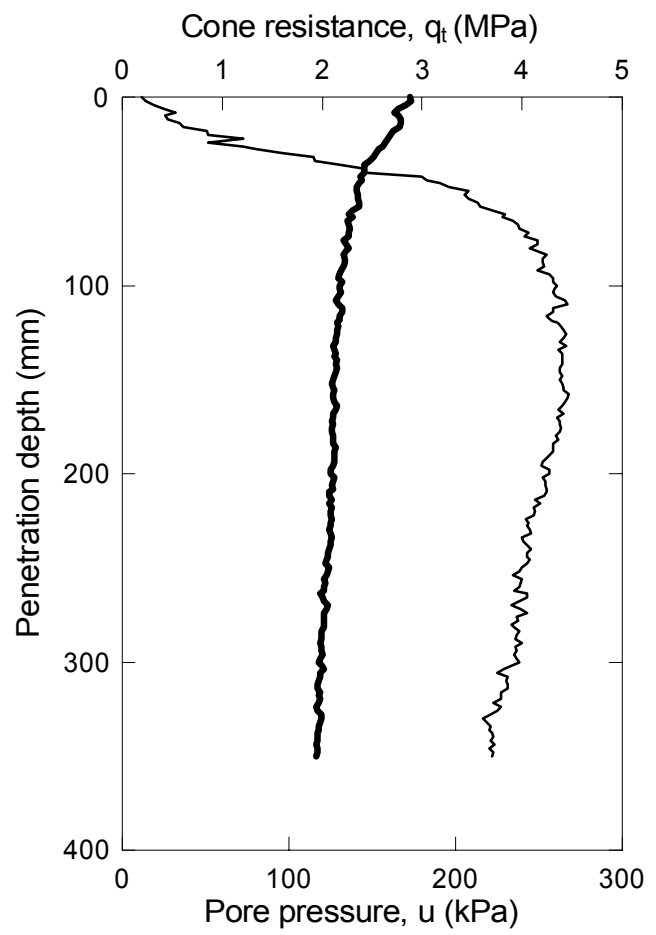

(a) Penetration rate: $20 \mathrm{~mm} / \mathrm{sec}$

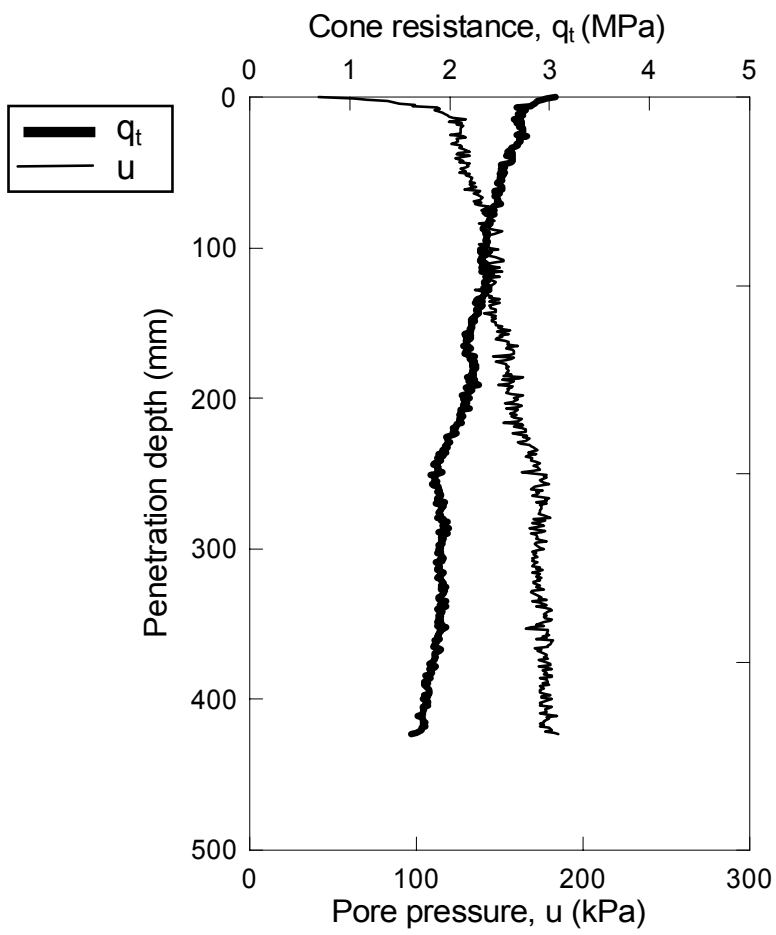

(b) Penetration rate: $5 \mathrm{~mm} / \mathrm{sec}$

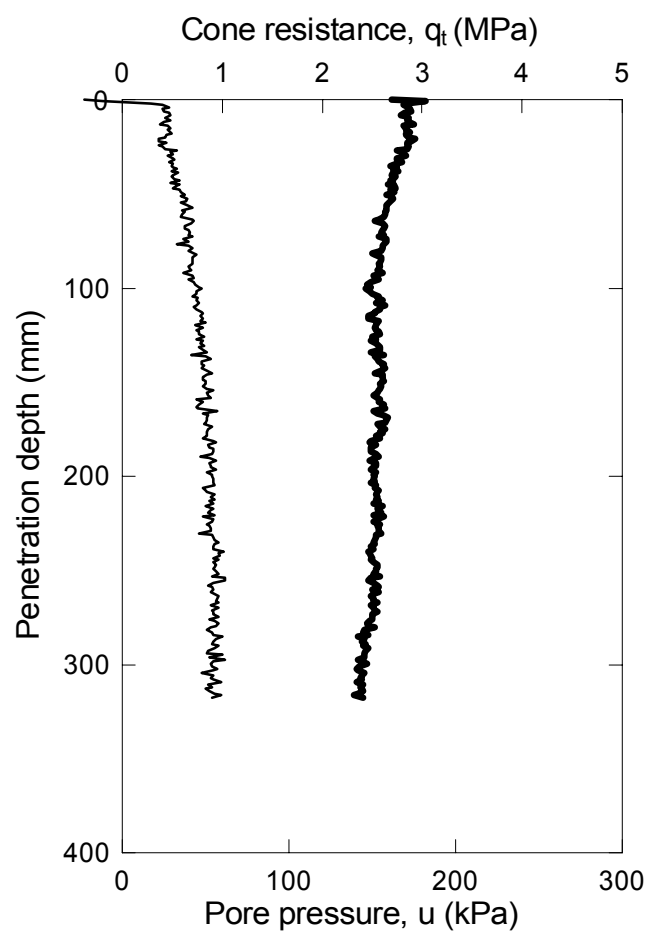

(c) Penetration rate: $1 \mathrm{~mm} / \mathrm{sec}$

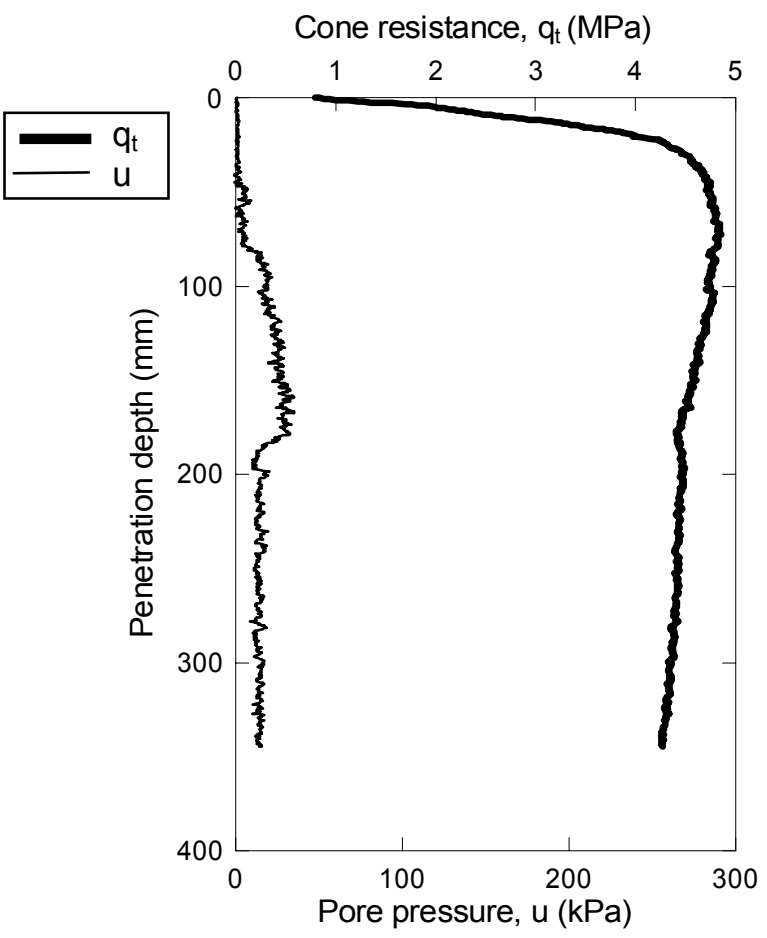

(d) Penetration rate: $0.2 \mathrm{~mm} / \mathrm{sec}$

Figure 5.13 Minipile penetration test results in P2. 


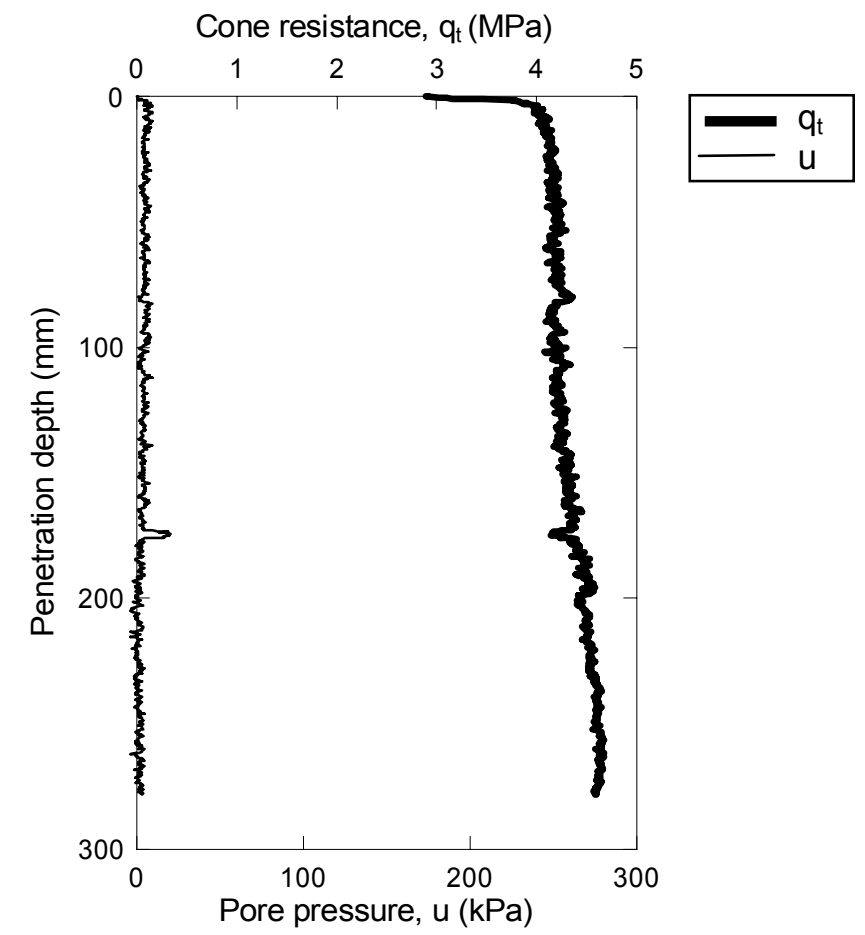

(e) Penetration rate: $0.1 \mathrm{~mm} / \mathrm{sec}$

Figure 5.13 Minipile penetration test results in P2 (continued). 


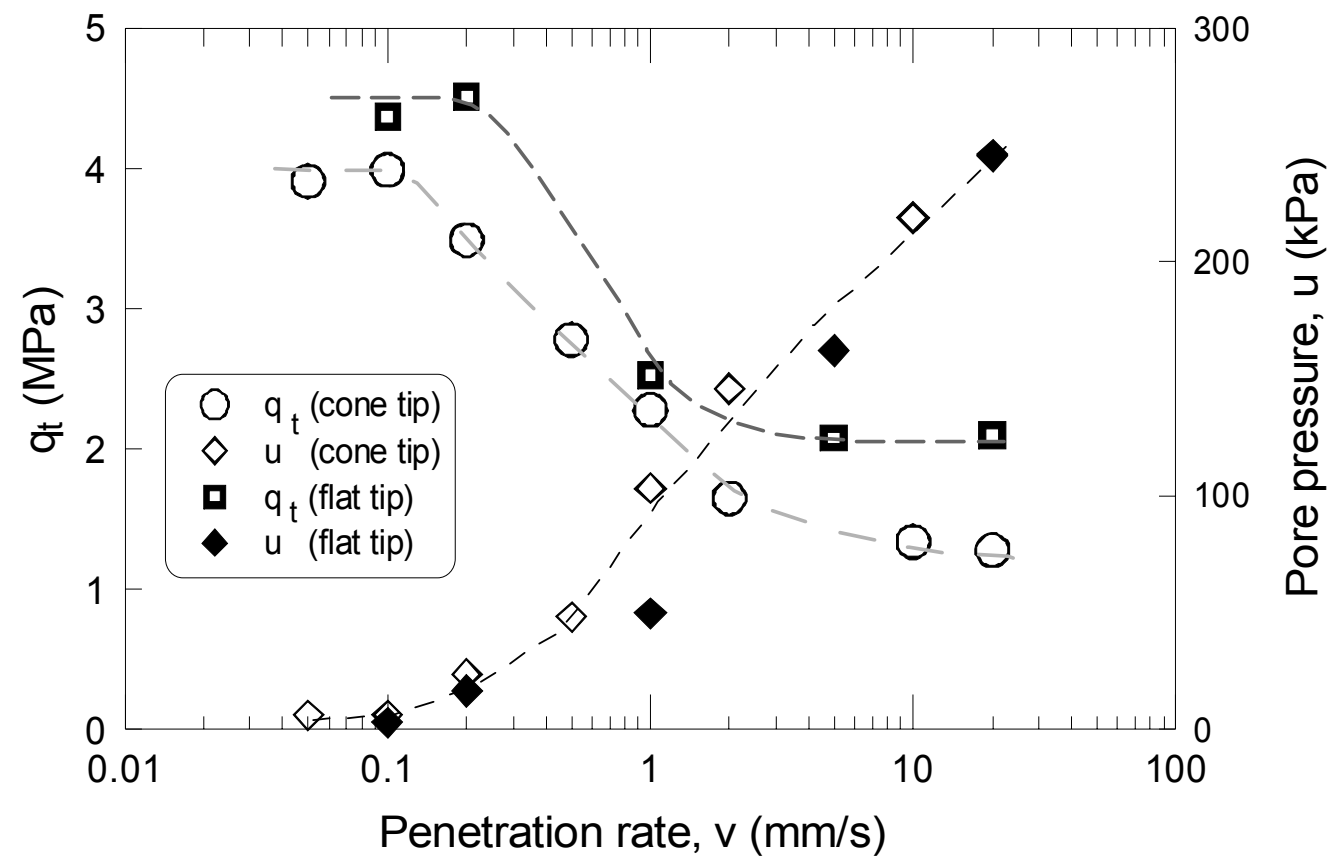

Figure 5.14 Effect of penetration rate on $\mathrm{q}_{\mathrm{t}}$ and $\mathrm{U}$ in $\mathrm{P} 2$.



Figure 5.15 Effect of penetration rate on sleeve friction in $\mathrm{P} 2$. 


\subsection{Determination of $\mathrm{c}_{\mathrm{v}}$}

As discussed earlier, the normalized penetration rate $\mathrm{V}$ is the appropriate nondimensional velocity for assessing the degree of consolidation during cone penetration. $\mathrm{V}$ is calculated as $\mathrm{vd} / \mathrm{c}_{\mathrm{v}}$ (Eq. 2.25). Since the penetration rate $\mathrm{v}$ and the cone diameter $\mathrm{d}$ are given, $\mathrm{c}_{\mathrm{v}}$ is the critical factor to accurately determine $\mathrm{V}$. The values of $\mathrm{c}_{\mathrm{v}}$ for $\mathrm{P} 1$ and $\mathrm{P} 2$ were obtained by four different methods: the flexible-wall permeability test, the 1D consolidation test, the data obtained from the calibration chamber specimen consolidation, and the data obtained from triaxial consolidation of specimens extracted from the calibration chamber. These values are all shown in Table 5.5.

\section{(1) Flexible wall permeability test}

As described in Chapter 4, several flexible-wall permeability tests had been performed initially on samples with different clay and sand percentages. The mixing ratios for $\mathrm{P} 1$ and $\mathrm{P} 2$ were decided based on the obtained $\mathrm{c}_{\mathrm{v}}$ from the tests. The values of $\mathrm{c}_{\mathrm{v}}$ from the permeability tests were $0.0381 \mathrm{~cm}^{2} / \mathrm{sec}$ for the mixing ratio used in $\mathrm{P} 1$ and $0.571 \mathrm{~cm}^{2} / \mathrm{sec}$ for the mixing ratio used in $\mathrm{P} 2$. As stated in section 4.3 , the flexible wall permeability test is a very effective method for evaluating accurate values of $c_{v}$. One thing that can reduce the reliability of the result from this test is the fact that reconstituted soil samples were used. Although a similar process was used for the preparation of the reconstituted test samples, small differences in the reconstitution technique can influence consolidation properties of the soil samples. Also, this test was performed under isotropic confining stress, while the specimens for the cone penetration test were made under $\mathrm{K}_{\mathrm{o}}$ condition. Therefore, the obtained values of $\mathrm{c}_{\mathrm{v}}$ from this test are not perfect for the evaluation of $\mathrm{V}$. 
(2) Oedometer test

After the chamber tests, soil samples were carefully collected using thin wall tubes and several sets of single drainage oedometer tests were performed. The same equipment and test procedure described in section 3.2.1.2 were used for this test. The bottom drainage line was locked and only upward drainage was allowed to extend the drainage length of the sample so that more accurate $c_{v}$ values could be obtained. The specimens for the oedometer tests were $25.4 \mathrm{~mm}$ thick and had a diameter of $63.5 \mathrm{~mm}$. Specimens were loaded in increments up to maximum applied vertical stresses of 1.6 MPa. Two graphical methods, logarithm of time method and square root of time method were used to obtain $\mathrm{c}_{\mathrm{v}}$ values. The average values of $\mathrm{c}_{\mathrm{v}}$ obtained by the two graphical methods, were $0.0424 \mathrm{~cm}^{2} / \mathrm{sec}$ for the soil samples from $\mathrm{P} 1$ and $0.314 \mathrm{~cm}^{2} / \mathrm{sec}$ for the samples from P2.

\section{(3) Consolidation stage of triaxial tests}

Triaxial consolidation before starting compression in the CU test can also be carried out for the determination of $\mathrm{c}_{\mathrm{v}}$. The end of consolidation time could be obtained by a procedure similar to the square-root time method. The value of $\mathrm{c}_{\mathrm{v}}$ was calculated by Eq. $5.1($ Head 1986):

$$
c_{v}=\frac{\pi D^{2}}{4 t_{100}}
$$

The values of $\mathrm{c}_{\mathrm{v}}$ from this method are $0.0169 \mathrm{~cm}^{2} / \mathrm{sec}$ for $\mathrm{P} 1$ and $0.208 \mathrm{~cm}^{2} / \mathrm{sec}$ for P2.

\section{(4) Chamber test consolidation stage}

After the initial consolidation of the slurry in the consolidometer, reconsolidation of the calibration chamber sample was performed under $\mathrm{K}_{0}$ conditions. The vertical consolidation stress was increased from $200 \mathrm{kPa}$ to $230 \mathrm{kPa}$ in this stage, and the vertical 
displacement during consolidation was measured over time. This consolidation was conducted under perfect 1D conditions, without sidewall resistance. Therefore, the consolidation data obtained from this stage can be regarded as a scaled-up 1D consolidation. Moreover, the data was produced from the original and undisturbed soil sample under the same stress conditions as those applied during the penetration tests. The values of $\mathrm{c}_{\mathrm{v}}$ obtained from these data are the most appropriate values to use in calculations. Figure 5.16 (a) and (b) shows the $\mathrm{K}_{0}$-consolidation results for specimens P1 and P2 from the calibration chamber test consolidation stage. The values of $\mathrm{c}_{\mathrm{v}}$ are equal to $3.53 \times 10^{-6}$ $\mathrm{m}^{2} / \mathrm{s}$ for $\mathrm{P} 1$ and $3.12 \times 10^{-5} \mathrm{~m}^{2} / \mathrm{s}$ for $\mathrm{P} 2$.

Table $5.5 \mathrm{c}_{\mathrm{v}}$ values from several different tests.

\begin{tabular}{c||cc}
\hline $\mathrm{c}_{\mathrm{v}}\left(\mathrm{cm}^{2} / \mathrm{sec}\right)$ & $\mathrm{P} 1(25 \%$ clay $+75 \%$ sand $)$ & $\mathrm{P} 2(18 \%$ clay $+82 \%$ sand $)$ \\
\hline flexible wall test & 0.0381 & 0.571 \\
oedometer & 0.0424 & 0.314 \\
Triaxial test & 0.0169 & 0.208 \\
chamber test & $\mathbf{0 . 0 3 5 3}$ & $\mathbf{0 . 3 1 2}$ \\
\hline
\end{tabular}






(a) 1D-consolidation in P1



(b) 1D-consolidation in P2

Figure 5.16 Calibration chamber $\mathrm{K}_{0}$-consolidation test. 


\subsection{Normalized Penetration versus Normalized Penetration Rates}

The results of penetration tests in the calibration chamber may be presented as a plot of normalized cone resistance $q_{t} / \sigma_{v}^{\prime}$ versus the normalized rate $\mathrm{V}$. The normalized results for $\mathrm{P} 1$ and $\mathrm{P} 2$ are shown in Fig. 5.17, as a function of $\log \mathrm{V}$. The plots suggest that the cone resistance increases when $\mathrm{V}$ drops below approximately 1, with the transition between partially drained and fully drained conditions occurring around $\mathrm{V}=0.05$. The effect of cone penetration rate on the excess pore pressure measured is shown in Fig. 5.17 (b). In this graph, it may be seen that the transition from undrained to partially drained penetration occurs around $\mathrm{V} \approx 10$, and the transition from partially drained to fully drained conditions occurs around $\mathrm{V}=0.05$. We identify the transition from fully drained to partially drained conditions at $\mathrm{V}=0.05$ by observing both the stabilization of cone resistance as $\mathrm{V}$ drops below that value and the disappearance of the excess pore pressure. The plot of pore pressure versus normalized penetration rate shows that the transition from undrained to partially drained conditions occurs at about $\mathrm{V} \approx 10$; however, if all we are interested in is the stabilization of cone resistance at a low value associated with undrained penetration, this transition is observed at about $\mathrm{V} \approx 1$ in the normalized cone resistance versus penetration rate graph. For $1 \leq \mathrm{V} \leq 10$, we have the "offset range" discussed earlier,

within which gains in $\mathrm{q}_{\mathrm{c}}$ due to faster loading rates offset the drops due to the decreasing opportunity for drainage during penetration. These transition limits are similar to the ones observed in the field tests discussed earlier. 


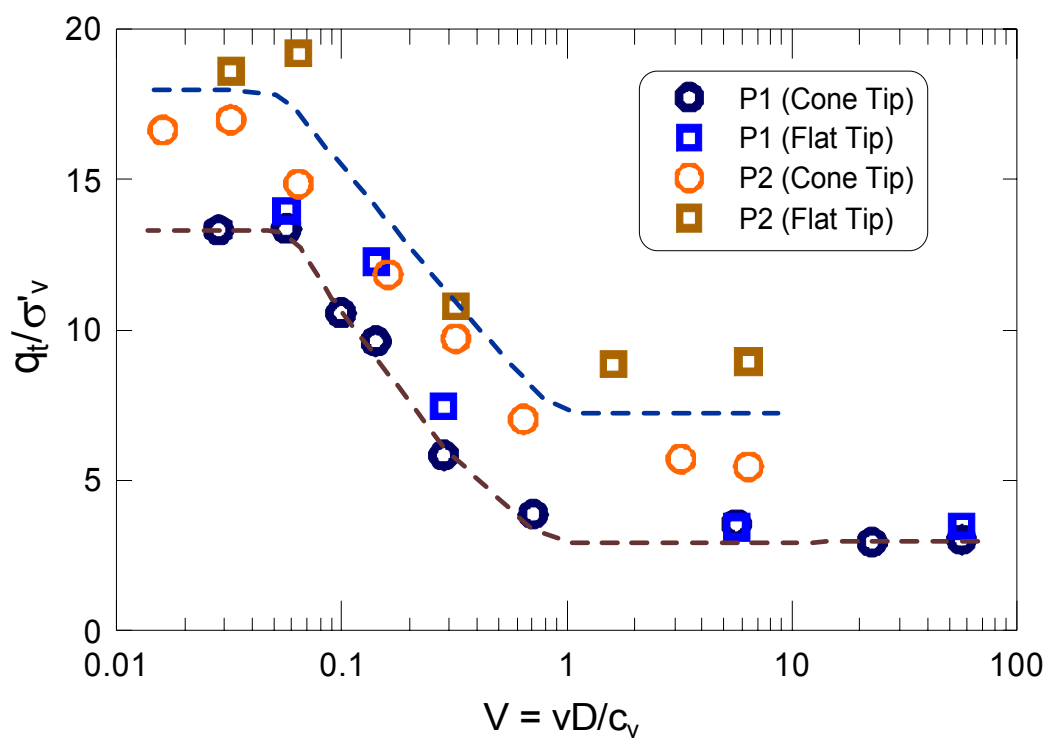

(a)

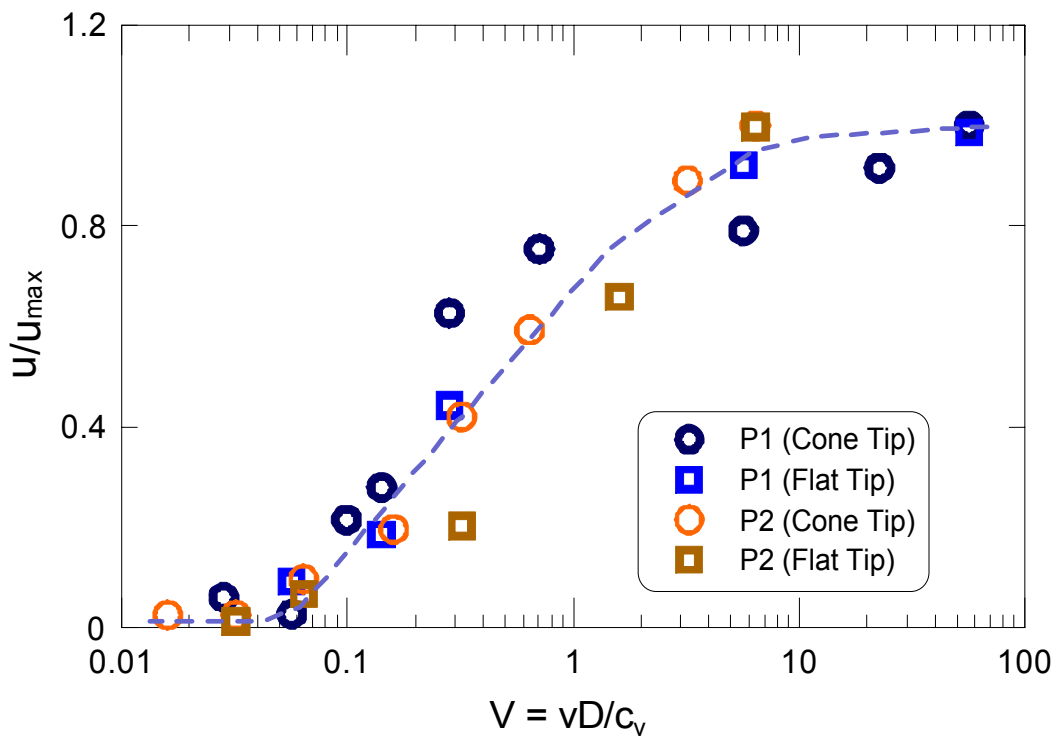

(b)

Figure 5.17 Variation of (a) normalized cone resistance and (b) normalized excess pore pressure, with normalized penetration rate.

\subsection{Summary}

In this chapter, the results of the cone penetration tests in the calibration chamber and their interpretation were presented. The standard cone, the miniature cone with a 
conical tip and miniature flat-tip penetrometer were used for the penetration tests in two different specimens. From the results of penetration tests in the calibration chamber, the correlation between cone resistance and drainage condition was proved and quantified. When the drainage condition was changed from undrained to fully drained, cone resistance increased 4 times $(\mathrm{P} 1)$ and 3.1 times $(\mathrm{P} 2)$, and excess pore pressure decreased to zero. The transition between undrained and partially drained conditions based on $\mathrm{q}_{t}$ observations takes place for $\mathrm{V}$ around 1; the transition between partial and full drainage (based on pore pressure observations) happens for $\mathrm{V}$ approximately equal to 10 . In the range from 1 to 10 drainage effects are partially offset by rate effects on shear strength. The transition between partially drained and fully drained penetration takes place at $\mathrm{V} \approx 0.05$.

The penetration results obtained using the flat-tip penetrometer in P1 showed that the values of tip resistance and pore pressure from the flat-tip penetrometer correspond to those from the conical tip at the same speed. Also the same transition points as the ones obtained by the conical tip were observed in the drainage curve. On the other hand, the penetration test with the flat-tip penetrometer in P2 showed different results. The tip resistance for a rate of penetration of $20 \mathrm{~mm} / \mathrm{s}$ was $64 \%$ higher than the cone resistance for the normal tip at the same speed. Tip resistance was higher than cone resistance for all penetration rates. These results suggest that the tip shape can affect the tip resistance in soil with non-floating fabric at relatively high rates of penetration. At low penetration rates, the tip resistance is nearly the same for conical and flat tips. 


\section{CHAPTER 6. DETERMINATION OF CONE PENETRATION RATE EFFECTS AND CONE FACTOR $\mathbf{N}_{\mathbf{k}}$}

\subsection{Rate Effects in Cone Penetration Testing}

As illustrated by the field and calibration chamber cone penetration tests, there is a rate effect on the cone measurements during penetration. Conclusions reached in previous chapters for the undrained, partially drained and drained penetration ranges are discussed next together with considerations concerning the shear strength at various rates of loading.

A series of penetration tests performed in the field and in a calibration chamber using a miniature cone have shown that there are rate effects on cone measurements made during penetration. The change in drainage conditions during penetration is the main cause of the rate effects. The rate effects can be discussed separately for the undrained, partially drained and fully drained penetration ranges:

(1) Undrained penetration: the undrained behavior of clayey soils is rate-dependent (the higher the loading rate, the higher the $s_{u}$ of the clay). This is due to the fact that clay has a viscous strength component. Thus, if CPTs are performed in clayey soils at various rates under undrained conditions, the test results are affected by the "viscosity" of the clayey soil. The field test results illustrate this viscous effect. The average $\mathrm{q}_{\mathrm{t}}$ for $\mathrm{v}=20 \mathrm{~mm} / \mathrm{s}$, obtained between $7.4 \mathrm{~m}$ and $8.4 \mathrm{~m}$ at the SR 18 site under undrained conditions, was $20 \%$ higher than that for $\mathrm{v}=1 \mathrm{~mm} / \mathrm{s}$.

(2) Partially drained penetration: When drainage conditions change from undrained to partially drained during penetration, the soil around the cone starts to consolidate as the cone advances. Thus, $\mathrm{q}_{\mathrm{c}}$ increases due to the increase in soil shear strength around the cone tip. The change of cone resistance and pore pressure under partially drained conditions was examined through the field CPTs and the calibration chamber penetration tests. It is clear that observation of the cone resistance alone does not allow 
establishing the rate at which penetration changes from undrained to partially drained. This is because the gain in soil strength due to increased drainage during penetration is very closely balanced over a range of penetration rates by the drop in strength due to lower loading rates. So the transition from undrained to partially drained conditions observed from pore pressure changes does not coincide with the pattern of variation of cone resistance. The transition from a stable, low $\mathrm{q}_{\mathrm{t}}$ value (associated with undrained penetration) to increasingly higher values with decreasing penetration rates occurs at $\mathrm{V}$ of about 1 for our calibration chamber tests and at about 4 for our field tests, whereas the transition from undrained to partially drained conditions as estimated from excess pore pressure readings occurred for $\mathrm{V}$ of about 10 for both the field and calibration chamber tests. The transition from partially drained to fully drained penetration was only observed for the chamber penetration tests for a $\mathrm{V}$ of approximately 0.05 .

(3) Fully drained penetration: Under fully drained conditions, cone penetration results are not affected by penetration rate change. The chamber test results obtained under fully drained conditions showed that the same cone resistances are obtained regardless of the penetration rate.

Fig. 6.1 shows a summary plot of $\mathrm{q}_{\mathrm{t}} / \sigma_{\mathrm{v}}^{\prime}$ versus normalized penetration rate. The boundaries between drained, partially drained and fully drained conditions are represented by the solid vertical lines shown in the figure. The standardized cone penetration rate and diameter are $20 \mathrm{~mm} / \mathrm{s}$ and $35.7 \mathrm{~mm}$ (IRTP, ASTM D 5778). The results may be used to obtain the limiting values of $\mathrm{c}_{\mathrm{v}}$ that soils would have to have for penetration to take place under drained and undrained conditions for these standard values of penetration rate and cone diameter used in practice. As discussed previously, the drainage conditions change from undrained to partially drained at a value of $\mathrm{V} \approx 10$, which corresponds to a $\mathrm{c}_{\mathrm{v}} \approx$ $7.1 \times 10^{-5} \mathrm{~m}^{2} / \mathrm{s}$ for the standard cone penetration rate and diameter. However, because of the offsetting effect of rate-dependent shear strength, the cone resistance starts to change at a value of $\mathrm{V} \approx 1$, which corresponds to a $\mathrm{c}_{\mathrm{v}} \approx 7.1 \times 10^{-4} \mathrm{~m}^{2} / \mathrm{s}$. Therefore, we can conclude that undrained cone resistance is expected to be measured in CPTs performed with the standard cone at the standard rate in soils having $c_{v}$ values lower than $7.1 \times 10^{-4} \mathrm{~m}^{2} / \mathrm{s}$. On the other 
end of the spectrum, our results suggest that a value of $c_{v}$ larger than about $1.4 \times 10^{-2} \mathrm{~m}^{2} / \mathrm{s}$ is necessary for fully drained conditions to be achieved with a standard CPT.

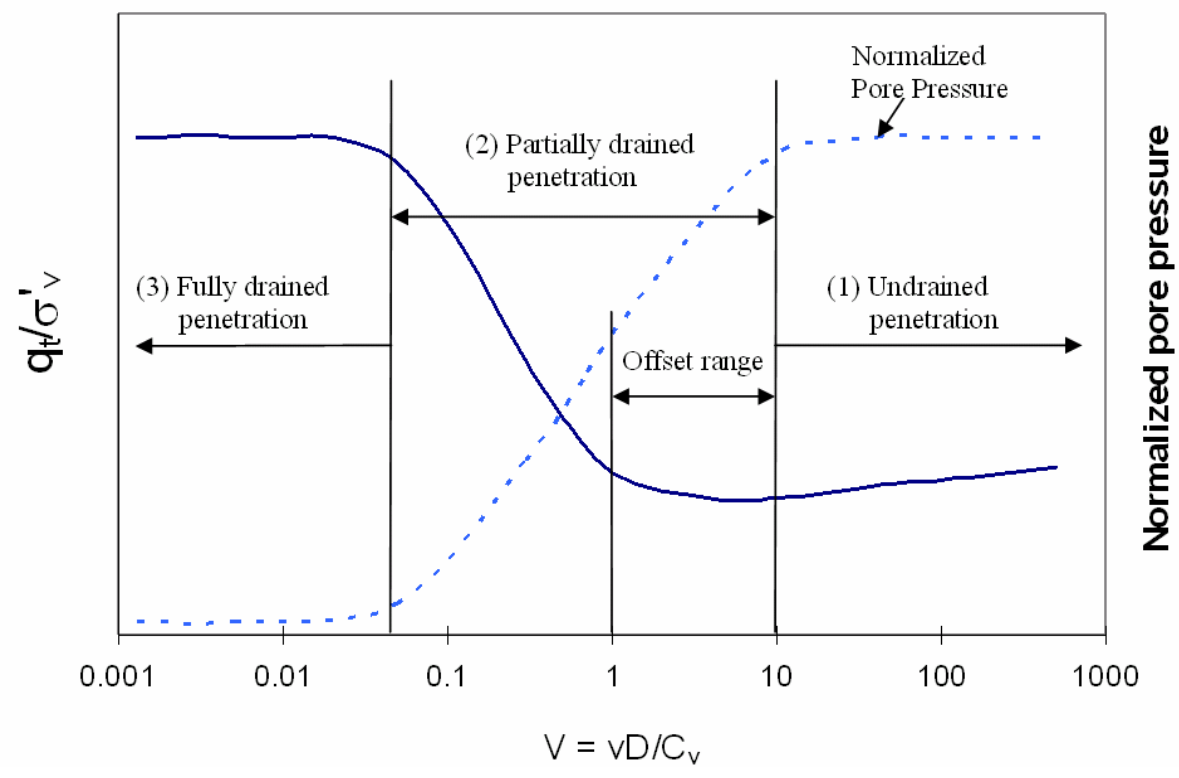

Figure 6.1 Effect of penetration rate on normalized cone resistance and pore pressure. 


\subsection{Criteria for Establishing Drainage Condition Rate Thresholds for CPT}

The standardized cone penetration rate and diameter are $20 \mathrm{~mm} / \mathrm{sec}$ and $35.7 \mathrm{~mm}$ (ASTM, IRTP). The transition points defined by normalized penetration rate in Figure 6.1 can be generalized by coefficient of consolidation for standard cone penetration tests using the standard penetration rate and diameter. Figure 6.2 shows normalized cone resistance change versus $\mathrm{c}_{\mathrm{v}}$ for the standard CPT. As discussed already, drainage condition changed from undrained to partially drained for $\mathrm{c}_{\mathrm{v}} \approx 7.14 \times 10^{-5} \mathrm{~m}^{2} / \mathrm{sec}$, which corresponds to $\mathrm{V} \approx 10$. However, cone resistance starts to increase from $\mathrm{c}_{\mathrm{v}} \approx 7.14 \times 10^{-4} \mathrm{~m}^{2} / \mathrm{sec}$ because of rate effects on the shear strength. Therefore, the cone resistance of standard CPTs performed in soil having $\mathrm{c}_{\mathrm{v}}$ values lower than $7.14 \times 10^{-4} \mathrm{~m}^{2} / \mathrm{sec}$ can be considered as undrained. Some example values of $c_{v}$ for soils containing small percentage of fines are shown in Table 6.1. The soil generally classified as "clay" usually has values of $c_{v}$ lower than $7.14 \times 10^{-4} \mathrm{~m}^{2} / \mathrm{sec}$. Therefore CPTs performed in soils containing high percentage of clay can be considered to be undrained. Based on the testing done for this thesis, the limit value of $c_{v}$ for drained condition in standard CPT is about $1.0 \times 10^{-2} \mathrm{~m}^{2} / \mathrm{sec}$. 
Table $6.1 \mathrm{c}_{\mathrm{v}}$ for soils containing small percentage of fines.

\begin{tabular}{|c|c|c|}
\hline Material & $\sigma_{3}^{\prime}(\mathrm{kPa})$ & $\mathrm{c}_{\mathrm{v}}\left(\mathrm{m}^{2} / \mathrm{sec}\right)$ \\
\hline \multirow{2}{*}{$\begin{array}{l}16 \% \text { kaolin clay with Jumun } \\
\text { sand }\end{array}$} & 100 & $3.08 \times 10^{-4}$ \\
\hline & 150 & $2.69 \times 10^{-4}$ \\
\hline \multirow{2}{*}{$\begin{array}{l}\text { 10\% kaolin clay with Ottawa } \\
\text { sand }\end{array}$} & 100 & $2.16 \times 10^{-4}$ \\
\hline & 150 & $1.77 \times 10^{-4}$ \\
\hline \multirow{2}{*}{$\begin{array}{l}14.5 \% \text { kaolin clay with Ottawa } \\
\text { sand }\end{array}$} & 100 & $3.66 \times 10^{-5}$ \\
\hline & 150 & $3.46 \times 10^{-5}$ \\
\hline \multirow{2}{*}{$\begin{array}{l}15 \% \text { Silty Sand } \\
\text { (Cararro 2004) }\end{array}$} & 180 & $6.7 \times 10^{-4}$ \\
\hline & 260 & $1.3 \times 10^{-3}$ \\
\hline $\begin{array}{c}\text { 15\% Silty Sand } \\
\text { (Thevanayagam 2001) }\end{array}$ & $30-90$ & $4 \times 10^{-4}-1.2 \times 10^{-3}$ \\
\hline $\begin{array}{c}\text { 25\% Silty Sand } \\
\text { (Thevanayagam 2001) }\end{array}$ & $30-90$ & $4 \times 10^{-5}-8 \times 10^{-5}$ \\
\hline $\begin{array}{c}\text { 100\% Silt } \\
\text { (Thevanayagam 2001) }\end{array}$ & $30-90$ & $\sim 1 \times 10^{-5}$ \\
\hline
\end{tabular}






Figure 6.2 Normalized cone resistance versus $\mathrm{c}_{\mathrm{v}}$ in standard CPT. 


\subsection{Evaluation of Cone Factor $\mathrm{N}_{\mathrm{k}}$}

Many researchers have tried to obtain values of $\mathrm{N}_{\mathrm{k}}$ from field cone penetration data. Many authors have proposed the use of an average value of 15 or some value in the range of 10-20 in clays (Aas et al. 1986, Baligh et al. 1980, La Rochelle et al. 1988, Lunne and Kleven 1981, O’Riordan et al. 1982, Stark and Juhrend 1989). In contrast, analytical methods based on cavity expansion analysis or the strain path method suggested that $\mathrm{N}_{\mathrm{k}}$ values are close to 10 (Table 2.2, 2.3). A comparison of the values of $\mathrm{N}_{\mathrm{k}}$ derived by various researchers from empirical/experimental data is complicated by different practices regarding type of cone, reference values of $s_{u}$ and overburden pressure.

Some researchers suggest that $\mathrm{N}_{\mathrm{k}}$ is related to the plasticity index $\mathrm{I}_{\mathrm{p}}$ and have tried to correlate $\mathrm{N}_{\mathrm{k}}$ and $\mathrm{I}_{\mathrm{p}}$ (Lunne at el. 1976, Baligh et al. 1980, Lunne and Kleven 1981, Aas et al. 1986, Rochelle et al. 1988). The suggested correlations were shown in section 2.2. As explained earlier, different mobilization of viscous resistance according to soil type can be partly responsible for the correlation between $\mathrm{q}_{t}$ and $\mathrm{s}_{\mathrm{u}}$ for undrained penetration. Also OCR was found to have a strong influence on the CPT results in clayey soils (Rad \& Lunne 1988). Rad \& Lunne (1988) selected soil properties which can affect cone resistance and examined possible correlations. The soil properties include plastic limit, liquid limit, plasticity index, water content, clay content, over consolidation ratio (OCR), and sensitivity. Their results proved that the OCR has the strongest influence on CPT results. In the following sections, the factors that affect the cone factor $\mathrm{N}_{\mathrm{k}}$ are studied and a new empirical correlation for $\mathrm{N}_{\mathrm{k}}$ is proposed.

\subsubsection{CPT Database}

A piezocone database was compiled to examine the correlation between cone resistance and undrained shear strength in clay deposits. The data was gathered from published literature and also contains field test data for this research. The database contains 38 piezocone soundings for which both the corresponding undrained shear strength values and detailed soil information. 
Table 6.2 summarizes the data, which include soil description, cone type, cone resistance, undrained shear strength, method used to determine $\mathrm{s}_{\mathrm{u}}, \mathrm{OCR}, \mathrm{I}_{\mathrm{r}}$, clay content, LL, IP and calculated $\mathrm{N}_{\mathrm{k}}$. The results from previous studies on the value of $\mathrm{N}_{\mathrm{k}}$ described in chapter 2 are also summarized in Table 6.2. The table includes only data satisfying the following selection criteria:

- CPT data obtained using an electrical cone.

- Low-permeability clay layer present in the soil profile.

- Undrained shear strength data obtained from triaxial tests used for reference data for calculation of $\mathrm{N}_{\mathrm{k}}$.

There are some obstacles to obtaining the correct values of undrained shear strength from the vane test. For this reason, only $\mathrm{N}_{\mathrm{k}}$ values based on undrained triaxial compression tests were selected for reliable evaluation. Since the mechanical cone cannot produce reliable data as accurate as those achievable by the electric cone, the results obtained using the mechanical cone were also eliminated from the database. 
Table 6.2 Summary of empirical cone factor $\mathrm{N}_{\mathrm{k}}$.

\begin{tabular}{|c|c|c|c|c|c|c|c|c|c|c|c|}
\hline Name \& Year & Site & Soil description & CPT type & $\begin{array}{c}\text { Cone } \\
\text { resistance }\end{array}$ & method for $\mathrm{S}_{\mathrm{u}}$ & OCR & $\mathrm{I}_{\mathrm{r}}$ & $\%$ clay & $\operatorname{LL}(\%)$ & $\mathrm{I}_{\mathrm{p}}(\%)$ & $\mathrm{N}_{\mathrm{k}}$ \\
\hline \multirow{10}{*}{$\begin{array}{l}\text { Rad et al. } \\
\text { (1988) }\end{array}$} & Vancouver & Clayey silt & Electric & $\mathrm{q}_{\mathrm{t}}$ & CAUC & 1.45 & & 23 & 37 & 12.5 & 8.5 \\
\hline & Brag 2 & Silty clay & $"$ & $"$ & $"$ & 1.85 & & 29 & 33 & 18 & 8.7 \\
\hline & Drammen & Lean clay & $"$ & $"$ & $"$ & 1.35 & & 48 & 40 & 26 & 9.5 \\
\hline & Emmerstad & Silty quick clay & $"$ & $"$ & $"$ & 1.93 & & - & 28.3 & 6.5 & 11.3 \\
\hline & Onsoy & Plastic clay & $"$ & $"$ & $"$ & 1.45 & & 57.3 & 69.5 & 42.5 & 12.5 \\
\hline & Hega & Plastic OC clay & $"$ & $"$ & $"$ & 4.5 & & 54.3 & 48.3 & 21.3 & 12.6 \\
\hline & Troll & Plastic clay & $"$ & $"$ & $"$ & 1.6 & & 31.8 & 42.4 & 23.4 & 13.0 \\
\hline & Cowden & Unweathered stony clay & $"$ & $"$ & CIUC & 3.15 & & - & 34.5 & 18.8 & 15.7 \\
\hline & Haltenbanken & silty sandy clay w/ gravel & $" \prime$ & $"$ & CAUC & 6.1 & & - & 33 & 18 & 15.7 \\
\hline & Brent $\mathrm{X}$ & Clay & $"$ & $"$ & CIUC & 35.3 & & 58.7 & 28.3 & 46.7 & 24.5 \\
\hline \multirow{3}{*}{$\begin{array}{c}\text { La Rochelle et } \\
\text { al. } \\
(1988)\end{array}$} & Louisville & $\begin{array}{c}\begin{array}{c}\text { silty clay with pine seams } \\
\text { of silt, sensitive }\end{array} \\
\end{array}$ & Electric & $\mathrm{q}_{\mathrm{t}}$ & Field vane & $1.7-2.6$ & & & 66 & 40 & 11 \\
\hline & Berthierville & Grey silty clay & $"$ & $"$ & $"$ & $1.1-1.3$ & & & $37-50$ & $16-26$ & 12.5 \\
\hline & $\begin{array}{c}\text { Saint-Jean- } \\
\text { Vianney }\end{array}$ & & $"$ & $"$ & $"$ & $25-50$ & & & 31 & 8 & 16 \\
\hline \multirow{2}{*}{$\begin{array}{c}\text { Stark et al. } \\
(1989)\end{array}$} & & soft to medium silty clay & & & $\mathrm{UU}$ & \multirow{2}{*}{$1-2$} & & & \multirow{2}{*}{40} & \multirow{2}{*}{20} & 11 \\
\hline & & with low plasticity & & & Field vane & & & & & & 13 \\
\hline \multirow{3}{*}{$\begin{array}{l}\text { Lunne et al. } \\
\text { (1986) }\end{array}$} & Gullfaks A & Silty clay & Electric & $\mathrm{q}_{\mathrm{t}}$ & CAUC & 5 & & $15-40$ & $41-50$ & $22-28$ & 15 \\
\hline & Sleipner & Stiff clay & $"$ & $"$ & $"$ & $1-2$ & & $23-35$ & $34-46$ & $18-25$ & 12 \\
\hline & Emmerstad & Onshore quick clay & $" \prime$ & $"$ & $"$ & & & & & & 10.5 \\
\hline \multirow{3}{*}{$\begin{array}{c}\text { Lambson et al. } \\
\text { (1992) }\end{array}$} & Pentre & Clayey silt & & & UU-TXL & $1.6 \sim 1.8$ & & & & & 11.3 \\
\hline & Pentre & Silty clay & & & $\mathrm{UU}, \mathrm{CIU}$ & 1.5 & & & & & 9.6 \\
\hline & Tilbrook & Hard silty clay & & & UU, CIU & $8 \sim 35$ & & & $50 \sim 60$ & $30 \sim 40$ & $13 \sim 26$ \\
\hline \multirow{2}{*}{$\begin{array}{l}\text { Denver, } \mathrm{H} \\
(1988)\end{array}$} & Niverod site & glacial meltwater clay & Electric & & & & & & & & 9.5 \\
\hline & Niva site & lake glacial clay & Electric & & & & & & $25-35$ & $10-15$ & 7.3 \\
\hline
\end{tabular}


Table 6.2 Summary of empirical cone factor $\mathrm{N}_{\mathrm{k}}$ (Continued).

\begin{tabular}{|c|c|c|c|c|c|c|c|c|c|c|c|}
\hline Name & Site & Soil description & CPT type & $\begin{array}{c}\text { Cone } \\
\text { resistance } \\
\end{array}$ & method for $S_{u}$ & OCR & $\mathrm{I}_{\mathrm{r}}$ & $\%$ clay & LL & $\mathrm{I}_{\mathrm{p}}$ & $\mathrm{N}_{\mathrm{k}}$ \\
\hline \multirow{6}{*}{$\begin{array}{c}\text { Luke, K. } \\
(1995)\end{array}$} & Yold clay & & Electric & $\mathrm{q}_{\mathrm{t}}$ & Triaxial test & $8-11$ & 49 & 62 & 65 & 39 & 9.9 \\
\hline & Clay till & & " & " & & $3-4$ & $\begin{array}{c}188 \\
77 \\
\end{array}$ & 15 & 22 & 7 & $\begin{array}{l}12.2 \\
10.5\end{array}$ \\
\hline & Tert clay & & $"$ & $"$ & & $2-3$ & 111 & 83 & 174 & 137 & 9.9 \\
\hline & Holoc clay & & $"$ & $"$ & & $1-2$ & 35 & 21 & 37 & 15 & 10.6 \\
\hline & Clay till 2 & & $"$ & $"$ & & $10-11$ & $\begin{array}{l}23 \\
16 \\
\end{array}$ & 32 & 23 & 10 & $\begin{array}{c}8.5 \\
10.6 \\
\end{array}$ \\
\hline & Org mud & & $"$ & $"$ & & $1-2$ & $\begin{array}{l}15 \\
32 \\
\end{array}$ & 35 & 97 & 53 & $\begin{array}{l}8.4 \\
9.5 \\
\end{array}$ \\
\hline \multirow{2}{*}{$\begin{array}{l}\text { Anagnostopou } \\
\text { los, A. et. al. } \\
\text { (2003) }\end{array}$} & \multirow{2}{*}{ Various } & & Mechanical & & UU & & & & & & 18.9 \\
\hline & & & Electric & & UU & & & & & & 17.2 \\
\hline \multirow{3}{*}{$\begin{array}{l}\text { Jamiolkowski, } \\
\text { M. et. al. } \\
\text { (1982) }\end{array}$} & Porto Tolle & $\begin{array}{c}\text { Very young silty clay of } \\
\text { medium plasticity }\end{array}$ & Electric & & Field vane & & $96 \sim 144$ & & & & $11 \pm 3$ \\
\hline & $\begin{array}{l}\text { Montalto di } \\
\text { Castro } \\
\end{array}$ & $\begin{array}{c}\text { Clayey deposit of hard } \\
\text { marine clay }\end{array}$ & Electric & & $\mathrm{CK}_{0} \mathrm{U}$ & $2.5 \sim 4$ & $150 \sim 210$ & & & & $9 \pm 1$ \\
\hline & Taranto & $\begin{array}{c}\text { very stiff non-fissured } \\
\text { clay }\end{array}$ & & & & $15 \sim 25$ & 30 & & & & $16 \pm 2$ \\
\hline $\begin{array}{c}\text { Carpentier, R. } \\
(1982)\end{array}$ & & Boom clay & Mechanical & & Field vane & & & & & & $9 \pm 1.5$ \\
\hline $\begin{array}{c}\text { Tani and } \\
\text { Craig (1995) } \\
\end{array}$ & Centrifuge test & $\begin{array}{c}\text { Remoulded glacial clay } \\
\text { till }\end{array}$ & \begin{tabular}{c|} 
Miniature \\
cone
\end{tabular} & & UU \& vane & 1 & & & & 23 & 12.5 \\
\hline \multirow{3}{*}{$\begin{array}{l}\text { Almeida } \\
\text { (1996) }\end{array}$} & \begin{tabular}{|l|} 
Canons Park \\
\end{tabular} & Brown London clay & Electric & $\mathrm{q}_{\mathrm{c}}$ & CU-TXL & $17 \sim 25$ & & & & & 19 21 \\
\hline & Cowdon & Stiff clay & & & UU-TXL & $4 \sim 7.5$ & & & 40 & 18 & 20 \\
\hline & Cowdon & Stiff clay & & & UU-TXL & $2 \sim 3$ & & & 35 & 17 & 13.2 \\
\hline $\begin{array}{l}\text { Van Impe } \\
(2004) \\
\end{array}$ & Sint-Katelijne & Boom clay & Electric & $\mathrm{q}_{\mathrm{c}}$ & UU-TXL & $14 \sim 30$ & & & $\begin{array}{c}65 \sim \\
71 \\
\end{array}$ & $\begin{array}{c}40 \sim \\
50 \\
\end{array}$ & 13 24 \\
\hline
\end{tabular}




\subsubsection{Correlation between $\mathrm{N}_{\mathrm{k}}$ and Rigidity Index $\mathrm{I}_{\mathrm{r}}$}

The fact that most of the theoretical methods based on cavity expansion theory and strain path methods consider rigidity index $I_{r}$ as an input factor into the cone factor $N_{k}$ was discussed in chapter 2 (Vesic 1972, Baligh 1985, Teh and Houlsby 1988, Yu 1993). Examples of some equations using $I_{r}$ for $N_{k}$ are summarized in Table 6.2. It is seen that $N_{k}$ increases with increasing $I_{r}$. Several methods suggested that calculated values of $N_{k}$ increase from 9 to 14 for $\mathrm{I}_{\mathrm{r}}$ ranging from 50 to 400 (Ladanyi and Johnston 1974, Vesic 1977, Yu 1993, Baligh 1985, Teh and Houlsby 1991). Besides, Luke (1995) proved this correlation between $\mathrm{N}_{\mathrm{k}}$ and $\mathrm{I}_{\mathrm{r}}$ with collected field CPT data from Danish soils and data reported by Lunne et al. (1985). The plot by Luke (1995) suggested that $\mathrm{N}_{\mathrm{k}}$ rises from 8 to 11 by an increase in $I_{r}$ from 10 to 250 .

For clays, the rigidity index $I_{r}$ can be obtained from measured triaxial stress-strain curves or pressuremeter tests. Keaveny and Mitchell (1986) suggested a useful empirical correlation for $\mathrm{I}_{\mathrm{r}}$ based on anisotropically-consolidated triaxial compression test data in terms of OCR and plasticity index (PI). The correlation is shown in Figure 6.3. From this figure, the correlation between $I_{r}$ and $I_{p}$ for normally consolidated soil was derived; it is shown in Figure 6.4. The plot in this Figure shows that $I_{r}$ decreases with increasing PI. Calculated values of $\mathrm{N}_{\mathrm{k}}$ from the equations in Table 6.2 for various values of $\mathrm{I}_{\mathrm{r}}$ can be compared with $\mathrm{I}_{\mathrm{p}}$ by the corresponding number obtained from Figure 6.4. The correlation between $\mathrm{N}_{\mathrm{k}}$ and $\mathrm{I}_{\mathrm{p}}$ resulting from the correlation between $\mathrm{N}_{\mathrm{k}}$ and $\mathrm{I}_{\mathrm{r}}$ is shown in Figure 6.5. As can be seen in the plot, $\mathrm{N}_{\mathrm{k}}$ decreases when $\mathrm{I}_{\mathrm{p}}$ increases. 


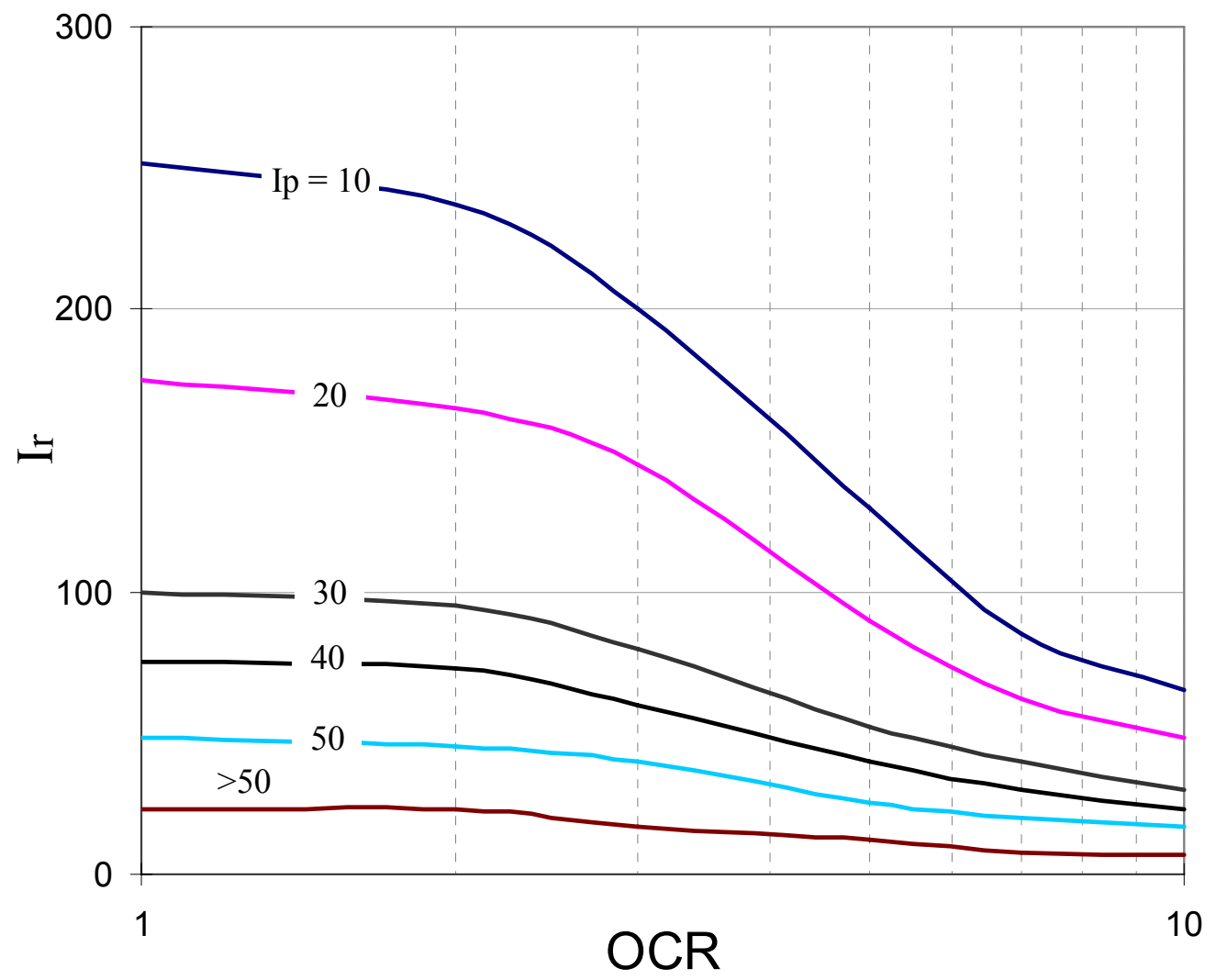

Figure 6.3 Chart for estimating the rigidity index for fine-grained soil (after Keaveny and Mitchell 1986). 


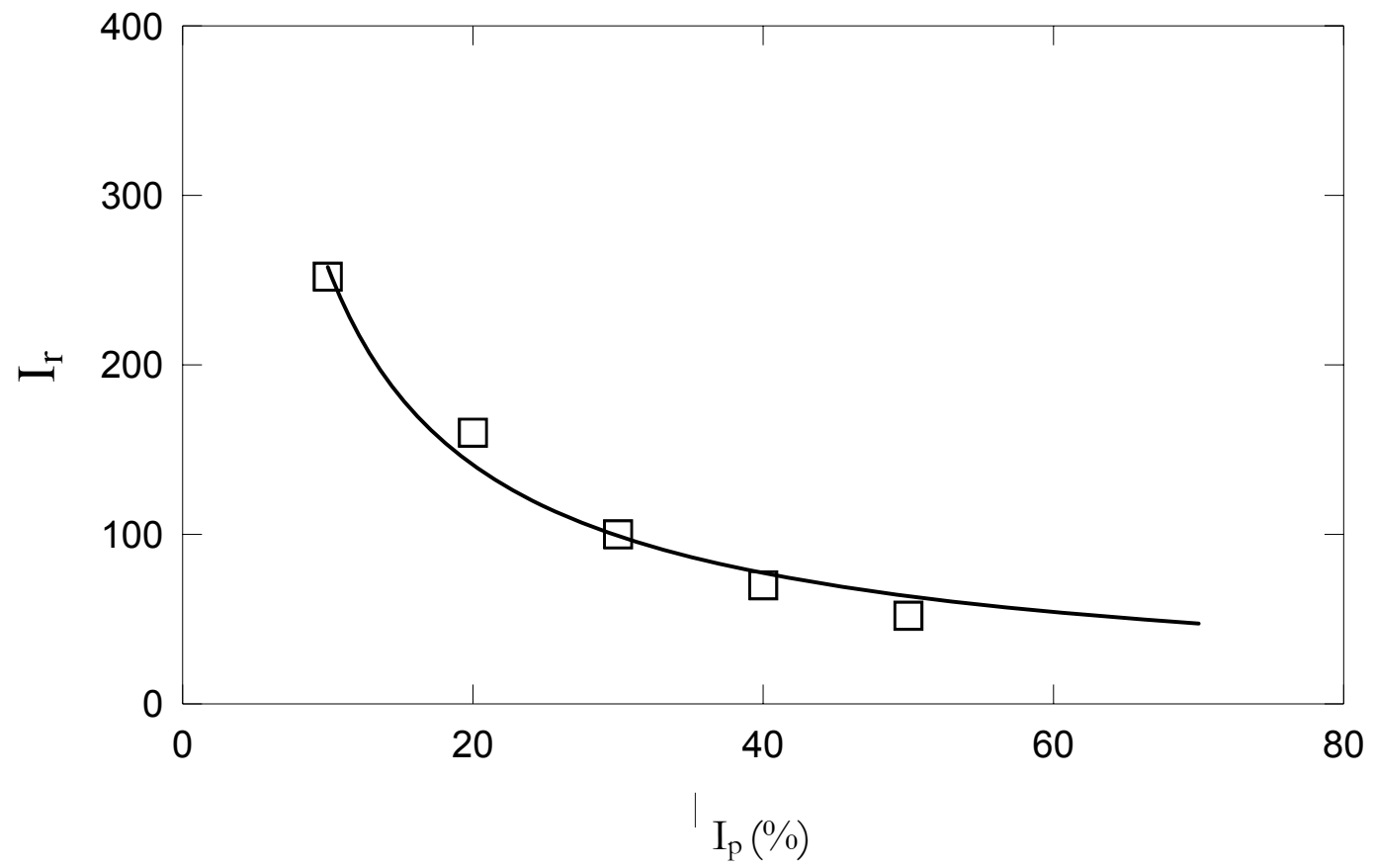

Figure 6.4 Correlation between $\mathrm{I}_{\mathrm{r}}$ and $\mathrm{I}_{\mathrm{p}}$ for normally consolidated soil. 
Table 6.3 Equations using $\mathrm{I}_{\mathrm{r}}$ for $\mathrm{N}_{\mathrm{k}}$.

\begin{tabular}{|c|c|c|}
\hline Authors & Equation for $\mathrm{N}_{\mathrm{k}}$ & Assumptions \\
\hline Vesic (1972) & $N_{k}=\frac{4}{3}\left(\operatorname{In} I_{r}+1\right)+2.57$ & Spherical cavity limit pressure \\
\hline Baligh (1985) & $N_{k}=1.51+2 \ln I_{r}$ & Smooth cone, $\mathrm{K}_{0}=1$ \\
\hline $\begin{array}{c}\text { Teh and } \\
\text { Houlsby (1988) }\end{array}$ & $N_{k}=\frac{4}{3} \cdot\left(1+\ln I_{r}\right)\left(1.25+\frac{I_{r}}{2000}\right)$ & $\begin{array}{c}\text { Smooth and rigid cone, } \\
\text { Yu (1993) }\end{array}$ \\
\hline$N_{k}=4.18+1.155 \cdot \ln \frac{\sqrt{3}}{2} I_{r}$ & $\begin{array}{c}\text { The cone resistance is obtained by } \\
\text { combining the cylindrical cavity } \\
\text { solution and plasticity solution }\end{array}$ \\
\hline
\end{tabular}

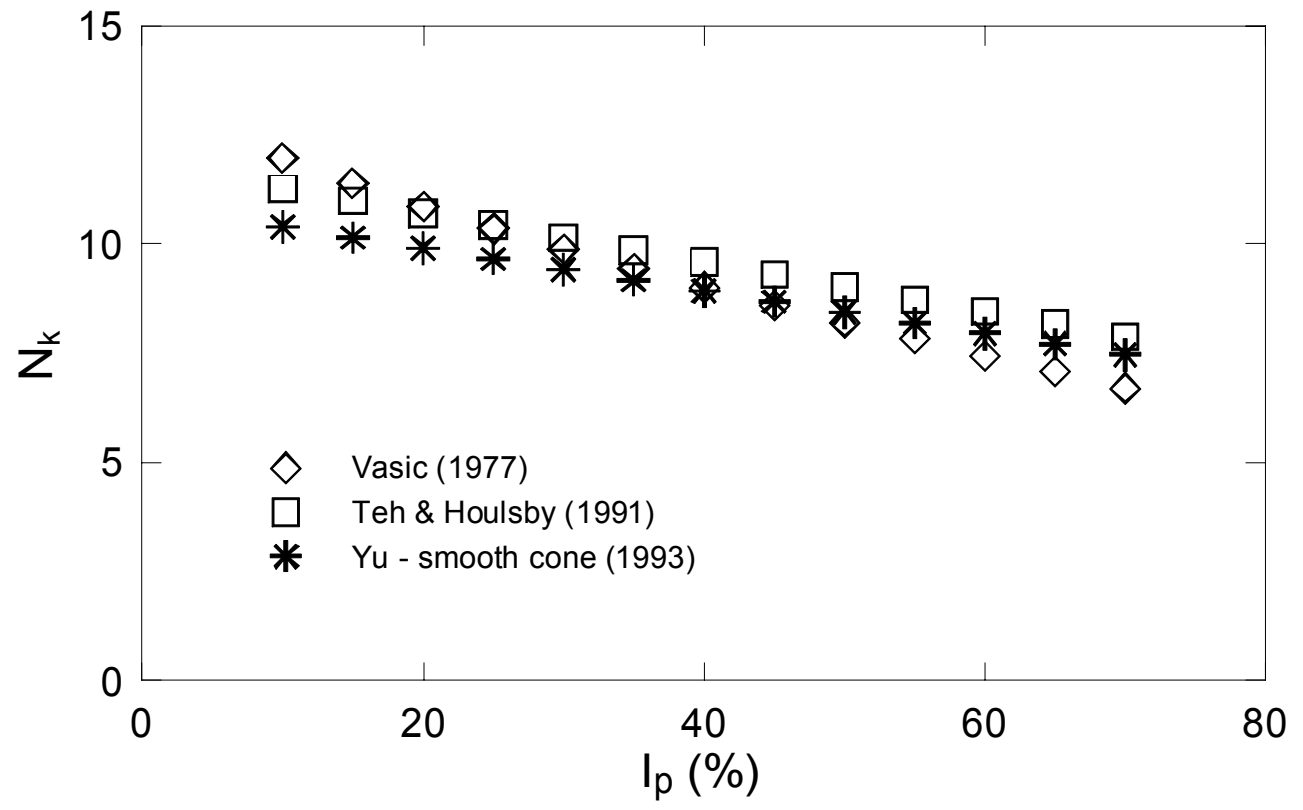

Figure 6.5 Correlation between $\mathrm{N}_{\mathrm{k}}$ obtained from theoretical solutions and $\mathrm{I}_{\mathrm{p}}$ based on the correlation between $\mathrm{I}_{\mathrm{r}}$ and $\mathrm{N}_{\mathrm{k}}$. 


\subsubsection{Correlation between $\mathrm{N}_{\mathrm{k}}$ and Rate of Loading}

The correlation between $\mathrm{N}_{\mathrm{k}}$ and the rate of loading can be expressed as a function of $I_{p}$ by evaluating the relation between $I_{p}$ and soil viscosity. The higher the $I_{p}$ is, the higher the soil viscosity is. The increase of viscous resistance according to $I_{p}$ increase is shown in Figure 6.6 in terms of the normalized cone resistance $q_{t} / \sigma_{v}^{\prime}$ and $\mathrm{I}_{\mathrm{p}}$.

\subsubsection{Correlation between Real $\mathrm{N}_{\mathrm{k}}$ and $\mathrm{I}_{\mathrm{p}}$}

The theoretical solutions explained in section 6.2.2 relate cone resistance to a given $s_{u}$. They do not account for the dependence of $s_{u}$ on the rate of loading. Therefore, the value of $\mathrm{N}_{\mathrm{k}}$ from theoretical solutions has to be increased to account for rate effects.

The correction for "viscosity" is shown in Figure 6.7. As shown in Figure 6.5, the theoretical $\mathrm{N}_{\mathrm{k}}$ decreases with increasing $\mathrm{I}_{\mathrm{p}}$. On the other hand, "viscosity" increases with increasing $I_{p}$. By way of combining these two values, $N_{k}$ has a fairly constant value for soils having different $I_{p}$ values, and the value is somewhat greater than 10. Previous researchers believed in some trend of $\mathrm{N}_{\mathrm{k}}$ with $\mathrm{I}_{\mathrm{p}}$ - either an increasing trend (Aas et al. 1986) or a decreasing one (Baligh et al. 1980, Lunne and Kleven 1981). They based their considerations on collected field data, but the values of $\mathrm{N}_{\mathrm{k}}$ in Figures 2.1(a) and (b), which are from field tests, are scattered and do appear to show either trend. Instead, they seem to show a constant $\mathrm{N}_{\mathrm{k}}$ with varying PI. 


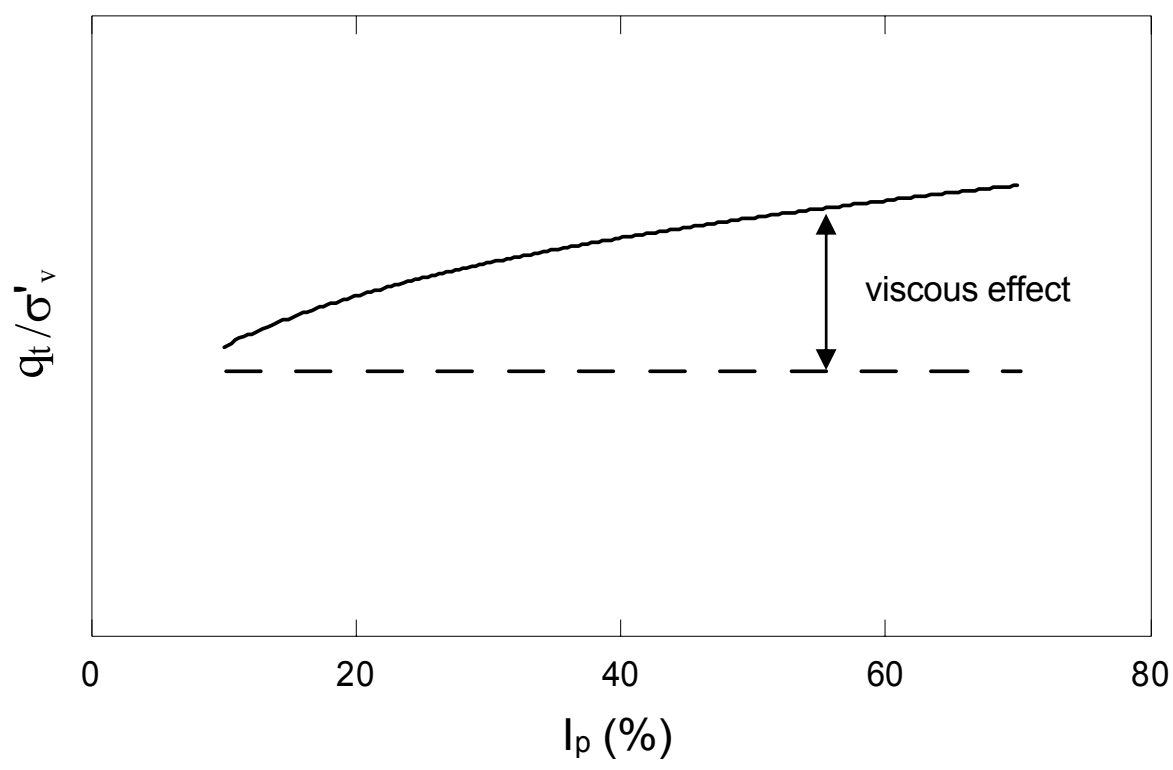

Figure 6.6 Correlation of viscous effect in $q_{t}$ and $I_{p}$.

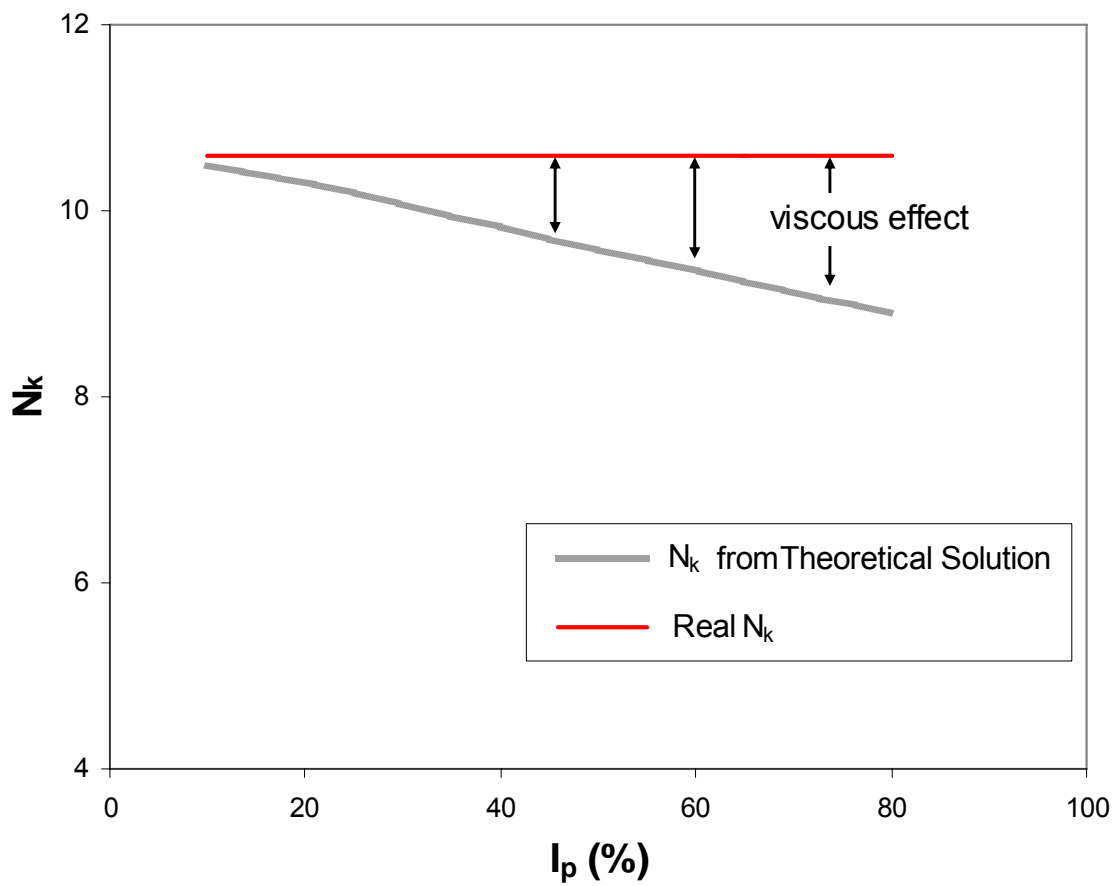

Figure 6.7 Correlation of actual values of $\mathrm{N}_{\mathrm{k}}$ and PI. 


\section{CHAPTER 7. CURRENT PILE DESIGN METHODS}

\subsection{Introduction}

The general function of a pile is to transfer a load that cannot be adequately supported by a surface soil layer to depths where soil capable of providing shaft or base resistance exists. Piles can be classified by installation method (driven, bored, cast in situ, etc), degree of displacement (displacement or non-displacement), material (steel, concrete), pile shape, etc.

The search for suitable methods to predict the axial capacity of a pile has been an integral part of geotechnical engineering research and practice. The bearing capacity of a pile is generally mobilized from skin friction resistance of the pile shaft and base resistance from the pile tip. Therefore, the ultimate bearing capacity of a pile $\mathrm{Q}_{\text {ult }}$ is expressed as the summation of ultimate base resistance, $Q_{b}$, and ultimate shaft resistance, $Q_{s}$. The base and shaft resistances are simply the multiplication of shaft and base areas, $A_{s}$ and $A_{b}$, by the respective unit resistances $\mathrm{q}_{\mathrm{b}}$ and $\mathrm{q}_{\mathrm{s}}$ :

$$
Q_{u l t}=Q_{s}+Q_{b}=\sum_{i=1}^{n}\left(q_{s i} A_{s i}\right)+q_{b} A_{b}
$$

where $\mathrm{i}=$ soil layer index, $\mathrm{q}_{\mathrm{si}}=$ unit shaft resistance in a layer labeled $\mathrm{i}, \mathrm{A}_{\mathrm{si}}=$ pile shaft area interfacing with layer i. Generally the soil where a pile is installed is not a homogenous layer. Therefore the soil penetrated by the pile is divided into $\mathrm{n}$ layers depending on the soil type, and the shaft resistance of each layer is summed up over the $\mathrm{n}$ layers to compute the total shaft resistance.

Several methods have been developed to determine the bearing capacity of piles using different approaches. These methods can be divided into 3 main groups: 
1. Interpretation of a pile behavior from full scale pile load tests;

2. Design methods based on the evaluation of soil parameters from results of laboratory tests or by other means and use of the values of these parameters in effective stress or total stress analyses (indirect methods);

3. Design methods based on direct use of in-situ test results for base and shaft resistance.

A full scale pile load test performed on a construction site is the best method to predict the load capacity of a pile at a specific site. However, because of the high cost of the test in terms of time and money, it is often difficult to perform for ordinary design projects. Therefore, the prediction methods based on direct or indirect use of in-situ test results or lab test results are generally used. In clayey soils, pile capacity is usually estimated by a correlation with $\mathrm{s}_{\mathrm{u}}$, or by applying some suggested modification to cone resistance or N-value of SPT.

Determining pile capacity from the CPT was one of the first applications of the cone penetration test. It was realized that the cone penetrometer can be regarded as smallscale model pile and there must be some relationship between the cone point resistance and the unit toe resistance of a pile. Moreover, the direct use of CPT results has several advantages for pile design in clay. Using electric CPT equipment gives more reliable and repeatable results and a continuous profile. Also, CPT results can be used immediately without waiting for protracted laboratory tests.

In this chapter, the widely used pile shaft prediction methods based on soil parameters obtained from lab tests or the methods directly using CPT results are reviewed and discussed. For the methods using soil parameters, the review is focused on the total stress method in clayey soils.

The load carrying capacity of the pile can be drained or undrained depending on the values of the soil parameters. While calculating the undrained load carrying capacity of the soil, the soil parameters should be "undrained" values, and the stresses should be the total 
stresses, whereas the soil parameters used in calculations of the drained load carrying capacity of a pile should be "drained" values and the stresses should be effective stresses.

\subsection{Pile Design Methods Based on Soil Parameters}

\subsection{1. $\alpha$-Method}

Since a pile is assumed to fail under undrained conditions in clayey soils, a total stress analysis can be used for the estimation of shaft resistance. Many attempts have been made to correlate the shaft resistance of a pile in clayey soil with undrained shear strength $\mathrm{s}_{\mathrm{u}}$ (Tomlinson 1957, 1971, McClelland 1972, Semple 1984, Randolph and Wroth 1982, Kolk and Velde 1996). The main concept of the $\alpha$ method is to correlate pile shaft capacity to the $s_{u}$ of an in-situ soil through a reduction factor referred to as $\alpha$. Many variations of the $\alpha$ method have been developed based on empirical correlations induced from collected pile load test results.

In 1957, Tomlinson proposed initial values of $\alpha$. He later improved the method based on the results of 94 pile load tests. His method, proposed in 1971, provides charts for factor $\alpha$ based on the composition of the soil layer and pile length. Once $\alpha$ is determined from these charts, the unit shaft resistance is computed using following equation:

$$
q_{s}=\alpha s_{u}
$$

Skempton (1959) recognized early on that $\alpha$ for the stiff London clay was much lower than 1 due to swelling of the clay at the walls of the shafts and the remolding due to drilling operations. He proposed at the time an average $\alpha=0.45$ for typical sizes of drilled shafts and a value as low as 0.3 for very short shafts installed through more heavily cracked clay.

Reese and O’Neill (1988, 1999), based on their own empirical and experimental observations of the response of drilled shafts installed in clay, proposed $\alpha=$ 0.55 . 
Randolph and Wroth (1982) found that the ratio $s_{u} / \sigma_{v}^{\prime}$ correlates well with $\alpha$. Randolph and Murphy (1985) proposed an improved relationship for $\alpha$. in terms of the ratio $s_{u} / \sigma_{v}^{\prime}$.This method was adopted for the revised API design method (1993). A detailed explanation of this method is given later.

Semple and Rigden (1984) selected 24 high-quality pile load tests from over 1000 pile load tests in the API database and developed graphical criteria to obtain $\alpha$ based on the review of the selected test results. They considered a length effect as a factor for the calculation of skin friction. They established a peak adhesion factor $\alpha_{\mathrm{p}}$ and $s_{u} / \sigma_{v}^{\prime}$ relationship, as well as length factor $\mathrm{F}$ according to pile aspect ratio $\mathrm{L} / \mathrm{D}$. The correlations between $\alpha_{\mathrm{p}}$ and $s_{u} / \sigma_{v}^{\prime}$, and F and L/D are shown in Figure 7.1. Once $\alpha_{\mathrm{p}}$ and F are determined from these charts, the unit side resistance is computed using:

$$
f=F \alpha_{p} s_{u}
$$

where $\mathrm{F}=$ length factor; $\alpha_{\mathrm{p}}=$ peak adhesion factor. Since the correlations were derived using average results for each test pile, these correlation may not be applicable to calculations where the soil is broken in layers.

Recent research carried out by Salgado (2006a) led to the following value of $\alpha$ for drilled shafts:

$$
\alpha=0.4\left[1-0.12 \ln \left(\frac{s_{u}}{p_{A}}\right)\right] \quad \text { for } 3 \leq \text { OCR } \leq 5
$$

This value is conservative for an overconsolidation ratio less than 3 . 


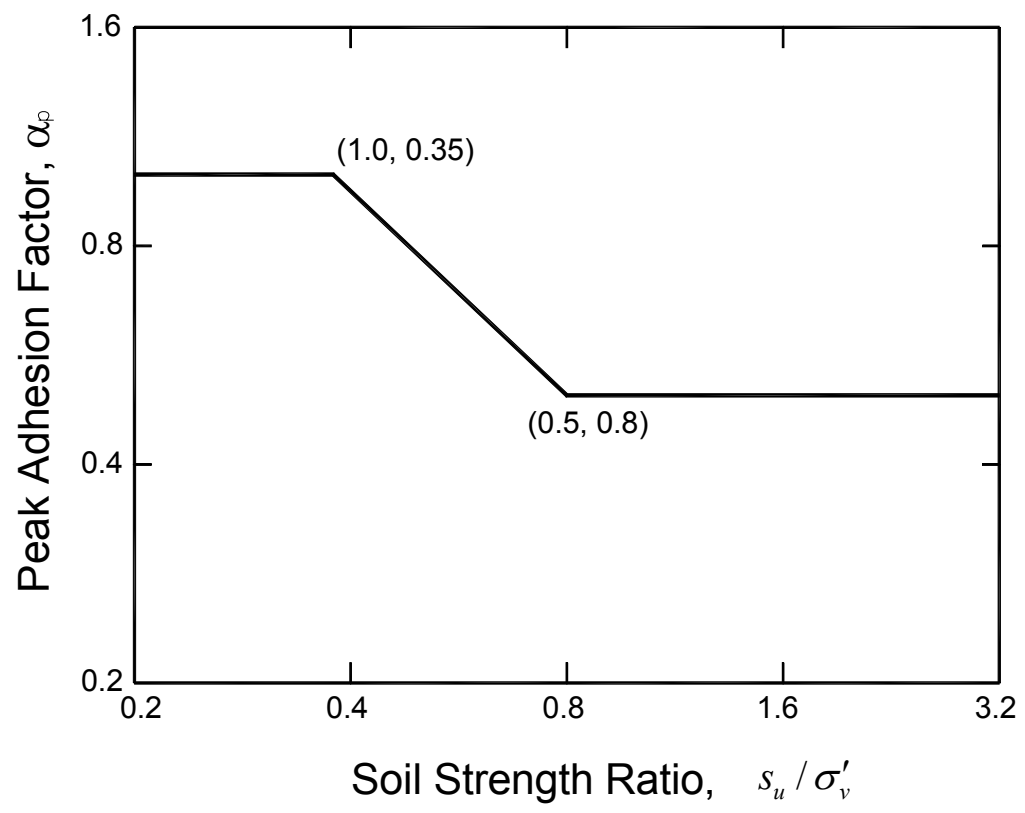

(a)

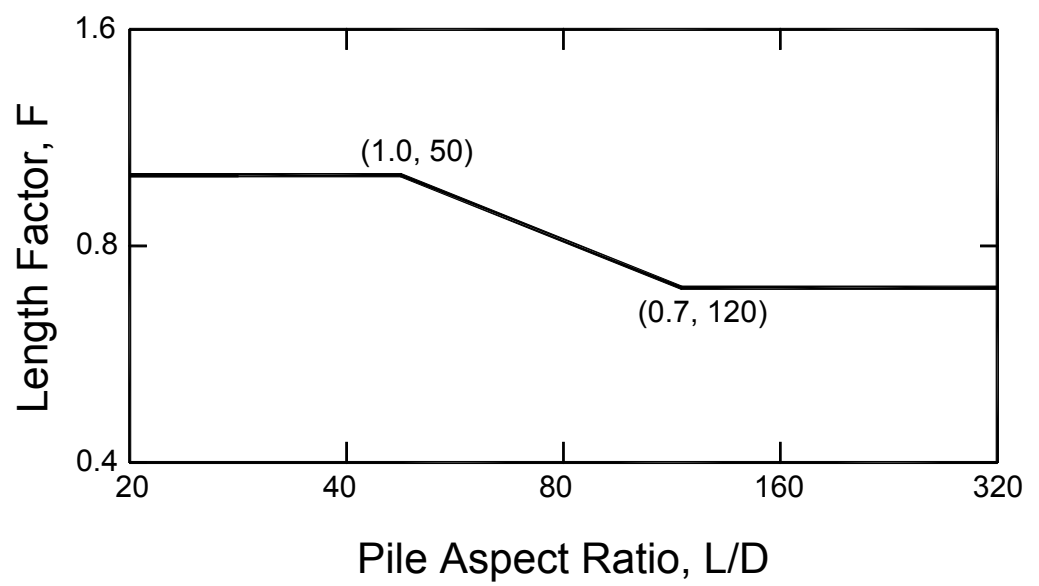

(b)

Figure 7.1 Criteria of $\alpha$ and F for pile capacity prediction (a) Correlation between $\alpha_{\mathrm{p}}$ and $\mathrm{s}_{\mathrm{u}} / \sigma_{\mathrm{v}}$ (b) Correlation between F and L/D. 


\subsubsection{American Petroleum Institute (API) Method}

Randolph and Murphy (1985) proposed an equation for $\alpha$ for use in the $\alpha$-method that was developed based on the database compiled by Olson and Dennis (1982). They assumed that the mobilized skin friction depends on the angle of friction between pile and soil, undrained shear strength, and effective stress. According to them, the effects of all these parameters are captured by the factor $s_{u} / \sigma_{v}^{\prime}$. The method developed by Randolph and Murphy (1985) was included in the API design method published in 1993. In the API method, the equations for estimating the shaft friction are defined as the following equations:

$$
\begin{aligned}
& f=\alpha s_{u} \\
& \alpha=0.5\left(s_{u} / \sigma_{v}^{\prime}\right)^{-0.5} \quad s_{u} / \sigma_{v}^{\prime} \leq 1.0 \\
& \alpha=0.5\left(s_{u} / \sigma_{v}^{\prime}\right)^{-0.25} \quad s_{u} / \sigma_{v}^{\prime}>1.0
\end{aligned}
$$

where $\sigma_{v}^{\prime}=$ effective overburden pressure. The shaft resistance degradation of a long pile -

- due to (1) continued shearing of a particular soil during pile installation and (2) lateral movement of soil derived from "pile whip" during driving and (3) progressive failure in the soil due to strength reduction - is not explicitly dealt with in the API method, although references are provided.

\subsection{Methods based on CPT Results}

\subsubsection{LCPC Method}

Bustamante and Gianeselli (1982) presented a pile design method using CPT results with factors related to both pile and soil types. This method is often referred to as LCPC method. The LCPC method was developed based on 96 load tests performed on several pile types. Both the base and shaft capacity are determined from the cone resistance $\mathrm{q}_{\mathrm{c}}$. The basic formula for the LCPC method can be written as: 


$$
\begin{aligned}
& \mathrm{q}_{\mathrm{si}}=\mathrm{c}_{\mathrm{si}} \mathrm{q}_{\mathrm{ci}}, \quad \mathrm{c}_{\mathrm{si}}=\frac{1}{\varphi} \\
& \mathrm{q}_{\mathrm{b}}=\mathrm{c}_{\mathrm{b}} \mathrm{q}_{\mathrm{ca}}
\end{aligned}
$$

where $c_{\mathrm{si}}=$ shaft resistance factor in layer $\mathrm{i} ; \mathrm{q}_{\mathrm{ci}}=$ average cone resistance for layer $\mathrm{i} ; \varphi=\mathrm{a}$ coefficient factor; $\mathrm{c}_{\mathrm{b}}=$ base resistance factor; $\mathrm{q}_{\mathrm{c}}=$ equivalent cone resistance at pile base level; given by soil and pile type. Skin friction $\mathrm{q}_{\mathrm{s}}$ is calculated by dividing average $\mathrm{q}_{\mathrm{c}}$ corresponding to the given level by a coefficient $\varphi$. The values of $\varphi$ classified by soil type and pile installation methods are given in Table 7.1. The values of $\varphi$. are suggested for 8 different categories of soil types. The equivalent cone resistance $\mathrm{q}_{\mathrm{ca}}$ corresponds to an arithmetical mean of the cone resistance $\mathrm{q}_{\mathrm{c}}$ measured within a zone of $1.5 \mathrm{~B}$ above and below the pile base. The values of $c_{b}$ for base capacity are governed by type of the soil, density and the pile placement technique. Table 7.2 shows the values of $c_{b}$ with different soil and pile types. 
Table 7.1 Values of $\varphi$ for different soil and pile types.

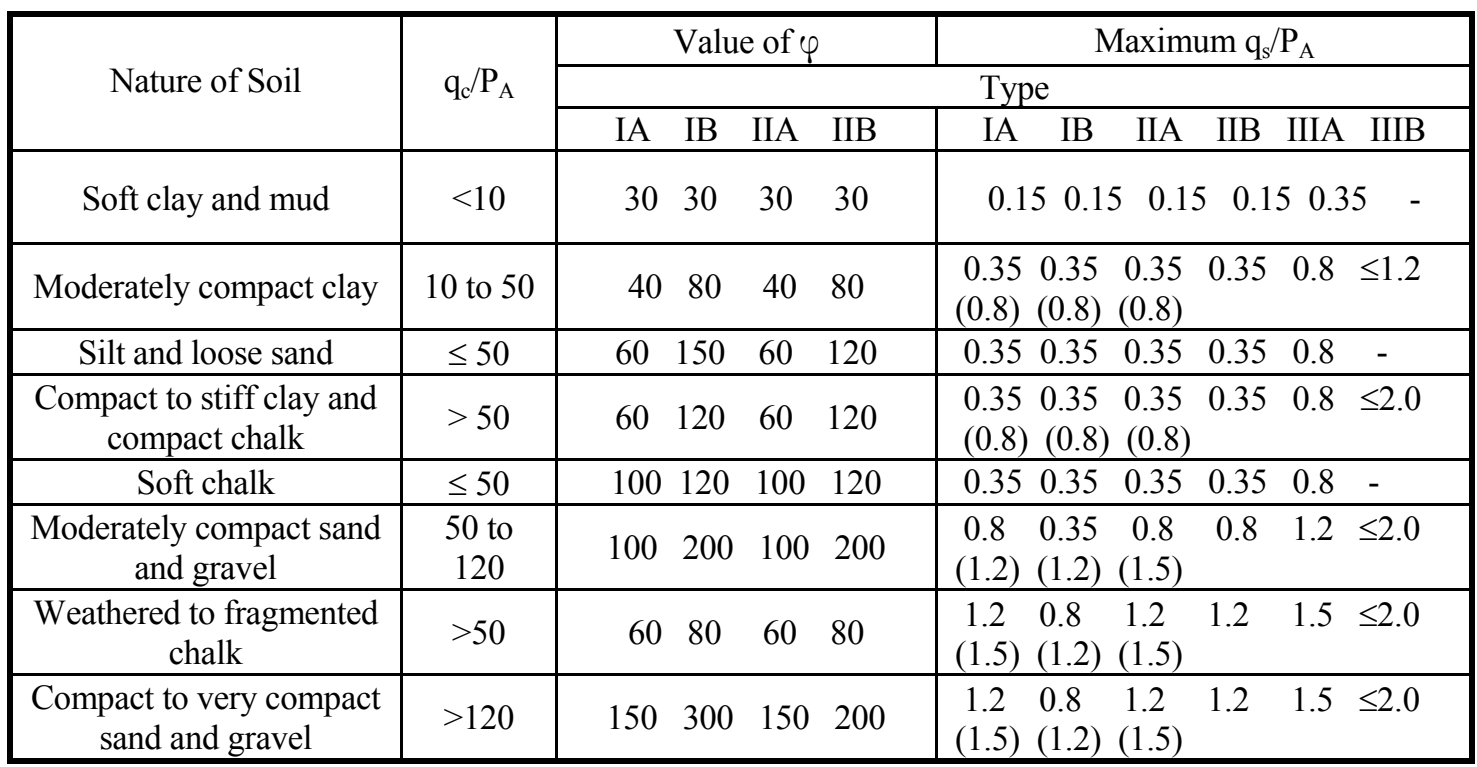

- $\mathrm{P}_{\mathrm{A}}=$ reference stress $=100 \mathrm{kPa}=0.1 \mathrm{MPa}=1 \mathrm{tsf}$

- Type IA: Plane bored piles, mud bored piles, hollow auger piles, cast screwed piles, piers, barrettes, and micropiles with low injection pressure.

- Type IB: Bored piles with steel casing and driven cast piles.

- Type IIA: Driven or jacked precast piles and prestressed concrete piles.

- Type IIB: Driven or jacked steel piles.

- Type IIIA: Driven grouted piles and driven lam piles.

- Type IIIB: High pressure grouted piles with diameter greater than $250 \mathrm{~mm}$ and micropiles installed with high injection pressure.

Table 7.2 values of bearing capacity factor $\mathrm{c}_{\mathrm{b}}$

\begin{tabular}{|c|c|c|c|}
\hline \multirow{2}{*}{ Nature of Soil } & \multirow{2}{*}{$\mathrm{q}_{\mathrm{c}} / \mathrm{P}_{\mathrm{A}}$} & \multicolumn{2}{|c|}{ factors $\mathrm{c}_{\mathrm{b}}$} \\
\cline { 3 - 4 } & & Group I & Group II \\
\hline Soft clay and mud & $<10$ & 0.4 & 0.5 \\
\hline Moderately compact clay & 10 to 50 & 0.35 & 0.45 \\
\hline Silt and loose sand & $\leq 50$ & 0.4 & 0.5 \\
\hline $\begin{array}{c}\text { Compact to stiff clay and compact } \\
\text { chalk }\end{array}$ & $>50$ & 0.45 & 0.55 \\
\hline $\begin{array}{c}\text { Soft chalk } \\
\text { gravel }\end{array}$ & $\leq 50$ & 0.2 & 0.3 \\
\hline $\begin{array}{c}\text { Moderately compact sand and } \\
\text { Weathered to fragmented chalk }\end{array}$ & 50 to 120 & 0.4 & 0.5 \\
\hline $\begin{array}{c}\text { Compact to very compact sand and } \\
\text { gravel }\end{array}$ & $>120$ & 0.2 & 0.4 \\
\hline
\end{tabular}

- Group I: bored piles, piers, barrettes, micropiles grouted under low pressure

- Group II: driven cast-in-place piles and piles in Type IIA, IIB, IIIA, and IIIB of Table 7.1 


\subsubsection{Aoki \& Velloso’s CPT Method}

Based on pile load test and in-situ test, Aoki and de Alencar Velloso (1975) defined the $\mathrm{c}_{\mathrm{si}}$ and $\mathrm{c}_{\mathrm{b}}$ resistance factors for the prediction of pile shaft and base resistance as follows:

$$
\begin{array}{rr}
\mathrm{q}_{\mathrm{si}}=\mathrm{c}_{\mathrm{si}} \mathrm{q}_{\mathrm{ci}}, & \mathrm{c}_{\mathrm{si}}=\frac{\kappa}{\mathrm{F}_{2}} \\
\mathrm{q}_{\mathrm{b}}=\mathrm{c}_{\mathrm{b}} \mathrm{q}_{\mathrm{c}}, & \mathrm{c}_{\mathrm{b}}=\frac{1}{\mathrm{~F}_{1}}
\end{array}
$$

where $\mathrm{q}_{\mathrm{ci}}=$ average cone tip resistance for layer $\mathrm{i}$ along the pile shaft; $\mathrm{F}_{1}, \mathrm{~F}_{2}=$ empirical factors that depend on the pile type. $\kappa=$ empirical factor depending on soil type. The values of $\kappa$ are presented in Table 7.3 for 15 different soil types. Factors $F_{1}$ and $F_{2}$ are given in Table 7.4.

Table 7.3 Values of $\kappa$ for different soil types.

\begin{tabular}{|l||c|}
\hline \multicolumn{1}{|c||}{ Type of Soil } & $\kappa(\%)$ \\
\hline Sand & 1.4 \\
Silty sand & 2.0 \\
Clayey silty sand & 2.4 \\
Clayey sand & 3.0 \\
Silty clayey sand & 2.8 \\
\hline Silt & 3.0 \\
Sandy silt & 2.2 \\
Clayey sandy silt & 2.8 \\
Clayey silt & 3.4 \\
Sandy clayey silt & 3.0 \\
\hline Clay & 6.0 \\
Sandy clay & 2.4 \\
Sandy silty clay & 2.8 \\
Silty clay & 4.0 \\
Silty sandy clay & 3.0 \\
\hline
\end{tabular}


Table 7.4 Values of $F_{1}$ and $F_{2}$ for different pile types.

\begin{tabular}{|l||c|c|}
\hline \multicolumn{1}{|c|}{ Type of Pile } & $\mathrm{F}_{1}$ & $\mathrm{~F}_{2}$ \\
\hline Franki Piles & 2.50 & 5.0 \\
Steel Piles & 1.75 & 3.5 \\
Precast Concrete Piles & 1.75 & 3.5 \\
Bored Piles & $3.0-3.50$ & $6.0-7.0$ \\
\hline
\end{tabular}

\subsubsection{De Ruiter \& Beringen Method}

The De Ruiter \& Beringen (1979) method is based on experimental data obtained from offshore construction in the North Sea. For the estimation of pile shaft and base resistance, the undrained shear strength for each soil layer is evaluated from the values of average cone resistance. Then, the unit shaft and base resistance are computed by applying suitable factors. For clays, the following equations are used:

$$
\begin{array}{cc}
\mathrm{q}_{\mathrm{si}}=\mathrm{c}_{\mathrm{si}} \mathrm{S}_{\mathrm{ui}} & \mathrm{S}_{\mathrm{ui}}=\frac{\mathrm{q}_{\mathrm{ci}}}{\mathrm{N}_{\mathrm{k}}} \\
\mathrm{q}_{\mathrm{b}}=9 \cdot \mathrm{S}_{\mathrm{u}}, & \mathrm{S}_{\mathrm{u}}=\frac{\mathrm{q}_{\mathrm{ca}}}{\mathrm{N}_{\mathrm{k}}}
\end{array}
$$

where $\mathrm{N}_{\mathrm{k}}=$ cone factor that values in the 10-20 range, depending on the local experience; $\mathrm{q}_{\mathrm{ca}}=$ average cone tip resistance around the pile tip; $\mathrm{c}_{\mathrm{si}}=$ adhesion factor of 1 for normally consolidation clays and 0.5 for over consolidated clays; $\mathrm{q}_{\mathrm{ci}}=$ average cone tip resistance for layer $i$ along the pile shaft. De Ruiter \& Beringen imposed an upper limit of $15 \mathrm{MPa}$ for the unit base resistance and $120 \mathrm{kPa}$ for the unit shaft resistance. 


\subsubsection{Price and Wardle Method}

Price and Wardle (1982) proposed the following expression to estimate the base and shaft capacity of the pile from the cone tip resistance and sleeve friction based on analysis conducted on pile load tests in stiff London clay. The base capacity of a pile can be calculated by:

$$
\begin{aligned}
\mathrm{q}_{\mathrm{b}} & =\mathrm{k}_{\mathrm{b}} \mathrm{q}_{\mathrm{c}} \\
\mathrm{q}_{\mathrm{si}} & =\mathrm{c}_{\mathrm{si}} \mathrm{f}_{\mathrm{si}}
\end{aligned}
$$

where $k_{b}$ is a factor that depends on the pile type $\left(k_{b}=0.35\right.$ for driven piles and 0.3 for jacked piles $), \mathrm{c}_{\mathrm{s}}=\mathrm{a}$ factor that depends on the pile type $\left(\mathrm{c}_{\mathrm{s}}=0.53\right.$ for driven piles, 0.62 for jacked piles, and 0.49 for bored piles).

\subsubsection{Thorburn \& McVicar and Eslami \& Fellenius Method}

Thorburn \& McVicar (1979) proposed the following expression to estimate the shaft capacity of the piles.

$$
\mathrm{q}_{\mathrm{sL}}=\mathrm{q}_{\mathrm{c}} \mathrm{c}_{\mathrm{s}}
$$

where $\mathrm{c}_{\mathrm{s}}=0.025$ and this holds true for displacement piles. Also in 1997 Eslami and Fellenius proposed the same expression to estimate the shaft capacity of the piles. But they had different values of $c_{\mathrm{s}}$ depending on the type of clay. $\left(\mathrm{c}_{\mathrm{s}}=0.074-0.086\right.$ for sensitive clay, $\mathrm{c}_{\mathrm{s}}=0.046-0.056$ for soft clay and $\mathrm{c}_{\mathrm{s}}=0.021-0.028$ for silty clay or stiff clay )

\subsection{Pile Load and Settlement}

As the main function of a pile is to limit settlement, pile settlement prediction is an important aspect of design. In clays, pile settlement may be comprised of immediate and long-term settlement. The immediate settlement includes elastic shortening of the pile body and elasto-plastic movements that occur between the pile and soil as well as within the mass of the supporting soil below the pile tip. After the initial response, time-dependant 
movements progress due to volume changes from consolidation and creep in the supporting soil (McClelland 1972). Traditional methods of calculating the settlement of a pile have used an assumed stress distribution along the pile for one-dimensional theory or developed empirical correlations. Several settlement analysis methods are presented in this section.

From the basic idea of Seed and Reese (1957), Coyle and Reese (1966) developed "load transfer method". In the method, the pile is idealized as a series of elements connected to the soil along the pile segment with an elastic spring. Pile settlement is obtained through an iterative calculation. This method is simple, and easily implemented using a computer program containing non-linear soil responses and layered soils. Kiousis and Elansary (1987) updated this method and showed that the predicted curves fit well to observed values.

Poulos and Davis (1980) suggested a simplified method for both a shaft load versus settlement relationship and a base load versus settlement relationship based on elastic solutions. Assuming a linear shaft load versus settlement relationship up to failure of the shaft, the relationship between settlement of the pile and the load carried by the shaft can be expressed as;

$$
\begin{aligned}
& S_{s}=\frac{I}{E_{s} \cdot d} \cdot \frac{P_{s}}{(1-\kappa)} \\
& I=I_{0} R_{K} R_{h} R_{v}
\end{aligned}
$$

where $\mathrm{I}=$ displacement-influence factor for the pile; $\mathrm{R}_{\mathrm{K}}=$ correction factor for pile compressibility; $\mathrm{R}_{\mathrm{h}}=$ correction factor for finite depth of layer on a rigid base; $\mathrm{R}_{\mathrm{V}}=$ correction factor for Poisson's ratio $v_{\mathrm{s}} ; \mathrm{P}_{\mathrm{s}}=$ Load carried by the shaft; $\kappa=$ proportion of applied load transferred to the pile tip; $\mathrm{E}_{\mathrm{s}}=$ average soil modulus along the pile shaft. The base load versus settlement relationship is also assumed as a linear relationship, and is expressed as: 


$$
\begin{aligned}
& s_{b}=\frac{I}{E_{s} \cdot d} \cdot \frac{P_{b}}{\beta}+\left[P_{b}-\frac{P_{s u} \cdot \beta}{(1-\beta)}\right] \cdot \frac{L}{A_{p} \cdot E_{p}} \\
& I=I_{0} R_{K} R_{h} R_{v}
\end{aligned}
$$

where $\mathrm{P}_{\mathrm{b}}=$ load carried at the pile tip; $\mathrm{E}_{\mathrm{p}}=$ soil modulus at the pile tip. Therefore, the overall load-settlement curve can be constructed by superposition of the two curves from these equations. The overall load-settlement curve obtained from these relations is shown in Figure 7.2.

Jardine et al. (1986) employed a finite element analysis involving the use of a non-linear elasto-plastic soil model referred to as LPC2. It is important to recognize that the initial stress-strain of soil is much stiffer than at higher strains. In this model, this nonlinear reaction is properly expressed through a decreasing Young's modulus as the axial strain level increases. They simulated a $30 \mathrm{~m}$ long pile with $0.75 \mathrm{~m}$ diameter embedded into a $50 \mathrm{~m}$ deep soil layer and analyzed the load versus settlement relationship. A general form of the relationship between Young's modulus of soil and axial strain for the analysis was developed from triaxial tests performed with reconstituted specimens. The analysis was performed with a pile material modulus of $30 \times 10^{3} \mathrm{MN} / \mathrm{m}^{2}$, a proper number for either a steel pipe pile or a reinforced concrete pile. The results from the non-linear model were compared with results from linear elastic analysis. Figure 7.3 shows the results of the analysis for two different Young's moduli, $30 \times 10^{3} \mathrm{MN} / \mathrm{m}^{2}$ and $30 \times 10^{6} \mathrm{MN} / \mathrm{m}^{2}$ and a result from a linear elastic model.

Based on the assumption used for the well known Chin's method, Fleming developed a hyperbolic-type load versus settlement correlation. Initially, individual shaft and base performances were assumed to be linear and elastic shortening was considered. The shape of induced settlement curves are decided by soil modulus and undrained shear strength below a pile base for base settlement and a shaft flexible factor $M_{s}$. The relationships are shown at Figure 7.4 (a) and (b). 


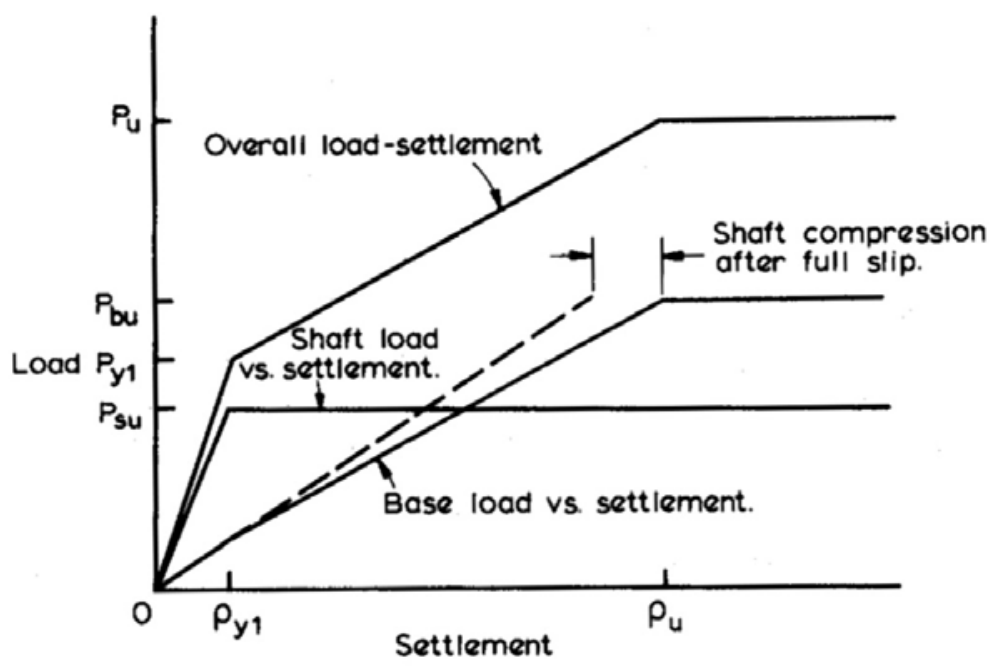

Figure 7.2 Construction of load-settlement curve.



Figure 7.3 Load-settlement curves for a pile $30 \mathrm{~m}$ long. 


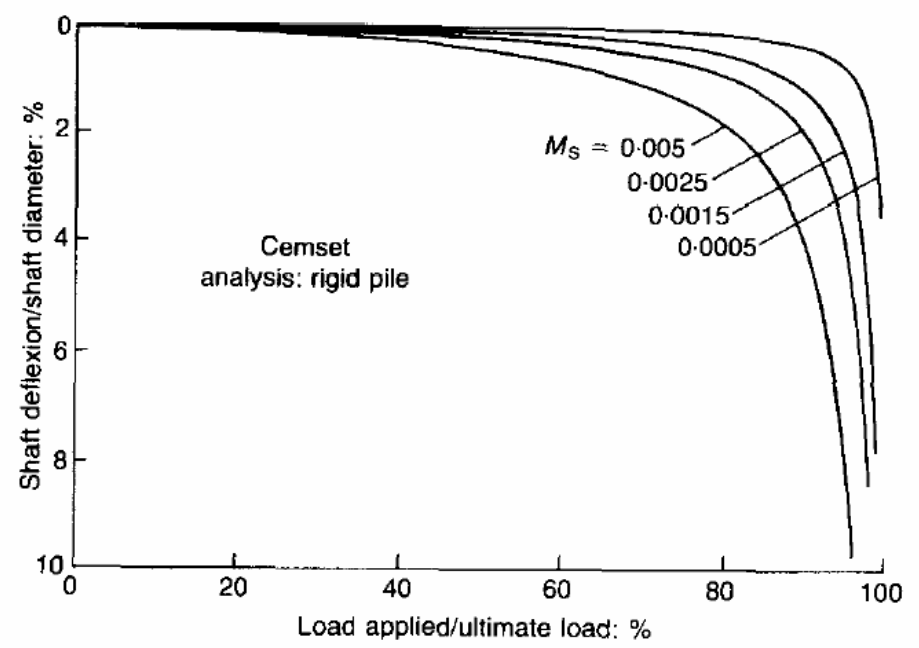

(a)

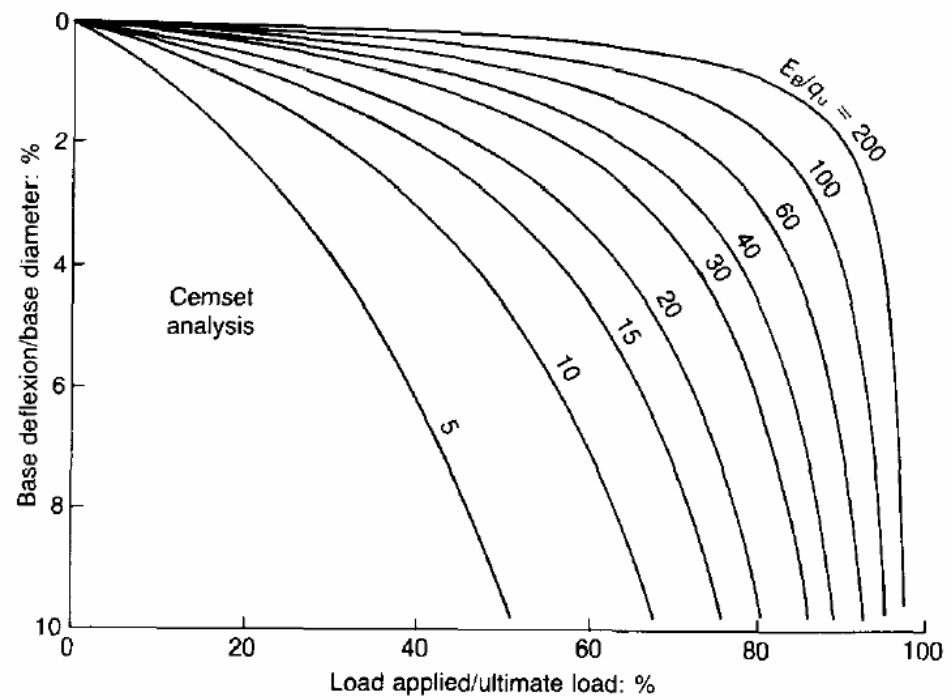

(b)

Figure 7.4 (a) Normalized plot of shaft friction settlement relationships for a range of soils from soft to very soft (b) Normalized plot of end bearing versus settlement relationships from soft to very stiff. 


\subsection{Design Considering Penetration Rate Effects}

In order to design piles using the results of our research, the following steps should be followed:

1) Determine whether the soil is potentially one for which penetration will not be fully drained from examination of the grain size distribution. Percentages of silt above $50 \%$ or sand above $35 \%$ would suggest the possibility of that.

2) If a more definitive assessment is needed, obtain estimates of the coefficient of consolidation $\mathrm{c}_{\mathrm{v}}$ of the soil.

3) Calculate the normalized penetration rate.

4) If the normalized penetration rate $\mathrm{V}$ is between 1 and 4 then penetration is likely partially drained.

5) If the penetration falls in the partially drained range and the undrained pile resistance is desired, correct the $\mathrm{q}_{\mathrm{c}}$ value down using the preliminary curves proposed by this report.

6) If the penetration test is fully undrained, use methods developed for undrained loading without any corrections.

\subsection{Summary}

In general, the CPT may be used to design piles in two ways: directly through correlations between pile unit resistances and $\mathrm{q}_{\mathrm{c}}$ or indirectly through first estimating the undrained shear strength and then using that to estimate pile capacity. The total stress analysis methods using undrained shear strength as a parameter were discussed. These methods include the $\alpha$-method from Tomlinson (1971), Randolph and Wroth (1982), Semple and Rigden (1984), API method (1993), and $\lambda$-method from Vijayvergiya \& Focht (1972) and Kraft et al. (1981). 
In recent years, in-situ testing instruments and techniques, especially for the CPT, have rapidly developed and improved. Accordingly, the design methods based on the direct evaluation of pile capacity from in-situ data have shown an increase in use. The cone penetration test is regarded as a better alternative to the SPT for pile capacity prediction, because it is more reliable and has a similar failure mechanism to the pile. The discussed CPT based methods include the LCPC method (1982), Aoki-Velloso (1975), DeRuiter and Beringen (1979), Price \& Wardle (1982). Most CPT based methods derived correlations between cone resistance and base or shaft capacities from empirical data.

Guidelines were provided to design piles in soils with excessive silt or sand content, in which $\mathrm{q}_{\mathrm{c}}$ would be too high due to partial drainage effects. 


\section{CHAPTER 8. CONCLUSIONS AND RECOMMENDATIONS}

\subsection{Summary}

The main focus of this research was the evaluation and quantification of the factors affecting the results of cone penetration testing in saturated clayey soils, and accordingly, to improve the methods used to apply CPT results to the prediction of pile shaft capacity.

First, effects of drainage conditions around the cone tip were studied. In order to investigate drainage during cone penetration, penetration tests were performed in the field and in a calibration chamber. For the field tests, two sites which have homogeneous clayey soil layers under the groundwater table were selected by evaluating boring data, and CPTs were performed at various penetration rates.

Calibration chamber cone penetration tests were used to investigate the transition points between undrained and partially drained, and between partially drained and fully drained conditions based on cone penetration rate and clay content. The coefficient of consolidation $\mathrm{c}_{\mathrm{v}}$ was a key factor to determine mixing ratios of chamber specimens. Hence, a series of flexible wall permeameter tests were conducted to determine values of $c_{\mathrm{v}}$ for various mixing ratios of clays and sands. The correlation between mixing ratio and $\mathrm{c}_{\mathrm{v}}$ was obtained from the test results and the mixing ratios of the two chamber specimens were defined based on the results. By using two-stage consolidation, homogenous soil specimens could be prepared. Nine miniature piezocone penetration tests were conducted at

different penetration rates in specimen P1 (mixture of $25 \%$ kaolin clay and $75 \%$ Jumun sand) and eight penetration tests were carried out in P2 (mixture of $18 \%$ clay and $82 \%$ Jumun sand). 
Combination of the results from the field and chamber tests indicate that, for a standard cone penetration test, with $d_{c}=35.7 \mathrm{~mm}$ and penetration rate of $20 \mathrm{~mm} / \mathrm{s}$, the test is drained for coefficient of consolidation greater than roughly $10^{-2} \mathrm{~m}^{2} / \mathrm{s}$, undrained for coefficient of consolidation less than roughly $10^{-5} \mathrm{~m}^{2} / \mathrm{s}$, and partially drained for intermediate values.

\subsection{Conclusions}

Based on the findings of the present study, the following conclusions are drawn:

(1) From the field cone penetration tests performed at various penetration rates, it was observed that cone resistance increased when the drainage condition around the cone tip changed from the undrained state to the partially drained state. The value of $\mathrm{V}$ at which the transition between undrained and partially drained conditions took place was approximately 10 but the cone resistance stabilized for $\mathrm{V}$ greater than about 4 .

(2) The results of flexible wall permeability tests show that coefficient of consolidation for mixtures of clay and sand is primarily affected by the clay content. From the test results, it was recognized that $\log \mathrm{c}_{\mathrm{v}}$ has a linear relationship with clay content. Values of $c_{v}$ increased linearly from $3.45 \times 10^{-6} \mathrm{~m}^{2} / \mathrm{sec}$ for $25 \%$ clay to $2.69 \times 10^{-4}$ $\mathrm{m}^{2} / \mathrm{sec}$ for the Jumun sand mixture with $16 \%$ clay under the isotropic confining stress of $150 \mathrm{kPa}$. The value of $\mathrm{c}_{\mathrm{v}}$ for the mixture of Jumun sand and kaolin clay is higher than that of the mixture of Ottawa sand and kaolin clay at the same mixing ratio. The difference in the values of $c_{v}$ between the mixtures may be attributed to the difference in void ratios between Ottawa sand and Jumun sand.

(3) From the results of penetration tests in the calibration chamber specimens, the correlation between cone resistance and drainage condition was proved and quantified. When the drainage condition was changed from undrained to fully drained, cone resistance increased 4 times (P1) and 3.1 times $(\mathrm{P} 2)$, and excess pore 
pressure dissipated to zero. The value of $\mathrm{V}$ at which the transition between undrained and partially drained conditions took place was approximately 10 but the cone resistance stabilized for $\mathrm{V}$ greater than about 1 . This value was slightly lower than the one from the field tests $(\mathrm{V} \approx 4)$. The transition between partially drained and fully drained was observed at $\mathrm{V} \approx 0.05$. The normalized $\mathrm{V}$ can be converted to $\mathrm{c}_{\mathrm{v}}$ for the standard CPT. The cone resistance of standard CPT performed in soil having $\mathrm{c}_{\mathrm{v}}$ values lower than $7.14 \times 10^{-4} \mathrm{~m}^{2} / \mathrm{sec}$ can be considered to be undrained. The limit value of $\mathrm{c}_{\mathrm{v}}$ for drained condition in standard CPT is about $1.0 \times 10^{-2} \mathrm{~m}^{2} / \mathrm{sec}$.

(4) The cone factor $\mathrm{N}_{\mathrm{k}}$ is reasonably well known from theoretical considerations. Field tests confirm the theoretical values so long as soil properties that affect cone resistance are carefully determined.

(5) CPTs should include dissipation tests in soils in which penetration may be partially drained. A method to more accurately interpret CPT tests in such soils is needed. 


\subsection{Recommendations for Future Research}

Future research on the topic of this report is suggested as follows:

(1) The relationship between cone resistance and drainage conditions was observed experimentally in this project. Observations should be expanded both in the laboratory and in the field, and both the rates delimiting drained and undrained response and the values of cone resistance need to be better defined. Analytical solutions need to be developed that can handle drained, undrained and partially drained penetration.

(2) The importance of soil fabric was obvious from the experiments. The difference in cone resistance due to the difference in soil fabric was shown in the results of the calibration chamber tests. More penetration tests in soils with different soil fabrics are needed to clearly define the correlation between cone resistance and soil fabric.

(3) Direct pile design methods for the CPT need to be placed fully on an analytical basis. Theoretical work on pile resistance calculation combined with CPT testing in the field and pile load tests should be pursued.

(4) A shaft resistance design criterion for direct CPT methods in intermediate soil layers, where cone resistance is possibly obtained under partially drained conditions, should be developed.

(5) Interporlation laws of easy use in design for CPTs performed under partially drained conditions should be proposed. 


\section{LIST OF REFERENCES}

Aas, G., Lacasse, S., Lunne, T., and Hoeg, K. (1986). "Use of in situ tests for foundation design on clay", Proceedings of In situ '86, Use of In Situ Tests in Geotechnical Engineering. ASCE GSP 6, Blacksburg, Virginia, 1-30.

Acar, Y.B. (1981), "Piezocone penetration testing in soft cohesive soils." Fugro Postdoctoral Geotechnical Engineering Report No.Ge-81/01, Louisiana State University, Baton Rouge, LA

Almeida, M.S.S., Danziger, F.A.B., \& Lunne, T. (1996). "Use of the piezocone test to predict the axial capacity of driven and jacked piles in clay", Canadian Geotechnical Journal, 33 (1), 23-41.

American Petroleum Institute, API, RP2A (1993). "Recommended practice of planning, designing and constructing fixed offshore platforms." $20^{\text {th }}$ edition, Washington.

Anagnostopoulos, A., Koukis, G., Sabatakis, N. and Tsiambaos, G, (2003). "Empirical correlations of soil parameters based on Cone Penetration Tests (CPT) for Greek soils" Geotechnical and Geological Engineering, Vol. 21, 377-387.

Aoki, N. and Velloso, D.A. (1975). "An approximate method to estimate the bearing capacity of piles", Proceeding of $5^{\text {th }}$ Pan-American Conference of Soil Mechanics and Foundation Engineering, Bueno Aires, Vol. 1, 367-376.

Baligh, M. M. (1975). "Theory of deep site static cone penetration resistance”, Research Report R75-56, Dept. of Civil Engg., MIT, Cambridge, 141p.

Baligh, M. M. (1985). "Strain path method", Journal of the Geotechnical Engineering Division, ASCE 111 (9), 1108-1136.

Baligh, M., Vivatrat, V., Wissa, A., Martin R., and Morrison, M., (1981). "The piezocone penetrometer. Proceedings of Symposium on Cone Penetration Testing and Experience", American Society of Civil Engineers, National Convention, St. Louis, 247 - 263.

Baligh, M.M., Vivatrat, V., and Ladd, C.C., (1980). "Cone penetration in soil profiling", Journal of the Geotechnical Engineering Division, 106 (4), 447-461. 
Bandini, P. and Salgado, R. (1998). "Methods of Pile Design Based on CPT and SPT results", Proceedings of $1^{\text {st }}$ International Conference on Site Characterization, Balkema, Rotterdam, 967- 976.

Bazaraa, A.R. and Kurkur, M.M. (1986). "N-values used to predict settlements of piles in Egypt", Proceedings of In situ '86, Use of In Situ Tests in Geotechnical Engineering. ASCE GSP 6, Blacksburg, Virginia, 462-474.

Been, K., Crooks, J.H.A., and Rothenburg, L. (1988). "A critical appraisal of CPT calibration chamber tests", Proceedings of the International Symposium on Penetration Testing, ISOPT-1, Orlando, Balkema Pub., Rotterdam, 651-659.

Bemben, S.M. and Myers, H.J. (1974). "The influence of rate of penetration on static cone resistance in Connecticut river valley varved clay", Proceedings of the European Symposium on Penetration Testing, ESOPT, Stockholm, 2.2, 33-34.

Briaud, J.L., Ballous, M., and Nasr, G. (2000). "Static capacity by dynamic methods for three bored piles", Journal of Geotechnical and Geoenvironmental Engineering, ASCE, Vol. 126 (7), 640-649.

Bullock, P.J. (1999). "Pile Friction Freeze: A Field and Laboratory Study", Ph.D. Dissertation, University of Florida.

Burland, J. (1973). "Shaft Friction of Piles in Clay - A Simple Fundamental Approach", Ground Engineering, Vol.6(3), 30-42

Burland, J.E. and Cooke, R.W. (1974). "The design of bored piles in Stiff Clays", Ground Engineering Vol. 7(4), 28-30.

Bustamante, M. and Gianeselli, L. (1982). "Pile bearing capacity prediction by means of static penetration CPT", Proceedings of $2^{\text {nd }}$ European Symposium on Penetration Testing, ESOPT-2, Amsterdam, Vol. 2, 493 - 500.

Campanella R.G., Robertson P.K., and Gillespie D. (1983). "Cone penetration testing in deltaic soils", Canadian Geotechnical Journal, 20(1), 23-35.

Campanella, R.G., Gillespie, D., and Robertson, P.K., (1982). "Pore pressures during cone penetration testing", Proceedings of the $2^{\text {nd }}$ European Symposium on Penetration Testing, ESOPT-2, Amsterdam, May 24 - 27, Vol. 2, 507-512.

Campanella, R.G., and Robertson, P.K., (1988). "Current status of the piezocone test", Proceedings of First International Symposium on Penetration Testing, ISOPT-1, Orlando, March 22-24, Vol. 1, 93-116. 
Campanella, R. G., Robertson, P. K., Davies, M. P., and Sy, A. (1989). "Use of In-Situ Tests in Pile Design", XII International Conference of the International Society for Soil Mechanics and Foundation Engineering, Rio de Janeiro, Vol. 1, 199-205.

Carpentier, R. (1982). " Relationship between the cone resistance and the undrained shear strength of stiff fissured clays", Proceedings of $2^{\text {nd }}$ European Symposium on Penetration Testing, ESOPT-2, Amsterdam, Vol. 2, 519-528.

Carraro, J. A. (2004). "Mechanical Behavior of Silty and Clayey Sands", Ph.D. Thesis, Purdue University, West Lafayette.

Carter, J.P., Booker, J.R., and Yeung, S.K. (1986). "Cavity Expansion in Cohesive Frictional Soils", Géotechnique, 36(3), 349-58.

Casagrande, A. (1936). "The determination of preconsolidation load and its practical significance. International Conference on Soil Mechanics and Foundation Engineering. 2226 June, Cambridge, MA, Vol. 3, 60-64.

Chen, Y. J., and F. H. Kulhawy (1994) "Case History Evaluation of the Behavior of Drilled Shaft Under Axial and Lateral Loading," Final Report, Project 1493-04, EPRI TR-104601, Geotechnical Group, Cornell University, Ithaca, NY.

Chin, F.K. (1970). "Estimation of Ultimate Load of Piles not Carried to Failure", Proceedings 2 Southeast Asian Conference on Soil Engineering, 81-90.

Coyle, H. M., and Reese, L. C. (1966). "Load Transfer for Axially Loaded Piles in Clay," Proceedings, American Society of Civil Engineers, New York, NY, Vol 92, SM2, 1-26.

Dayal, U. and Allen, J.H. (1975) "The effect of penetration rate on the strength of remolded clay and sand samples", Canadian Geotechnical Journal, 12(3), 336-48.

De Cock F., Van Impe W.F., Peiffer H. (1993). "Atlas screw piles and tube screw piles in stiff tertiary clays", Proceedings of Deep Foundations on Bored and Auger Piles, Balkema, 359-367.

De Ruiter, J. and Beringen, F.L., (1979). “ Pile Foundations for Large North Sea Structures", Marine Geotechnology, 3(3), 267-314.

Denver, H. (1988). "CPT and shear strength of clay", Proceedings of the International Symposium on Penetration Testing, ISOPT-1, Orlando, 2, Balkema Pub., Rotterdam, 723727.

Eslami, A. (1996). "Bearing Capacity of Piles from Cone Penetrometer Test Data", Ph.D. thesis, Department of Civil Engineering, University of Ottawa, Ottawa. 
Eslami, A. and Fellenius, B.H. (1997). "Pile Capacity by Direct CPT and CPTu methods Applied to 102 Case Histories”, Canadian Geotechnical Journal, 34, 886-904.

Fellenius, B.H. (2002). "Determining the True Distributions of Load in Instrumented Piles", Proceedings of the International Deep Foundations Congress 2002, Geotechnical Special Publication No. 116, Vol. 2, ASCE, 1455-1470.

Finnie, I.M.S. and Randolph, M.F. (1994). "Punch-through and liquefaction induced failure of shallow foundations on calcareous sediments", Proc. Int. Conf. on Behavior of Offshore Structures, BOSS '94, Boston, 1: 217-230.

Finno, R.J. (1989). "Surface Conditions and Pile Installation Data." Proc. Pile Prediction Symposium, ASCE, Foundation Engineering Congress, Northwestern University, Evanston, IL, R.J. Finno (Ed.), 1-74.

Finno, R.J., Cosmao, T. and Gitskin, B. (1989). "Results of Foundation Engineering Congress Pile Load Tests." Proc. Pile Prediction Symposium, ASCE, Foundation Engineering Congress, Northwestern University, Evanston, IL, 338-355.

Graham, J., Crooks, J. H. A. and Bell, A. L. (1983). "Time effects on the stress-strain behavior of natural soft clays", Géotechnique, 33(3), 327-340.

Gwizdala, K. and Tejchman, A. (1998). "Field Test of Shaft Resistance of Bored Piles", Proceedings of Deep Foundations on Bored and Auger Piles, Balkema, 287-292.

Head, K. H. (1992). "Manual of soil laboratory testing. Vol. 3. Effective Stress Tests", 2nd ed. Pentech Press, London.

Houlsby, G. T. and Teh, E. I. (1988). "Analysis of the Piezocone in Clay. In Penetration Testing", Proc. of 1st Int. Symp. on Penetration Testing, Orlando, Florida, Vol. 2, de Ruiter, J. (ed.), A. A. Balkema, Rotterdam, 777-783.

Houlsby, G.T., and Hitchman, R. (1988). "Calibration Chamber Tests of a Cone Penetrometer in Sand", Géotechnique , 38(1), 39-44.

House, A.R., Oliveira, J.R.M.S., and Randolph, M.F. (2001). "Evaluating the coefficient of consolidation using penetration tests", The International Journal of Physical Modeling in Geotechnics, 1(3), 17-26.

Jamiolkowski, M., Ghionna, V. N., Lancellotta, R. \& Pasqualini, E. (1988). "New correlations of penetration tests for design practice", Proceedings of the International Symposium on Penetration Testing, Orlando, 1, 263-296. 
Jamiolkowski, M., Lancellotta, R., Tordella, L. and Battaglio, M. (1982). "Undrained Strength from CPT", Proc. of 2nd European Symposium on Penetration Testing, Amsterdam, 599-606.

Jardine, R.J., Potts, D.M., Fourie, A.B., and Burland, J.B. (1986). "Studies of the influence of non-linear stress-strain characteristics in soil-structure interaction", Géotechnique, No. 3, 377-396.

Jardine, R., Chow, F.C., Matsumoto, T. (1998). "A new design procedure for driven piles and its application to two Japanese clays In: Soils and Foundations", Vol 38, Issue 1, 207219.

Jardine, R., Lehane, B.M, Chow, F.C. and McCabe, B.A. (2000). "Relationships between shaft capacity of driven piles and CPT end resistance In: Proceedings of the Institution of Civil Engineers-Geotechnical Engineering”, Vol 143, Issue 2, 93-101.

Kamp, W.G.B te (1982) "The influence of the rate of penetration on the cone resistance ' $\mathrm{q}_{\mathrm{c}}$ ' in sand" Proceedings of the $2^{\text {nd }}$ European Symposium on Penetration Testing, ESOPTII, Amsterdam, 2, 627-33.

Katagiri, M., and Imai, G. (1994). "A new laboratory method to make homogenous clayey samples and their mechanical properties", Soils and Foundations, 34(2), 87-93.

Keaveny, J.M. and Mitchell, J.K. (1986). "Strength of Fine-Grained Soils Using the Piezocone", Proceedings of In situ '86, Use of In Situ Tests in Geotechnical Engineering. ASCE GSP 6, Blacksburg, Virginia, 668-685.

Kim, K., Salgado, R., Lee, J. and Paik, K. (2001). "Pile Load Tests for Development of CPT-Based Pile Design Method", Joint Transportation Research Project, FHWA/IN/JTRP2002/4, Purdue University.

Kim, T. J. (2005). "Dissipation of Pore Water Pressure due to Piezocone Penetration in OC Clay", Ph.D thesis.

Kiousis, P.D. and Elansary A.S.E. (1987). "Load-Settlement Relation for Axially Loaded Piles", ASCE Journal of Geotechnical Engineering, Vol. 113, No. 6, 655-661.

Kolk, H.J. and van der Velde, E. (1996). "A reliable method to determine friction capacity of piles driven into clays", Proc. Offshore Technology Conf., Houston, Paper OTC 7993.

Konrad, J.M. and Law, K.T. (1987). "Undrained shear strength from piezocone tests", Canadian Geotechnical Journal, 24(3), 392-405. 
Kraft, L. M., Jr., Focht, J. A., and Amarasinghe, S. R. (1981). "Friction Capacity of Piles Driven into Clay, " Journal of Geotechnical Engineering Division, Vol 107, 1521-1541.

Kuerbis, R., and Vaid., Y.P. (1988). "Sand sample preparation - the slurry deposition method", Soils and Foundations, 28(4), 107-118.

Kulhawy, F.H. and Mayne, P.W. (1990). "Manual on Estimating Soil Properties for Foundation Design", Report No. EL-6800, Electric Power Research Institute, Palo Alto, CA, August 1990, 306 p.

Kulhawy, F.H. and Phoon, K.K. (1993). "Drilled shaft side resistance in clay soil to rock", Design and Performance of Deep Foundations: Piles \& Piers in Soil \& Soft Rock, GSP No. 38, ASCE, Reston/VA, 172-183.

La Rochelle, P., Zebdi, P.M., Leroueil, S., Tavenas, F. and Virely, D. (1988). "Piezocone Tests in Sensitive Clays of Eastern Canada". Proceedings of the International Symposium on Penetration Testing, ISOPT-1, Orlando, 2, Balkema Pub., Rotterdam., 831-841.

Lacasse, S. \& Lunne, T. (1982). "Penetration tests in two Norwegian clays", Proceedings of the $2^{\text {nd }}$ European Symposium on Penetration Testing, ESOPT-II, Amsterdam, 2, 661-669.

Ladanyi, B. and Eden, W.J. (1969). "Use of the deep penetration test in sensitive clays", Proceedings of the $7^{\text {th }}$ ICSMFE, Mexico, 1, 225-230.

Ladanyi, B. and Johnston, G. H. (1974). "Behavior of Circular Footings and Plate Anchors embedded in Permafrost", Canadian Geotechnical Journal, 11, 531-553.

Lee, J. and Salgado, R. (2000). "Analysis of Calibration Chamber Plate Load Testing." Canadian Geotechnical Journal, Feb., 37(1), 14-25.

Levadoux, J.N. and Baligh, M.M. (1986). "Consolidation after undrained piezocone penetration”, Journal of Geotechnical Engineering, Vol. 112 (7), 707-745.

Luke K. (1995). "The use of $c_{u}$ from Danish triaxial tests to calculate the cone factor", Proc. Of the Intern. Symp. On Cone Penetration Testing, CPT'95, Linkoping, Sweden, 209-214.

Lunne, T. and Kleven, A. (1981). "Role of CPT in North Sea Foundation Engineering", Symposium on Cone Penetration Engineering Division, ASCE, 49-75.

Lunne, T., Christoffersen, H. P. and Tjelta, T. I. (1985). "Engineering use of piezocone data in North Sea clays", Proc. 11th Int. Conf. Soil Mech. Found. Engg, San Francisco 2, 907912. 
Lunne, T., Eide, O. and de Ruiter, J. (1976). "Correlations between cone resistance and vane shear strength in some Scandinavian soft to medium stiff clays", Canadian Geotechnical Journal, 37(4), 430-441.

Lunne, T., Eidsmoen, T., Gillespie, D., and Howland, J.D., (1986). "Laboratory and field evaluation of cone penetrometer", Proceedings of In situ '86, Use of In Situ Tests in Geotechnical Engineering. ASCE GSP 6, Blacksburg, Virginia, 714-729.

Mandolini, A., Ramondini, M., Russo, G. \& Viggiani, C. (2002) "Full Scale Loading Tests on Instrumented CFA Piles", Proceedings of the International Deep Foundations Congress 2002, GSP No. 116, Vol. 2, ASCE, 1089-1097.

Mayne, P.W. and Kulhawy, F.H., (1991). "Calibration Chamber Database and Boundary Effects Correction for CPT Data", Calibration Chamber Testing (ISOCCT-1), Elsevier, New York, 257-264.

McClelland, B. (1972). "Design and Performance of Deep Foundations." Proceedings, ASCE Specialty Conference on Performance of Earth and Earth-Supported Structures, Purdue University, Vol. 2, 111-144.

McNeilan, T.W. and Bugno, W.T., (1985). "Jack up rig performance in predominantly silty soils”, Paper OTC 5082, Offshore Technology Conference.

Meyerhof, G.G. (1951). "The Ultimate Bearing Capacity of Foundations”, Géotechnique, Vol. 2, 301-332.

Mitchell, J.K. and Brandon, T.L. (1998). "Analysis and use of CPT in earthquake and environmental engineering”, Keynote Lecture, Proceedings of ISC'98, Vol.1, 69-97.

Muromachi, T. (1974). "Experimental study on application of static cone penetrometer to subsurface investigations of weak cohesive soils", Proceedings of the European Symposium on Penetration Testing, ESOPT, Stockholm, Vol.2.2, 285-293.

O’Reilly, M.P., Brown, S.F. and Overy, R.F., (1989). "Viscous effects observed in tests on an anisotropically normally consolidated silty clay", Géotechnique, vol. 39, 153-158.

O'Riordan, N.J., Davis, J.A., and Dauncey, P.C. (1982). "The interpretation of static cone penetrometer tests in soft clays of low plasticity", $2^{\text {nd }}$ European Symposium on Penetration Testing, ESOPT-II, Amsterdam, 755-760.

Olsen, R.E., and Dennis, N.D., (1982). "Review and compilation of pile test results, axial pile capacity", Geotechnical Engineering Report CR83-4, University of Texas, Department of Civil Engineering, Austin, Texas. 
Parkin, A., and Lunne, T. (1982). "Boundary effects in the laboratory calibration of a cone penetrometer in sand." Proceedings of $2^{\text {nd }}$ European Symposium on Penetration Testing, Amsterdam, Vol. 2, 761-768.

Poulos, H.G., and Davis, E.H. (1980). “ Pile Foundation Analysis and Design”, Wiley, New York.

Poulos, H.G. (1989). "Pile behavior: theory and application", Géotechnique 39 (3), 363415.

Powell, J.J.M., Quarterman, R.S.T. \& Lunne, T. (1988). "Interpretation and use of the piezocone test in UK", Penetration Testing in the UK, Thomas Telford, London, 47-52.

Price, G., and Wardle, I.F. (1982). "A Comparison Between Cone Penetration Test Results and the Performance of Small-Diameter Instrumented Piles in Stiff Clay", Proceedings of the Second European Symposium on Penetration Testing, Amsterdam, May 24-27, 775780 .

Rad, N.S. \& Lunne, T. (1988). Direct correlations between piezocone test results and undrained shear strength of clay. Proc. 1st Int. Symp. Penetration Testing, Orlando 2, 911917.

Randolph, M.F., Carter, J.P. \& Wroth, C.P. (1979). Driven piles in clay the effects of installation and subsequent consolidation. Géotechnique, Vol. 29(4), 361-393.

Randolph, M.F. and Hope, S. (1995). "Effect of cone velocity on cone resistance and excess pore pressures", Proc. Int. Conf. Soil Mechanics and Foundation Engineering, Osaka.

Randolph, M.F. and Murphy, B.S. (1985). "Shaft Capacity of Driven Piles in Clay", Proceedings of the $17^{\text {th }}$ Offshore Technology Conference, Houston, Vol. 1, 371-378.

Randolph, M.F. and Worth, C.P. (1982). "Recent Developments in Understanding the Axial Capacity of Piles in Clay", Ground Engineering, Vol. 15, 17-25.

Reese, L.C., and O'Neill, M.W. (1988). "Drilled Shafts: Construction Practices and Design Methods", FHWA-HI-042, Federal Highway Administration, Office of Implementation, Washington, D. C., June.

Richardson, A.M., and Whitman, R.V. (1963). "Effect of strain-rate upon undrained shear resistance of a saturated remolded fat clay", Géotechnique, 13 (4), 310-324.

Robertson, P.K. (1990). "Soil classification using the CPT", Canadian Geotechnical Journal. 27 (1), 151-158. 
Robertson, P.K. and Campanella, R.G. (1983). "Interpretation of cone penetration tests", Canadian Geotechnical Journal. 20 (4), 718-733.

Robertson, P.K., Campanella, R.G., Gillespie, D., and Grieg, J. (1986). "Use of piezometer cone data". Proceedings of In situ '86, Use of In Situ Tests in Geotechnical Engineering. ASCE GSP 6, Blacksburg, Virginia, 1263-1280.

Robinson, R.G. and Allam, M.M. (1998). "Effect of clay mineralogy on coefficient of consolidation”, Clays and Clay Minerals Vol.46, 596-600.

Rocha Filho, P. (1982). "Influence of excess pore pressure on cone measurements. Proceedings of the $2^{\text {nd }}$ European Symposium on Penetration Testing, ESOPT-II, Amsterdam, 2, 805-11.

Roy, M., Tremblay, M., Tavenas, F. \& Rochelle, P. L. (1982). "Development of pore pressure in quasi-static penetration tests in sensitive clay", Canadian Geotechnical Journal, $19(1), 124-138$.

Salgado, R. (1993). "Analysis of penetration resistance in sands", PhD Thesis, University of California, Berkeley.

Salgado, R. and Randolph, M. F. (2001). "Analysis of Cavity Expansion in Sand." International Journal of Geomechanics, Vol. 1, No. 2, 175-192.

Salgado, R., Bandini, P. and Karim, A. (2000). "Shear Strength and Stiffness of Silty Sands." Journal of Geotechnical and Geoenvironmental Engineering, ASCE, 126(5), 451462.

Salgado, R., Lyamin, A. V., Sloan, S. W. and Yu, H. S. (2004). "Two- and threedimensional bearing capacity of foundations in clay", Géotechnique 54 (5), 297-306.

Salgado, R., Mitchell, J.K., and Jamiolkowski, M. (1998). "Calibration Chamber Size Effects on Penetration Resistance in Sand." Journal of Geotechnical and Geoenvironmental Engineering, ASCE, Vol. 124 (9), September, 878-888.

Salgado, R. (2007). “The Engineering of Foundations”.

Samingan, A.S., Leong, E.C. and Rahardjo, H. (2003). "A flexible wall permeameter for measurements of water and air coefficients of permeability of residual soils", Canadian Geotechnical Journal, 40(3), 559-574.

Schmertmann, J.H. (1975). "Measurement of in-situ shear strength", Proceedings of the Specialty Conference on in-situ Measurement of Soil Properties, ASCE, Raleigh, Vol. 2, $57-138$ 
Schmertmann, J.H. (1978). "Guidelines for Cone Penetration Test, Performance and Design”, U.S. Department of Transportation, FHWA-TS-78-209.

Schnaid, F., and Houlsby, G.T. (1991). "An Assessment of Chamber Size Effects in the Calibration of In Situ Tests in Sand”, Géotechnique, 41(3), 437-445.

Seed, H.B., and Reese, L.C. (1957). "The Action of Soft Clay Along Friction Piles", Transactions, American Society of Civil Engineers, NY, Vol 122, 731-753.

Semple, R.M. and Rigden, W.J. (1984). "Shaft Capacity of Driven Pipe Piles in Clay", ASCE Symposium on Analysis and Design of Pile Foundations, 59-79.

Sheeran, D.E. and Krizek, R.J., (1971). "Preparation of Homogeneous Soil Samples by Slurry Consolidometers," Journal of Materials, No. 2, Vol. 6, 356-373.

Sridharan, A and Nagaraj, H.B., (2004). "Coefficient of Consolidation and its Correlation with Index Properties of Remolded Soils". Geotechnical Testing Journal, 27(5), 469-474.

Stark, T. D. and Juhrend, J. E., (1989). "Undrained shear strength from cone penetration tests", Proceedings of the 12th International Conference on Soil Mechanics and Foundation Engineering, Rio de Janeiro, Vol. 1, 327-330.

Stas, C.V. and Kulhawy, F.H., (1984). "Critical Evaluation of Design Methods for Foundations Under Axial Uplift and Compression Loading”, Report EL-3771, EPRI, Palo Alto, Calif.

Tani, K., Craig, W.H., (1995). "Bearing capacity of circular foundations on soft clay of strength increasing with depth", Soils and Foundations. 35 (4), 21-35.

Teh, C.I. and Houlsby, G.T., (1991). "An analytical study of the cone penetration test in clay", Geotechnique, 41(1), 17-34.

Terzaghi, K., (1943). Theoretical Soil Mechanics, Wiley, NY.

Terzaghi, K., Peck, R.B., and Mesri, G., (1996). "Soil Mechanics in Engineering Practice", third edition, John Wiley \& Sons, Inc.

Thevanayagam, S., (1998). "Effects of fines and confining stress on undrained shear strength of silty sands", Journal of Geotechnical and Geoenvironmental Engineering, ASCE, 124(6), 479-491.

Thevanayagam, S., Martin, G.R., Shenthan, T. and Liang, J. (2001). "Post-liquefaction pore pressure dissipation and densification in silty soils." 4th Intl Conf. Recent Adv. Geot. Earthq. Eng. \& Soil Dyn., San Diego. 
Tomlinson, M.J. (1957). "The adhesion of Clay Piles Driven in Clay Soils", Proc. 4th Intl. Conf. on Soil Mechanics and Foundation Engineering, London.

Vaid, Y.P. and Campanella, R. G. (1977). "Time dependent behavior of undisturbed clay", Journal of Geotechnical Engineering, ASCE, 103 (7), 693-709.

Van Impe, (2004). "Two decades of full scale research on screw piles", Laboratory of Solid Mechanics.

Vesic, A.S. (1972). "Expansion of cavities in infinite soil mass",. Journal of Soil Mechanics and Foundation Division, ASCE, 98 (3), 265-290.

Vesic, A.S. (1977). "Design of pile foundations", National Cooperative Highway Research Program Synthesis of Highway Practice, No. 42, Transportation Research Board, Washington, DC.

Vijayvergiya, V.A., and Focht, J.A., Jr., (1972). "A New Way to Predict Capacity of Piles in Clays," Proceedings of the Fourth Offshore Technology Conference, Houston, Vol. 2, 865-874.

Yasufuku, N. and Hyde, A.F.L. (1995). "Pile end-bearing capacity in crushable sands" Géotechnique, 45 (4), 663-676.

Yu, H.S. (1993). "Discussion of 'Singular plastic fields in steady penetration of a rigid cone,' by D. Durban and N. A. Fleck”, Journal Appl. Mech., 60, 1061-1062.

$\mathrm{Yu}$, H.S. and Houlsby, G.T. (1991). "Finite cavity expansion in dilatant soils: loading analysis", Géotechnique, 41, 173-183.

Yu, H.S. and Mitchell J.K. (1998). "Analysis of cone resistance: review of methods", Journal of Geotechnical and Geoenvironmental Engineering, ASCE, 124(2), 140-149. 